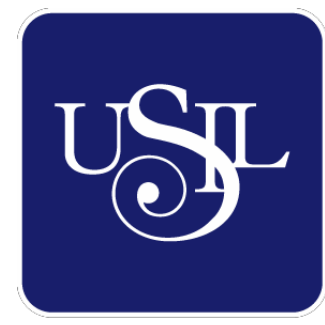

UNIVERSIDAD

SAN IGNACIO

DE LOYOLA

ESCUELA DE POSTGRADO

Maestría en Administración de Negocios - Executive MBA

\title{
PLAN DE NEGOCIOS PARA LA \\ COMERCIALIZACIÓN DE SOFTWARE PARA MEDIO AMBIENTE, INGENIERÍA Y SISTEMA DE INFORMACIÓN GEOGRÁFICA
}

Trabajo de Investigación para optar el grado de Maestro en Administración de Negocios - Executive MBA

HILBER JAVIER QUINTANA LLANCO

Asesor:

Dr. José Antonio Chou Flores

Lima - Perú

2018 

Plan de Negocios para la Comercialización de software para Medio Ambiente, Ingeniería y Sistema de Información Geográfica 


\section{Resumen Ejecutivo}

El presente proyecto se ha desarrollado en base a una investigación de cinco meses, cuyo universo de empresas en estudio corresponden al sector Minería comprendidas en el compendio "Perú: The Top 10,000 companies 2017".

El estudio analiza la comercialización de software especializado en Diseño Asistido por Computadora (CAD) y Sistema de Información Geográfica (GIS), los que se comercializará en forma de solución, que incluye implementación, capacitación y soporte presencial local.

El proyecto tiene el nombre de GeoTI S.A.C., la organización tendrá una estructura plana con una cantidad total de cinco (5) colaboradores que estarán compuestos por un administrador, asistente administrativo, ejecutivo comercial, consultor senior y un responsable de sistemas.

El estudio se sustenta básicamente en el estudio de mercado realizado mediante entrevistas en profundidad y encuestas directas. La inversión total requerida para el proyecto asciende a S/ 289,234 Soles, las que se encuentran divididas en tres componentes (1) inversión en activos fijos S/ 46,810 (2) Activos intangible y pre operativos S/ 56,676 y (3) Capital de trabajo S/ 185,749 las que deben ser financiados con capital propio (accionistas)

El costo de oportunidad (COK) determinado es $20.96 \%$ con el que se realizó los descuentos a los resultados del flujo de caja proyectado, cuyo VAN resulta S/ 216,267 y una TIR de $37.08 \%$. Otros indicadores de rentabilidad del proyecto son el Margen Bruto 35\% en 
promedio, Margen Operativo $3.71 \%$ y Margen Neto de $2.74 \%$ el primer año, siendo mayor $7.68 \%, 5.68 \%$, en el año dos y similares a estos en los años siguientes.

Al final se presentan las conclusiones y recomendaciones obtenidas en la investigación del presente proyecto 


\section{ÍNDICE}

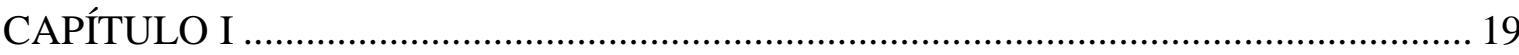

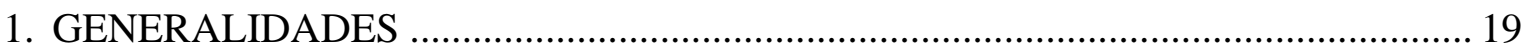

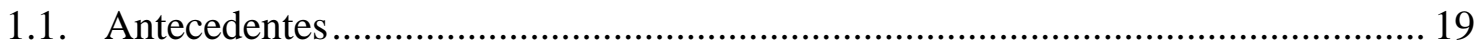

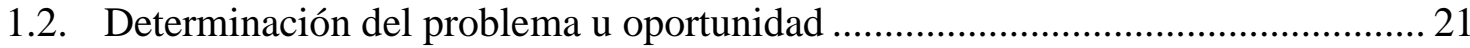

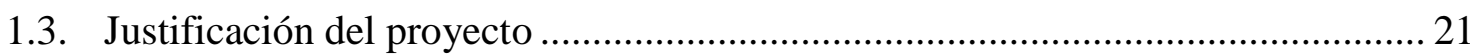

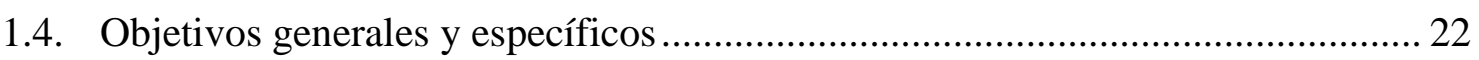

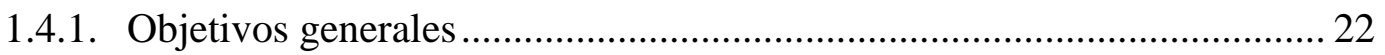

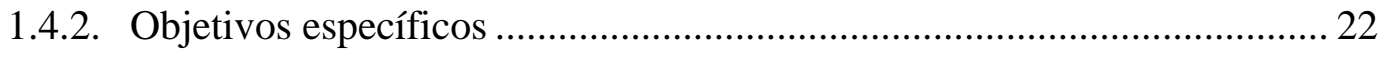

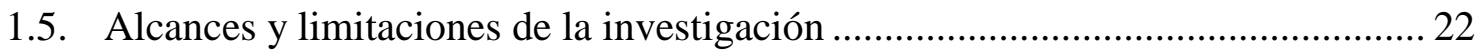

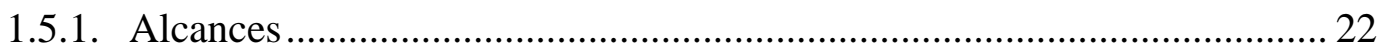

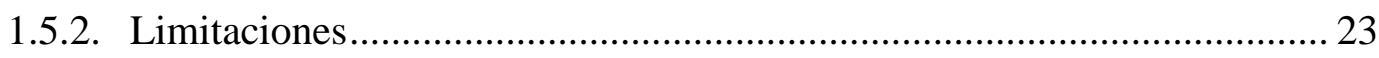

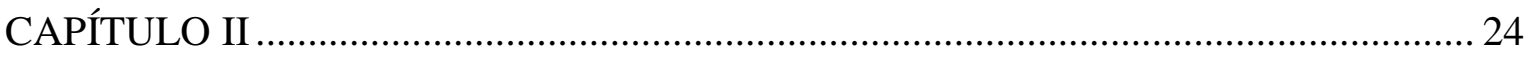

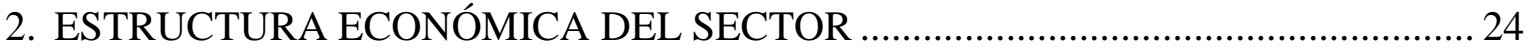

2.1. Descripción del estado actual de la industria.................................................... 24

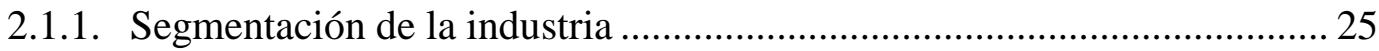

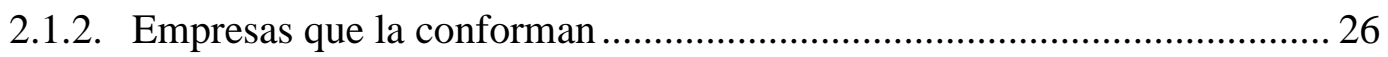

2.2. Tendencias de la industria (crecimiento, inversiones) ...................................... 27

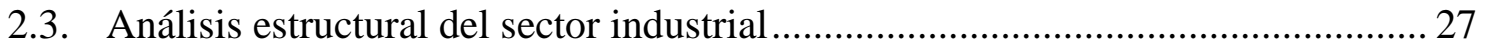

2.3.1. Poder de negociación de los clientes ..................................................... 28

2.3.2. Poder de negociación de los proveedores ............................................... 29

2.3.3. Amenaza de competidores potenciales ............................................. 31

2.3.4. Amenaza de productos sustitutos .......................................................... 32

2.3.5. Rivalidad entre competidores actuales................................................... 33 


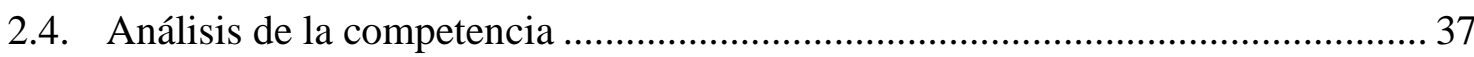

2.4.1. Empresas que ofrecen el mismo productos o servicio ........................... 37

2.4.2. Participación de mercado de cada uno de ellos ...................................... 40

2.4.3. Matriz de perfil competitivo .............................................................. 41

2.5. Análisis del contexto actual y esperado.......................................................... 42

2.5.1. Análisis Político-Gubernamental ......................................................... 42

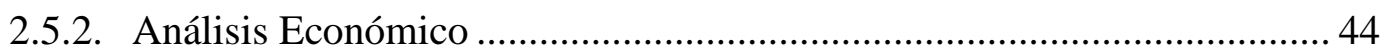

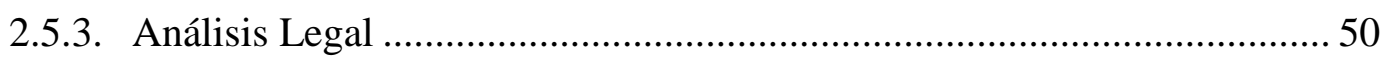

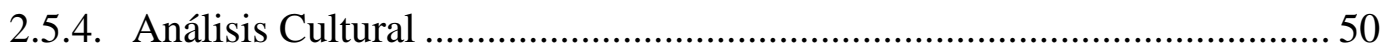

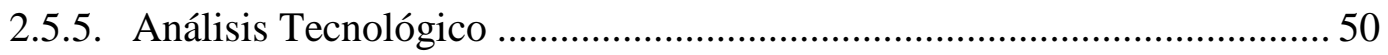

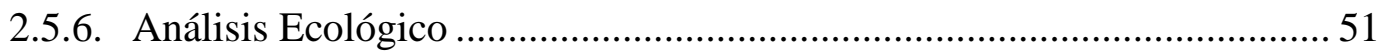

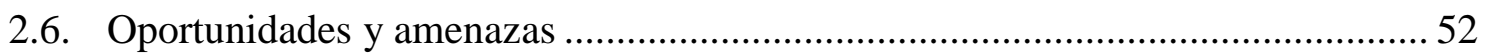

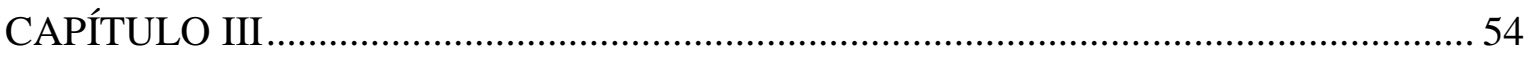

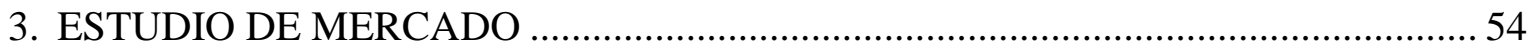

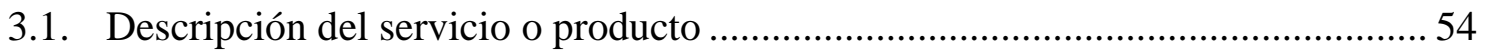

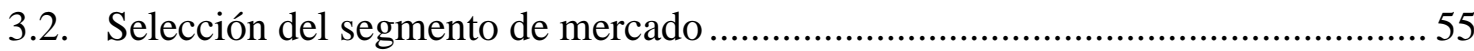

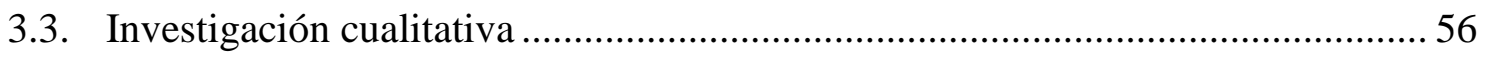

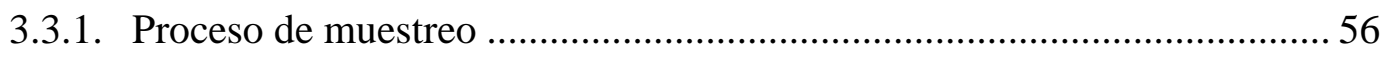

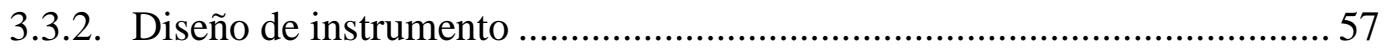

3.3.3. Análisis y procesamiento de datos .................................................... 57

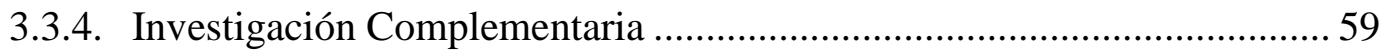

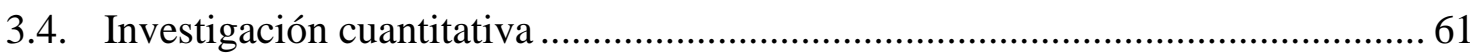

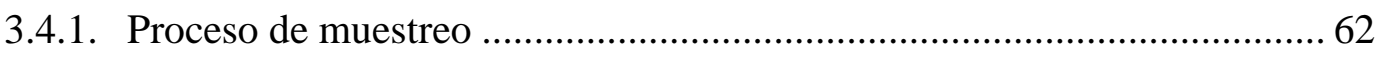

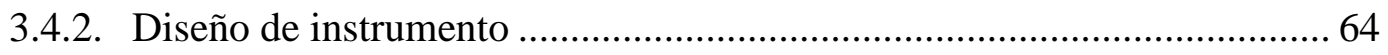

3.4.3. Análisis y procesamiento de datos ............................................................ 64 


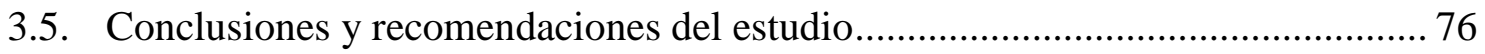

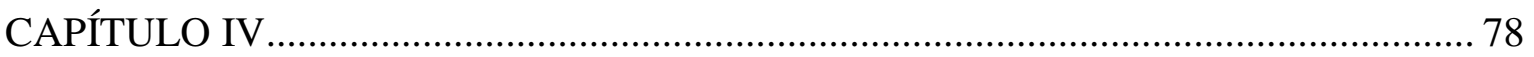

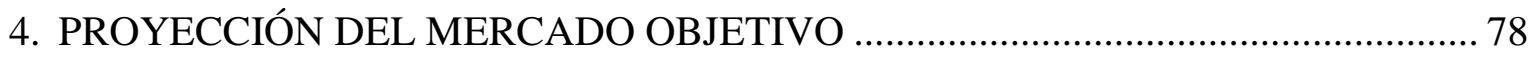

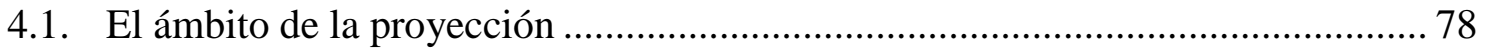

4.2. Selección del método de proyección .................................................................... 78

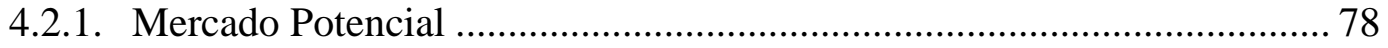

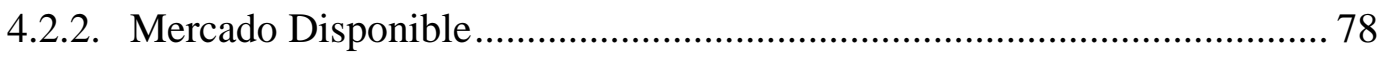

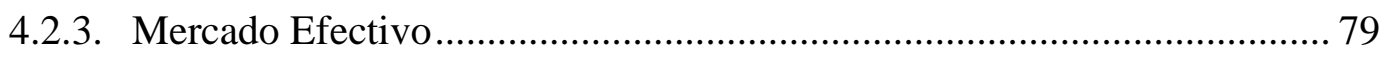

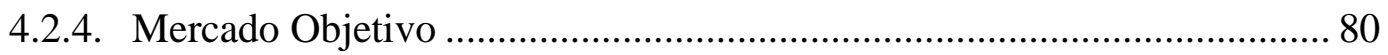

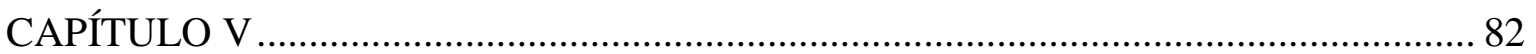

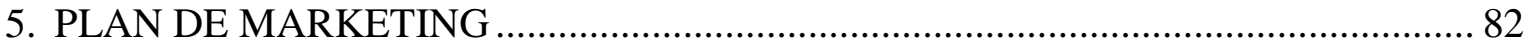

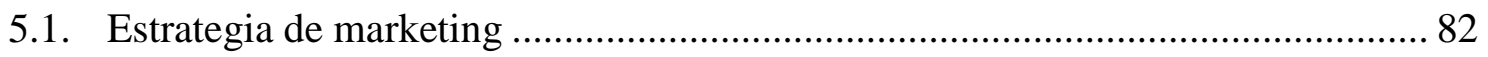

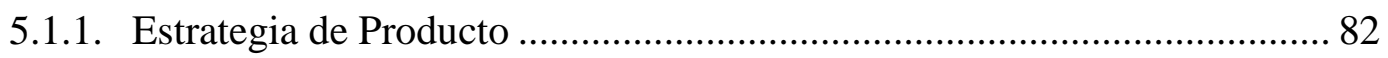

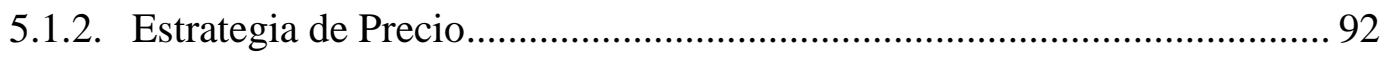

5.1.3. Estrategia de Plaza y Distribución ............................................................ 94

5.1.4. Estrategia de Promoción y publicidad ....................................................... 95

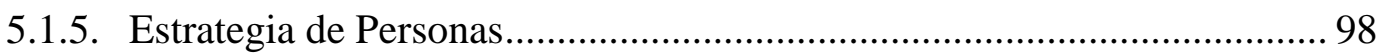

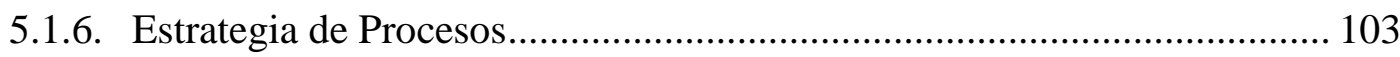

5.1.7. Estrategia de Presencia física........................................................... 103

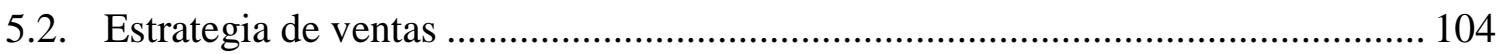

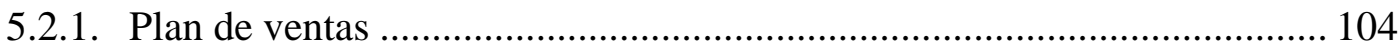

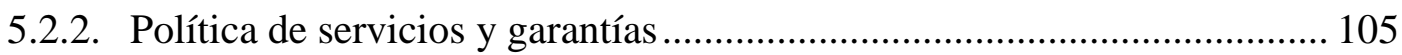

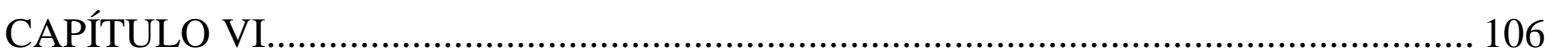

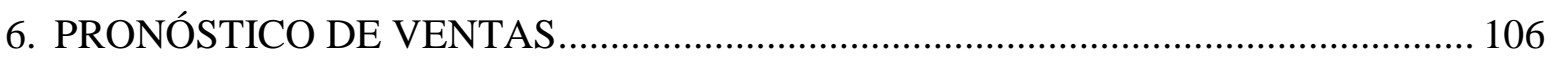

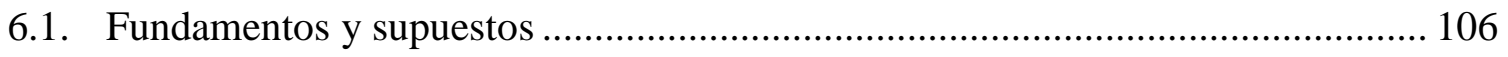


6.2. Justificación 106

6.3. Análisis de los riesgos y aspectos críticos que impactan en el proyecto 109

CAPÍTULO VII 110

7. INGENIERÍA DEL PROYECTO 110

7.1. Estudio de ingeniería 110

7.1.1. Modelamiento y selección de procesos productivos 111

7.1.2. Selección del equipamiento 115

7.1.3. Lay out 116

7.1.4. Distribución de equipos y maquinarias 116

7.2. Determinación del tamaño 117

7.2.1. Proyección de crecimiento 117

7.2.2. Recursos 118

7.2.3. Tecnología 118

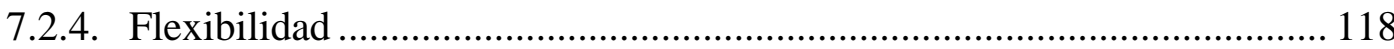

7.2.5. Selección del tamaño ideal....................................................................... 118

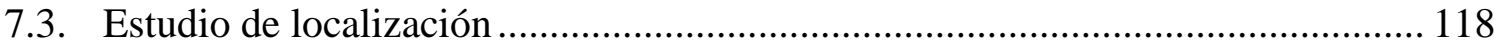

7.3.1. Definición de factores locacionales ......................................................... 119

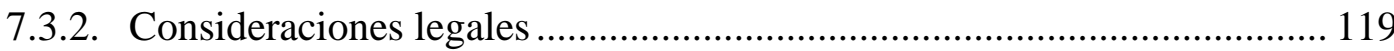

7.3.2.1. Identificación de marco legal ......................................................... 120

7.3.2.2. Ordenamiento Jurídico de la empresa ............................................... 120

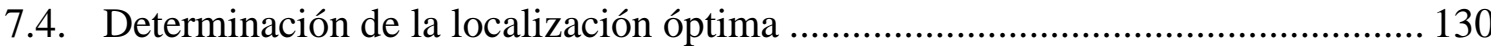

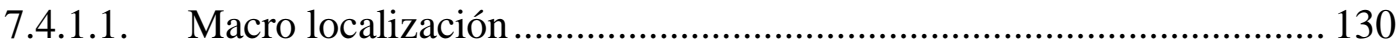

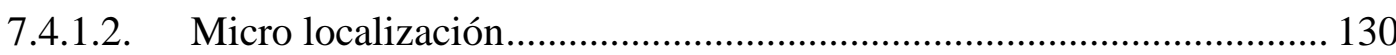

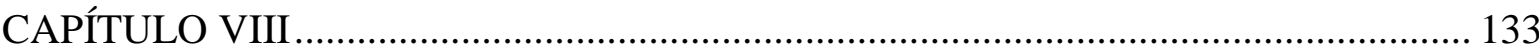

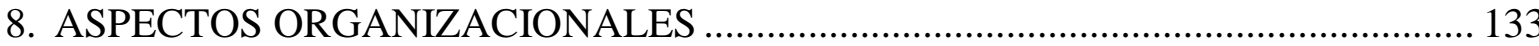


8.1. Caracterización de la cultura organizacional deseada

8.1.1. Visión

8.1.2. Misión

8.1.3. Principios

8.2. Formulación de estrategias de negocio

8.3. Determinación de las ventajas competitivas críticas .......................................... 134

8.4. Diseño de la estructura organizacional deseada .............................................. 135

8.5. Diseño de los perfiles de los puestos clave......................................................... 135

8.6. Remuneraciones, compensaciones e incentivos .............................................. 140

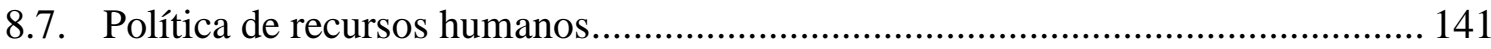

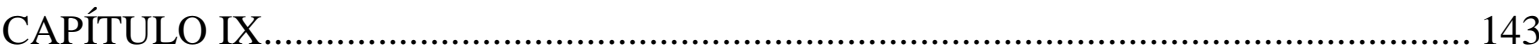

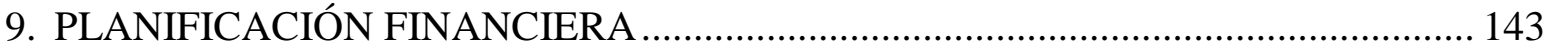

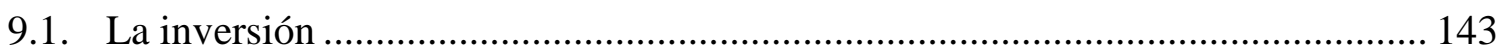

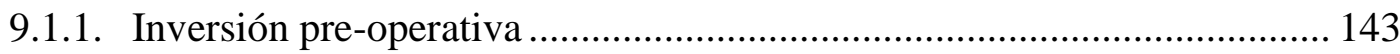

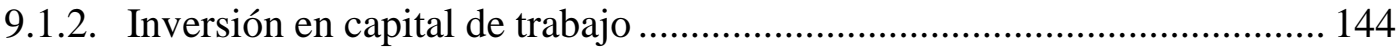

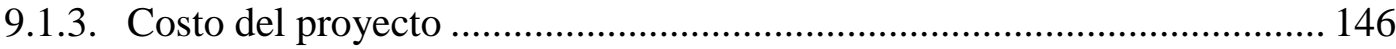

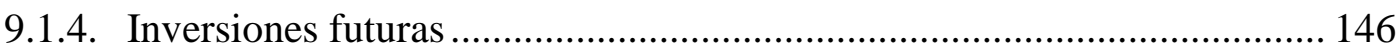

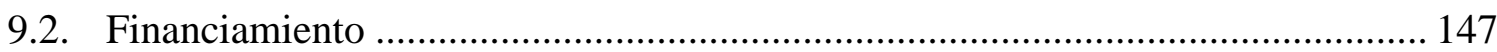

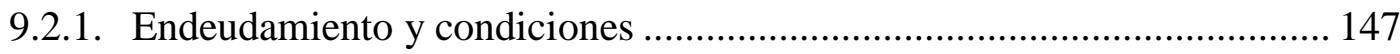

9.2.2. Capital y costo de oportunidad .......................................................... 147

9.2.3. Costo de capital promedio ponderado..................................................... 150

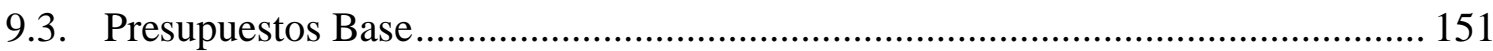

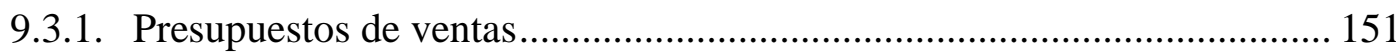

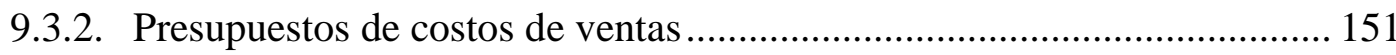

9.3.3. Presupuestos de gastos administrativos ............................................... 152 
9.3.4. Presupuestos de marketing y ventas

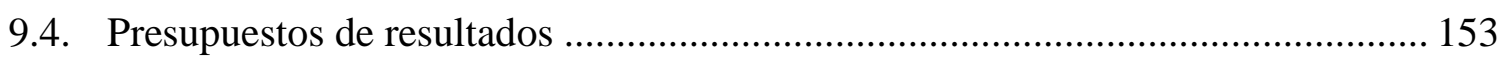

9.4.1. Estado de ganancias y pérdidas proyectado........................................ 153

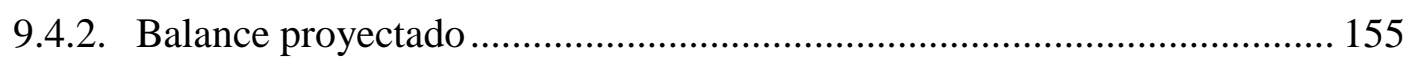

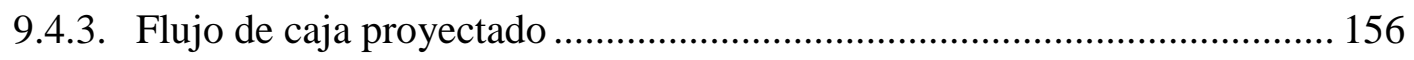

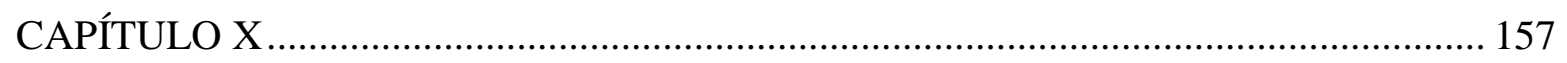

10. EVALUACIÓN ECONÓMICA FINANCIERA.......................................... 157

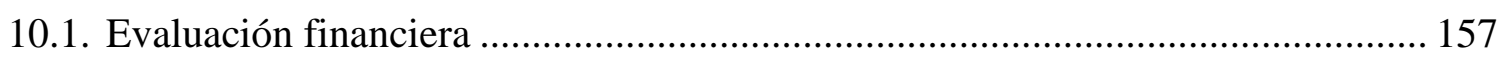

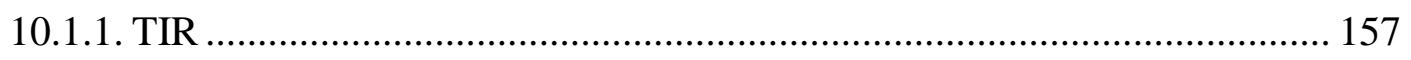

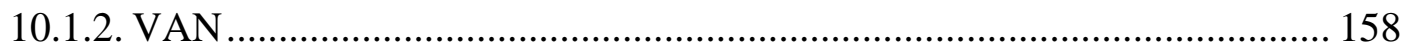

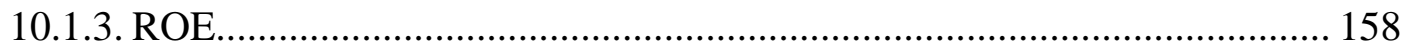

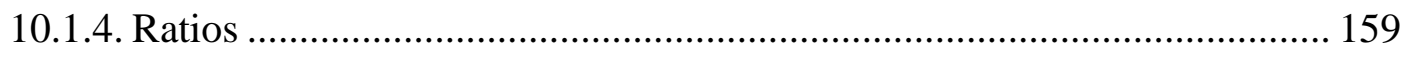

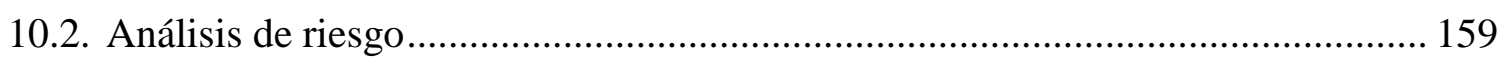

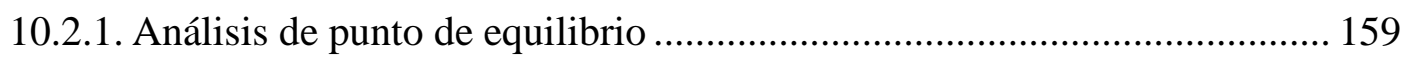

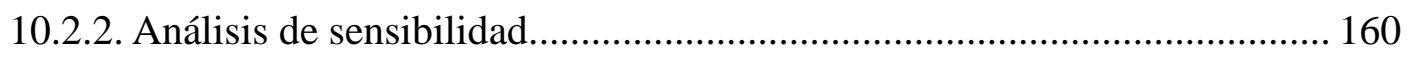

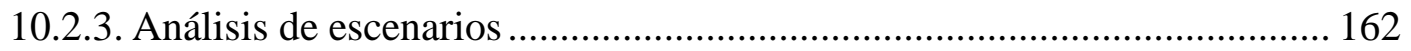

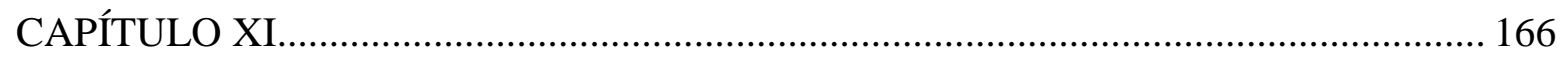

11. CONCLUSIONES Y RECOMENDACIONES ............................................ 166

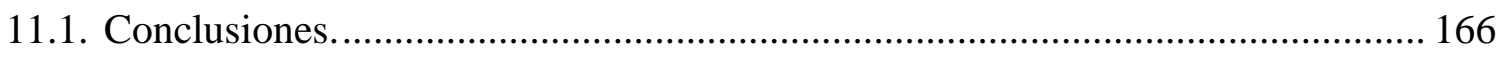

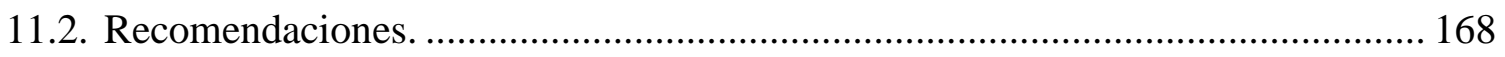

REFERENCIAS ELECTRÓNICAS ....................................................................... 210 


\section{ÍNDICE DE FIGURAS}

Figura 1. Participación de mercado de empresas que distribuyen software GIS.............. 40

Figura 2. Participación de mercado de empresas que distribuyen software CAD............. 41

Figura 3. El primer sondeo con Martín Vizcarra como presidente. .................................. 43

Figura 4. El primer sondeo con Martín Vizcarra como presidente. .................................. 44

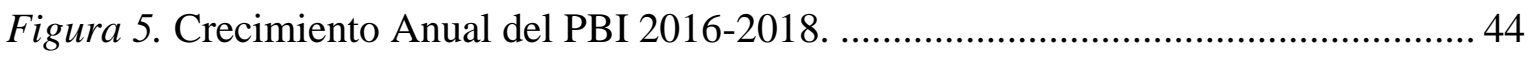

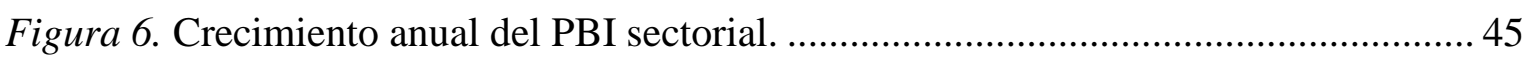

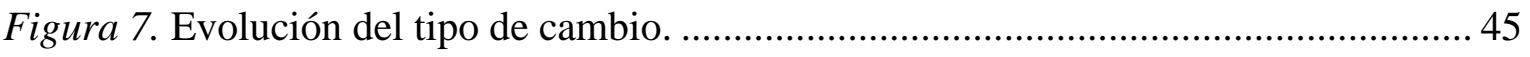

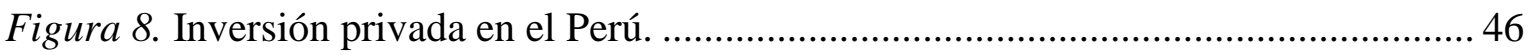

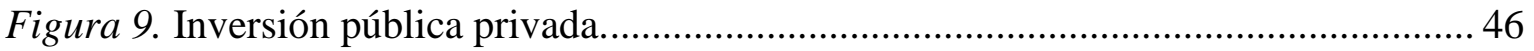

Figura 10. Ciclo reciente de la actividad Minera. ........................................................ 47

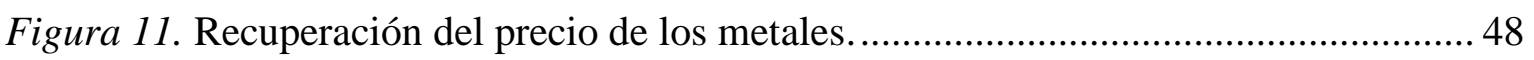

Figura 12. Indicadores que favorecen la inversión. ....................................................... 48

Figura 13. Recuperación de la Inversión en el sector minero. ........................................... 49

Figura 14. Inversión minera en el Perú.. ......................................................................... 50

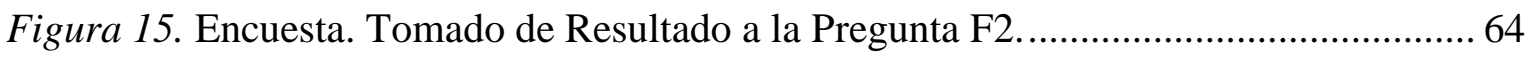

Figura 16. Encuesta. Tomado de Resultado a la Pregunta F3 ........................................... 65

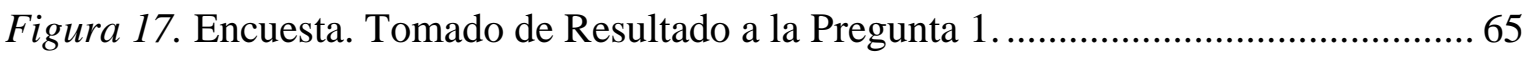

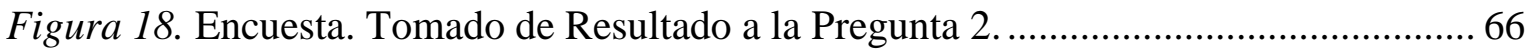

Figura 19. Encuesta. Tomado de Resultado a la Pregunta 3............................................. 66

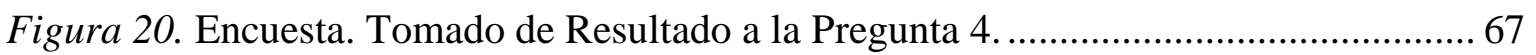

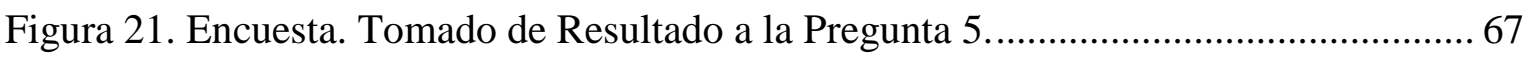

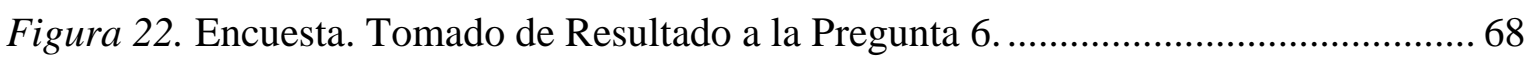

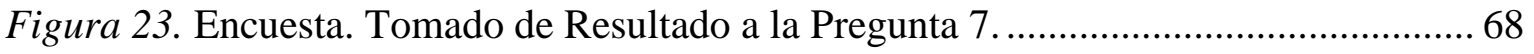


Figura 24. Encuesta. Tomado de Resultado a la Pregunta 8............................................... 69

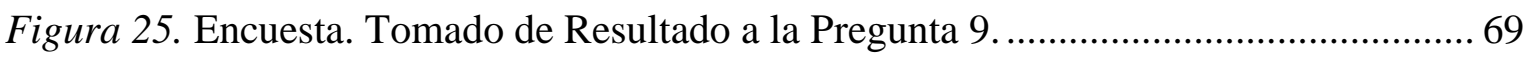

Figura 26. Encuesta. Tomado de Resultado a la Pregunta 10 ............................................ 70

Figura 27. Encuesta. Tomado de Resultado a la Pregunta 11 .......................................... 70

Figura 28. Encuesta. Tomado de Resultado a la Pregunta 12......................................... 71

Figura 29. Encuesta. Tomado de Resultado a la Pregunta 13......................................... 71

Figura 30. Encuesta. Tomado de Resultado a la Pregunta 14.......................................... 72

Figura 31. Encuesta. Tomado de Resultado a la Pregunta 15......................................... 72

Figura 32. Encuesta. Tomado de Resultado a la Pregunta 16........................................ 73

Figura 33. Encuesta. Tomado de Resultado a la Pregunta 17........................................ 73

Figura 34. Encuesta. Tomado de Resultado a la Pregunta 18............................................ 74

Figura 35. Raster para tratamiento imágenes en diferentes intensidades de color.............. 87

Figura 36. Tratamiento de imágenes con funcionalidad raster considerando altitud .......... 87

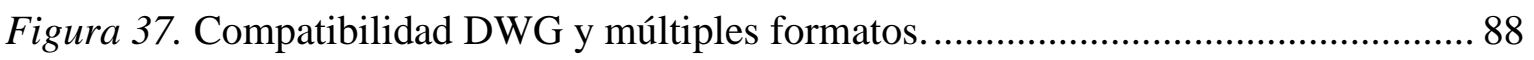

Figura 38. CAD Poket para dispositivos móviles ............................................................ 89

Figura 39. File Compare para detectar diferencia entre dibujos. ..................................... 89

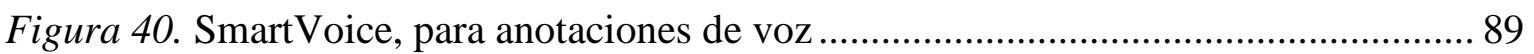

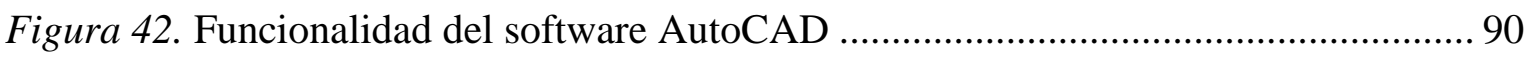

Figura 43. Funcionalidad del software ZwCAD ......................................................... 90

Figura 44. Modelo referencial de entrega de licencia electrónica..................................... 94

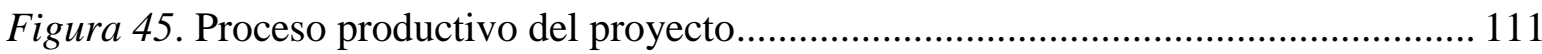

Figura 46. Proceso de prospección. Elaboración propia ....................................................... 112

Figura 47. Proceso de prospección. Elaboración propia ................................................. 112

Figura 48. Proceso de compra o adquisición. Elaboración propia ................................... 113

Figura 49. Proceso de comercialización. Elaboración propia ............................................. 114 
Figura 50. Proceso de servicio al cliente. Elaboración propia

Figura 51. Lay Out o plano de distribución de oficina. Elaboración propia ...................... 116

Figura 52. Plano de ubicación de la oficina elegida. Fuente: Google Maps ..................... 131

Figura 53 Detalle de inmueble. Fuente: Adondevivir.com ........................................... 132

Figura 54. Imagen del edificio de la oficina. Fuente: Adondevivir.com ......................... 132

Figura 55. Imagen del edificio de la oficina. Fuente: Adondevivir.com .......................... 132

Figura 56. Estructura organizacional del proyecto......................................................... 135 


\section{ÍNDICE DE TABLAS}

Tabla 1 Empresas que comercializan software especializado CAD y GIS......................... 26

Tabla 2 Software legal e ilegal en el Perú …................................................................... 27

Tabla 3 Resumen del análisis estructural del sector industrial ..................................... 35

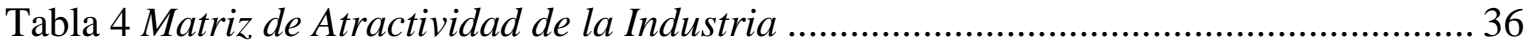

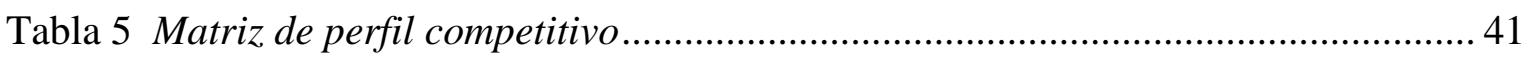

Tabla 6 Concentración de empresas por actividad económica .......................................... 55

Tabla 7 Relación de expertos para entrevistas en profundidad ..................................... 56

Tabla 8 Matriz de resumen de las entrevistas en profundidad ........................................ 58

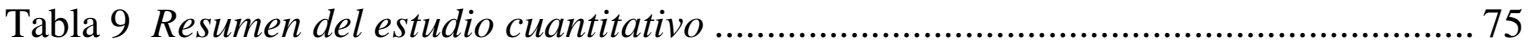

Tabla 10 Resultado marcas de software CAD y GIS que utilizan ...................................... 79

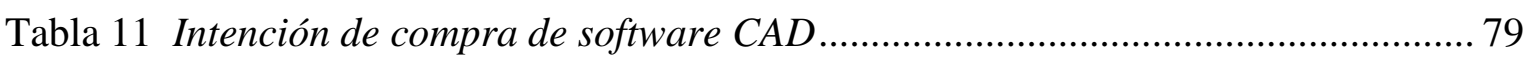

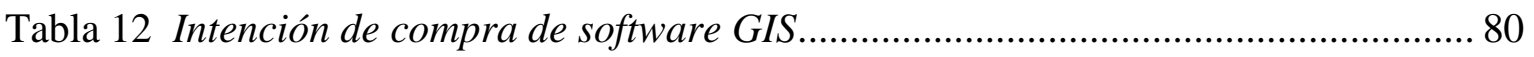

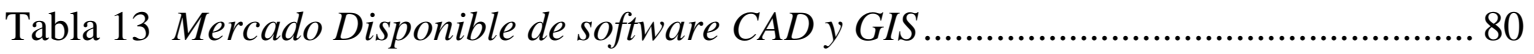

Tabla 14 Determinación de mercado objetivo de software CAD y GIS ............................ 81

Tabla 15 Oferta de Valor del proyecto y la competencia ................................................. 91

Tabla 16 Precios de venta de software ArcGIS y MapInfo Pro......................................... 92

Tabla 17 Precios de venta de software AutoCAD y ZwCAD ........................................... 93

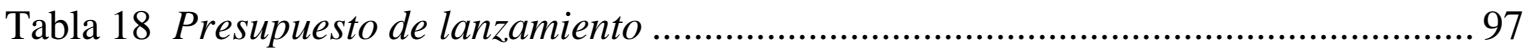

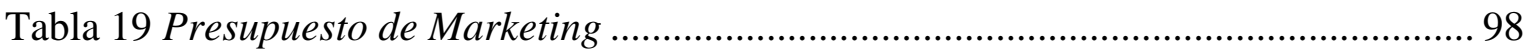

Tabla 20 Proyección de ventas de licencias ZwCAD y MapInfo Pro .................................. 107

Tabla 21 Crecimiento del sector en nuevas inversiones ................................................. 108

Tabla 22 Proyección de ventas de licencias y mnatenimientos de software CAD y GIS... 108

Tabla 23 Selección de Equipamiento ............................................................................. 115 
Tabla 24 Impuesto a la renta

Tabla 25 Evaluación de Macro localización 130

Tabla 26 Evaluación de Micro localización. 131

Tabla 27 Perfil de Administrador General 136

Tabla 28 Perfil de Consultor Senior 137

Tabla 29 Perfil de Ejecutivo Comercial. 138

Tabla 30 Perfil de Responsable de Sistemas 139

Tabla 31 Perfil de Asistente Administrativo 140

Tabla 32 Remuneraciones mensuales 141

Tabla 33 Inversión Pre Operativo

Tabla 34 Inversión en Capital de Trabajo Anualizado.... 144

Tabla 35 Determinación del capital de trabajo Inicial 145

Tabla 36 Costo del proyecto 146

Tabla 37 Inversiones futuras..... 146

Tabla 38 Determinación del Costo de Oportunidad (COK) 150

Tabla 39 Determinación del Costo Promedio Ponderado de Capital (WACC) 150

Tabla 40 Presupuesto de ventas proyectado 151

Tabla 41 Presupuesto de costo de ventas

Tabla 42 Presupuesto de gastos de administración 152

Tabla 43 Presupuesto de gastos de ventas y marketing

Tabla 44 Estado de ganancias y perdidas proyectado

Tabla 45 Balance general proyectado 155

Tabla 46 Flujo de caja proyectado 156

Tabla 47 La tasa interna de retorno (TIR). 157

Tabla 48 El valor actual neto (VAN) 
Tabla 49 Retorno de la Inversión.

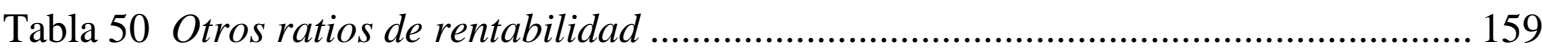

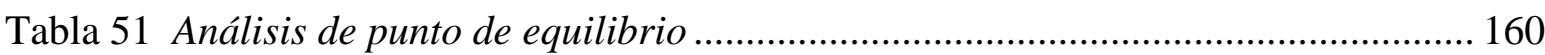

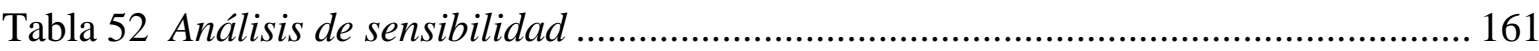

Tabla 53 Análisis de escenarios (Ingreso - Costo de ventas) .......................................... 163

Tabla 54 Análisis de escenarios (Ingreso - Gasto de ventas) .......................................... 164

Tabla 55 Resultado de análisis de escenarios (Ingresos - Costo de ventas)..................... 165

Tabla 56 Resultado de análisis de escenarios (Ingresos - Gasto de ventas) .................... 165 


\begin{abstract}
ANEXOS
\end{abstract}
Anexo 1 Propuesta para Distribuidores de ZwSoft 170

Anexo 2 Propuesta para Distribuidores de Pitney Bowes Software 171

Anexo 3 Guía de Preguntas para expertos en sistemas CAD y GIS 172

Anexo 4 Guía de Preguntas para Gerente de Sistemas y Usuarios 174

Anexo 5 Guía de Preguntas para ejecutivos de distribuidores de software 176

Anexo 6 Transcripción de entrevista en profundidad a Dr. Marino Carhuapoma 179

Anexo 7 Entrevista en profundidad a César Palacios Torres 191

Anexo 8 Entrevista en profundidad a César Palacios 196

Anexo 9 Entrevista en profundidad a Ruben Cabanillas 201

Anexo 10 Ficha técnica 205

Anexo 11 Cuestionario de Encuesta 206

Anexo 12 Precio de licencia ArcGIS 208

BIBLIOGRAFÍA 209 


\section{CAPÍTULO I}

\section{Generalidades}

\subsection{Antecedentes}

Todos los productos o servicios para llegar a los usuarios o consumidores necesitan necesariamente ser comercializadas, sin ser ajeno a ello el software, cuyos fabricantes utilizan diferentes formas y medios de comercialización; Wikipedia (2018) establece que por lo general utilizan el comercio electrónico, filiales, mayoristas o realizan alianzas comerciales con empresas locales, dependiendo del enfoque de cada fabricante.

Las principales compañías fabricantes de software se encuentran ubicados en países desarrollados, como Estados Unidos, Reino Unido, Suiza, Alemania, España, Japón, Rusia y otros como China, Australia e India, que requieren tener presencia en países en crecimiento como Perú. Además, conforme a las predicciones de Gartner (2017) la industria de la tecnología informática, seguirá en crecimiento en inteligencia artificial, digital y redes; por lo que la industria del software seguirá el mismo rumbo en razón que es complementario.

También se sabe que el Perú es un país emergente, donde la inversión privada mantiene la tendencia de crecimiento desde el año 2002, entre ellas empresas especializadas de ingeniería, arquitectura, telecomunicaciones, medio ambiente, geología y consumo masivo; siendo la transformación digital un objetivo de las empresas, como señaló el diario Gestión (2017). La transformación digital permite a las organizaciones optimizar sus proyectos, brindando herramientas tecnológicas como el software con valor agregado (como capacitación, soporte, 
mantenimiento, etc.) que ayuden a mejorar su productividad y competir con empresas de otras partes del mundo por efectos de la globalización.

Existen muchos software (programas informáticos) masificados, como los de ofimática (Hojas de cálculo, procesadores de textos, sistemas operativos para computadores personales (PCs) y Notebooks, los cuales son fáciles de adquirirlos, mediante tiendas comercializadores de productos informáticos o vía internet. Este tipo de software al ser masificados sus precios son relativamente bajos y otorga un margen muy bajo (entre $2 \%$ y $10 \%$ ) para aquellas empresas que los comercializan como señaló Wikipedia (2018).

También existen software especializado que están enfocados a mercados específicos y de alta especialización, como: ingeniería, arquitectura, procesamiento de imágenes satelitales, telecomunicaciones, medio ambientales, geociencia, seguridad, entre otros. Este tipo de software requieren una forma de comercialización diferenciado, para el cual los fabricantes requieren de empresas que tengan especialización y cuenten con personal calificado para comercializar dichos productos, inclusive en muchos casos ofrecen exclusividad, y normalmente otorgan un margen superior (Entre $20 \%$ y $50 \%$ ) respecto a los software de gran demanda; como establece en una publicación que "estar enfocado en un nicho de mercado específico trae grandes ventajas" (Gómez, 2014, parr 1). 


\subsection{Determinación del problema u oportunidad}

Como señaló el diario Gestión (2017) la transformación digital es una realidad para cualquier empresa que quiere competir en este mundo globalizado y los directivos saben de su importancia por lo que se encuentran en una acelerada implementación, siendo así; que la industria del software y la tecnología de información (IT) se encuentran en constante crecimiento.

Ser un distribuidor especializado otorga un mayor margen de descuento de los fabricantes de software, inclusive en muchos casos otorgan la exclusividad para la comercialización en un país o región, el cual garantiza el trabajo planificado a largo plazo.

Para los fabricantes de software es de interés querer llegar a nuevos mercados sin incurrir en gastos, por lo que buscan alianzas comerciales para llegar a dichos mercados (Gómez, 2014, parr 3). Abrir una filial es muy costoso para los fabricantes de software, por lo que prefieren hacerlo mediante empresas comercializadoras locales.

\subsection{Justificación del proyecto}

La experiencia de más de 15 años gestionando negocios en distintas industrias, las redes de contactos formados a lo largo este tiempo y los nuevos conocimientos adquiridos en la maestría, son razones para realizar este proyecto, con la finalidad de implementarlo si resulta rentable. 


\subsection{Objetivos generales y específicos}

\subsubsection{Objetivos generales}

Elaborar un plan de negocio que permita plantear, analizar y establecer la factibilidad y viabilidad para la comercialización de software enfocado a ingeniería, medio ambiente y sistema de información geográfica.

\subsubsection{Objetivos específicos}

Los objetivos específicos que se realizarán son los siguientes:

- Analizar el entorno de la industria del comercio de software

- Analizar el mercado para determinar el pronóstico de demanda y estrategia.

- Determinar los requerimientos técnicos y organizacionales.

- Calcular la inversión, el capital de trabajo y futuras inversiones del proyecto.

- Determinar el punto de equilibrio, riesgo y la rentabilidad del proyecto.

\subsection{Alcances y limitaciones de la investigación}

\subsubsection{Alcances}

El proyecto se encuentra contemplado para el territorio peruano. Las organizaciones a ser analizadas son aquellas que cumplan con la clasificación de medianas y grandes empresas del sector minería que se encuentren dentro de la lista de las Top 10,000 Perú 2017. 


\subsubsection{Limitaciones}

- Dificultad para conseguir datos, información y estadísticas de competidores directos e indirectos.

- Dificultad para concertar cita con ejecutivos, para realizar las entrevistas a profundidad.

- Tiempo para culminar con el proyecto, el cual es contemplado solamente hasta el 17 de marzo del 2018. 


\section{CAPÍTULO II}

\section{Estructura económica del sector}

\subsection{Descripción del estado actual de la industria}

La comercialización de software de gran demanda, como los software de ofimática (Hojas de cálculo, procesador de textos y etc.), antivirus para el hogar, diseño gráfico, entre otros; cuyos fabricantes son Microsoft, Adobe, Kaspersky, Eset NOD32 normalmente se realizan mediante empresas intermediarias que son distribuidores mayoristas de productos de tecnología de información, entre las que se encuentran: Ingram Micro Perú S.A.C., Intcomex Perú S.A., Grupo Deltron S.A., Maxima Internacional S.A., Nexsys del Perú S.A.C. y Sonda del Perú S.A. quienes revenden a empresas distribuidores de tecnología de información locales.

Mientras los software especializados, como los de Ingeniería, arquitectura, sistema de información geográfico, medio ambiente, geociencia, procesamiento de imágenes satelitales, telecomunicaciones, seguridad informática, base de datos, minería de datos, Big Data, Inteligencia de Negocios (Business Intelligence), ERP y otras soluciones empresariales como para financieras, cuyos fabricantes son: Esri, Bentley, Pitney Bowes, Datamine, Hexagon geospatial, Intergraph, ZWSoft, Microstrategy, IBM, SAP, GData, entre otras; la comercialización es realizada mediante empresas especializadas, autorizadas por el fabricante.

Aproximadamente el 90\% de mercado de Sistema de Información Geográfica (GIS) es dominado por productos de la marca Esri y el 95\% 
aproximadamente del mercado de Diseño Asistido por Computadora (CAD) es dominado por productos de la marca Autodesk

\subsubsection{Segmentación de la industria}

De acuerdo a la forma de comercialización se clasifican en dos tipos:

\section{a. Comercializadores TI}

Son aquellas empresas que simplemente se dedican a la compra y venta de productos de tecnología de información, donde se encuentran los paquetes (software empaquetado) sin agregar valor, por lo general son software para ofimática, como procesadores de textos, hojas de cálculos u otros software comunes.

\section{b. Comercializadores Especializados}

Son aquellas empresas que además de comprar y vender software empaquetado, agregan valor, por tratarse de productos especializados, para el cual brindan capacitación, implementación, soporte y mantenimiento periódico, las que principalmente se subdividen en:

- Especializadas en Seguridad informática

- Especializadas en base de datos (BD) y Big Data

- Especializados en Exploración geológica y minería

- Especializados en tratamiento de imágenes satelitales

- Especializado en aeronáutica

- Especializadas en inteligencia de negocios (BI) 
- Especializadas en sistemas de Planificación de Recursos Empresariales (ERP)

- Especializadas en Fabricación asistida por Computadora (CAM)

- Especializadas en sistemas de Diseño Asistido por Computadora (CAD) y Sistema de Información Geográfico (GIS)

El proyecto en estudio está enfocado a este segmento.

\subsubsection{Empresas que la conforman}

Las principales empresas que comercializan software especializados para Medio Ambiente, CAD y GIS (ver Tabla 1).

\section{Tabla 1}

Empresas que comercializan software especializado CAD y GIS.

\begin{tabular}{lrccc}
\hline Razón Social & $\begin{array}{c}\text { Venta } \\
\text { Anual en S/ }\end{array}$ & \multicolumn{1}{c}{ Especialización } & Empleados & Ubicación \\
\hline Profile Consulting Group S.A.C. & $10,000,000$ & CAD, GIS y Consultoría & 13 & LIMA \\
Telemática S.A. & $12,000,000$ & GIS y Consultoría & 40 & LIMA \\
Business Technology S.A.C. & & CAD y Otros & 30 & LIMA \\
Cardo Consultants S.A.C. & 300,000 & GIS y Consultoría & 1 & LIMA \\
Softland Perú S.A. & & CAD, GIS y Otros & 12 & LIMA \\
Réplica S.R.LTDA & CAD y Otros & 21 & LIMA \\
\hline
\end{tabular}

Nota. Los montos de las ventas anuales corresponden solamente a software CAD y GIS y fueron obtenidos mediante entrevista a especialistas de dos empresas indicadas en la tabla. 
2.2. Tendencias de la industria (crecimiento, inversiones)

Según menciona la Business Software Alliance (2016), la industria del comercio legal de software de aplicación en el Perú, equivalía a 123 millones de dólares en el año 2015, considerando que en los informes bianuales realizados por esta misma entidad las que fueron 103 y 134 millones de dólares en el 2011 y 2013 respectivamente, con el que el crecimiento estimado es $10.94 \%$ (ver Tabla 2).

\section{Tabla 2}

Software legal e ilegal en el Perú

\begin{tabular}{lccccccc}
\hline & \multicolumn{2}{c}{$\mathbf{2 0 1 5}$} & \multicolumn{2}{c}{$\mathbf{2 0 1 3}$} & \multicolumn{2}{c}{$\mathbf{2 0 1 1}$} \\
& Ilegal & Legal & Ilegal & Legal & Ilegal & Legal \\
\hline Porcentaje (Ilegal-Legal) & $63 \%$ & $37 \%$ & $65 \%$ & $35 \%$ & $67 \%$ & $33 \%$ \\
Valor en Millones de U\$ & 210 & 123 & 249 & 134 & 209 & 103 \\
\hline
\end{tabular}

Nota. El mercado ilegal está disminuyendo de 67\% a 65\% y 63\% al 2011, 2013 y 2015 respectivamente. Adaptado de informe de BSA del 2016.

Otro aspecto importante obtenidos de las entrevistas en profundidad a ejecutivos de ventas, es que el comercio de software que en la actualidad es mediante licencias de uso, en el mediano plazo se hará como servicio, es decir se cobrará anualmente, luego se reducirá a semestral, mensual y finalmente serán cobrados por minutos de uso.

\subsection{Análisis estructural del sector industrial}

Para analizar el sector industrial se seguirá el modelo de las cinco fuerzas competitivas (Porter, 2004). 


\subsubsection{Poder de negociación de los clientes}

Para el análisis del poder de negociación de los clientes, hemos considerado los siguientes factores (Porter, 2004).

\section{a. Concentración de Clientes}

No existe una concentración de empresas o clientes

\section{b. Grado de dependencia de canales de distribución de software}

Existe un nivel medio de dependencia, ya que los clientes son empresas del sector minería, cuyo rubro es el medio ambiente, Ingeniería, arquitectura o aquellos que requieran de sistemas de información geográfico, que requieren no solamente el software si no lo más importante para ellos es el valor agregado como las capacitaciones o soluciones a inconvenientes de manera rápida y para ello necesitan empresas que tengan especialización y personal calificado para atender dichas necesidades, existiendo en el medio muy pocas empresas enfocado a este mercado.

\section{c. Volumen de compra}

Las compras de software o soluciones en CAD y GIS que estas realizan no son de alto volumen, por lo que su poder de negociación en este aspecto es bajo. 


\section{d. Políticas corporativas}

La mayoría de las empresas del sector minero son medianas o grandes compañías y tiene exigencias específicas que sus proveedores deben cumplir, entre ellos políticas respecto código de conducta de buenas prácticas, certificaciones tipo ISO, política de pagos que en su mayoría son a 30 días, por lo que se considera que el poder de negociación de los clientes es medio.

\subsubsection{Poder de negociación de los proveedores}

Para analizar la amenaza que los proveedores imponen a la industria a consecuencia de su poder, se determinará utilizando los siguientes factores (Porter, 2004).

\section{a. Concentración de Proveedores.}

Los principales proveedores de software (Son los mismos fabricantes) y especialmente los especializados en medio ambiente, Ingeniería, arquitectura y sistema de información geográfico son del exterior, Estados Unidos, Australia y China. Específicamente para el proyecto se ha decidido representar a dos marcas, ZwSoft y Pitney Bowes Software, reconocidos entre los tres principales desarrolladores de software CAD y GIS respectivamente, siendo el grado de concentración alto, basado en su participación de mercado. 


\section{b. Patentes y código fuente.}

El código fuente y patente de las marcas MapInfo y ZwCAD son propiedad de cada uno de los proveedores, por lo que se encuentran pleno derecho de hacer uso en base a sus conveniencias de los mismos, pudiendo colocar o quitar distribuidores basados en sus políticas o cambios que pudieran realizar, en este caso el poder de negociación del proveedor es alta.

\section{c. El costo en relación al precio de venta.}

ZwSoft, es una compañía de nacionalidad China, que desarrolla software CAD llamado ZwCAD, cuya forma de comercialización es mediante Distribuidores Autorizados (ZwSoft, 2018). Para ser Distribuidor Autorizado de ZwSoft, es necesario firmar un contrato entre ambas partes y hacer un pago único por ingreso equivalente a U\$ 5,000 Dólares Americanos. Para mantener dicha condición es necesario haber comercializado como mínimo 40 licencias por año. El precio sugerido de venta al usuario final por licencia es U\$ 1,000 libre de impuestos y el margen para el distribuidor equivale al $50 \%$ de dicho valor y $25 \%$ para el caso de mantenimiento anual, el cual es un servicio anual que inicia a partir del inicio del segundo año, el que garantiza el soporte técnico, parches y entrega de nuevas versiones que pudieran salir durante el periodo de vigencia de dicho valor (ver Anexo 1). 
Pitney Bowes Software Inc, es una compañía de Estados Unidos, con sede en Texas y desarrolla software y soluciones para Sistema de Información Geográfica (GIS), Comunicación con el Cliente (CCM) y data a nivel mundial. Su principal software reconocido a nivel mundial es llamado MapInfo Pro (Pitney Bowes, 2018). Para ser distribuidores Autorizados es necesario la firma de un contrato entre ambas partes y hacer un pago inicial único de U\$ 5,000 Dólares Americanos, por lo que se recibe 2 Licencias NFR del software de MapInfo Pro y una capacitación de 24 horas online. El precio sugerido de venta al usuario final por licencia es U\$2,395 Dólares Americanos libre de impuestos y el margen para el distribuidor equivale al $30 \%$ de dicho valor y $20 \%$ para el caso de mantenimiento anual, el cual es un servicio anual que inicia a partir del inicio del segundo año, el que garantiza el soporte técnico, parches y entrega de nuevas versiones que pudieran salir durante el periodo de vigencia. (ver Anexo 2).

\subsubsection{Amenaza de competidores potenciales}

El análisis de la amenaza de ingreso de competidores potenciales al comercio de software CAD y GIS, se ha utilizando los siguientes factores (Porter, 2004). 


\section{a. Barrera de ingreso}

Existe la posibilidad que otras empresas incursionen en el negocio, ya que la barrera de ingreso es baja, la cual está limitada solamente por la especialización, personal calificado.

\section{b. Inversión}

La inversión requerida para ser reconocidos como distribuidor autorizado de cada una de las marcas es solamente U\$ 5,000 Dólares Americanos

\section{c. Políticas Gubernamentales}

La legislación aplicable para este tipo de proyectos es general, es decir no necesita ningún requisito especial para la constitución de una empresa comercializadora de software CAD y GIS.

\subsubsection{Amenaza de productos sustitutos}

Para analizar la amenaza de productos sustitutos al comercio de software CAD y GIS, se ha utilizando los siguientes factores (Porter, 2004).

\section{a. Tendencia de compra alternativos}

La tendencia de los usuarios es la utilización de múltiples tecnologías, por lo que en una misma compañía pueden usar más de una. Es probable que en el futuro cercano, se encuentre otras formas de ser más productivos haciendo uso de la inteligencia artificial, pero 
de todos modos incluye como un componente el software, por lo que la amenaza de productos sustitutos siempre estará presente.

\section{b. Percepción de los productos}

La percepción sobre los productos que se pretende comercializar es de ser muy reconocida, específicamente MapInfo Pro (GIS) es percibida como el software GIS más liviano y estable con renombre a nivel mundial, mientras que $\mathrm{ZwCAD}(\mathrm{CAD})$ es reconocida como el software CAD alternativo a AutoCAD, líder mundial en software CAD.

\section{c. Disponibilidad de productos sustitutos}

En la actualidad hay muchos productos alternativos o sustitutos, tanto de tipo comercial que tiene un costo por sus licenciamientos, pero no tienen presencia local o en su defecto no son muy conocidos. Otro tipo es el software de uso libre, cuyo licenciamiento es gratuito, pero requiere de un alto conocimiento técnico para su implementación y el soporte, capacitación y mantenimientos son escasos.

\subsubsection{Rivalidad entre competidores actuales}

El análisis de la rivalidad entre competidores actuales de la industrial de comercio de software CAD y GIS se realizó considerando los siguientes factores (Porter, 2004). 


\section{a. Cantidad de proveedores}

La cantidad de proveedores potenciales de software GIS identificado solo son tres y de software CAD son ocho, siendo relativamente bajos, considerando que estas tecnologías son aplicables a muchos mercados.

\section{b. Tasa de crecimiento de la Industria}

La tasa de crecimiento de la industrial del comercio de software muestra un crecimiento de $10.9 \%$ según informe de la Business Software Alliance (2016).

\section{c. Valor de la marca}

Las marcas MapInfo y ZwCAD tienen prestigio mundial y presencia en más de 80 países. El primero tiene más de 30 años en el mercado y el segundo 20 años.

\section{d. Barrera de salida}

La barrera de salida se encuentra limitada por las normas generales, sin ser nada excepcionales. Decidida la salida, se debe comunicar a los proveedores y clientes, hacer los pagos de impuestos, luego a los trabajadores y finalmente a los accionistas. 


\section{El resumen del análisis estructural del sector industrial se realizó}

utilizando el método de 5 las fuerzas competitivas (Porter, 2004), cuyo

resumen se describe a continuación (ver Tabla 3).

Tabla 3

Resumen del análisis estructural del sector industrial

\begin{tabular}{|c|c|c|}
\hline Fuerzas competitivas & Justificación & Calificación \\
\hline Poder de negociación de los clientes & $\begin{array}{l}\text { No existe una concentración de las las empresas o clientes. } \\
\text { El volumen de compra del cliente es baja. } \\
\text { El grado de dependencia con el distribuidor es alta, por requerir } \\
\text { personal calificado. } \\
\text { La capacidad de integración no justifica por el poco volumen de } \\
\text { compra. } \\
\text { No es relevante la sensibilidad al precio. }\end{array}$ & Bajo \\
\hline Poder de negociación de los proveedores & $\begin{array}{l}\text { El grado de concentración del proveedor GIS se mantiene entre los } \\
\text { líderes del mundo. El proveedor CAD tiene una fuerte presencia en } \\
\text { muchos países. } \\
\text { Los proveedores (Fabricantes) están en EEUU y China, y llegar a } \\
\text { muchos mercados mediante Distribuidores Autorizados las que } \\
\text { deben ser especializadas. } \\
\text { Tienen la potestad de incrementar o sacar distribuidores conforme } \\
\text { a sus políticas o estrategias. }\end{array}$ & Medio \\
\hline Amenaza de competidores potenciales & $\begin{array}{l}\text { La barrera de ingreso es baja, las pocas restricciones son: } \\
\text { especialización, personal calificado y una inversión } \$ 5,000 \text { para } \\
\text { contrato con el fabricante. } \\
\text { Afecto a la legislación general (ninguna especial) }\end{array}$ & Alta \\
\hline Amenaza de productos sustitutos & $\begin{array}{l}\text { La tendencia de compra del usuario es usar múltiples herramientas } \\
\text { (software) pudiendo existir más un tipo de software en una misma } \\
\text { empresa. } \\
\text { La percepción de MapInfo Pro (GIS) es muy bien reconocida, } \\
\text { mientras que ZwCAD es percibida como una muy buena } \\
\text { alternativa a AutoCAD, líder del mercado CAD }\end{array}$ & Medio \\
\hline Rivalidad entre competidores actuales & $\begin{array}{l}\text { La cantidad de competidores identificados para MapInfo Pro (GIS) } \\
\text { son tres empresas. Mientras que para ZwCAD (CAD) son ocho } \\
\text { empresas. } \\
\text { La tasa de crecimiento de la industria del comercio de software en } \\
\text { el Perú equivale a } 10.9 \% \text { según la BSA. } \\
\text { La barrera de salida es bajo. } \\
\text { El valor de la marca MapInfo es reconocido a nivel mundial. }\end{array}$ & Bajo \\
\hline
\end{tabular}

Nota. Las calificaciones son subjetivas en base a las entrevistas en profundidad y la recopilación de fuentes secundarias. 
Para concluir, se ha realizado una matriz de atractividad de la industria, basado en el poder de cada una de las cinco fuerzas competitivas y sus respectivos factores de cada una de ellas. La calificación del nivel de atractividad van desde 1 hasta 5, siendo 1 menos atractivo y 5 muy atractivo, además los pesos otorgados a cada fuerza es 0.2 cuya suma es igual a 1. (ver Tabla 4)

\section{Tabla 4}

Matriz de Atractividad de la Industria

\begin{tabular}{lcccc}
\hline \multicolumn{1}{c}{ Fuerzas Competitivas } & Poder & Ponderación & $\begin{array}{c}\text { Nivel de } \\
\text { atractividad }\end{array}$ & $\begin{array}{c}\text { Nivel de } \\
\text { atractividad } \\
\text { Ponderada }\end{array}$ \\
\hline Poder de negociación de los clientes & Bajo & 0.2 & 4.0 & 0.8 \\
Poder de negociación de los proveedores & Medio & 0.2 & 2.5 & 0.5 \\
Amenaza de competidores potenciales & Alto & 0.2 & 1.0 & 0.2 \\
Amenaza de productos sustitutos & Medio & 0.2 & 2.5 & 0.5 \\
Rivalidad entre competidores actuales & Bajo & 0.2 & 3.5 & 0.5 \\
\hline \multicolumn{1}{c}{ Total } & & 1.0 & & $\mathbf{2 . 7}$ \\
\hline
\end{tabular}

Nota. Las calificaciones son subjetivas en base al poder de cada una de las cinco fuerzas competitivas, siendo los resultados el nivel de atractividad que tiene la industria, cuya calificación va desde 1 , como nada atractivo hasta 5 , como muy atractivo.

En conclusión:

a. El poder de negociación de los clientes es bajo, en razón que no existe una concentración de compradores, su nivel de compra es baja y mantiene un buen grado de dependencia de su proveedor de software especializado.

b. El poder de negociación de los proveedores es "Alto", debido a que son propietarios de las marcas de los productos y tiene un grado importante de concentración de mercado en el mundo, pero no tienen presencia local, por lo que es necesario un reseller local. 
c. La amenaza de competidores potenciales, es alta en razón que la barrera de ingreso de nuevos competidores es baja, no existe restricciones legales especiales y el nivel de inversión requerido para la apertura es bajo.

d. La amenaza de productos sustitutos es medio, por que la tendencia de los usuarios finales es usar múltiples tecnologías, pero la percepción de los productos MapInfo y ZwCAD son reconocidos entre los principales y no existe una facilidad para productos alternativos como el software libre.

e. La rivalidad entre los competidores actuales es baja, debido a que no existen muchos proveedores especializado, el valor de las marcas a representar son altas, la barrera de salida es baja, además la tasa de crecimiento de la industrias promedio es $10.9 \%$.

\subsection{Análisis de la competencia}

En el análisis de la competencia se ha identificado aquellas empresas que tengan semejanzas con el proyecto, resaltando sus principales características y diferencias.

\subsubsection{Empresas que ofrecen el mismo productos o servicio}

\section{a. Profile Consulting Group}

Empresa fundada en el año 1995, especializada en CAD/

CAD/AEC/BIM/GIS representa a las marcas Autodesk, HP, MapInfo, Adobe, y Microsoft (Profile Consulting Group, 2017). 
Su principal enfoque son el sector público y las empresas del sector construcción y cuenta con personal calificado para el área de arquitectura e ingeniería mecánica.

\section{b. Telemática S.A.}

Empresa fundada en el año 1993, especializada en GIS representa a las marcas Esri, Envi y Lizardtech, enfocado a geomática en general.

Están orientado a las ventas y tienen la exclusividad para comercializar los productos de la marca ESRI (Telemática, 2018).

Cuenta solamente con especialistas junior, para proyectos específicos sub contratan a consultores externos.

\section{c. Business Technology S.A.C.}

Empresa fundada en el año 2010, compañía que integra soluciones de tecnología de información, representa a las marcas Autodesk, HP, MapInfo, Adobe, Corel, DiviceLock, RedHat, Oracle, Kaspersky, Symantec, Microsoft, IBM, Dell, Lenovo y otros (BTECH, 2018).

Su principal enfoque es la comercialización de software y hardware de muchas marcas. 
Cuenta con personal técnico, que brinda soporte a múltiples usuarios.

\section{d. Cardo Consultants S.A.C.}

Empresa fundada en el año 2000, especializada en Geología representa a la marca MapInfo. Al 14 de abril del 2018 el Gerente General Owen Miller, indicaba que dejó de representar a MapInfo (Datos Perú, 2018).

Su enfoque es la exploración geológica minera, y es el mismo dueño quien brinda el servicio en razón que es Ing. Geólogo.

\section{e. Softland Perú S.A.}

Empresa fundada en el año 1993, comercializa software variado y representa a las marcas Autodesk, Adobe, Corel, VMware, Golden Software, V-Ray, Kaspersky, Symantec, GeoTrust, TeamViewer y otros (Softland Perú, 2017).

Orientado a la venta software de diferentes tipos y cuenta con personal técnico especializado en soporte general.

\section{f. Réplica S.R.LTDA}

Empresa fundada en el año 1994, especializada en CAD entre otros, representa a las marcas Autodesk, HP, Adobe, Microsoft, VMware, Citrix, Amazon y otros (Replica, 2018). 
Su principal enfoque el el sector Arquitectura y Construcción, cuyos principales accionistas son Arquitectos.

Cuentan con equipo de ventas y soporte especializado en arquitectura.

\subsubsection{Participación de mercado de cada uno de ellos}

La participación de mercados de las empresas que comercializan software CAD y GIS, se indican el al Figura 1. y Figura 2. y corresponden a los resultados obtenidos de la investigación realizada para el presente proyecto.

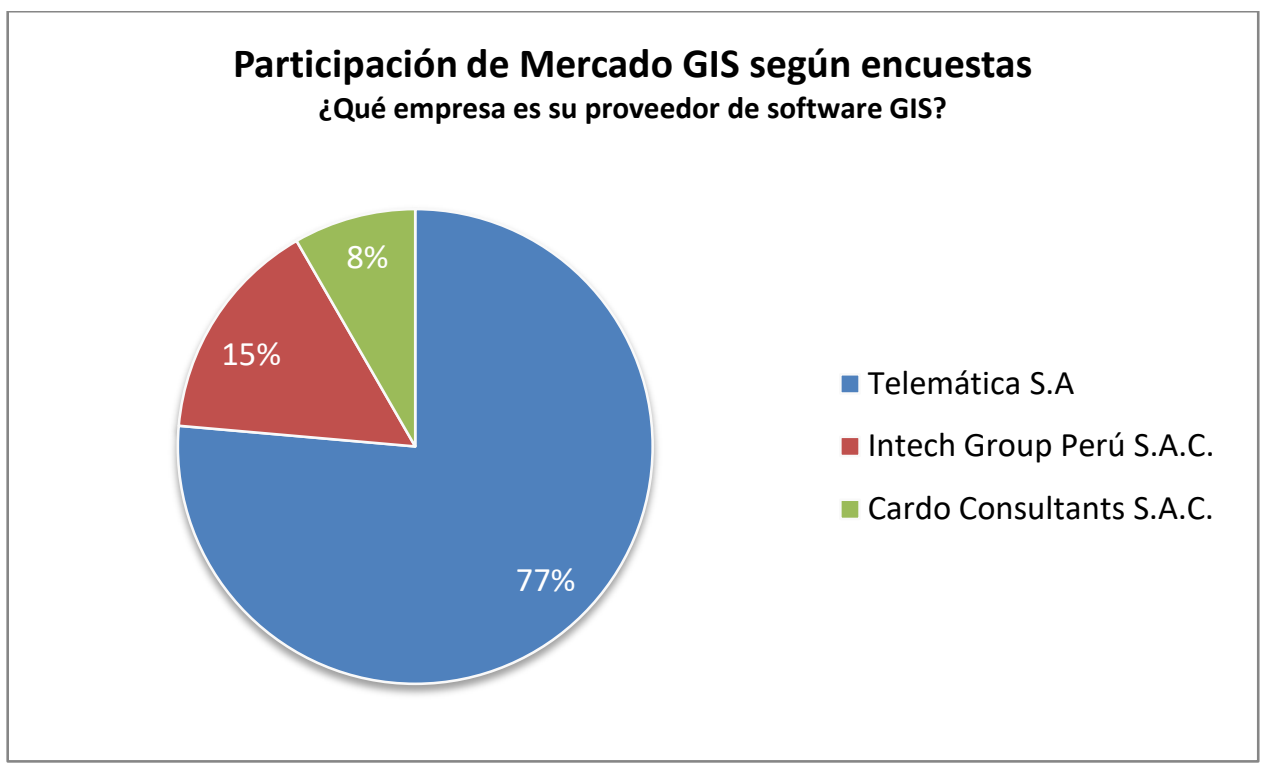

Figura 1. Participación de mercado de empresas que distribuyen software GIS. Elaboración propia, con información de investigación de mercado realizado para el proyecto. 


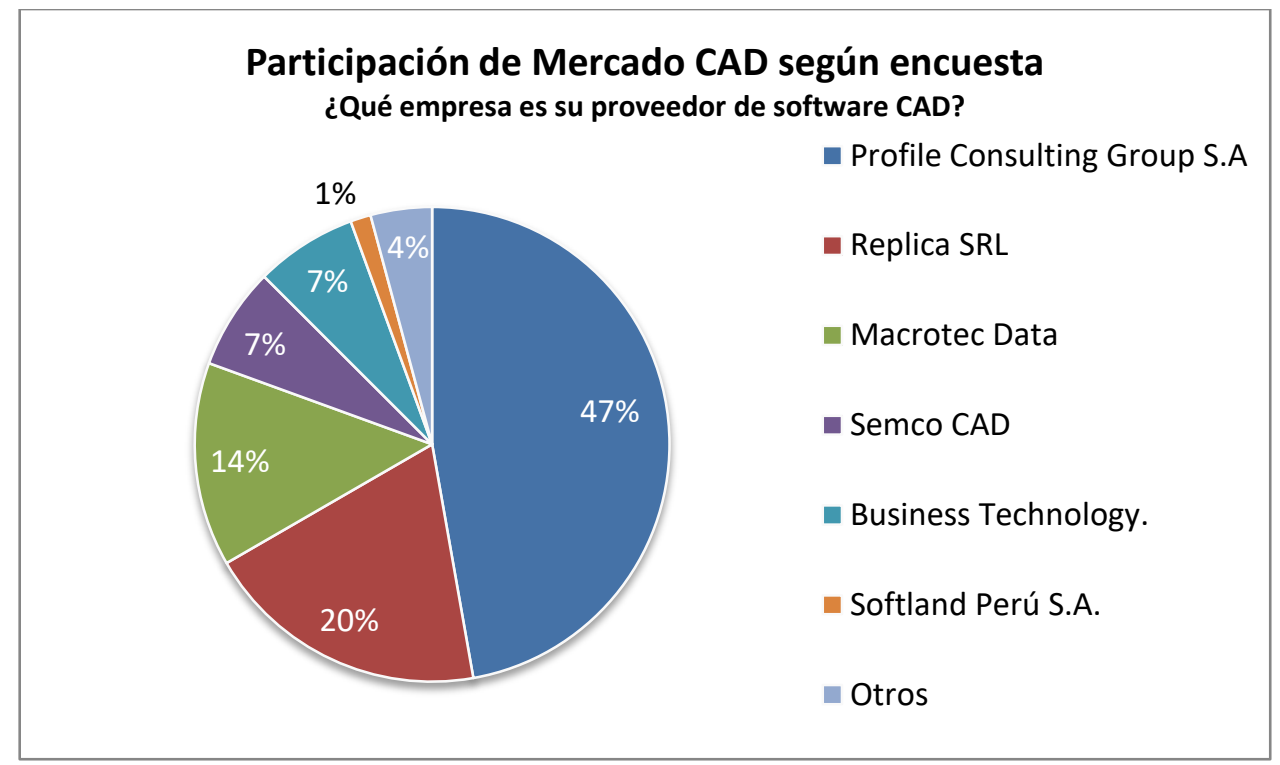

Figura 2. Participación de mercado de empresas que distribuyen software CAD. Elaboración propia, con información de investigación de mercado realizado para el proyecto.

\subsubsection{Matriz de perfil competitivo}

La matriz de perfil competitivo de las empresas que comercializan software se realizaron considerando factores que se identificaron mediante las entrevistas en profundidad a expertos, donde no se considera en la evaluación al proyecto, porque no se encuentra en el mercado (ver Tabla 5).

\section{Tabla 5}

Matriz de perfil competitivo

\begin{tabular}{|c|c|c|c|c|c|c|c|c|c|}
\hline \multirow[t]{2}{*}{$\begin{array}{c}\text { Factores críticos para el } \\
\text { éxito }\end{array}$} & \multicolumn{3}{|c|}{$\begin{array}{c}\text { Profile } \\
\text { Consulting S.A. }\end{array}$} & \multicolumn{2}{|c|}{ Telemática S.A. } & \multicolumn{2}{|c|}{ Replica SRL } & \multicolumn{2}{|c|}{$\begin{array}{c}\text { Cardo } \\
\text { Consultants } \\
\text { S.A.C. } \\
\end{array}$} \\
\hline & Peso & Calif. & $\begin{array}{c}\text { Peso } \\
\text { Ponderada }\end{array}$ & Calif. & $\begin{array}{c}\text { Peso } \\
\text { Ponderada }\end{array}$ & Calif. & $\begin{array}{c}\text { Peso } \\
\text { Ponderada }\end{array}$ & Calif. & $\begin{array}{c}\text { Peso } \\
\text { Ponderada }\end{array}$ \\
\hline Personal calificado & 0.15 & 3 & 0.45 & 3 & 0.45 & 2 & 0.3 & 2 & 0.3 \\
\hline Calidad de los productos & 0.25 & 3 & 0.75 & 3 & 0.75 & 3 & 0.75 & 3 & 0.75 \\
\hline Participación del mercado. & 0.10 & 2 & 0.20 & 4 & 0.40 & 2 & 0.20 & 1 & 0.10 \\
\hline Lealtad del cliente. & 0.12 & 3 & 0.36 & 4 & 0.48 & 2 & 0.24 & 2 & 0.24 \\
\hline Precio. & 0.15 & 2 & 0.30 & 2 & 0.30 & 2 & 0.30 & 2 & 0.30 \\
\hline $\begin{array}{l}\text { Nivel financiero de la } \\
\text { empresa. }\end{array}$ & 0.13 & 3 & 0.39 & 3 & 0.39 & 2 & 0.26 & 1 & 0.13 \\
\hline Imagen Corporativa. & 0.10 & 2 & 0.20 & 3 & 0.30 & 3 & 0.30 & 1 & 0.10 \\
\hline Total & 1.00 & & 2.65 & & 3.07 & & 2.35 & & 1.92 \\
\hline
\end{tabular}

Nota. Los factores críticos y las calificaciones son realizados en base a las entrevistas a expertos, cuyo rango de calificación es la siguiente: (1) debilidad mayor, (2) debilidad menor, (3) fortaleza menor y (4) fortaleza mayor. 


\section{Conclusiones de la Matriz MPC}

La mayor fortaleza de las empresas del sector identificadas es la calidad de los productos, por lo tanto, la marca que se representa debe desarrollar productos de alta calidad.

El personal calificado es un factor de gran importancia para incursionar en este mercado, ya que la comercialización, implementación y soporte requieres de especialistas técnicos, la que puede ser determinante para permanecer en este mercado.

La lealtad del cliente es otro factor importante, cuyos resultados otorgan a las dos mejores empresas un ponderado que los diferencia de los demás competidores, por lo que es de gran importancia la calidad de los servicios y valor agregado que perciba el cliente.

El nivel financiero es otro factor a tomar en cuenta, cuyo resultado es el tercero en orden en la calificación, por lo que el responsable financiero debe cumplir con ese desafío.

\subsection{Análisis del contexto actual y esperado}

\subsubsection{Análisis Político-Gubernamental}

El contexto político actual es incierto, (Bárbara \& Florencia, 2017) señalaron que el deteriorado contexto por los escándalos de corrupción del caso Odebretch, cuyos indicios involucran a casi la totalidad de la clase política, por lo que inclusive el ex presidente Ollanta Humala y esposa se 
encuentran con prisión preventiva, además de Alejandro Toledo otro ex presidente con orden de prisión preventiva quien se encuentra prófugo en Estados Unidos y Susana Villarán ex alcaldesa de Lima, con impedimento de salida por el mismo delito, a pesar de las graves problemas, el cambio de un nuevo presidente Martín Vizcarra, dan indicios de confianza de la ciudadanía (ver Figura 3).

El Comercio (2018), en su publicación del sondeo realizado por Ipsos, menciona que el aspecto negativo es la debilidad de partidos políticos y organizaciones gubernamentales entre ellos los tres principales poderes del estado: Ejecutivo, Legislativo y Judicial. Solo el Ejecutivo supera a la desaprobación de la ciudadanía con un $46 \%$ de aprobación, el Legislativo apenas un $25 \%$ y el Judicial $27 \%$. Conforme aparece publicado en la última encuesta del 8 y 9 de abril realizada por Ipsos, (ver Figura 4).

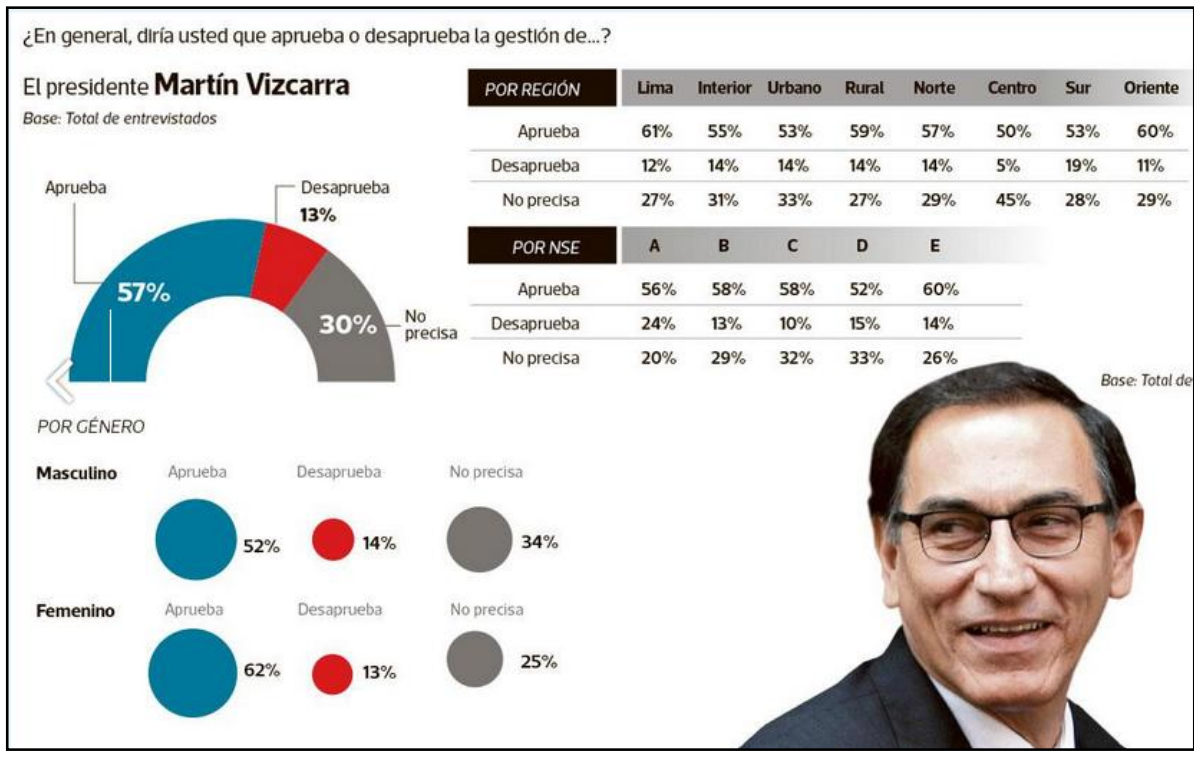

Figura 3. El primer sondeo con Martín Vizcarra como presidente. Tomado de Ipsos, 2018, Recuperado de https://elcomercio.pe/politica/ipsos-primer-sondeo-martin-vizcarra-presidente-noticia512207 ?foto $=1$ 


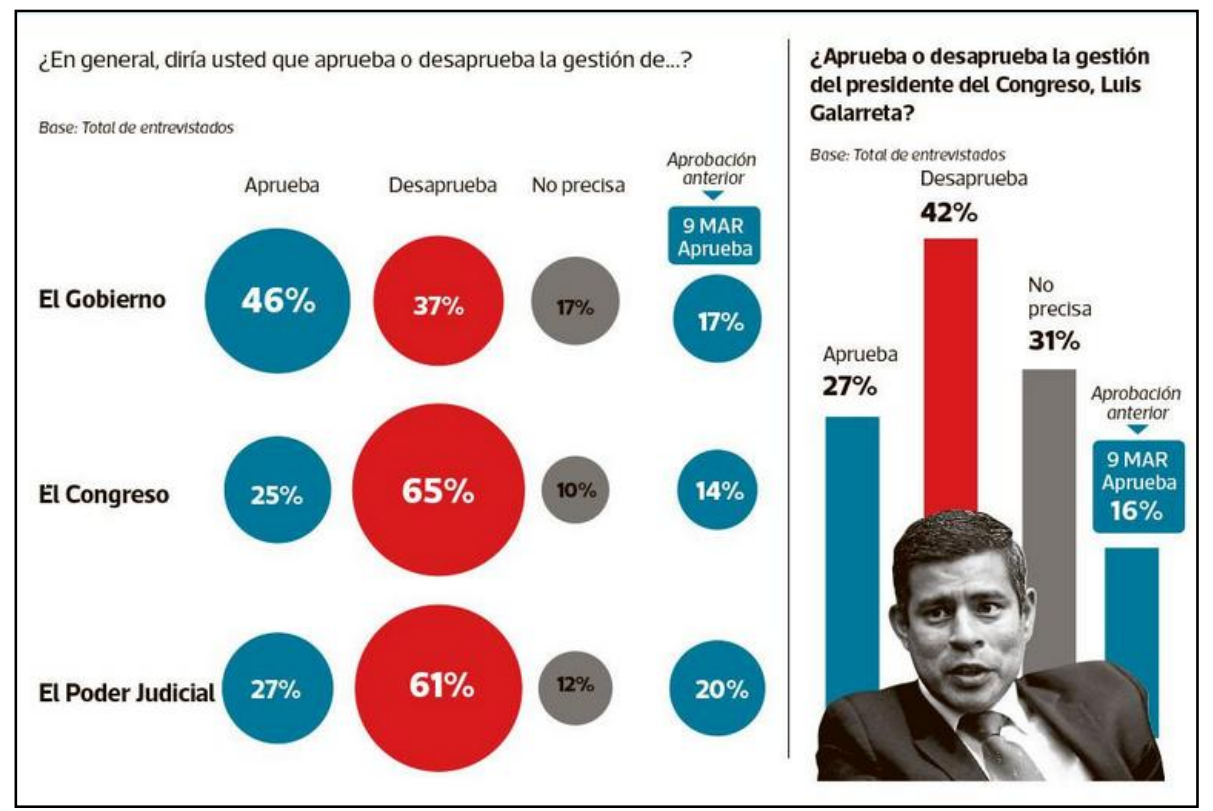

Figura 4. El primer sondeo con Martín Vizcarra como presidente. Tomado de Ipsos, 2018,

Recuperado de https://elcomercio.pe/politica/ipsos-primer-sondeo-martin-vizcarra-presidente-noticia512207 ?foto $=4$

\subsubsection{Análisis Económico}

De acuerdo a la estimación realizada por el BCR (2018) las cifras son alentadoras para el 2018, ya que prevé un crecimiento en el PBI el cual sería de 3.8\% superando a todos en América Latina (ver Figura 5).

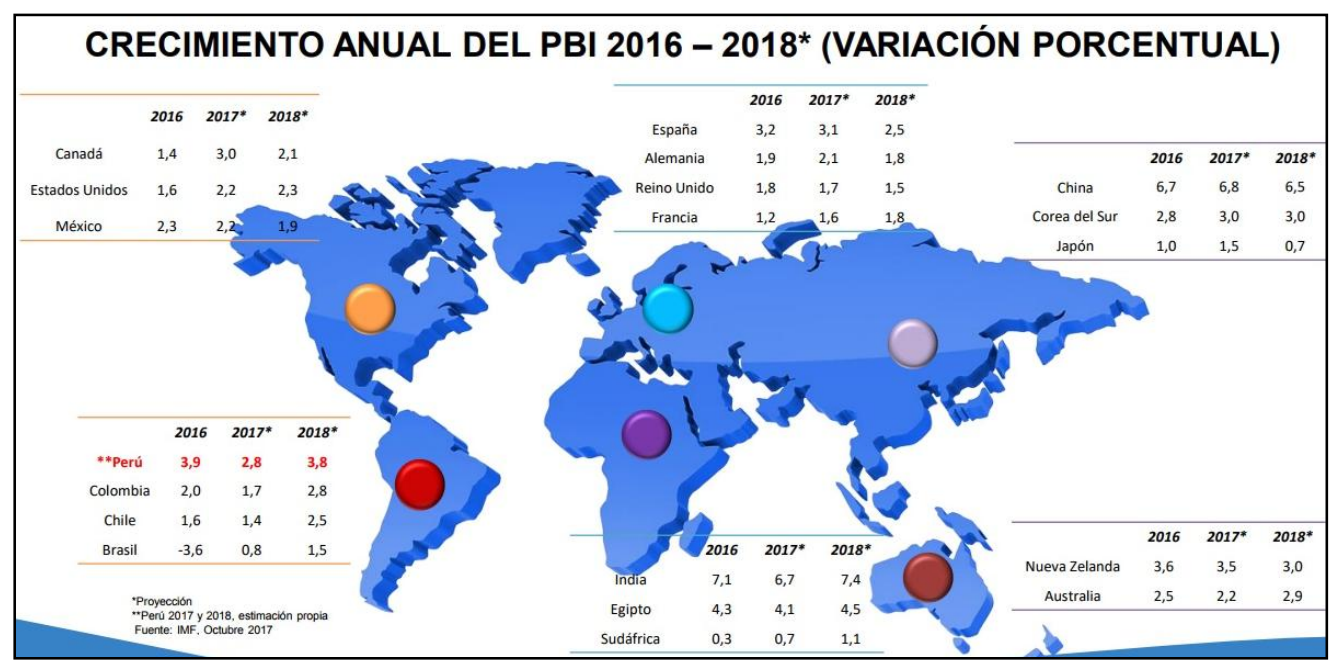

Figura 5. Crecimiento Anual del PBI 2016-2018. Tomado de IMF, 2018, Recuperado de http://blog.pucp.edu.pe/blog/competenciayconsumidor/wp-content/uploads/sites/89/2017/10/1.jpg 
El PBI por sector estima un crecimiento de $3.5 \%$ en minería para el 2018, sector de mayor importancia para efectos del proyecto (ver Figura 6).

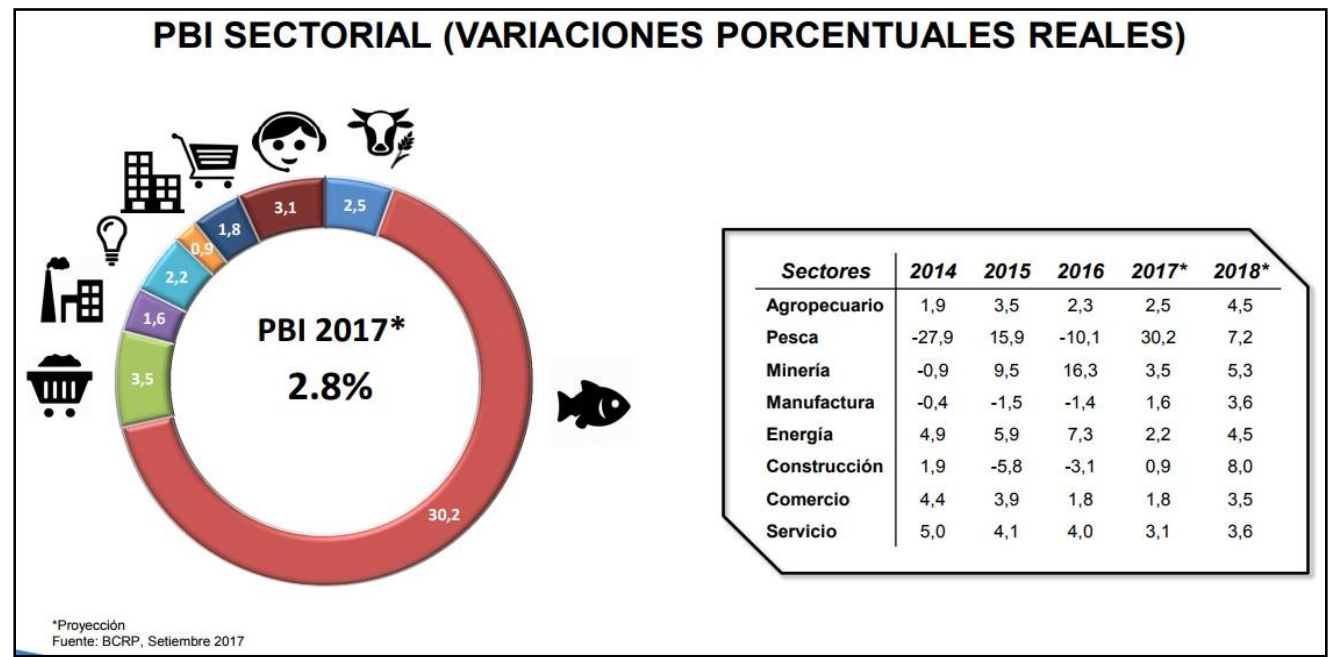

Figura 6. Crecimiento anual del PBI sectorial. Tomado de BCRP, 2018, Recuperado de http://blog.pucp.edu.pe/blog/competenciayconsumidor/wp-content/uploads/sites/89/2017/10/9.jpg

Otro indicador económico es el tipo de cambio, cuya evolución es casi estable desde el año 2016, el cual le otorga estabilidad en los precios de transacción para el pago a los fabricantes en dólares y la cobranza en soles. (ver Figura 7).

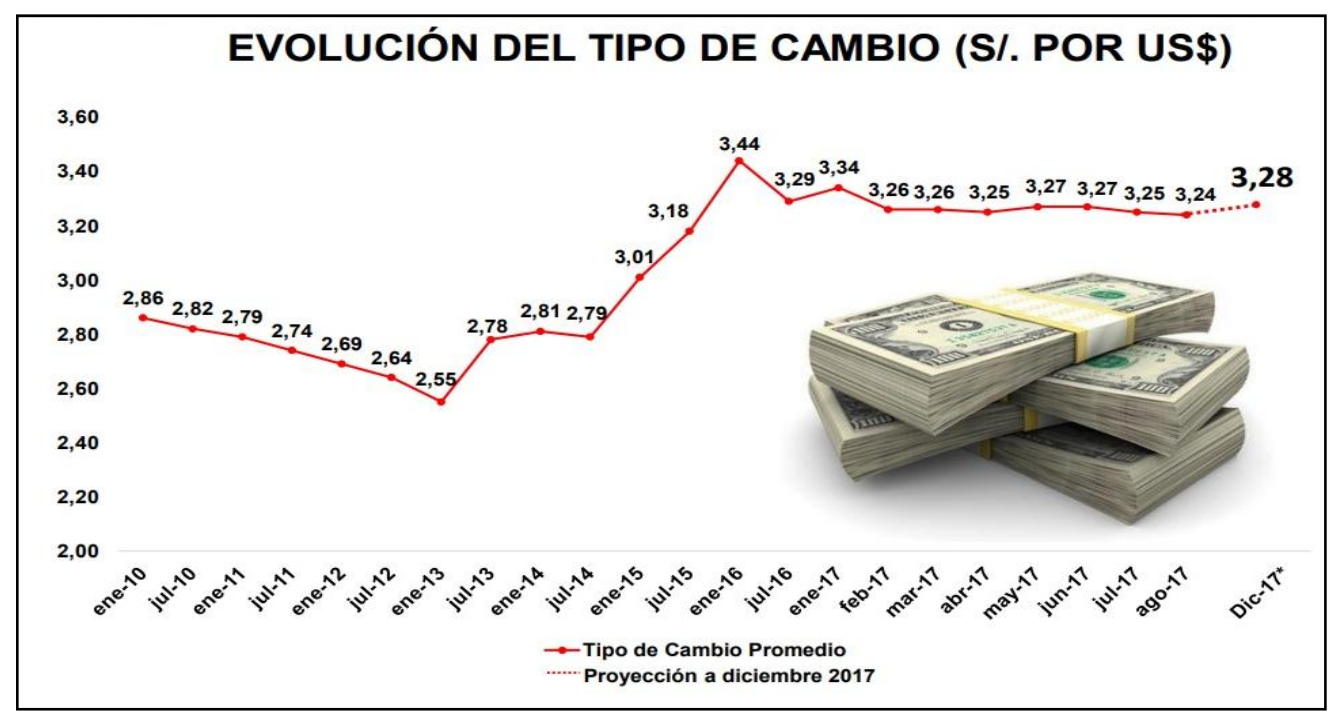

Figura 7. Evolución del tipo de cambio. Tomado de Banco Central de Reserva del Perú (BCR). 2018, Recuperado de http://blog.pucp.edu.pe/blog/competenciayconsumidor/wpcontent/uploads/sites/89/2017/10/6.jpg 
Según el Ministerio de Economía y Finanzas (2018), la inversión privada ha retomado el crecimiento, a pesar de haber tenido una pequeña caída en el 2015, las proyecciones para el 2018 estaría superando los 45,000 millones de dólares, el cual dinamizará la economía del Perú. Los detalles y la proyección (ver Figura 8)

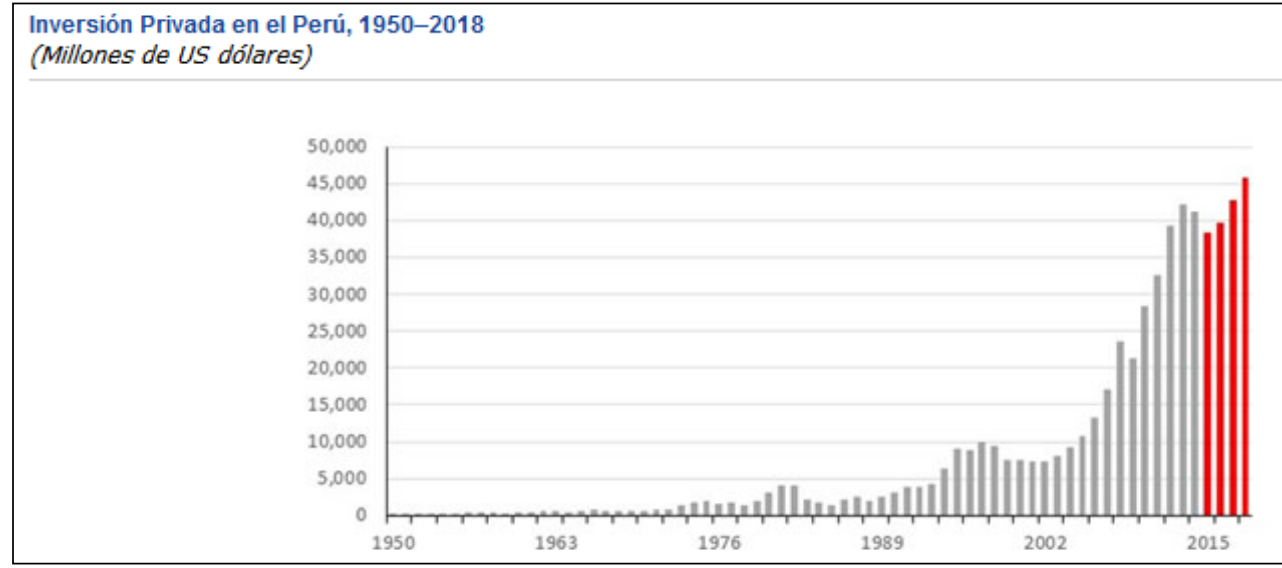

Figura 8. Inversión privada en el Perú. Tomado de Ministerio de Economía y Finanzas (MEF). 2018, Recuperado de https://www.mef.gob.pe/es/acerca-de-las-asociaciones-publico-privadas-apps/manualcomparador-publico

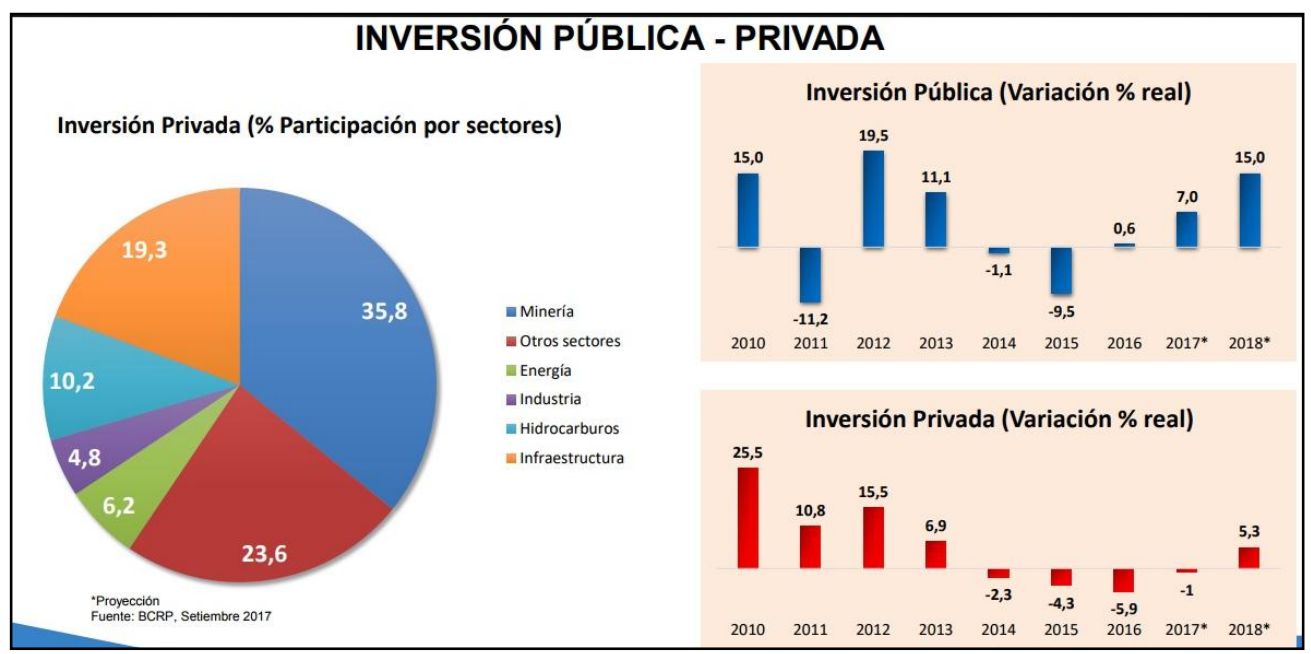

Figura 9. Inversión pública privada. Tomado de Banco Central de Reserva del Perú (BCRP), 2017, Recuperado de http://blog.pucp.edu.pe/blog/competenciayconsumidor/wpcontent/uploads/sites/89/2017/10/8.jpg 
El prestigioso equipo de estudios económico, BBVA Research (2018) en su publicación “Perú: Sector Minero” de noviembre del 2017, presenta el ciclo reciente de la actividad en inversión y producción (ver Figura 10).

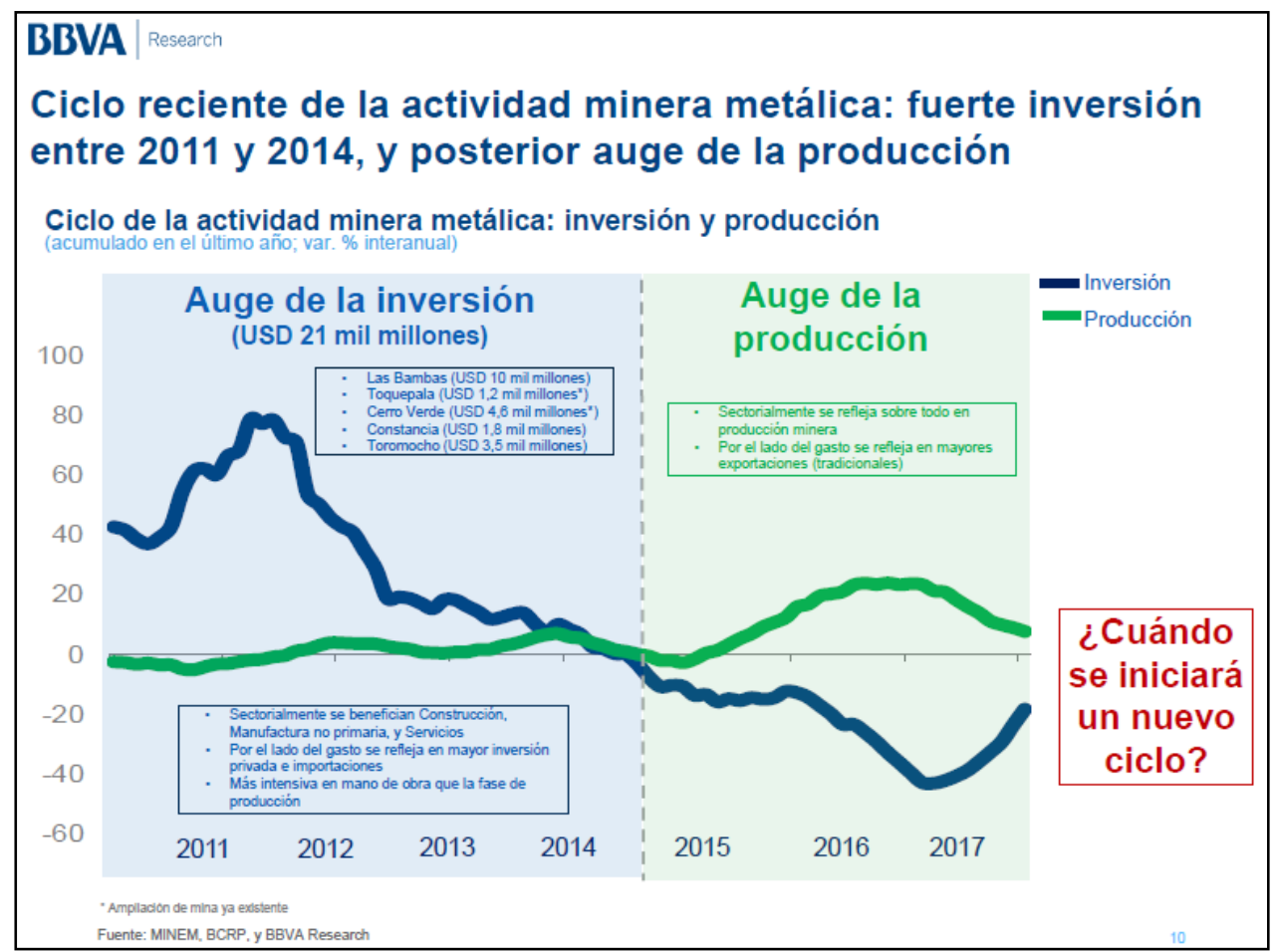

Figura 10. Ciclo reciente de la actividad Minera. Tomado de BBVA Research "Perú: Sector Minero", 2017. Recuperado de https://www.bbvaresearch.com/publicaciones/peru-situacion-del-sector-minero/

En la misma publicación indica que el precio de los metales han tenido una fuerte recuperación (ver Figura 11). 


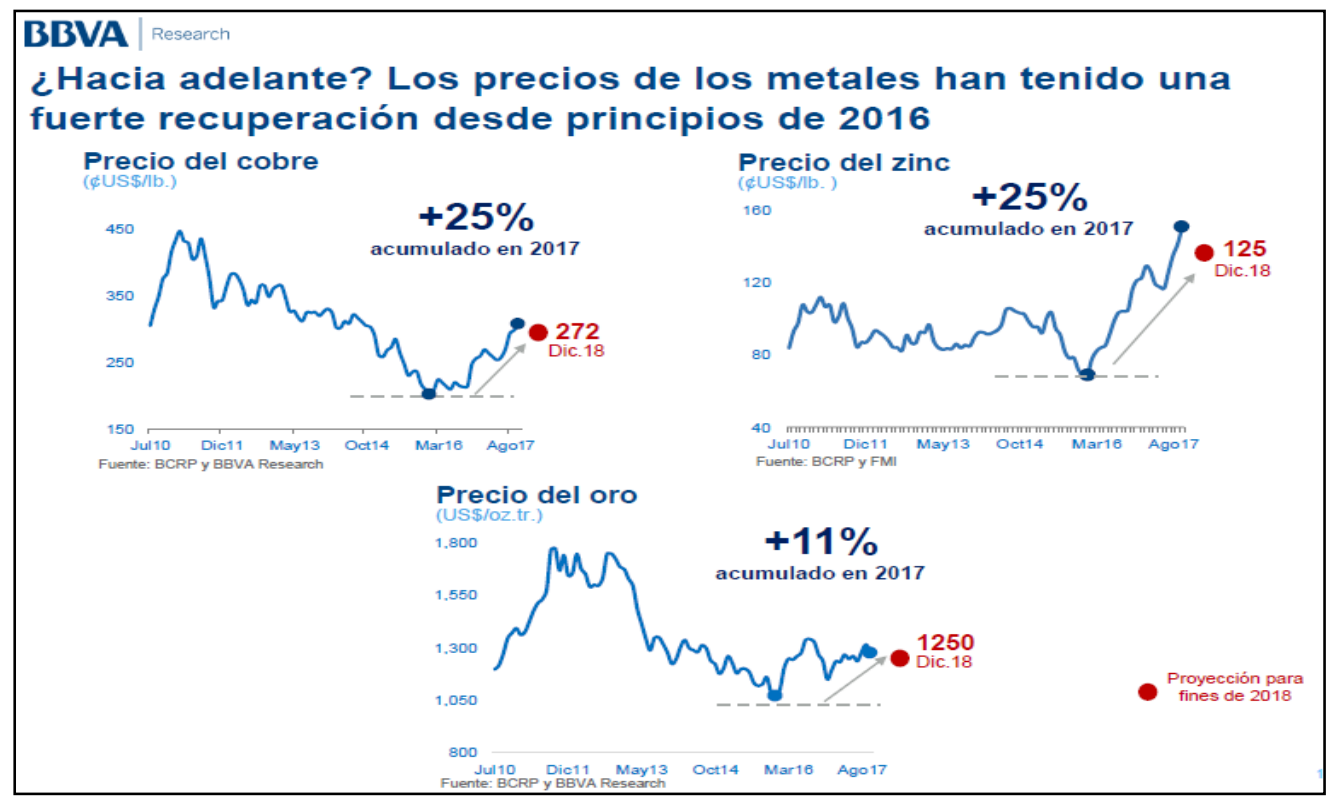

Figura 11. Recuperación del precio de los metales. Recuperado de BBVA Research "Perú: Sector Minero", 2017. Recuperado de https://www.bbvaresearch.com/publicaciones/peru-situacion-delsector-minero/

Otros indicadores de importancia son el ROE y la Razón deuda sobre activos, las que mejora gradualmente y favorecen la posición financiera de las empresas que operan en el sector minero (ver Figura 12).

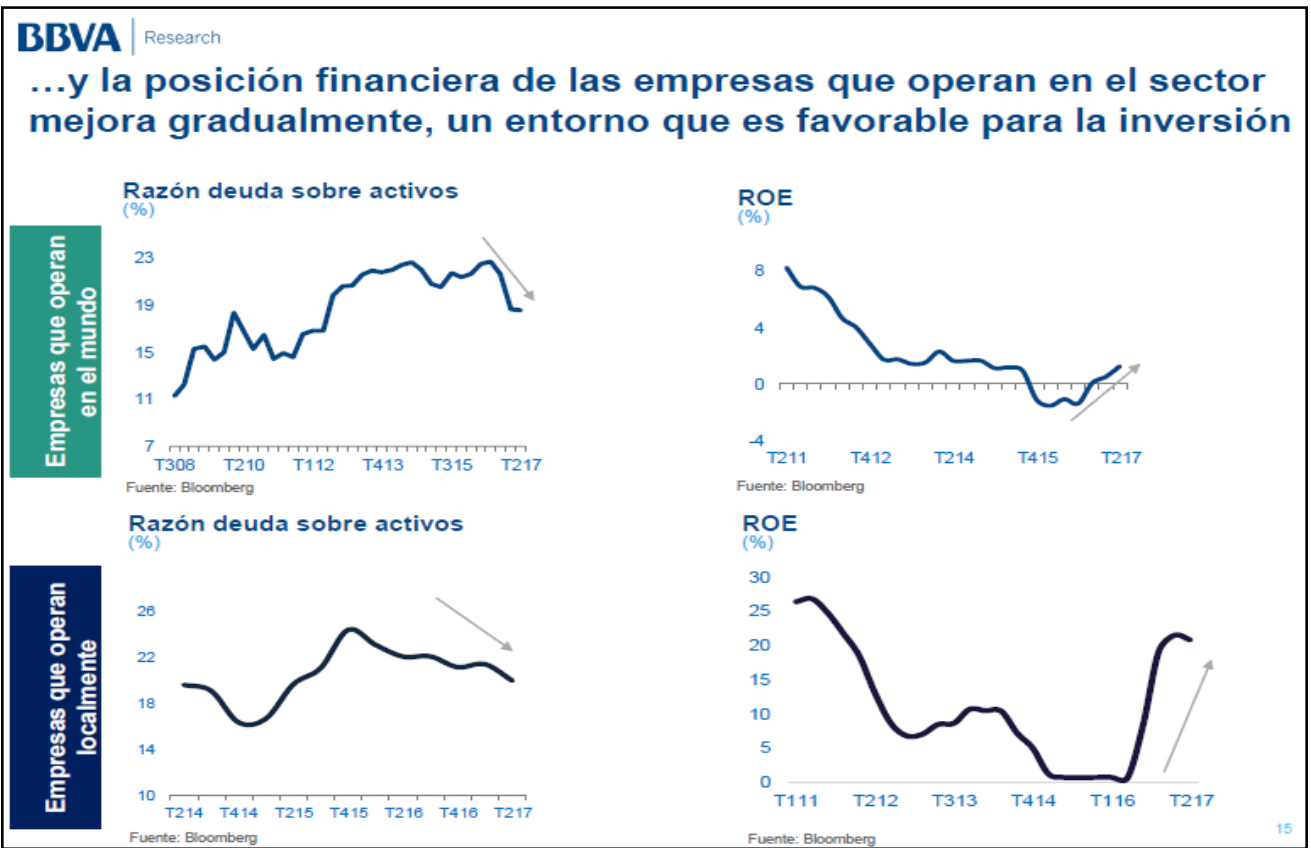

Figura 12. Indicadores que favorecen la inversión. Tomado de BBVA Research "Perú: Sector Minero", 2017. Recuperado de https://www.bbvaresearch.com/publicaciones/peru-situacion-delsector-minero/ 
Según la misma publicación, (BBVA Research, 2018) la inversión minera en el Perú ha empezado a recuperarse, siendo un 6\% en el 2017, además muestra dichos crecimientos por componentes, (1) Infraestructura 28\%, (2) Exploración 10\% y (3) Equipamiento 16\% (ver Figura 13)

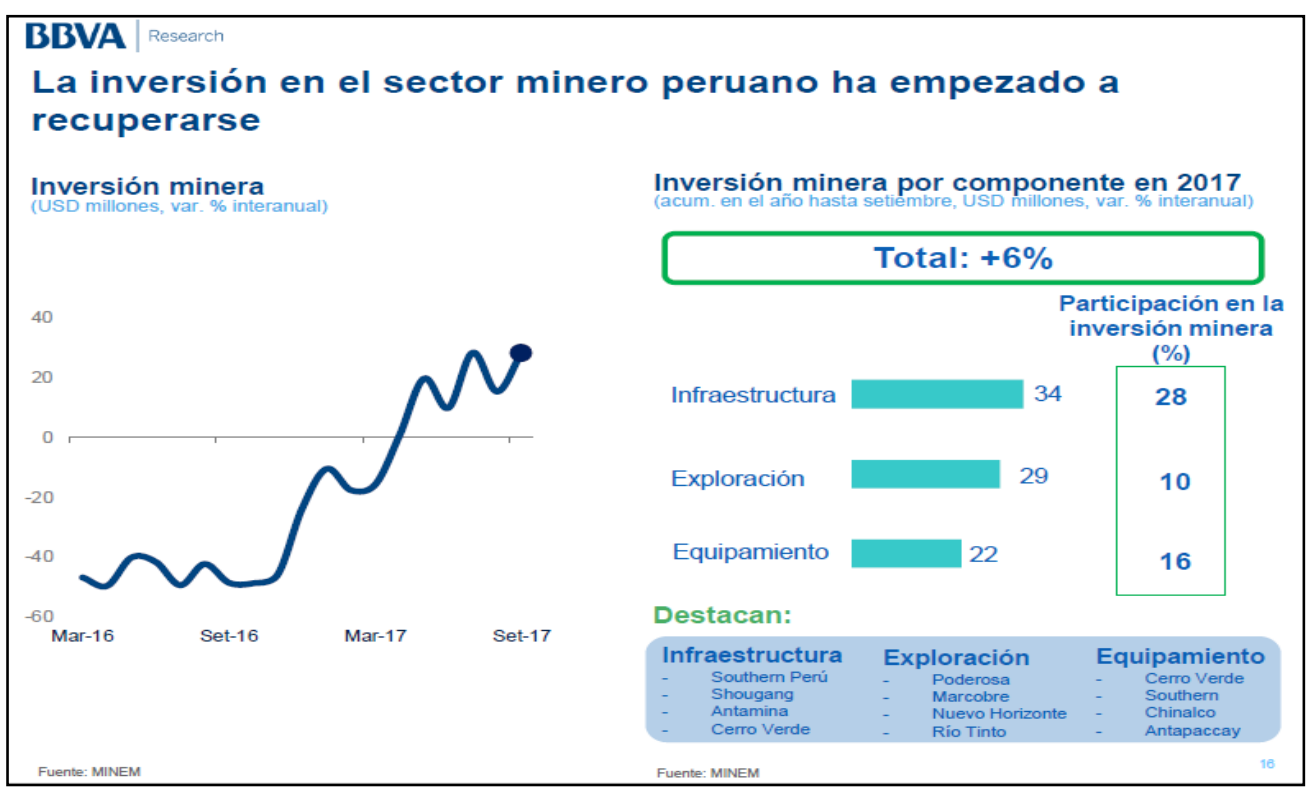

Figura 13. Recuperación de la Inversión en el sector minero. Fuente: BBVA Research "Perú: Sector Minero" (noviembre 2017). Recuperado de https://www.bbvaresearch.com/publicaciones/perusituacion-del-sector-minero/

Siendo el sector minero nuestro mercado potencial y especialmente el nivel de inversión de este sector, hicimos indagaciones adicionales, utilizando como fuente al Ministerio de energía y minas (2018), ratificando los informes anteriores, cuya tendencia de recuperación del crecimiento en inversión se viene presenciando a partir del año 2016, donde alcanzó \$4,252 millones de dólares, \$4,921 en el 2017 y estimado en $\$ 5,500$ para el 2018 (ver Figura 14) 


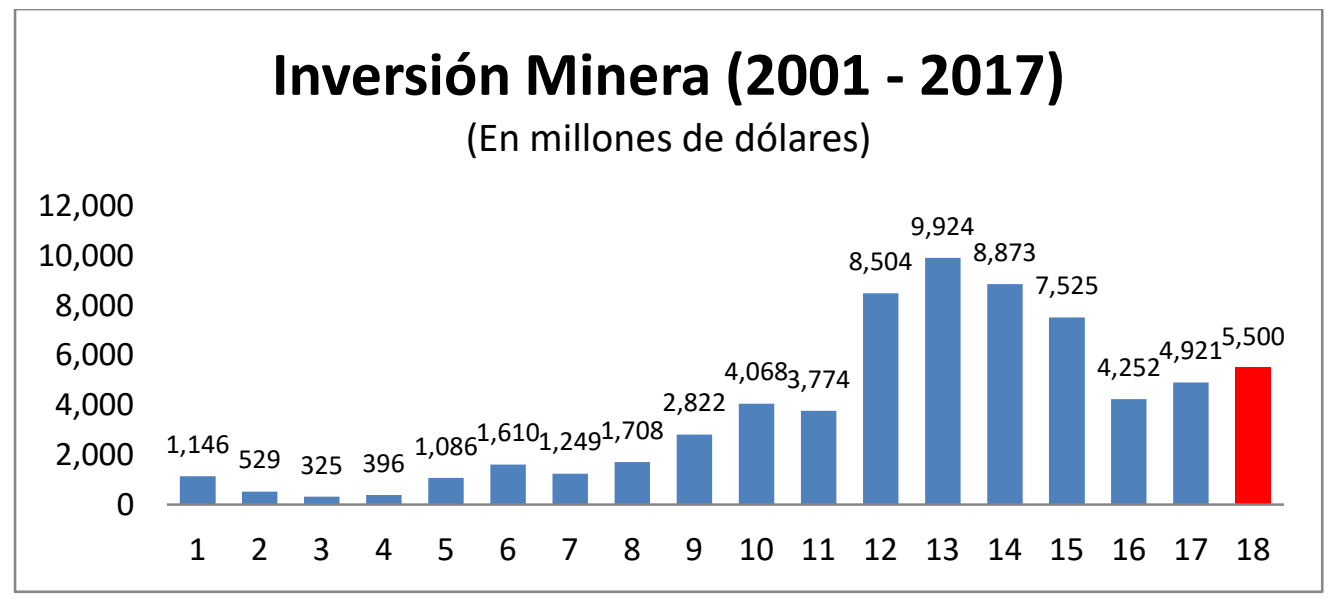

Figura 14. Inversión minera en el Perú. Tomado de Ministerio de Energía y Minas (MINEM), 2018. Elaboración propia.

\subsubsection{Análisis Legal}

Legalmente no existen restricciones para la comercialización de software, siempre que sean legales y se encuentren autorizados los licenciamientos por los desarrolladores o fabricantes.

La BSA es una asociación de empresas de clase mundial la principal organización de lucha contra la piratería, fomenta la innovación tecnológica favorece el comercio de software (Business Software Alliance, 2016).

\subsubsection{Análisis Cultural}

Culturalmente se considera que no hay ningún impacto positivo o negativo.

\subsubsection{Análisis Tecnológico}

Los avances tecnológicos, como la tecnología de información y comunicación, permiten brindar una atención más rápida. 
- La utilización de conexiones remotas, para soporte y solución inmediata.

- Entrega de licencias electrónicas para facilitar la activación del producto.

- La tendencia es eliminar las licencias perpetuas, las cuales solo se ofertarán como servicios, cuyo software se encontrarán alojados en la nube.

\subsubsection{Análisis Ecológico}

De acuerdo a la Constitución Política del Perú, Capitulo II (Del medio ambiente y los recursos naturales) Artículos 66 al 69 menciona que los recursos naturales renovables y no renovables, son patrimonios de la Nación, por lo que el estado es soberano en su aprovechamiento, fijando su utilización y otorgamiento, mediante la política ambiental, conservación de la diversidad bilógica y áreas naturales protegidas y el desarrollo de la Amazonía.

La industria del software a nivel mundial ha disminuido drásticamente su nivel de contaminación al medio ambiente, cambiando la forma de entrega de sus productos de manera física (Caja, manual impreso, discos compactos) a entregas electrónicas mediante el uso de internet con el que se encuentran comprometidos con la responsabilidad ecológica y cumple con la normatividad peruana y de muchos países. 


\subsection{Oportunidades y amenazas}

\section{Oportunidades}

De acuerdo con el análisis sobre atractividad de la industria, esta supera levemente la media quedando en zona de atractividad. La tasa de crecimiento de la industria de conforme con las cifras de BSA es 10.9\%. Analizado la matriz MPC el líder del sector apenas supera la media de la industria, lo que significa que hay necesidades que el cliente valora y aún no son atendidas.

Los diferentes indicadores y proyecciones económicas son muy alentadores, ya que la inversión privada estimada viene retomando la tendencia creciente. El PBI sigue el mismo rumbo con un $3.8 \%$ estimado para el 2018, con mayor énfasis en los sectores de construcción, comercio y minería, este último mercado de mayor importancia para el proyecto propuesto, porque es el sector a donde se encuentra dirigido los productos. La estabilidad del tipo de cambio garantiza un equilibrio para el proyecto, ya que el pago a los proveedores (Fabricantes de software) se realizan en moneda extranjera, mientras que algunos clientes exigen la facturación en moneda nacional.

Según todos los estudios y proyecciones, se estiman que las inversiones del sector minero han retomado el crecimiento, por las mejoras de los precios de los metales, principalmente el cobre y oro, además de mejora de los principales indicadores como el ROE y la razón deuda sobre activos de las empresas de este sector, hecho que atrae las inversiones. Las estimaciones de crecimiento previstas se encuentran alrededor de $10 \%$ para el 2018, estimado en \$5,500 millones de dólares. 


\section{Amenazas}

Por otra parte, las principales amenazas para el proyecto son: Dependencia de los fabricantes por tener la patente y el código fuente de los software y tener la potestad de rescindir el contrato de representación en caso considere conveniente para sus intereses. La posibilidad de ingreso de nuevos competidores por que las barreras de ingreso son bajas. El dominio del mercado se encuentra concentrado en solo dos empresas. La dependencia de los consultores por tratarse de productos especializados y la inestabilidad política pueden afectar las inversiones en el sector. 


\section{CAPÍTULO III}

\section{Estudio de mercado}

El estudio de mercado de este proyecto se desarrolló describiendo los productos y el segmento del mercado. Se realizó investigación cualitativa y cuantitativa para el cual se recurrió a fuentes primarias y secundarias. Con dicha información se realiza el análisis y procesamiento de datos al final del capítulo.

\subsection{Descripción del servicio o producto}

Consiste en la comercialización de dos tipos de software: La primera es el software conocido como CAD que viene de las siglas de "Diseño Asistido por Computadora", herramienta para dibujo y diseño de planos en 2D y 3D para ingeniería y arquitectura. La segunda es software conocido como GIS que viene de las siglas de "Sistema de Información Geográfica" que permite registrar, analizar y modelar cualquier información que tenga un componente geográfico, cuyo licenciamiento y entrega del producto es electrónico (vía correo electrónico), siendo la asistencia técnica presencial o remoto para Lima Metropolitana y El Callao; y solamente de manera remota para el resto del país.

Para diferenciarse de los demás competidores los productos serán comercializados en forma de solución, que incluye la licencia de software, implementación, capacitación y soporte. Otro factor diferenciador es el consultor senior especializado en Sistema de Información Geográfico y Diseño Asistido por Computadora, cuyo perfil se encuentra detallado en el diseño de los puestos clave (ver Tabla 28). 


\subsection{Selección del segmento de mercado}

Para la segmentación de mercado objetivo se utilizó el método demográfico, cuyas variables fueron el tipo de actividad y tamaño de empresa. Por el tipo de actividad se decidió el sector Minería y por su tamaño a las empresas que se encuentran comprendidas en el ranking de la publicación Perú: Top 10,000 Companies 2017, las que comprenden a 465 empresas (ver Tabla 6).

\section{Tabla 6}

Concentración de empresas por actividad económica.

\begin{tabular}{lrrr}
\hline \multicolumn{1}{c}{ Sector } & $\begin{array}{c}\text { Top 10 000 2016 } \\
\text { (No Empresas) }\end{array}$ & $\begin{array}{c}\text { Top 10 000 2015 } \\
\text { (No Empresas) }\end{array}$ & $\begin{array}{c}\text { Top 10 000 2014 } \\
\text { (No Empresas) }\end{array}$ \\
\hline Comercio & 3433 & 3445 & 3465 \\
Actividad Inmobiliaria & 1648 & 1441 & 1483 \\
Industria Manufacturera & 1373 & 1378 & 1332 \\
Transporte, Almacenamiento y & 821 & 1008 & 1005 \\
Comunicaciones & & 717 & 652 \\
Construcción & 653 & 375 & 288 \\
Minería & 465 & 369 & 324 \\
Agricultura, Ganadería y Silvicultura & 366 & 322 & 317 \\
Otras Actividades de Servicio & 340 & 187 & 167 \\
Intermediación Financiera & 186 & 153 & 149 \\
Educación & 160 & 142 & 146 \\
Hoteles y Restaurantes & 145 & 138 & 123 \\
Servicios sociales y Salud & 145 & 105 & 103 \\
Electricidad, Gas y Agua & 114 & 79 & 98 \\
Pesca & 100 & 141 & 348 \\
Administración Pública y Defensa & 51 & $\mathbf{1 0 0 0 0}$ & $\mathbf{1 0 0 0 0}$ \\
\hline \multicolumn{1}{c}{ Total } & $\mathbf{1 0 0 0 0}$ & & \\
\hline
\end{tabular}

Nota. Información basada en el ranking por rango de facturación de las Top 10000, Edición 2017 (p. 20). 


\subsection{Investigación cualitativa}

El objetivo es conocer problemas específicos de la industria (forma de pagos, ciclo evolutivo), determinar la importancia, valor, tipo de licenciamiento y las motivaciones que determinan la compra de software para Ingeniería, medioambiente y sistemas de información geográfica.

Por la especialización de los productos y tratarse de un negocio B2B el estudio cualitativo se realizará mediante entrevistas en profundidad, que según lo establecido por Malhotra (2008) es una investigación de mercados industriales.

\subsubsection{Proceso de muestreo}

Se realizó mediante un estudio no probabilístico, que comprende seis entrevistas por conveniencia, realizados a dos ejecutivos de empresas que comercializan software, dos especialistas en sistemas de información geográfica (GIS) y Diseño asistido por computadora (CAD), y dos jefes de sistemas o jefes de proyectos o similares. Para determinar la cantidad de entrevistas, se siguió lo indicado por (Malhotra, 2008).

\section{Tabla 7}

Relación de expertos para entrevistas en profundidad

\begin{tabular}{llll}
\hline Razón Social & \multicolumn{1}{c}{ Entrevistado } & \multicolumn{1}{c}{ Cargo } & \multicolumn{1}{c}{ Competencia } \\
\hline Astrum S.A.C. & Iván Collantes & Gerente General & Experto CAD y GIS \\
IdeasG S.A.C. & Marino Carhuapoma & Gerente de Proyectos & Experto en GIS \\
Ausenco S.A. & Miguel Palacios Torres & Jefe del área CAD & Ejecutivo de Ventas \\
Business Technology S.A.C. & Santiago Alvarado & Gerente de Ventas & Ejecutivo de ventas \\
Knight Piesold Consultores S.A. & Luis Cabanillas & Jefe de Sistemas & Jefe de Sistemas \\
Compañía Minera Corona S.A. & Marco Veliz & Jefe de Sistemas & Jefe de Sistemas \\
Minera Aruntani S.A.C. & César Torres & Experto en CAD & Experto en CAD \\
\hline
\end{tabular}

Nota. Relación de profesionales entrevistados. 


\subsubsection{Diseño de instrumento}

Con la finalidad de tener un mejor panorama para la investigación se determinó realizar entrevistas en profundidad, conforme se menciona en el proceso de muestreo, para el cual se elaboró tres tipos de guías de pautas:

1. Guía de Pautas para expertos en sistemas de información geográfica “GIS” y Diseño asistido por computadora "CAD” (ver Anexo 3).

2. Guía de Pautas para Jefes de Sistemas o jefes de Proyectos o similares (ver Anexo 4).

3. Guía de Pautas para Ejecutivos de ventas de empresas comercializadoras de software (ver Anexo 5).

Las entrevistas fueron realizadas por Hilber Quintana Llanco, autor de la presente tesis en las oficinas de cada entrevistado, entre los días 18 de diciembre del 2017 y el 15 de enero del 2018, la duración de cada una de estas entrevistas fue 40 minutos en aproximado.

\subsubsection{Análisis y procesamiento de datos}

Culminadas las entrevistas, se procedió con la transcripción de cada uno de los audios (ver Anexo 6).

Luego, se realizó el procesamiento de la información, así como el análisis de esta, haciendo uso de la matriz elaborada (ver Tabla 8). 


\section{Tabla 8}

Matriz de resumen de las entrevistas en profundidad

\begin{tabular}{|c|c|}
\hline Pregunta & Respuesta \\
\hline Sobre la empresa donde trabaja & $\begin{array}{l}\text { Ministerio de Energía y Minas, Ausenco Vector S.A., Knight Piesold Consultores } \\
\text { S.A., Astrum S.A.C., Minera Aruntani S.A.C. }\end{array}$ \\
\hline Sobre sistemas CAD y GIS & $\begin{array}{l}\text { Los sistemas CAD son para el trabajo netamente de dibujo y diseño de ingeniería, } \\
\text { mientras que los sistemas GIS data con mapas y presentan mediante gráficos } \\
\text { geoespaciales. }\end{array}$ \\
\hline $\begin{array}{l}\text { Sobre el mercado de soluciones } \\
\text { CAD y GIS }\end{array}$ & $\begin{array}{l}\text { A nivel mundial el mercado de software CAD es liderado por la Cia. Autodesk, } \\
\text { seguido por Bentley, ZwCAD, Archicad, entre otros y el mercado GIS es liderado } \\
\text { por la Cia. ESRI, Pitney Bowes Software, Geomedia, Bentley, entre otros. Los dos } \\
\text { líderes son de procedencia norteamericana. }\end{array}$ \\
\hline $\begin{array}{l}\text { Sobre Proveedores (Distribuidores) } \\
\text { de Software GIS }\end{array}$ & $\begin{array}{l}\text { Localmente Autodesk tiene distribuidores los cuales son Profile Consulting Group } \\
\text { S.A., Replica SRL, Macrotec Data Srl, Semco CAD, Softland Perú S.A., Business } \\
\text { Technology S.A.C. entre otros, mientras que el único distribuidor de ESRI es la } \\
\text { empresa Telemática S.A. El } 70 \% \text { u } 80 \% \text { del mercado CAD es dominado por Profile } \\
\text { Consultin Group y el } 80 \% \text { o } 90 \% \text { del mercado GIS es atendido por Telemática } \\
\text { S.A. }\end{array}$ \\
\hline $\begin{array}{l}\text { Sobre expertos en sistemas CAD y } \\
\text { GIS }\end{array}$ & $\begin{array}{l}\text { Ha aumentado estos últimos años, por la llegada de expertos extranjeros, } \\
\text { principalmente de España, pero sigue siendo atractivo para los expertos. El sueldo } \\
\text { promedio de un senior es } \$ 3,000 \text { mensuales. }\end{array}$ \\
\hline $\begin{array}{l}\text { Sobre los usos de software CAD y } \\
\text { GIS }\end{array}$ & $\begin{array}{l}\text { Es aplicable a muchos mercados, el sistema CAD especialmente para aquellas que } \\
\text { diseñan trabajos de ingeniería, en minería, catastro, edificaciones y los sistemas GIS } \\
\text { para los que trabajan con información de territorios. }\end{array}$ \\
\hline $\begin{array}{l}\text { Sobre Tendencias de software } \\
\text { CAD y GIS }\end{array}$ & $\begin{array}{l}\text { Las tendencias sobre licenciamiento van camino a convertirse en servicios, las } \\
\text { cuales serán cobrados anualmente, luego mensual, hasta llegar a ser cobrado por } \\
\text { minutos de uso. Las tendencias respecto a funcionalidades es integrarse con amplias } \\
\text { tecnologías como el BIM, BIG DATA e integración con otras tecnologías como } \\
\text { Inteligencia Artificial. }\end{array}$ \\
\hline
\end{tabular}

En conclusión, la investigación exploratoria realizada mediante entrevistas en profundidad dejó la siguiente información:

a. El mercado CAD es liderado por la marca Autodesk y sus

Distribuidores Autorizados son: Profile Consulting, Réplica SRL, Macrotec, entre otros, mientras mercado GIS es liderado por ESRI y su único distribuidor Autorizado es Telemática S.A.

b. Respecto a expertos, la mayoría indican que se han incrementado en los últimos años, por la llegada de extranjeros, principalmente 
españoles y los sueldos aproximados se encuentran alrededor de los \$3,000 Dólares Americanos.

c. Se pudo entender mejor el uso del software CAD y GIS, siendo el primero para aquellos que diseñan trabajos de ingeniería, en minería, catastro, edificaciones y el segundo para los que trabajan con información de territorios.

d. Respecto a las tendencias, el licenciamiento van camino a convertirse en servicios, las que se cobrará como servicio anual, mensual, hasta llegar a cobrarse por minutos de uso.

\subsubsection{Investigación Complementaria}

Se complementó con cinco entrevistas, con el objetivo de determinar la insatisfacción con sus proveedores de software. Dos entrevistas de manera presencial y tres mediante comunicación telefónica, Los especialistas entrevistados son los mismos entrevistados anteriormente (Miguel Palacios, César Torres Torres, Luis Cabanillas, Iván Collantes y Marino Carhuapoma, cuyas preguntas y respuestas fueron los siguientes:

\section{¿Cuál es el nivel de satisfacción que te otorga tu proveedor de software GIS y}

\section{CAD?}

Tres indicaron que no se sienten satisfechos ya que no otorgan valor más que el propio software. 
Uno si valora mucho a su proveedor porque siempre fue atendido y solucionado su requerimiento.

El último valora regularmente porque la única vez que fue atendido al hacer la instalación y hasta ahora no tiene inconvenientes con el software.

\section{¿Cuál es la razón de tu satisfacción o insatisfacción de tu proveedor?}

Los cinco valoran ser atendidos oportunamente y presencialmente mejor, que el ingeniero o técnico realice el trabajo.

La insatisfacción es por derivar la responsabilidad al usuario otorgando algún manual, ya que algunos temas técnicos propios de la gente de sistemas no son comunes para los usuarios del software.

Otros manifiestan que las veces que solicitaron soporte la demora fue excesivo en obtener respuesta entre tres a cuatro días y además fueron derivados al fabricante y por diferencias de horario la solución se hizo muy larga.

Dos de ellos menciona que muchas veces los mismos usuarios terminan solucionando algún inconveniente buscando ayuda en internet u otros usuarios del software.

\section{¿Qué productos o servicios complementarios debería vender tu proveedor de software GIS y CAD?}

Dos entrevistados recomiendan asesorías o talleres en temas específicos.

Tres indicaron que recomendarían abrir cursos avanzados, incluyendo enseñanza para hacer aplicativos para mejorar tareas frecuentes.

Uno indicó que deben ofrecer hardware que sean adecuadas para el software, plotter y sus respectivos suministros. 
Otro usuario recomienda tener una mayor cantidad de productos para otros usos como para procesamiento de imágenes satelitales, para análisis de contaminantes en el aire y el agua.

El resumen de las entrevistas complementarias nos indica que el tiempo de respuesta, la atención presencial, prefieren especialistas que solucionen sus requerimientos, esos son aspectos de gran valor para el cliente.

Como productos complementarios sugieren Capacitaciones avanzadas, consultorías especializadas, otro software para procesamiento de imágenes satelitales, análisis de contaminantes del aire y el agua.

\subsection{Investigación cuantitativa}

El objetivo es determinar el tamaño del mercado, frecuencia de compra, problemas específicos de la industria (forma de pagos, ciclo evolutivo), identificar el valor, aspectos y motivaciones que determinan la compra de software para Ingeniería, medioambiente y sistemas de información geográfica.

Se determinó realizar investigación formal y estructurada de muestra representativa, cuyos resultados permitieron someter a un análisis cuantitativo ya que dichos hallazgos tienen condiciones concluyentes (Malhotra, 2008). Para el cual se elaboró la ficha técnica (ver Anexo 10). 


\subsubsection{Proceso de muestreo}

1. La población meta u objetivo: Colaboradores (empleados) que son jefes o gerentes de sistemas, ingenieros, jefes o gerentes de compras (elemento), que trabajen en una empresa minera comprendida en la publicación de Perú Top 100002017 (unidad de muestreo), en el territorio peruano (Extensión) durante el periodo desde el 5 de enero al 17 de febrero del 2018 (tiempo).

2. Marco Muestral: La base de datos de Perú Top 100002017 correspondiente al sector minería.

3. Técnica de Muestreo: Probabilístico, aleatorio simple.

\section{Tamaño de la muestra:}

\section{Evaluación Inicial}

Para determinar el tamaño de la muestra se utilizó la ecuación de medición proporcional para muestras finitas $(\mathrm{N}<10,000)$

$$
n=\frac{(N) Z^{2}(P)(Q)}{E^{2}(N-1)+Z^{2}(P)(Q)}
$$

Dónde:

$\mathrm{N}$ = Tamaño de la población

$=465$

$\mathrm{n}=$ Tamaño de la muestra

$=i$ ?

$\mathrm{Z}=$ Nivel de confianza o coeficiente de confianza

$=1.96$

$\mathrm{E}=$ Error de la muestra $\mathrm{o}$ error permitido

$=+/-5 \%$

$\mathrm{P}=$ Probabilidad de aceptación o proporción a favor

$=0.5$

$\mathrm{Q}=$ Probabilidad de rechazo o proporción en contra

$=(1-\mathrm{P})$ 


$$
n=\frac{(465) 1.96^{2}(0.5)(0.5)}{0.05^{2}(465-1)+1.96^{2}(0.5)(0.5)}=211
$$

\section{Evaluación Final}

Al haber encontrado dificultades durante 20 días sin conseguir resultados (respuesta) a nuestras encuestas tanto mediante SurveyMonkey y presencial, se optó por realizar dos cambios (1) modificar el error de la muestra, (2) solicitar a la universidad una carta de presentación, el que nos facilitó apertura de los encuestados.

Utilizando la misma ecuación de medición proporcional para muestras finitas $(\mathrm{N}<10,000)$, la nueva muestra quedó:

$$
\boldsymbol{n}=\frac{(\boldsymbol{N}) \boldsymbol{Z}^{2}(\boldsymbol{P})(\boldsymbol{Q})}{\boldsymbol{E}^{2}(\boldsymbol{N}-\mathbf{1})+\mathbf{Z}^{2}(\boldsymbol{P})(\boldsymbol{Q})}
$$

Dónde:

$\mathrm{N}$ = Tamaño de la población $=465$

$\mathrm{n}=$ Tamaño de la muestra $=i$ ?

$\mathrm{Z}=$ Nivel de confianza o coeficiente de confianza $=1.96$

$\mathrm{E}=$ Error de la muestra o error permitido $=+/-10 \%$

$\mathrm{P}=$ Probabilidad de aceptación o proporción a favor $=0.5$

Q = Probabilidad de rechazo o proporción en contra $=(1-\mathrm{P})$

$$
n=\frac{(465) 1.96^{2}(0.5)(0.5)}{0.10^{2}(465-1)+1.96^{2}(0.5)(0.5)}=79
$$

5. Realización: Se realizó 80 encuestas directas o presenciales. 


\subsubsection{Diseño de instrumento}

El diseño de las encuestas (instrumento) también llamado Diseño de cuestionarios y formatos, según Malhotra (2009, p.296) fueron realizados en dos etapas, el primero incluyó 17 preguntas y fue utilizada a manera de piloto con 10 encuestados seleccionados convenientemente, el segundo fue mejorada en base a la encuesta piloto, que nos permitió realizar los análisis concluyentes la cual incluyó 22 preguntas (ver Anexo 9).

\subsubsection{Análisis y procesamiento de datos}

El análisis de los datos se realizó con el software SPSS v25

(Programa para análisis estadístico). Los resultados se muestran a continuación:

El 58.33\% de los encuestados trabajan en el área de Sistemas, el 31.94\% en Geología y el 9.72\% en el área de Ingeniería (ver Figura 15)

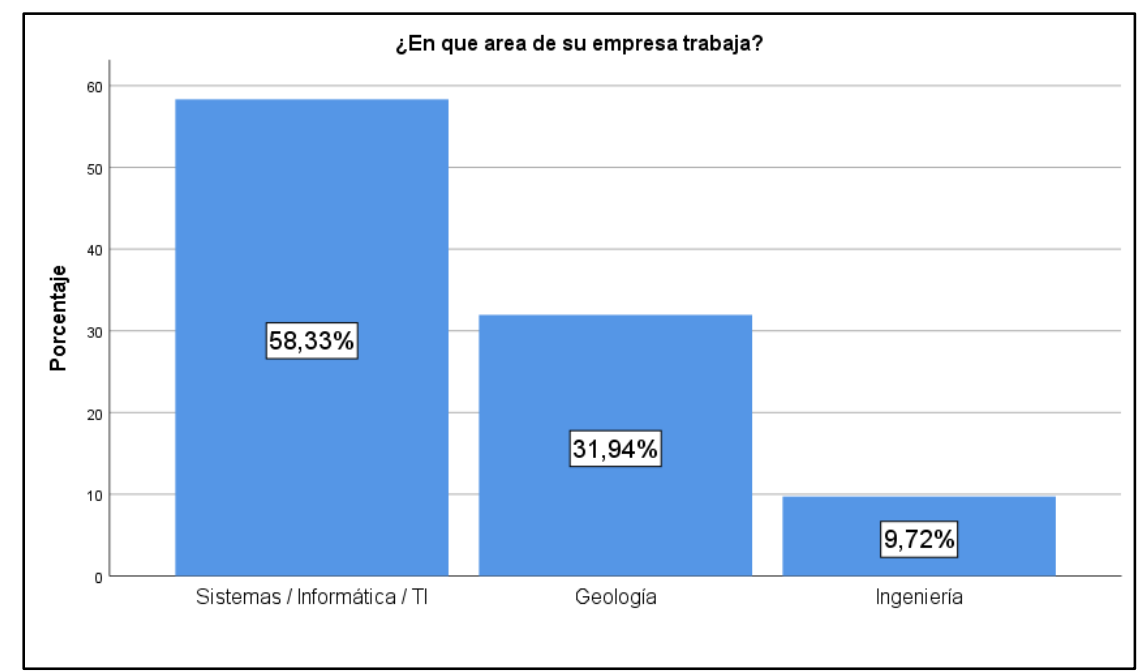

Figura 15. Encuesta. Tomado de Resultado a la Pregunta F2. ¿En qué área de su empresa trabaja? 
El $47.22 \%$ de las empresas del sector minería tienen entre 6 y 14 profesionales que son ingenieros, proyectistas, geógrafos y topógrafos. El $43.06 \%$ entre 15 y 24 y el $9.72 \%$ entre 25 y 40 de los profesionales mencionado (ver Figura 16)

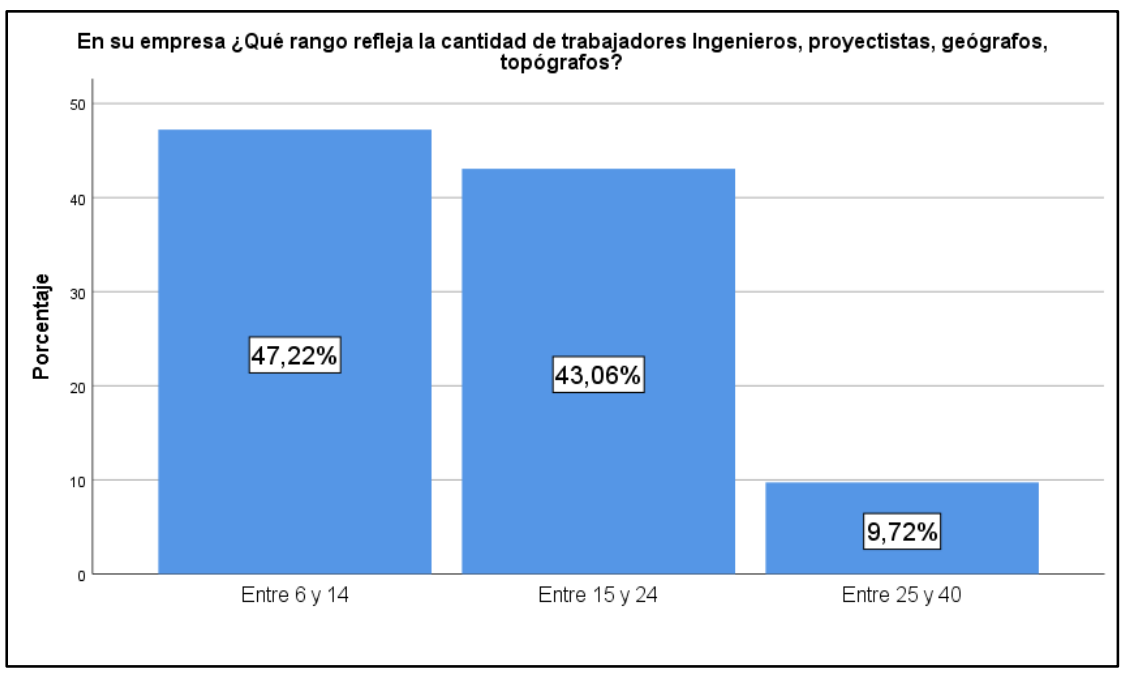

Figura 16. Encuesta. Tomado de Resultado a la Pregunta F3. En su empresa ¿Qué rango refleja la cantidad de trabajadores Ingenieros, proyectistas, geógrafos, topógrafos?

El software CAD más usado por las empresas del sector minero es el AutoCAD con un $97.22 \%$ de participación y solamente el1.39\% usan software MicroStation y $1.39 \%$ el ArchiCAD (ver Figura 17).

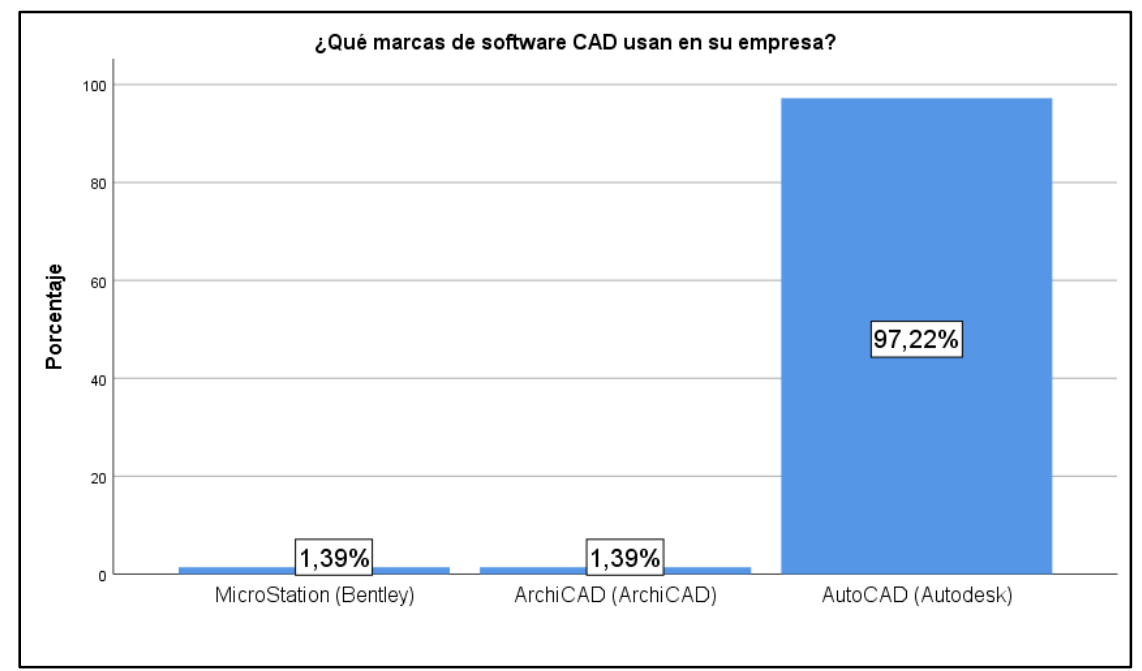

Figura 17. Encuesta. Tomado de Resultado a la Pregunta 1. ¿Qué marcas de software CAD usan en su empresa? 
Respecto a la cantidad de software CAD que tienen adquiridos las empresas mineras los resultados son: El 75\% tiene entre 6 y 14 licencias, el $19.44 \%$ entre 15 y 24 licencias y el $5.56 \%$ menos de 5 licencias (ver Figura 18).

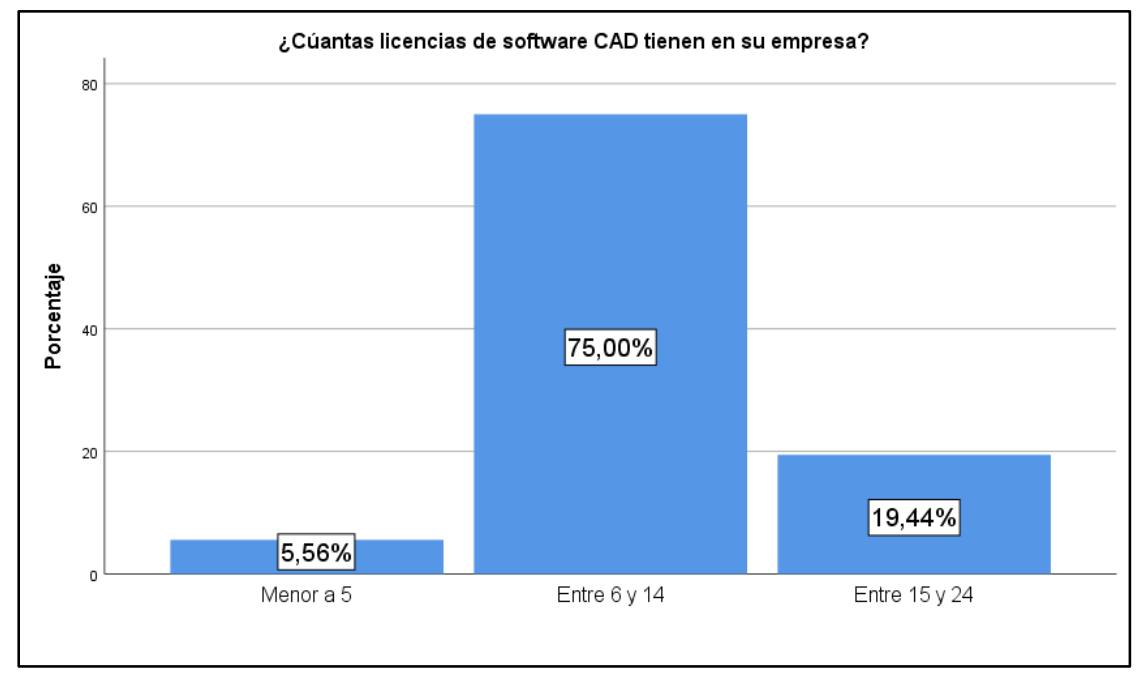

Figura 18. Encuesta. Tomado de Resultado a la Pregunta 2. ¿Cuántas licencias de software CAD tienen en su empresa?

Respecto a la intensión de compra de software CAD, el 22.22\% tiene planificado adquirir 2 Licencias, el 25\% 3 Licencias, $4.17 \% 4$ licencias, el 9.72\% 5 licencias, haciendo un total de $61.11 \%$ empresas las que tienen planificado adquirir el 2018 , el $38.89 \%$ no tiene planificado ninguna compra (ver Figura 19).

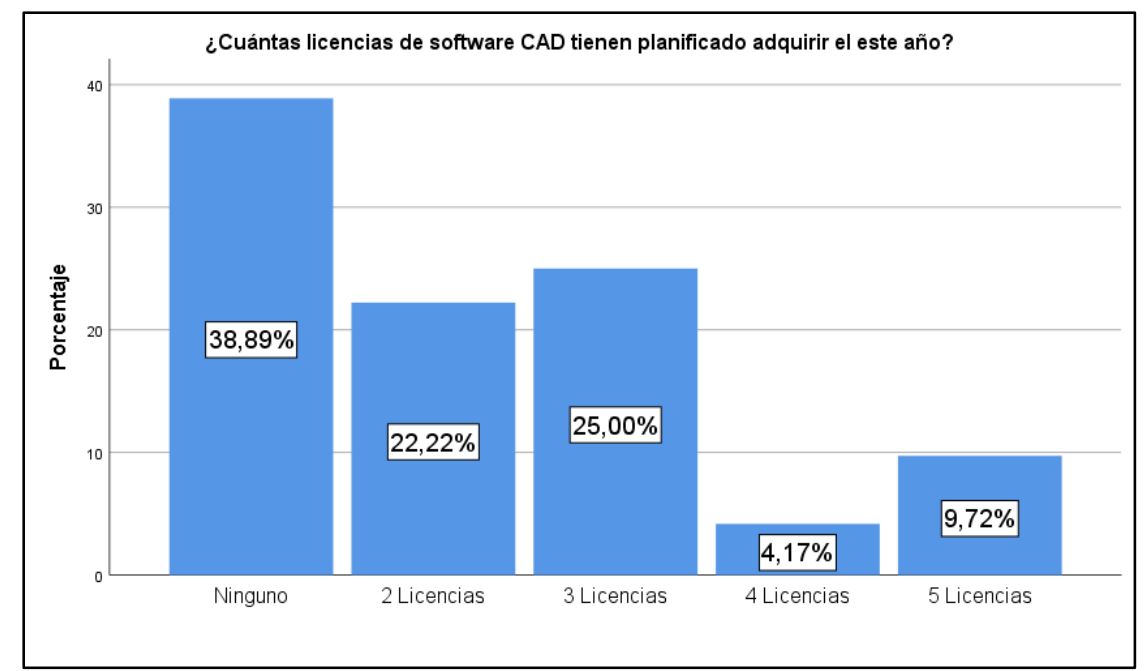

Figura 19. Encuesta. Tomado de Resultado a la Pregunta 3. ¿Cuántas licencias de software CAD tienen planificado adquirir el este año? 
La marca más usado por las empresas del sector minero es el ArcGIS con un 69.44\%, seguido por MapInfo con un 22.22\%, Geomedia con 5.56\% y Bentley Map con solo $2.78 \%$ (ver Figura 20).

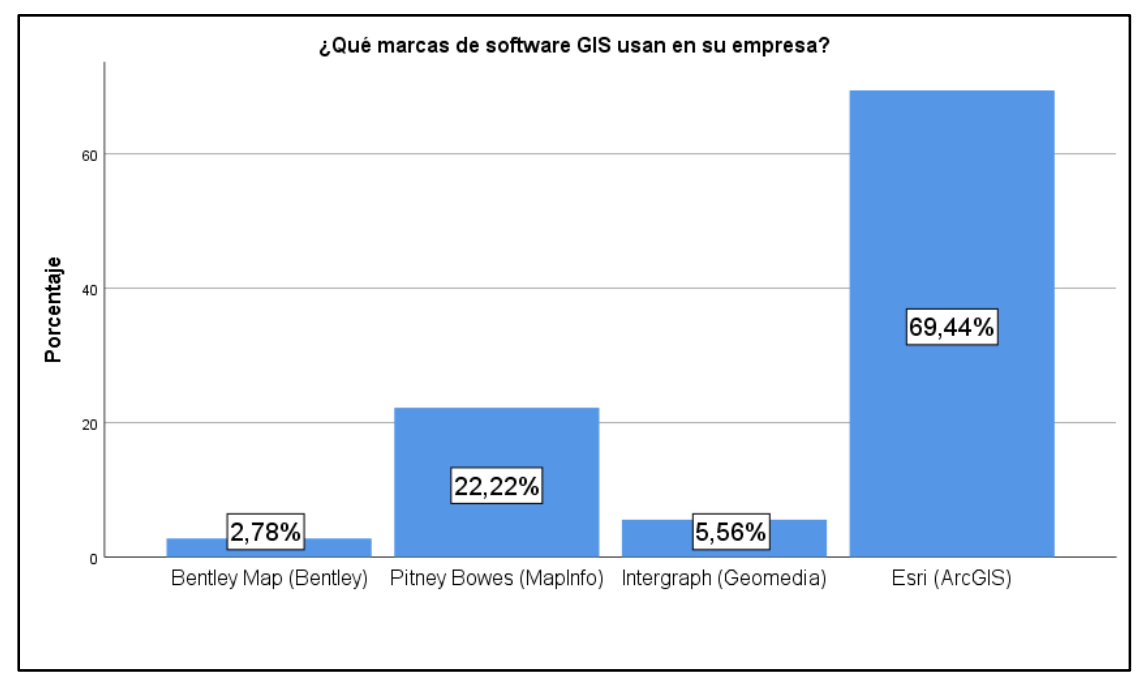

Figura 20. Encuesta. Tomado de Resultado a la Pregunta 4. ¿Qué marcas de software GIS usan en su empresa?

Respecto a la cantidad de software GIS que tienen adquiridos las empresas mineras los resultados son: El 36.11\% no tiene, el 26.39\% tiene 1 licencias, el $20.83 \%$ entre 2 y 4 licencias, el $11.11 \%$ entre 5 y 8 licencias, el $4.17 \%$ entre 9 y 13 ; y el $1.39 \%$ mayor a 14 (ver Figura 21).

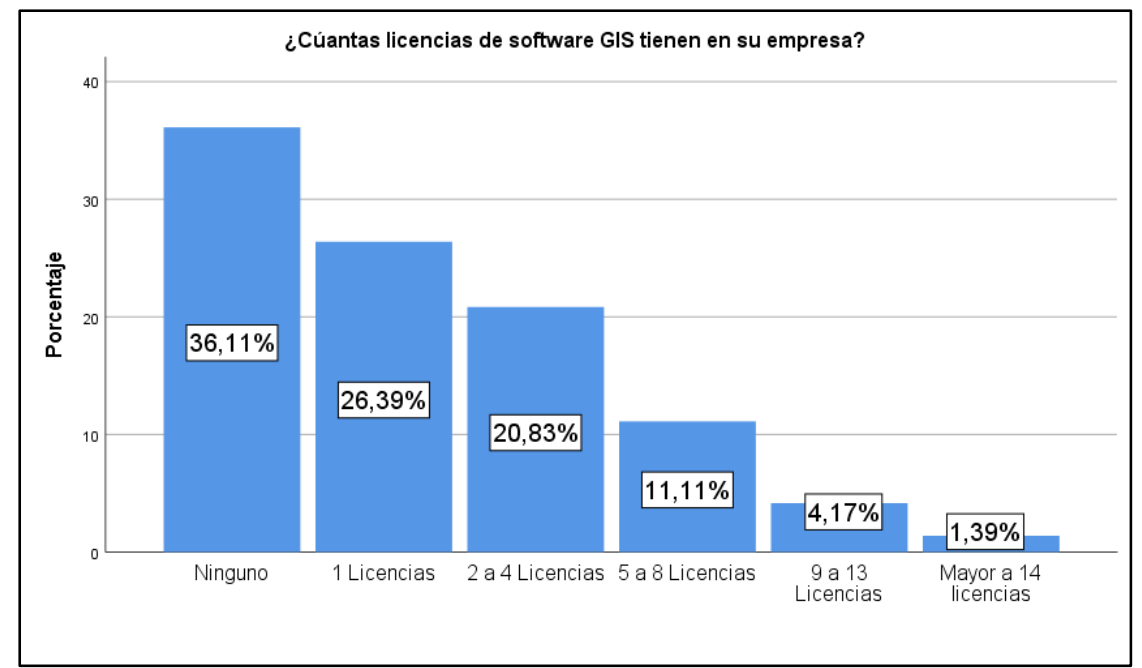

Figura 21. Encuesta. Tomado de Resultado a la Pregunta 5. ¿Cuántas licencias de software GIS tienen en su empresa? 
La intensión de compra de software GIS muestra los siguientes resultados, el $48.61 \%$ tiene planificado adquirir 2 Licencias, el $11.11 \% 3$ Licencias y el 1.39\% 4 licencias, haciendo un total de $61.11 \%$ empresas las que tienen planificado adquirir el 2018 , el $38.89 \%$ no tiene planificado ninguna compra (ver Figura 22).

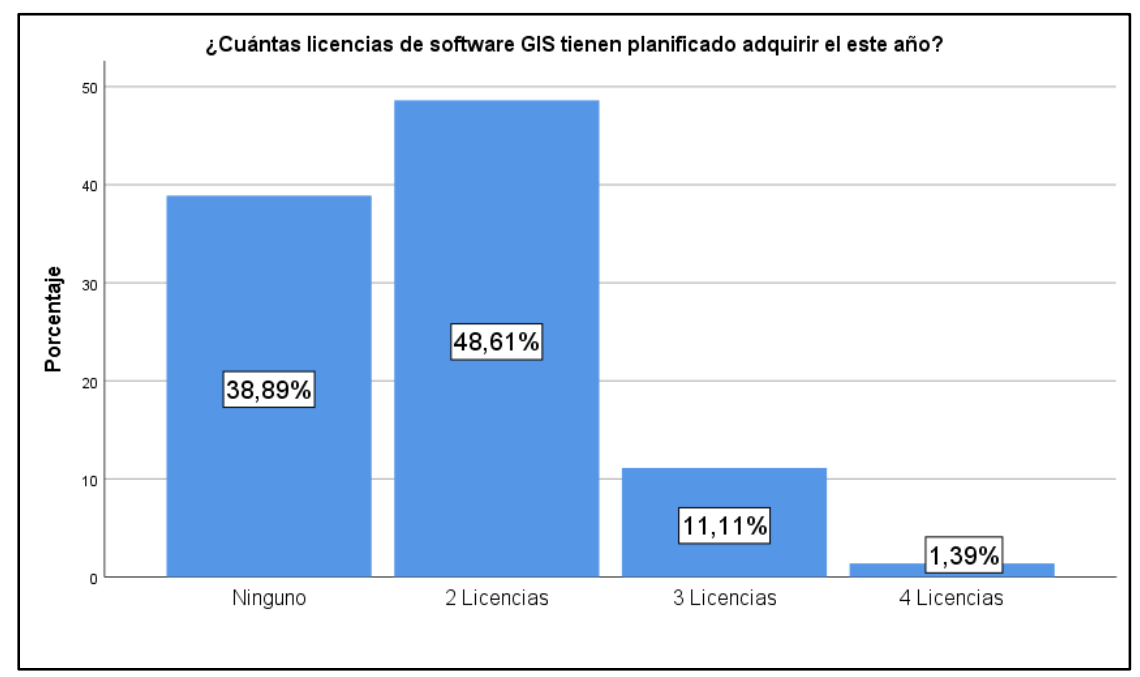

Figura 22. Encuesta. Tomado de Resultado a la Pregunta 6. ¿Cuántas licencias de software GIS tienen planificado adquirir el este año?

Consultado sobre ¿Qué empresa es su proveedor de software GIS? Las respuestas fueron las siguientes: el 76.39\% indicaron Telemática S.A., el 15.28\% Intech Group Perú S.A.C. y el $8.33 \%$ Cardo Consultants S.A.C. (ver Figura 23).

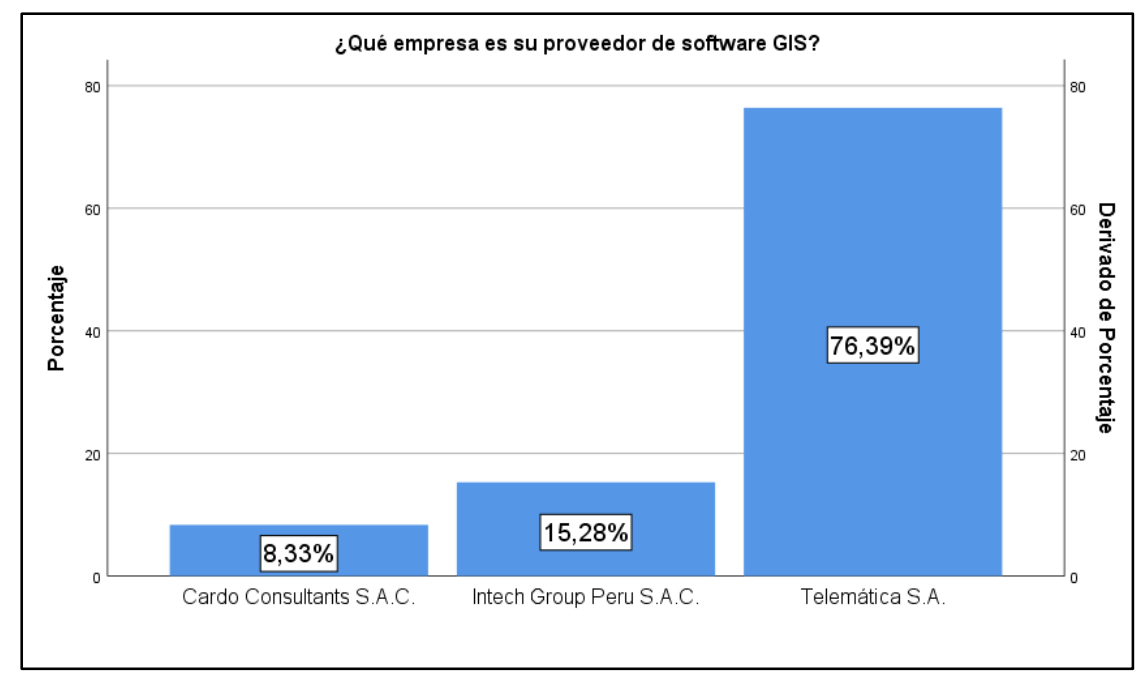

Figura 23. Encuesta. Tomado de Resultado a la Pregunta 7. ¿Qué empresa es su proveedor de software GIS? 
Consultado sobre la calificación a su proveedor GIS con la pregunta. En general ¿Cómo calificaría a su proveedor de software GIS? Las respuestas fueron: el 51.39\% indicó que es "Indiferente", el 43.06\% calificó como "Bueno" y un 5.56\% como "Malo" (ver Figura 24).

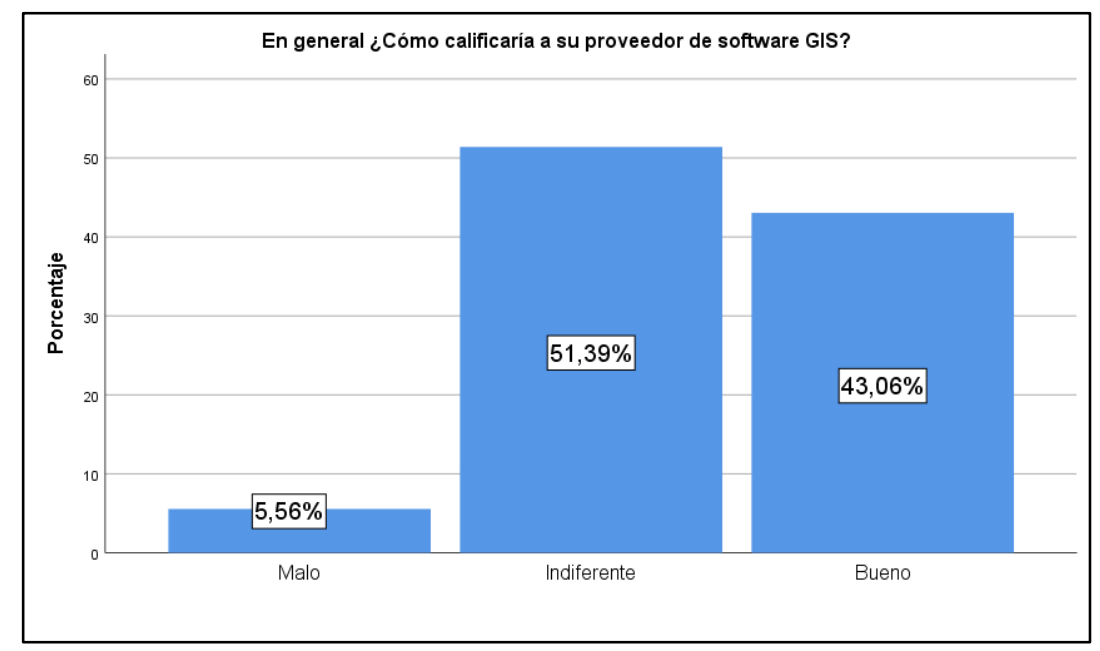

Figura 24. Encuesta. Tomado de Resultado a la Pregunta 8. En general ¿Cómo calificaría a su proveedor de software GIS?

Consultado sobre ¿Qué empresa es su proveedor de software CAD? Las respuestas fueron las siguientes: el 47.22\% Profile Consulting Group S.A., el 19.44\% Replica SRL, el 13.89\% Macrotec Data, el 6.94\% Semco CAD y Business Solutions, el 4.17\% Otros al cual no especificaron y el 1.39\% Softland Perú S.A. (ver Figura 25).

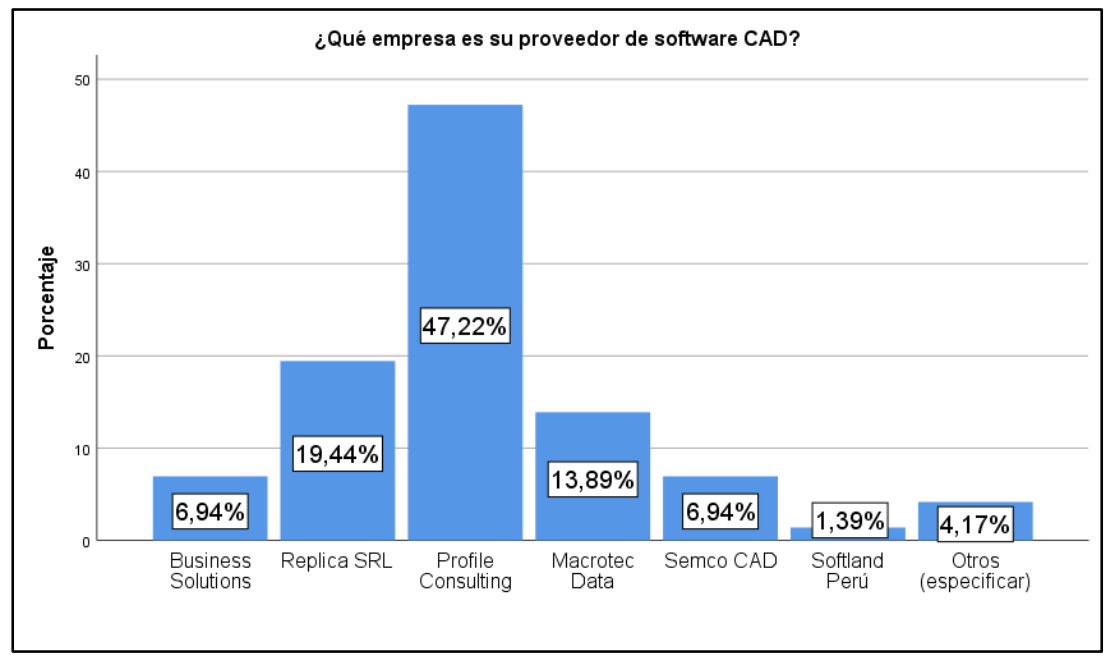

Figura 25. Encuesta. Tomado de Resultado a la Pregunta 9. ¿Qué empresa es su proveedor de software CAD? 
La calificación a su proveedor $\mathrm{CAD}$, respuesta a la siguiente pregunta. En general ¿Cómo calificaría a su proveedor de software CAD? Las respuestas fueron las siguientes: el 73.61\% indicó "bueno", el 25\% es "Indiferente" y un 1.39\% como "Muy Bueno" (ver Figura 26).

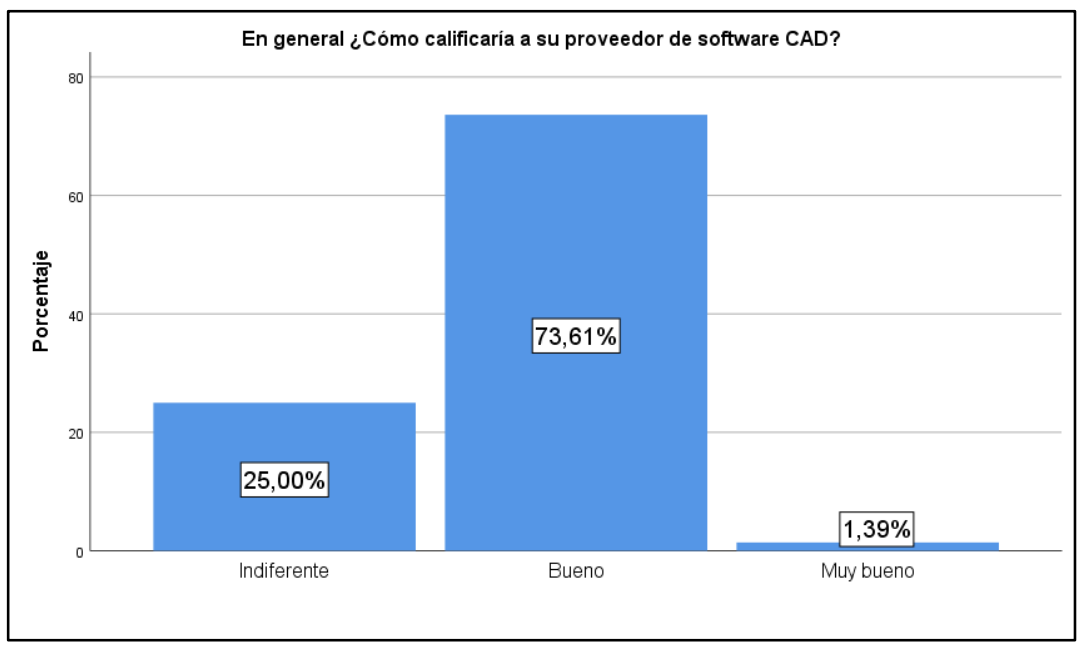

Figura 26. Encuesta. Tomado de Resultado a la Pregunta 10. En general ¿Cómo calificaría a su proveedor de software CAD?

Sobre la motivación de compra, consultado con la siguiente pregunta. ¿Qué es lo que le motiva a comprar una determinada marca de software? Se obtuvieron los siguientes resultados, el 79.17\% indicaron la "Funcionalidad", el 19.44\% la "Marca" y el 1.39\% "Otros" el cuál no especificaron (ver Figura 27).

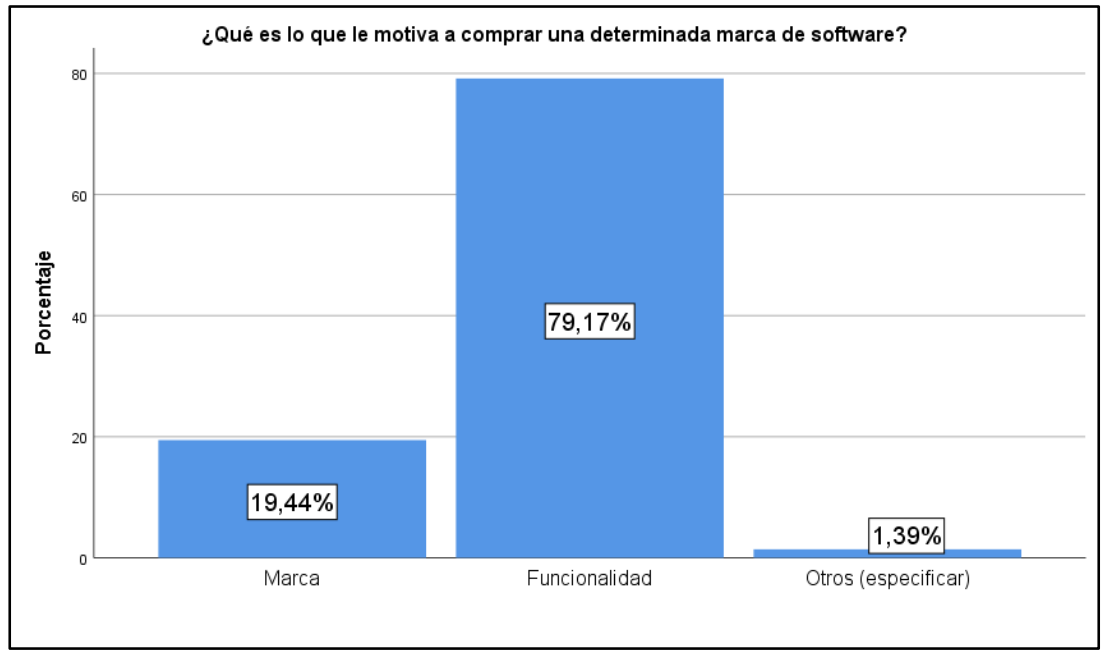

Figura 27. Encuesta. Tomado de Resultado a la Pregunta 11. ¿Qué es lo que le motiva a comprar una determinada marca de software? 
Respecto a la actualización de sus licencias de software, consultado con la pregunta ¿Con qué frecuencia actualizan las licencias de software de su empresa? Los resultados indicaron que el 76.39\% “Cada 1 Año", el 22.22\% "No realizan actualizaciones” y un 1.39\% “Cada 3 Años” (ver Figura 28).

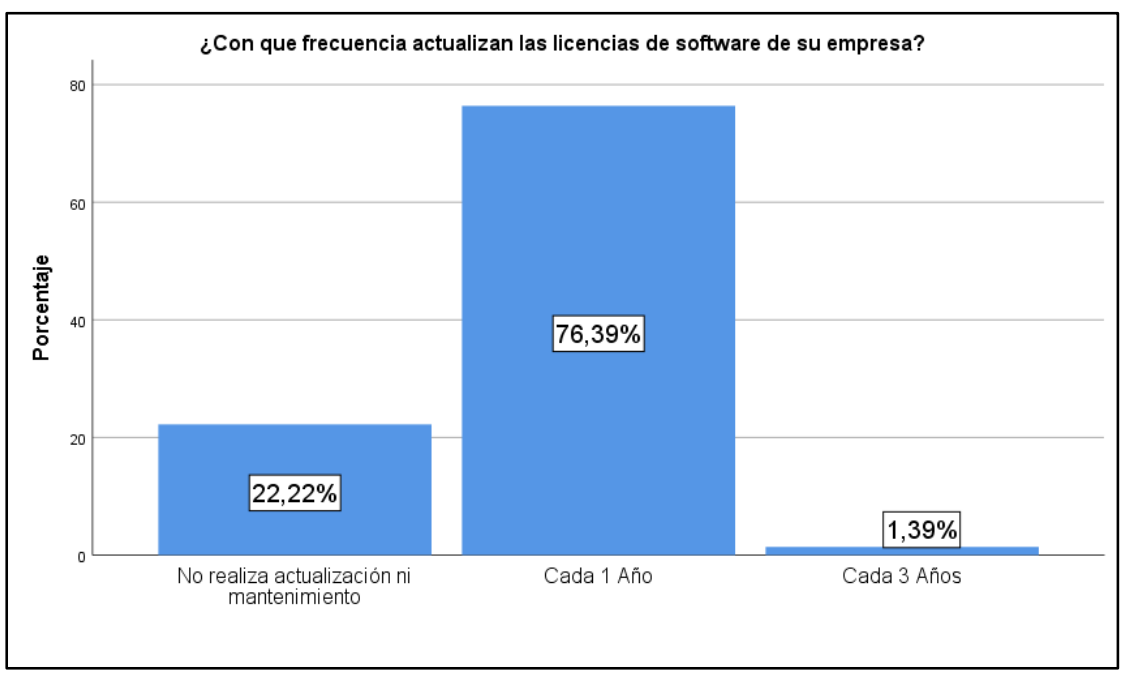

Figura 28. Encuesta. Tomado de Resultado a la Pregunta 12. ¿Con que frecuencia actualizan las licencias de software de su empresa?

Respecto a quien decide la compra, los resultados obtenidos fueron los siguientes: el 69.44\% indicaron "Los Usuarios", el 29.17\% "Jefe o Gerente de área” y el 1.39\% "Jefe o gerente de Sistemas" (ver Figura 29).

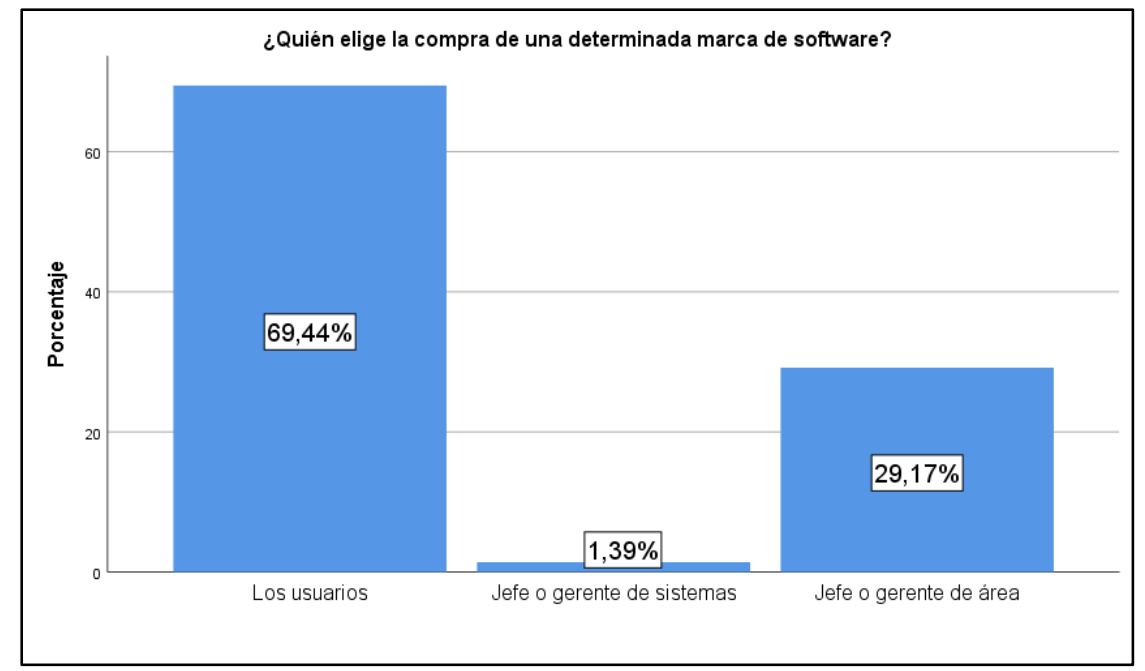

Figura 29. Encuesta. Tomado de Resultado a la Pregunta 13. ¿Cuándo o por qué adquieren nuevas licencias de software? 
En cuanto al tiempo de pago a proveedores, los resultados arrojaron los siguientes resultados, el 91.67\% "Pago a 30 días" y el 4.17\% "Pago a 15 días" y "Pago a 45 días" (ver Figura 30).

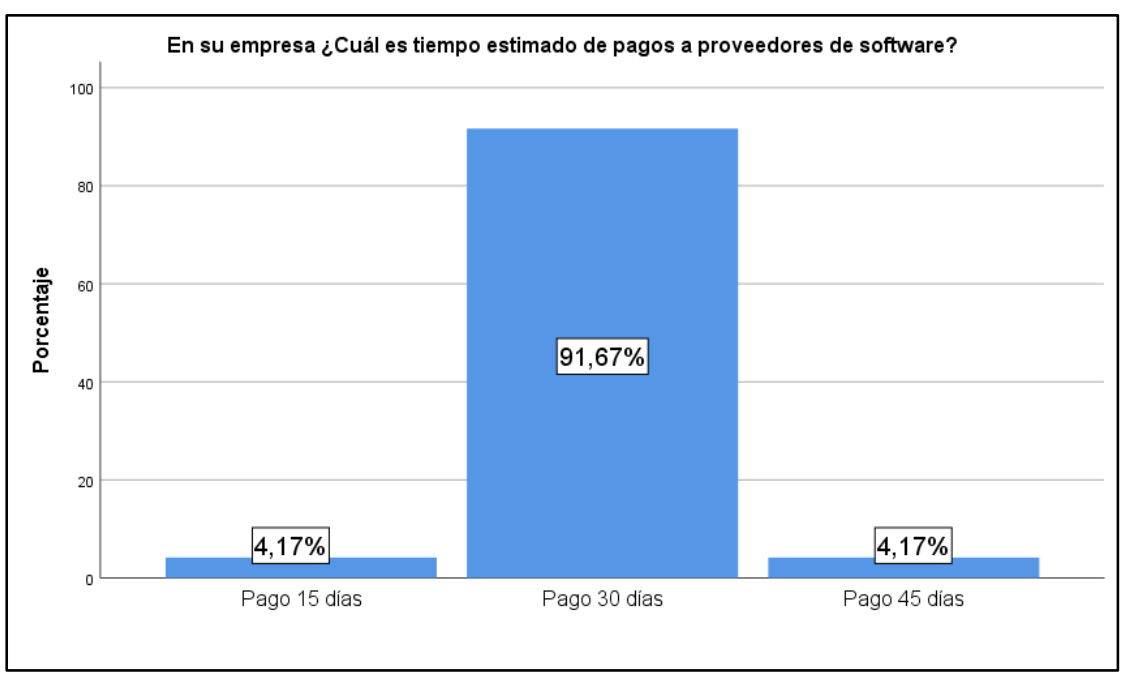

Figura 30. Encuesta. Tomado de Resultado a la Pregunta 14. En su empresa ¿Cuál es tiempo estimado de pagos a proveedores de software?

Consultado sobre la intensión de compra a un nuevo proveedor, las respuestas fueron lo siguiente: el 66.67\% indicó que "Probablemente si lo consumiría", el 30.56\% era "Indiferente", el 1.39\% "Probablemente no lo consumiría" y el restante 1.39\% "Definitivamente si lo consumiría" (ver Figura 31).

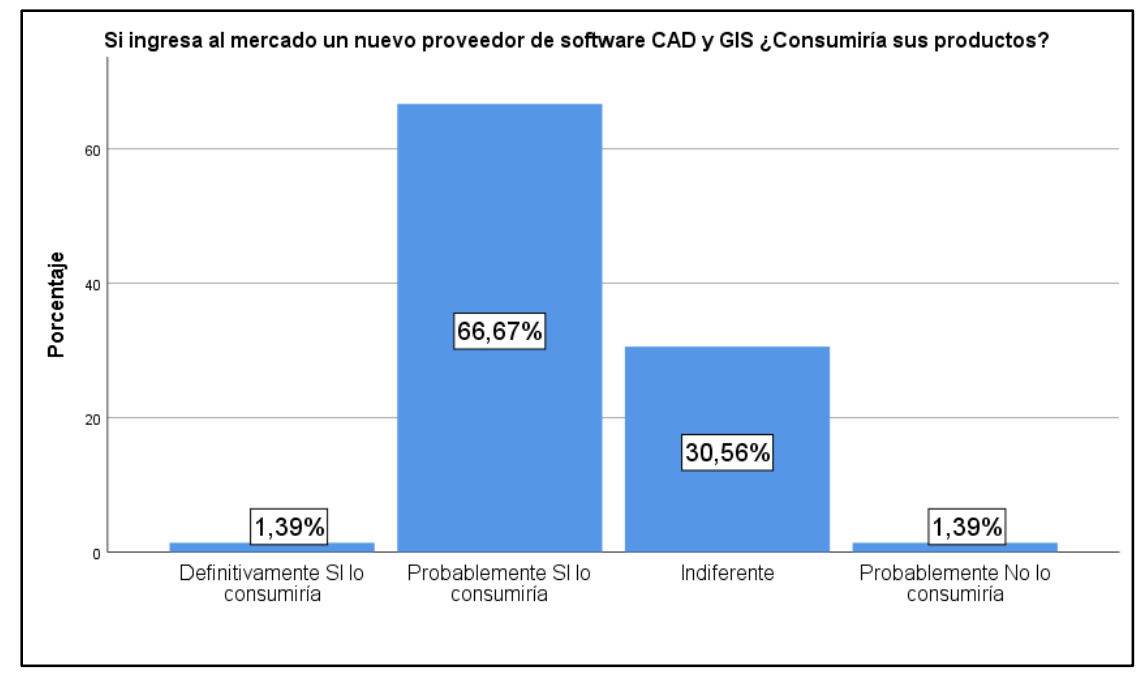

Figura 31. Encuesta. Tomado de Resultado a la Pregunta 15. Si ingresa al mercado un nuevo proveedor con software ZwCAD (CAD) y MapInfo (GIS) ¿compraría dichos productos? 
A la pregunta ¿Mediante qué medios le gustaría recibir información sobre soluciones CAD y GIS?, las respuestas fueron: el 59.72\% prefieren "Correo Electrónico", el 36.11\% mediante "Eventos" y un 4.17\% indicaron "Otros" (ver Figura 32).

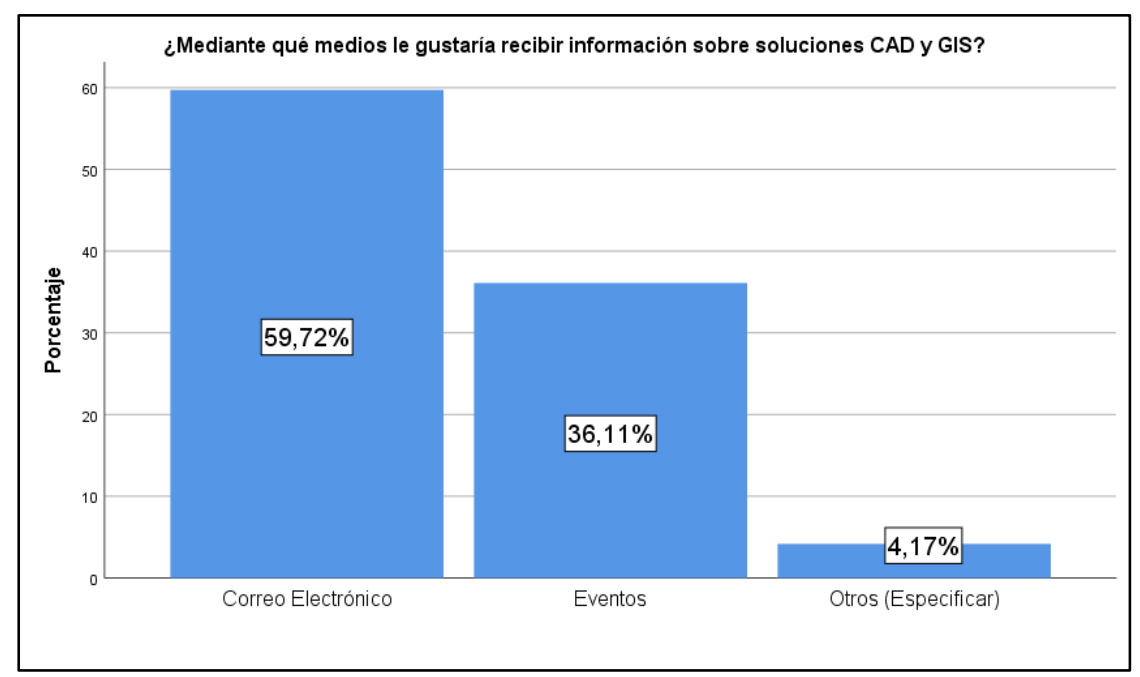

Figura 32. Encuesta. Tomado de Resultado a la Pregunta 16. ¿Mediante qué medios le gustaría recibir información sobre soluciones CAD y GIS?

Consultado, ¿Qué servicios adicionales les gustaría recibir de un proveedor de software CAD o GIS” los resultados indican que un 77.78\% prefieren “Capacitación”, el 13.89\% "Otros servicios", "Servicios de Consultoría" y "Hardware Especializado" el 4.17\% respectivamente (ver Figura 33).

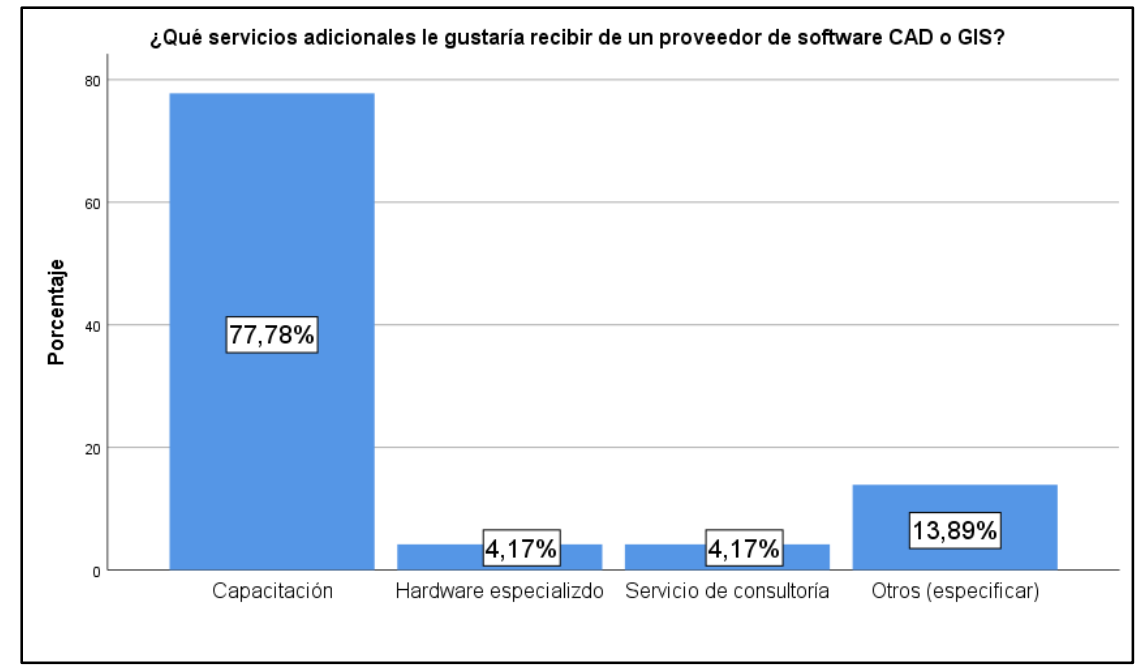

Figura 33. Encuesta. Tomado de Resultado a la Pregunta 17. ¿Qué servicios adicionales le gustaría recibir de un proveedor de software CAD o GIS? 
Respecto a la pregunta: En orden de importancia, establezca usted el criterio que más valora de un proveedor de software, para el cual se deberá considerar, 1 como el criterio más importante, así sucesivamente, siendo 7 el menos importante. La respuesta fue contundente a la alternativa "Personal Calificado" seguido por "Soporte Presencial" (ver Figura 34).

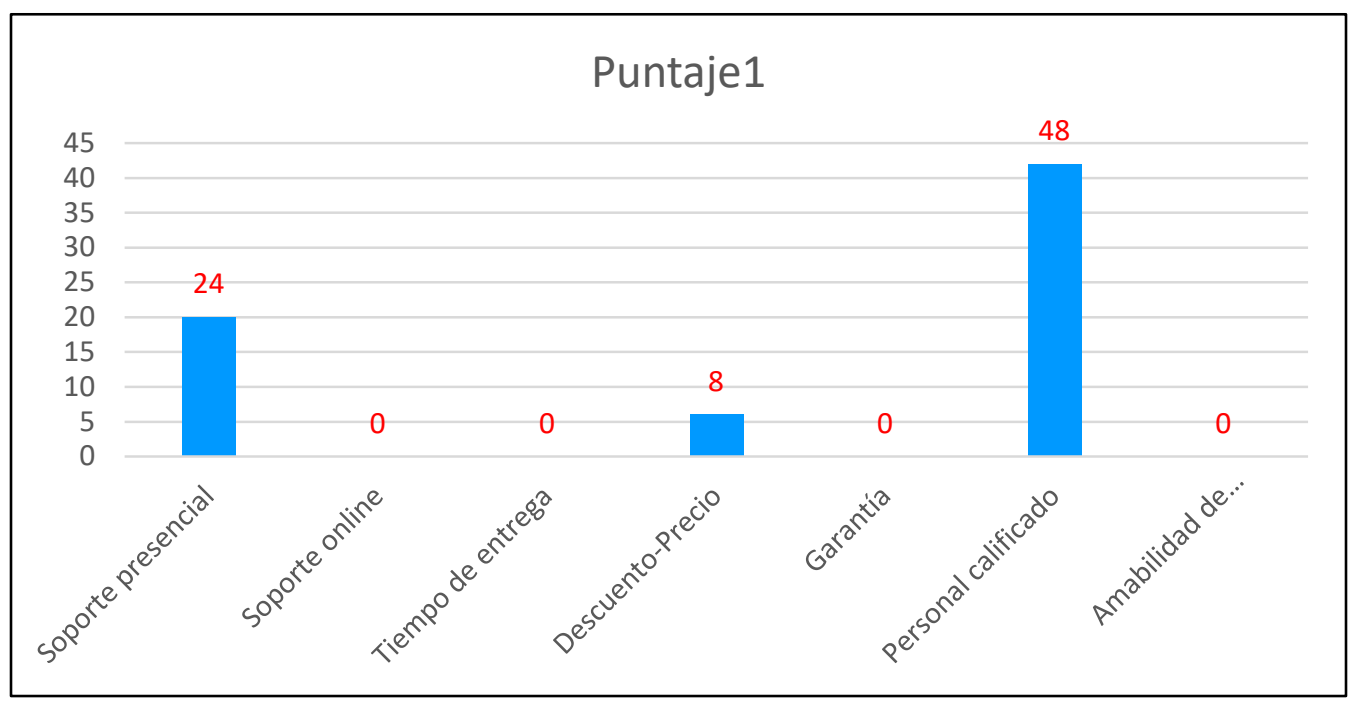

Figura 34. Encuesta. Tomado de Resultado a la Pregunta 18. En orden de importancia, establezca usted el criterio que más valora de un proveedor de software, para el cual se deberá considerar, 1 como el criterio más importante, así sucesivamente, siendo 7 el menos importante 


\section{Tabla 9}

\section{Resumen del estudio cuantitativo}

\begin{tabular}{|c|c|c|}
\hline & Pregunta & Respuesta \\
\hline 1. & ¿En qué área de su empresa trabaja? & $\begin{array}{l}\text { El } 58.33 \% \text { de los encuestados trabajan en el área de Sistemas, el } 31.94 \% \text { en Geología y el } \\
9.72 \% \text { en el área de Ingeniería }\end{array}$ \\
\hline 2. & $\begin{array}{l}\text { En su empresa ¿Qué rango refleja la } \\
\text { cantidad de trabajadores, ingenieros, } \\
\text { geógrafos, proyectistas y topógrafos? }\end{array}$ & $\begin{array}{l}\text { El } 47.22 \% \text { de las empresas del sector minería tienen entre } 6 \text { y } 14 \text { profesionales que son } \\
\text { ingenieros, proyectistas, geógrafos y topógrafos. El } 43.06 \% \text { entre } 15 \text { y } 24 \text { y el } 9.72 \% \text { entre } \\
25 \text { y } 40 \text { de los profesionales mencionado }\end{array}$ \\
\hline 3. & $\begin{array}{l}\text { ¿Qué marcas de software CAD usan en } \\
\text { su empresa? }\end{array}$ & $\begin{array}{l}\text { El software CAD más usado por las empresas del sector minero es el AutoCAD con un } \\
97.22 \% \text { de participación y solamente el } 1.39 \% \text { usan software MicroStation y } 1.39 \% \text { el } \\
\text { ArchiCAD }\end{array}$ \\
\hline 4. & $\begin{array}{l}\text { ¿Cuántas licencias de software CAD } \\
\text { tienen en su empresa? }\end{array}$ & $\begin{array}{l}\text { El } 75 \% \text { tiene entre } 6 \text { y } 14 \text { licencias, el } 19.44 \% \text { entre } 15 \text { y } 24 \text { licencias y el } 5.56 \% \text { menos de } \\
5 \text { licencias }\end{array}$ \\
\hline 5 . & $\begin{array}{l}\text { ¿Cuántas licencias de software CAD } \\
\text { tienen planificado adquirir el este año? }\end{array}$ & $\begin{array}{l}\text { El } 22.22 \% \text { tiene planificado adquirir } 2 \text { Licencias, el } 25 \% 3 \text { Licencias, } 4.17 \% 4 \text { licencias, el } \\
9.72 \% 5 \text { licencias, haciendo un total de } 61.11 \% \text { empresas las que tienen planificado } \\
\text { adquirir el } 2018 \text {, el } 38.89 \% \text { no tiene planificado ninguna compra }\end{array}$ \\
\hline
\end{tabular}

6. ¿Qué marcas de software GIS usan en su empresa?

La marca más usado por las empresas del sector minero es el ArcGIS con un $69.44 \%$, seguido por MapInfo con un 22.22\%, Geomedia con 5.56\% y Bentley Map con solo $2.78 \%$

7. ¿Cuántas licencias de software GIS tienen en su empresa?

8. ¿Cuántas licencias de software GIS tienen planificado adquirir este año?

9. ¿Qué empresa es su proveedor de software GIS?

10. En general ¿Cómo calificaría a su proveedor de software GIS?

11. ¿Qué empresa es su proveedor de software CAD?

12. ¿Cómo calificaría a su proveedor de software CAD?

13. ¿Qué es lo que le motiva a comprar una determinada marca de software?

14. ¿Con que frecuencia actualizan las licencias de software de su empresa?

15. ¿Cuándo o por qué adquieren nuevas licencias de software?

16. En su empresa ¿Cuál es tiempo estimado de pagos a proveedores de software?

El $36.11 \%$ no tiene, el $26.39 \%$ tiene 1 licencias, el $20.83 \%$ entre 2 y 4 licencias, el $11.11 \%$ entre 5 y 8 licencias, el $4.17 \%$ entre 9 y 13 ; y el $1.39 \%$ mayor a 14

El $48.61 \%$ tiene planificado adquirir 2 Licencias, el $11.11 \% 3$ Licencias y el $1.39 \% 4$ licencias, haciendo un total de $61.11 \%$ empresas las que tienen planificado adquirir el 2018, el $38.89 \%$ no tiene planificado ninguna compra

El 76.39\% indicaron Telemática S.A., el 15.28\% Intech Group Perú S.A.C. y el $8.33 \%$ Cardo Consultants S.A.C.

El 51.39\% indicó que es "Indiferente", el 43.06\% calificó como "Bueno" y un 5.56\% como "Malo"

El 47.22\% Profile Consulting Group S.A., el 19.44\% Replica SRL, el 13.89\% Macrotec Data, el $6.94 \%$ Semco CAD y Business Solutions, el $4.17 \%$ Otros al cual no especificaron y el $1.39 \%$ Softland Perú S.A.

El 73.61\% indicó "bueno", el 25\% es "Indiferente" y un 1.39\% como "Muy Bueno"

El 79.17\% indicaron la "Funcionalidad", el 19.44\% la "Marca" y el 1.39\% "Otros"

El 76.39\% "Cada 1 Año", el 22.22\% "No realizan actualizaciones" y un 1.39\% "Cada 3 Años"

El 69.44\% indicaron "Nuevos Proyectos", el 29.17\% "Compatibilidad" y el 1.39\%

"Nuevas Versiones"

El 91.67\% "Pago a 30 días" y el 4.17\% "Pago a 15 días" y "Pago a 45 días"

17. Si ingresa al mercado un nuevo proveedor de software ZwCAD (CAD) y MapInfo (GIS) ¿Consumiría sus productos?

18. ¿Mediante qué medios le gustaría recibir información sobre soluciones CAD y GIS?

19. ¿Qué servicios adicionales le gustaría recibir de un proveedor de software CAD o GIS?

20. En orden de importancia, establezca usted el factor que más valora de un proveedor de software, para el cual se deberá considerar, 1 como el criterio más importante, así sucesivamente, siendo 7 el menos importante

el 66.67\% indicó que "Probablemente si lo consumiría", el 30.56\% era "Indiferente", el $1.39 \%$ "Probablemente no lo consumiría" y el restante $1.39 \%$ "Definitivamente si lo consumiría"

El 59.72\% prefieren "Correo Electrónico", el 36.11\% mediante "Eventos” y un 4.17\% indicaron "Otros"

Un 77.78\% prefieren "Capacitación”, el 13.89\% "Otros servicios", "Servicios de

Consultoría" y "Hardware Especializado" el 4.17\% respectivamente

El 60\% valoran "Personal Calificado", un 30\% "Soporte Presencial" y solamente un 10\% "Precio-Descuento" 


\subsection{Conclusiones y recomendaciones del estudio}

En conclusión, de la investigación concluyente se determinó lo siguiente:

a. El tamaño del mercado interesado en adquirir los productos CAD y GIS el 2018 es el $61.11 \%$ y el $1.39 \%$ de estas afirmaron que definitivamente comprarían MapInfo Pro y ZwCAD y el $66.67 \%$ probablemente lo harían; por lo que se trabajará en desarrollar estrategias orientadas a estos prospectos.

b. Respecto a la frecuencia de compra, se pudo identificar que el $69.44 \%$ realizan cuando hay nuevos proyectos de los cuales el $76.39 \%$ realizan el pago por mantenimiento anual. Además el factor más importante en la decisión de uso de un determinado software es la "funcionalidad".

c. Otros hallazgos importantes de la investigación, es que el 56.95\% (51.39\% y 5.56\% calificados como "indiferente" y "malo" respectivamente), no se encuentran satisfechos con la atención de su proveedor de software GIS. Para el caso de software CAD el 25\% se muestra "Indiferente". Además se identificó los aspectos que más valoran de un proveedor de software es el "Personal calificado" y “soporte presencial”, dejando en un tercer lugar el "precio", por lo que las estrategias deben estar dirigidas para satisfacer estas necesidades.

d. En cuanto a la forma de pago el $91.67 \%$ de encuestados indicaron que pagan a 30 días y el medio de comunicación por el que prefieren recibir información es el "Correo Electrónico" con 59.72\%, seguido por "Eventos” con $36.11 \%$, por lo que en la estrategia financiera debe considerarse el tiempo de pago para la liquidez y los medios de comunicación deberían realizarse mediante correo electrónico y eventos. 
e. Los servicios adicionales por lo que muestran interés los entrevistados es la “Capacitación” y "servicios de consultoría” (77.78\% y 13.89\% respectivamente), habiendo una oportunidad para incrementar estos servicios que no se encuentran contemplados en el proyecto. 


\section{CAPÍtULO IV}

\section{Proyección del mercado objetivo}

En este capítulo se desarrolla los procesos necesarios utilizando los métodos de proyección para determinar el mercado potencial, disponible, efectivo y objetivo.

\subsection{El ámbito de la proyección}

El ámbito de la proyección definido para el proyecto es el territorio peruano.

\subsection{Selección del método de proyección}

El método de proyección utilizado es el método subjetivo, específicamente la investigación de mercado y el juicio propio basado en la experiencia y el análisis del contexto, en razón que no existe información exacta de negocios similares.

\subsubsection{Mercado Potencial}

Son todas las empresas que pertenecen al sector minero, según el compendio Perú Top 10,000 Companies 2017, son 465 empresas.

\subsubsection{Mercado Disponible}

Para determinar el mercado disponible se realizó el análisis al resultado de la pregunta 1 ¿Qué marca de software CAD usan en su empresa? y pregunta 4 ¿Qué marca de software GIS utilizan en su empresa? En ambos casos el 100\% de los entrevistados indicó que utiliza alguna marca (ver Tabla 10) 


\section{Tabla 10}

Resultado marcas de software CAD y GIS que utilizan

\begin{tabular}{lccccccc}
\hline $\begin{array}{l}\text { Pregunta } 1 \\
\text { softwaé marca de }\end{array}$ & $\begin{array}{c}\text { MicroStation } \\
\text { (Bentley) }\end{array}$ & $\begin{array}{c}\text { ArchiCAD } \\
\text { (ArchiCAD) }\end{array}$ & $\begin{array}{c}\text { AutoCAD } \\
\text { (Autodesk) }\end{array}$ & $\begin{array}{c}\text { ZwCAD } \\
\text { (ZWSoft) }\end{array}$ & $\begin{array}{c}\text { Otro } \\
\text { (Especificar) }\end{array}$ & Total \\
\cline { 2 - 7 } & $1.39 \%$ & $1.39 \%$ & $97.22 \%$ & $0 \%$ & $0 \%$ & $100 \%$ \\
\hline $\begin{array}{l}\text { Pregunta } 4 \\
\text { softwaé marca de } \\
\text { empresa? }\end{array}$ & $\begin{array}{c}\text { Bentley Map } \\
\text { (Bentley) }\end{array}$ & $\begin{array}{c}\text { Pitney } \\
\text { Bowes } \\
\text { (MapInfo) }\end{array}$ & $\begin{array}{c}\text { Intergraph } \\
(\text { Geomedia) }\end{array}$ & $\begin{array}{c}\text { Esri } \\
\text { (ArcGIS) }\end{array}$ & $\begin{array}{c}\text { Otro } \\
\text { (Especificar) }\end{array}$ & Total \\
\cline { 2 - 7 } & $2.78 \%$ & $22.22 \%$ & $5.56 \%$ & $69.44 \%$ & $0 \%$ & $100 \%$ \\
\hline
\end{tabular}

Nota. El total de encuestados indicaron que usan algún tipo de software CAD y GIS. Elaboración Propia.

\subsubsection{Mercado Efectivo}

En la encuesta realizada, la pregunta número seis ¿Cuántas licencias CAD tiene planificado comprar este año?, los resultados fueron: el $38.89 \%$ ninguno, el $48.61 \%$ dos licencias, el $11.11 \% 3$ Licencias y el $1.39 \%$ cuatro licencias y $0 \%$ más de cinco licencias, con lo que la intención de compra de software CAD para el año 2018 sería 633 licencias (ver Tabla 11).

\section{Tabla 11}

Intención de compra de software CAD

\begin{tabular}{lcccccc}
\hline \multicolumn{1}{c}{ Descripción } & Ninguno & 2 Lic. & 3 Lic. & 4 Lic. & $\begin{array}{c}\text { 5 Lic. a } \\
\text { más }\end{array}$ & Total \\
\hline Presupuesto de compras para software CAD (\%) & $38.89 \%$ & $48.61 \%$ & $11.11 \%$ & $1.39 \%$ & $0.00 \%$ & $61.11 \%$ \\
Presupuesto de compras para software CAD (\# Lic.) & 0 & 2 & 3 & 4 & 5 & \\
Mercado Efectivo de Software CAD (Empresas) & 181 & 226 & 52 & 6 & 0 & 284 \\
Mercado Efectivo de software CAD (Licencias) & 0 & 452 & 155 & 26 & 0 & 633 \\
\hline
\end{tabular}

Nota. Información basada en el resultado de encuestas, Pregunta 3.

En la encuesta realizada, la pregunta número tres ¿Cuántas licencias GIS tiene planificado comprar este año?, los resultados fueron los siguientes: el 38.89\% ninguno, el 22.22\% dos licencias, el 25\% 3 Licencias, 
$4.17 \%$ cuatro licencias y el $9.72 \%$ más de cinco licencias, con lo que la intención de compra de software GIS para el año 2018 sería 859 licencias (ver Tabla 12).

\section{Tabla 12}

Intención de compra de software GIS

\begin{tabular}{lcccccc}
\hline \multicolumn{1}{c}{ Descripción } & Ninguno & 2 Lic. & 3 Lic. & 4 Lic. & $\begin{array}{c}\text { 5 Lic. a } \\
\text { más }\end{array}$ & Total \\
\hline Presupuesto de compras para software GIS (\%) & $38.89 \%$ & $22.22 \%$ & $25.00 \%$ & $4.17 \%$ & $9.72 \%$ & $61.11 \%$ \\
Presupuesto de compras para software GIS (\# Lic.) & 0 & 2 & 3 & 4 & 5 & \\
Mercado Efectivo de software GIS (Empresas) & 181 & 103 & 116 & 19 & 45 & 284 \\
Mercado Efectivo de software GIS (Licencias) & 0 & 207 & 349 & 78 & 226 & 859 \\
\hline
\end{tabular}

Nota. Información basada en el resultado de encuestas, Pregunta 6.

Por lo tanto, en resumen el mercado Efectivo para licencias CAD y GIS son los mencionados a continuación (ver Tabla 13).

\section{Tabla 13}

Mercado Disponible de software CAD y GIS

\begin{tabular}{lc}
\hline \multicolumn{1}{c}{ Descripción } & $\begin{array}{c}\text { Total } \\
\text { Licencias }\end{array}$ \\
\hline Mercado Efectivo software CAD (Licencias) & 633 \\
Mercado Efectivo software GIS (Licencias) & 859 \\
\hline
\end{tabular}

Nota. Los resultados son resumidos del las dos tablas anteriores

\subsubsection{Mercado Objetivo}

El mercado Objetivo se determinó tomando como base los resultados del mercado disponible, y ajustados con los resultados de la encuesta, pregunta 15 de tipo escala de Liker, cuya pregunta dice: Si ingresa al mercado un nuevo proveedor con los software ZwCAD (CAD) y MapInfo (GIS) ¿Consumiría dichos productos? 
Las respuestas fueron los siguiente: el 1.39\% indicó que

“Definitivamente si compraría”, el 66.67\% "Probablemente Si compraría”, un $30.56 \%$ "Indeciso", un $1.39 \%$ "Definitivamente no compraría" y $0 \%$

"Definitivamente no compraría"

Los resultados de la respuesta fueron ajustados con la metodología de de McDaniels (2016, p254), en su libro de Investigación de mercados donde menciona que una estimación razonable pero conservadora 70\% de los que "Definitivamente si", 35\% de los que "Probablemente si", 25\% "Indecisos", $10 \%$ de los "Probablemente no", y $0 \%$ de los "Definitivamente no", obteniendo como mercado objetivo 203 Licencias para ZwCAD y 276 Licencias para MapInfo Pro (Ver Tabla 13).

\section{Tabla 14}

Determinación de mercado objetivo de software CAD y GIS

\begin{tabular}{lcccc}
\hline \multicolumn{1}{c}{ Descripción } & Respuesta $\%$ & McDaniels & Mdo. CAD & Mdo. GIS \\
\hline Definitivamente SI compraría & $1.39 \%$ & $70 \%$ & 6 & 8 \\
Probablemente SI compraría & $66.67 \%$ & $35 \%$ & 148 & 200 \\
Indeciso & $30.56 \%$ & $25 \%$ & 48 & 66 \\
Probablemente NO compraría & $1.39 \%$ & $10 \%$ & 1 & 1 \\
Definitivamente NO compraría & $0 \%$ & $0 \%$ & 0 & 0 \\
Total Mercado Objetivo (Licencias) & & & $\mathbf{2 0 3}$ & $\mathbf{2 7 6}$ \\
\hline
\end{tabular}

Nota. El resultado \% de las respuestas fueron multiplicados por la escala \% de McDaniels y por el resultado de mercado disponible CAD (633 Licencias), obteniendo como resultado el Mercado objetivo para ZwCAD (203 Licencias). De la misma forma se operó para determinar el mercado objetivo de MapInfo (276 Licencias) 


\section{CAPÍTULO V}

\section{Plan de Marketing}

El plan de marketing de este proyecto tiene la finalidad de alcanzar los objetivos comerciales, para el cual se ha identificado los principales productos más rentables, determinado el mercado objetivo y sus preferencias que otorgan valor y trabajar de manera estratégica las variables del marketing mix, con el que se pretende posicionar la marca en la mente de los clientes y mantener relaciones de largo plazo.

\subsection{Estrategia de marketing}

La estrategia de marketing se ha elaborado en base a los resultados de la investigación cuantitativa y cualitativa con la finalidad de satisfacer las necesidades del mercado objetivo y posicionar el nombre de la compañía como la organización TI de soluciones geográficas.

\subsubsection{Estrategia de Producto}

Los productos (soluciones) propuestos para el siguiente proyecto, tiene la finalidad de proveer software de Diseño Asistido por Computadora (CAD) y Sistema de Información Geográfica (GIS) especializado para ingeniería, medio ambiente y recursos naturales en forma de soluciones, dirigido para empresas del sector minero, para el cual se realizó la diferenciación entre producto básico, real y aumentado (Kother \& Armstrong, 2007). 


\section{a) Productos Básico}

El beneficio o servicio fundamental, comprende dos aspectos esenciales:

- Programa informático CAD que facilita dibujar, diseñar, corregir y almacenar proyectos de ingeniería y arquitectura.

- Programa informático GIS que permite Localizar, registrar, diseñar, analizar, modelar y almacenar información georeferenciada.

\section{b) Productos Real}

El beneficio o servicio real o esperado, comprende los siguientes aspectos:

- Software CAD llamado ZwCAD desarrollado por ZwSoft, cuyo licenciamiento y entrega del producto es electrónico vía correo electrónico (Series de productos y activación) e incluye un año de mantenimiento que comprende la garantía, parches y nuevas versiones por el periodo de un año.

- Software GIS llamado MapInfo Pro, desarrollado por Pitney Bowes Software Inc., cuyo licenciamiento y entrega del producto es electrónico vía correo electrónico (Series de productos y activación) e incluye un año de mantenimiento que comprende la garantía, parches y nuevas versiones por el periodo de un año.

- Licencia de Software.

Entrega electrónica mediante un correo electrónico al responsable del manejo de las licencias, donde se incluirá el link para la descarga del 
software, el cual permanecerá vigente de manera permanente en nuestro servidor para su acceso en cualquier momento.

\section{c) Productos Aumentado}

El beneficio o servicio aumentado del proyecto consiste en lo siguiente:

- Implementación.

Comprende en analizar, recomendar y coordinar con los especialistas del área de sistemas del cliente para una adecuada instalación, configuración o vinculación con su base de datos y pruebas hasta su correcto funcionamiento de la aplicación.

- Capacitación.

Luego de la correcta implementación se realizará 12 horas de capacitación que consiste en desarrollar temas esenciales para el uso apropiado a nivel usuario. Las fechas y horas de realización deben ser coordinadas con el responsable del cliente. Dicha capacitación será dictada por el consultor senior.

- Soporte.

Este servicio se realizará de manera presencial por el personal especializado. Para las incidencias fuera de Lima Metropolitana y El Callao, el soporte se realizará de manera remota. Este servicio inicialmente tiene una vigencia de 1 año, posteriormente estará sujeto a la vigencia del servicio de mantenimiento anual. 


\section{d) Oferta de Valor}

¿Cómo satisfacemos la necesidad de los usuarios?

$\checkmark$ Ofreciendo productos con valor agregado que incluye instalación, implementación, capacitación y servicio post venta de manera presencial.

¿Qué beneficios ofrece nuestro proyecto?

$\checkmark$ Información e instalación de nuevas versiones vigentes para clientes que tengan vigente el servicio de mantenimiento.

¿Cuál es valor diferencial del proyecto?

$\checkmark$ Consultor senior especializado en sistemas GIS y CAD orientado en recursos naturales.

Atención presencial para implementación coordinada con el cliente de manera flexible.

Asistencia técnica local y presencial por personal especializado en sistemas GIS y CAD.

A continuación se detalla las principales funcionalidades de los productos MapInfo Pro y ZwCAD

\section{Software MapInfo Pro}

El fabricante Pitney Bowes (2018) describe que MapInfo Pro es un producto especializado, basada en tecnología de Sistema de Información Geográfica, el cual ayuda a los profesionales de medio ambiente, 
exploración, geógrafos, manejo de recursos y activos a mejorar la toma de decisiones mediante el análisis geográfico y genera valor dando respuesta a una pregunta fundamental ¿dónde?, es decir esta solución pretende brindar información acerca de:

¿Dónde estamos ubicados y nuestros activos?

¿Dónde convendría construir el campamento?

¿Dónde están nuestros recursos?

¿Cuál es el volumen del cuerpo del mineral y áreas de influencia?

¿Dónde están distribuidos los diferentes tipos de minerales?

¿Cuáles son las localidades que...?

¿Dónde hay cambios en el ambiente forestal?

En síntesis este producto permitirá:

- Identificar tendencias geográficas, geológicas

- Comprender la demografía de los stake holder

- Localizar recursos

- Modelar tendencias

\section{Principales diferenciadores}

- Requiere de menor característica de hardware

- Una sola vista de edición y presentación

- Integra MapInfo Raster para tratamiento imágenes (ver Figura 35),

- Tratamiento de imágenes raster considerando altitud (ver Figura 36) 


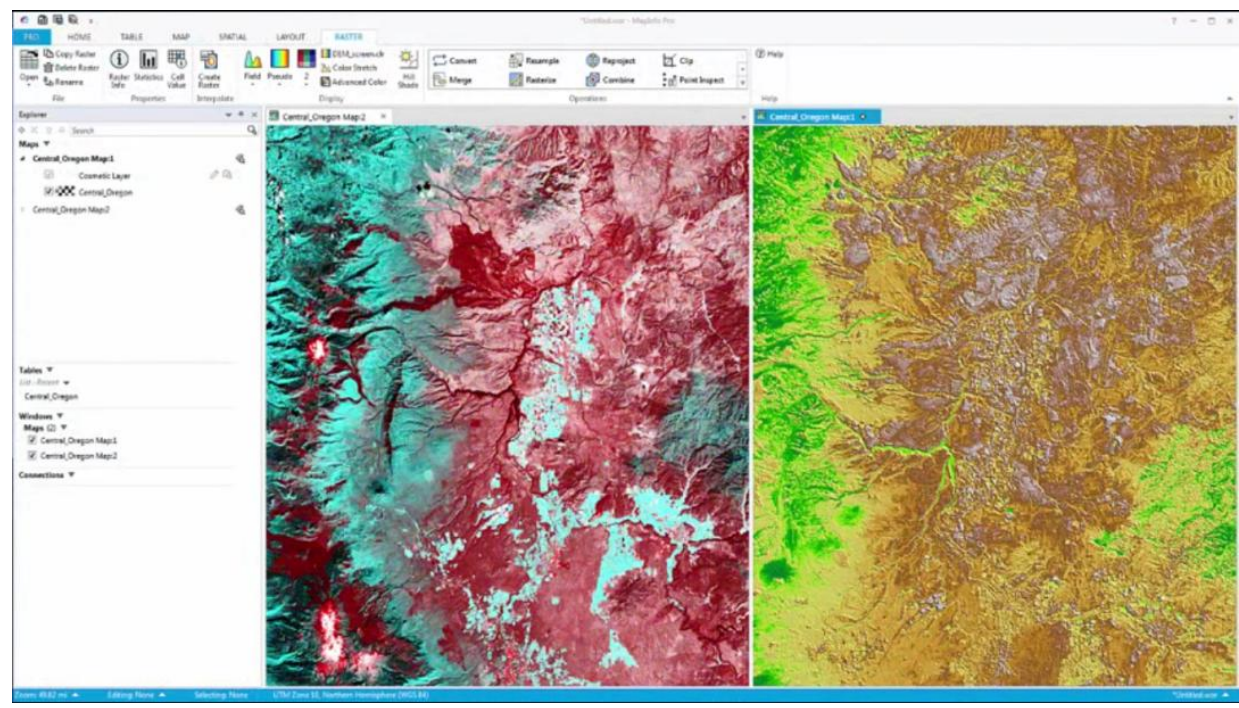

Figura 35. Raster para tratamiento imágenes en diferentes intensidades de color

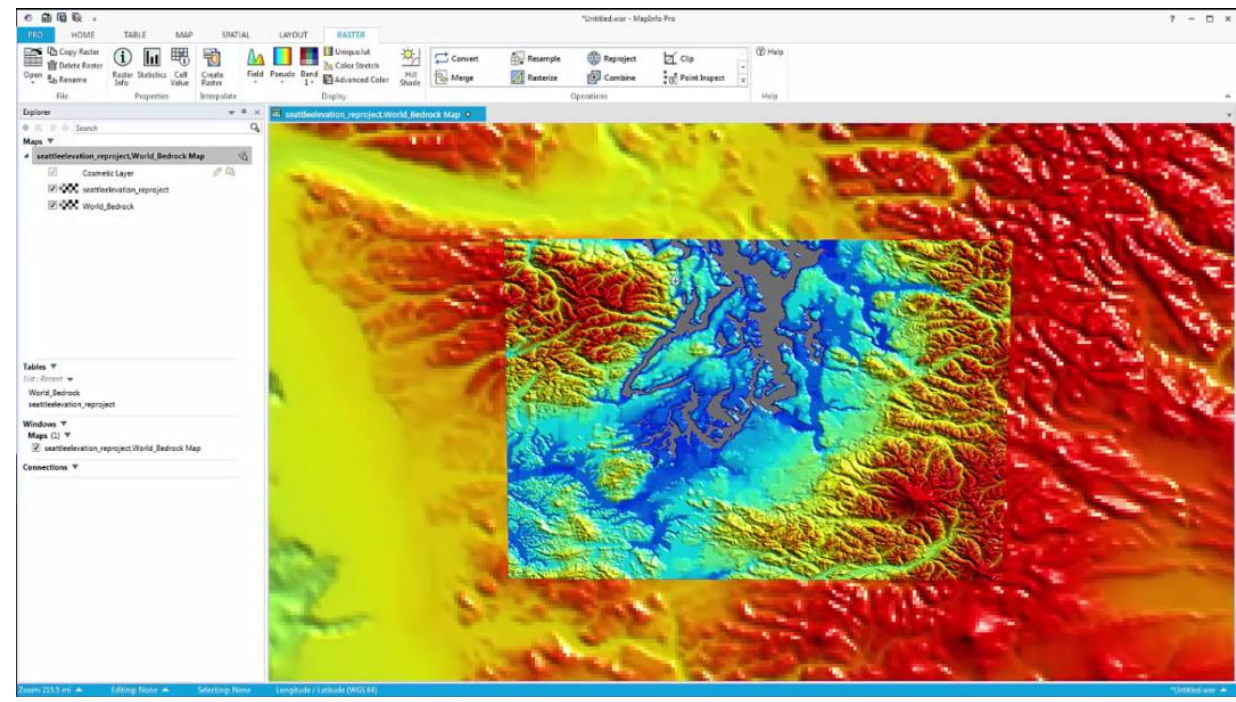

Figura 36. Tratamiento de imágenes con funcionalidad raster considerando altitud 


\section{ZwCAD}

El fabricante ZwSoft (2018) indica que ZwCAD es un producto especializado, basada en tecnología de Diseño Asistido por Computadora, el cual facilita a Ing. civiles, Ing. de minas, topógrafos entre otros, dibujar y diseñar proyectos de precisión con el que genera valor para cualquier organización que requiera este tipos de proyectos

- Compatibilidad DWG y múltiples formatos (ver Figura 37).

- Cad Poket, Para dispositivos móviles (ver Figura 38)

- File Compare, que detecta diferencias entre los dibujos (ver Figura 39)

- Smart Voice, para anotación vocal en archivo (ver Figura 40)

- Tecnología de optimización de memoria (ver Figura 41)

- Funcionalidad de AutoCAD (ver Figura 42)

- Funcionalidad de ZwCAD (ver Figura 43)

\section{Perfecta compatibilidad con otros programas de CAD}

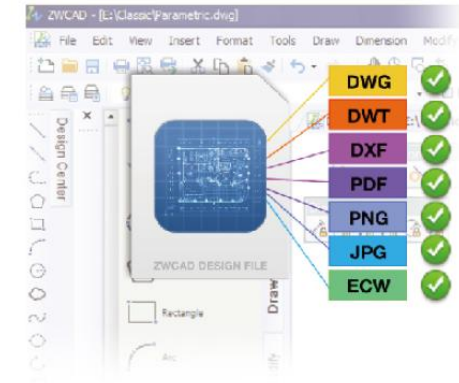

Después de haber realizado más de 50,000 pruebas rigurosas de dibujos para garantizar la compatibilidad con .dWg, zwCAD hace la comunicación entre diferentes plataformas más fácil que nunca.

Figura 37. Compatibilidad DWG y múltiples formatos. 


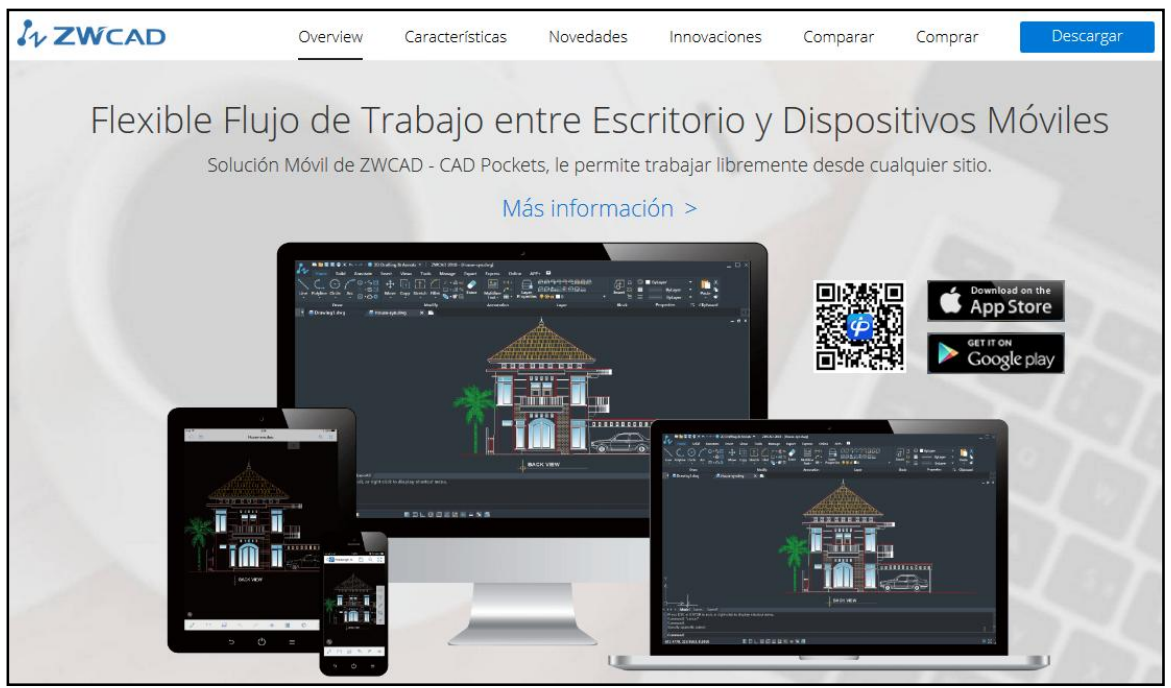

Figura 38. CAD Poket para dispositivos móviles

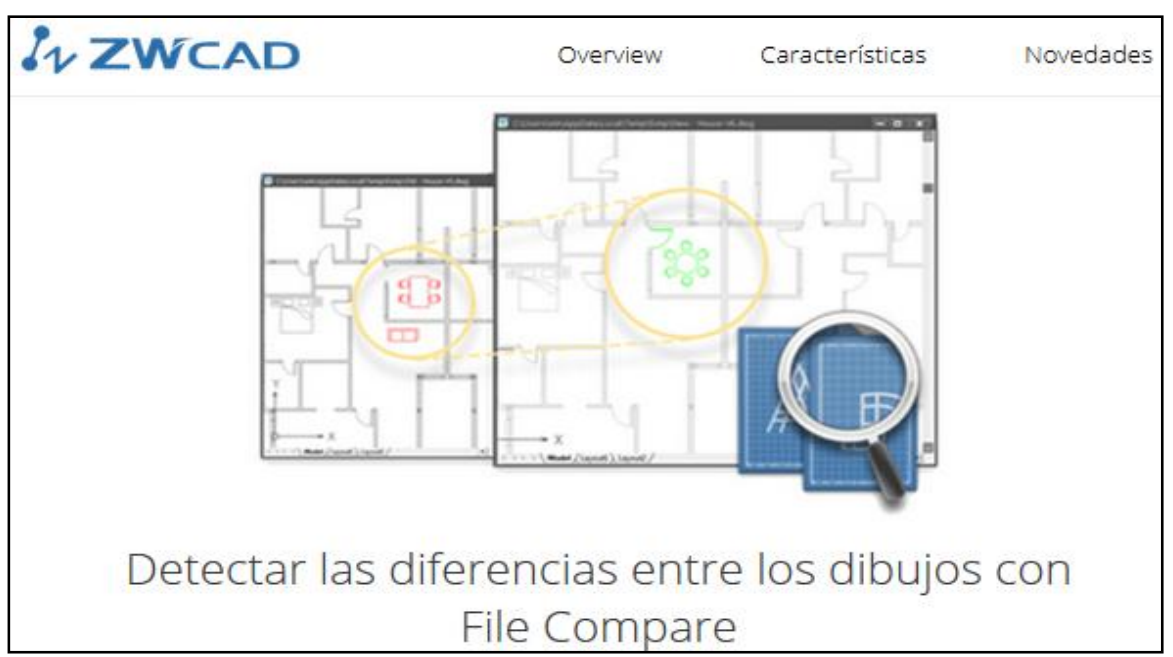

Figura 39. File Compare para detectar diferencia entre dibujos.

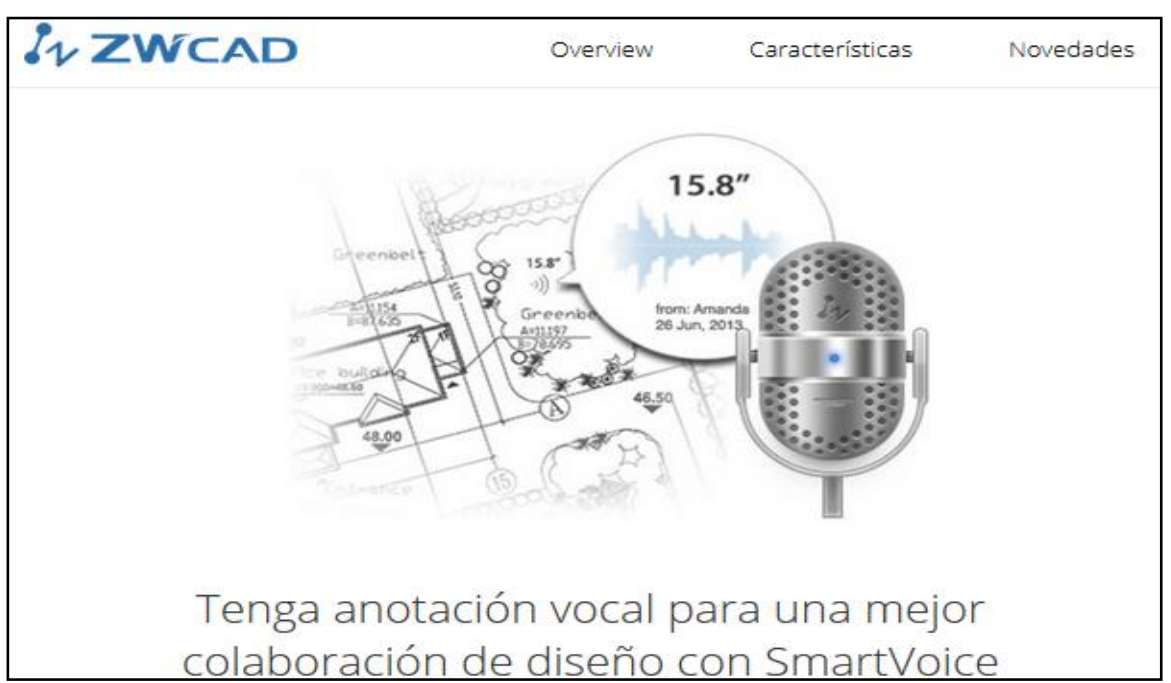

Figura 40. SmartVoice, para anotaciones de voz 


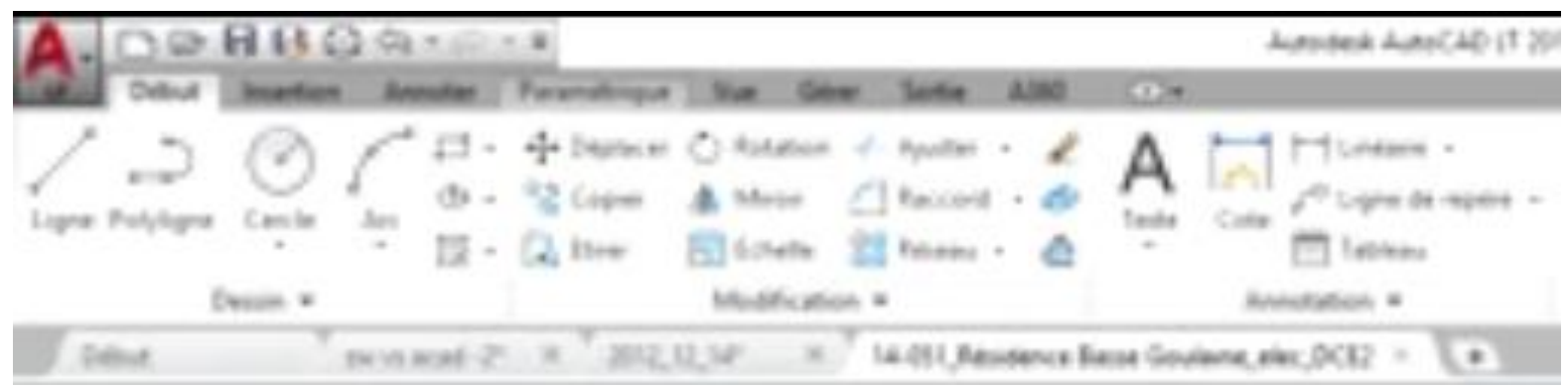

Figura 41. Funcionalidad del software AutoCAD

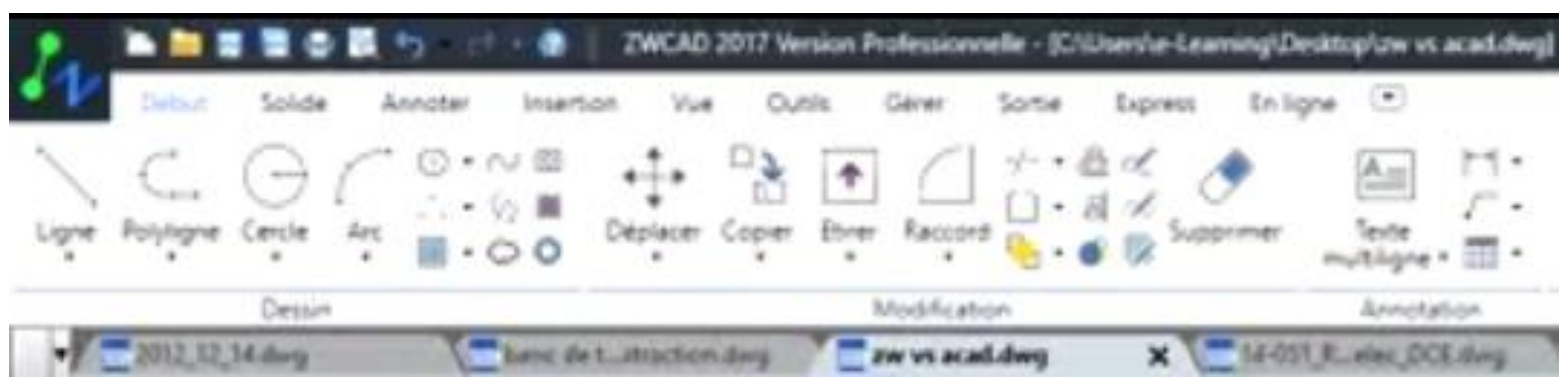

Figura 42. Funcionalidad del software ZwCAD

\section{e) Servicios complementarios}

Como servicios complementarios se recomienda ofertar servicios como la capacitación a nivel avanzado o consultorías para temas específicos, cuyo precio de venta promedio es de $\$ 75$ la hora y su respectivo costo máximo \$35 la hora, según los expertos entrevistados. 
Como resumen se elaboró una tabla comparativa de la oferta de valor del proyecto y

la competencia; donde los factores que los clientes consideran de alto valor, fueron

identificados mediante la investigación cualitativa y cuantitativa (ver Tabla 15).

\section{Tabla 15}

Oferta de Valor del proyecto y la competencia

\begin{tabular}{|c|c|c|c|}
\hline Valor para el cliente & Proyecto & Telemática & Profile Consulting \\
\hline \multirow{3}{*}{$\begin{array}{l}\text { Funcionalidad de } \\
\text { productos } \\
\text { (Peso: 0.22) }\end{array}$} & $\begin{array}{l}\text { Software MapInfo Pro (GIS ) } \\
\text { en un solo módulo, con } \\
\text { extensión .TAB }\end{array}$ & $\begin{array}{l}\text { Software ArcGis Desktop } \\
\text { (GIS), dos módulos, con } \\
\text { extensión .SHP }\end{array}$ & $\begin{array}{l}\text { Software AutoCAD Map 3D } \\
\text { (GIS), un solo módulo, con } \\
\text { extensión .DWG }\end{array}$ \\
\hline & $\begin{array}{l}\text { Software ZwCAD (CAD) un } \\
\text { solo módulo, con extensión } \\
\text {.DWG }\end{array}$ & & $\begin{array}{l}\text { Software AutoCAD (CAD) un } \\
\text { solo módulo, con extensión } \\
\text {.DWG }\end{array}$ \\
\hline & $\begin{array}{l}\text { Estándares del Open } \\
\text { Geospatial Consortium (OGC) } \\
\text { sistemas que facilitan el } \\
\text { intercambio de la información } \\
\text { geográfica en beneficio de los } \\
\text { usuarios }\end{array}$ & $\begin{array}{l}\text { Estándares del Open } \\
\text { Geospatial Consortium } \\
\text { (OGC) sistemas que facilitan } \\
\text { el intercambio de la } \\
\text { información geográfica en } \\
\text { beneficio de los usuarios }\end{array}$ & $\begin{array}{l}\text { Estándares del Open } \\
\text { Geospatial Consortium (OGC) } \\
\text { sistemas que facilitan el } \\
\text { intercambio de la información } \\
\text { geográfica en beneficio de los } \\
\text { usuarios }\end{array}$ \\
\hline \multirow{3}{*}{$\begin{array}{l}\text { Personal calificado } \\
\text { (Peso: 0.20) }\end{array}$} & $\begin{array}{l}\text { Project Manager Senior } \\
\text { (Consultor GIS y CAD) }\end{array}$ & $\begin{array}{l}\text { Project Manager Senior } \\
\text { (Gerencia de Proy. GIS) }\end{array}$ & $\begin{array}{l}\text { Project Manager Senior } \\
\text { (Gerencia de Proy. GIS y } \\
\text { CAD) }\end{array}$ \\
\hline & $\begin{array}{l}\text { Ejecutivo Comercial Senior } \\
\text { especializado en GIS y CAD }\end{array}$ & $\begin{array}{l}\text { Ejecutivo Comercial Senior } \\
\text { especializado en GIS }\end{array}$ & $\begin{array}{l}\text { Ejecutivo Comercial Senior } \\
\text { especializado en GIS y CAD }\end{array}$ \\
\hline & $\begin{array}{l}\text { Especialista TI GIS y CAD de } \\
\text { nivel "Junior" }\end{array}$ & $\begin{array}{l}\text { Especialista TI GIS de nivel } \\
\text { "Junior" }\end{array}$ & $\begin{array}{l}\text { Especialista TI GIS y CAD de } \\
\text { nivel "Junior" }\end{array}$ \\
\hline $\begin{array}{l}\text { Implementación } \\
\text { (Peso: 0.20) }\end{array}$ & $\begin{array}{l}\text { Instalación, activación, } \\
\text { configuración, vinculación } \\
\text { con BD o ERP y } 8 \text { horas de } \\
\text { capacitación a usuarios. }\end{array}$ & Instalación y activación. & Instalación y activación. \\
\hline $\begin{array}{l}\text { Soporte presencial } \\
\text { (Peso: 0.20) }\end{array}$ & $\begin{array}{l}\text { Si, dentro de las } 24 \text { horas, } \\
\text { con personal propio. }\end{array}$ & No & No \\
\hline $\begin{array}{l}\text { Soporte online } \\
\text { (Peso: 0.07) }\end{array}$ & $\begin{array}{l}\mathrm{Si} \text {, mediante teléfono, correo } \\
\text { electrónico o remoto, } \\
\text { incluyendo domingo y } \\
\text { feriados. Solo en casos } \\
\text { extremos se recurre al } \\
\text { fabricante. }\end{array}$ & $\begin{array}{l}\text { Si, mediante correo } \\
\text { electrónico o remoto de lunes } \\
\text { a viernes. En la mayoría de } \\
\text { los casos por el fabricante }\end{array}$ & $\begin{array}{l}\mathrm{Si}, \text { mediante teléfono y correo } \\
\text { electrónico o remoto de lunes a } \\
\text { viernes. }\end{array}$ \\
\hline $\begin{array}{l}\text { Capacitación } \\
\text { (Peso: 0.05) }\end{array}$ & $\begin{array}{l}\text { Si, nivel básico incluye en } \\
\text { implementación. Nivel } \\
\text { Avanzado tiene costo, pero } \\
\text { no se encuentra } \\
\text { contemplado en el proyecto. }\end{array}$ & Sí, pero tiene costo & Sí, pero tiene costo. \\
\hline $\begin{array}{l}\text { Tiempo de entrega } \\
\text { (Peso: 0.05) }\end{array}$ & 1 a 3 días & 20 a 30 días & 10 a 15 días \\
\hline \multirow{2}{*}{$\begin{array}{l}\text { Precio } \\
\text { (Peso: 0.01) }\end{array}$} & $\begin{array}{l}\text { GIS S/ } 9,326.13 \text { y } 25 \% \text { de } \\
\text { este costo a partir del } 2^{\circ} \text { año. }\end{array}$ & $\begin{array}{l}\text { GIS S/ } 10,192.00 \text { y } 25 \% \text { de } \\
\text { este costo a partir del } 2^{\circ} \text { año }\end{array}$ & GIS S/ 6,500 anuales \\
\hline & $\begin{array}{l}\text { CAD S/ } 3,300 \text { y } 25 \% \text { de este } \\
\text { costo a partir del } 2^{\circ} \text { año. }\end{array}$ & & CAD S/ 6,000 anuales \\
\hline
\end{tabular}




\subsubsection{Estrategia de Precio}

La estrategia de precios es penetración de mercado, por lo que los precios de los productos del proyecto fijado se encuentran por debajo del mercado.

\section{Fijación de precio para Software MapInfo Pro}

El precio del software ArcGIS es S/ 10,191 (ver Anexo 12), competencia principal para el software MapInfo Pro, que comercializará el proyecto.

El precio que se cobrará será el referencial o precio de venta sugerido por el fabricante (Pitney Bowes Software Inc.) cuyo precio por licencia stand alone (por usuario) es U\$ 2,395 dólares americanos (ver Tabla 15) al cual para el caso del mercado peruano se agregará el impuesto general a las ventas (18\%), cuya equivalencia en soles incluyendo el IGV a un tipo de cambio de S/ 3.30 es S/ 9,326.13.

\section{Tabla 16}

Precios de venta de software ArcGIS y MapInfo Pro

\begin{tabular}{lllr}
\hline \multicolumn{1}{c}{ Descripción } & \multicolumn{1}{c}{ Fuente } & Ubicación & Precio S/ \\
\hline ArcGIS Desktop & Cotización Telemática S.A. & (ver Anexo 12) & $10,192.00$ \\
MapInfo Pro & Propuesta Pitney Bowes & (ver Anexo 2) & $\mathbf{9 , 3 2 6 . 1 3}$ \\
\hline
\end{tabular}

Nota. Los precios son recopilados del principal competidor en software GIS llamado Telemática S.A. y la propuesta para distribuidor de Pitney Bowes Software para el caso del proyecto considerando un tipo de cambio de s/ 3.30 


\section{Fijación de precio para Software ZwCAD}

El precio del licenciamiento del software AutoCAD es anual y es S/

5,923.50 (ver Anexo 12), competencia principal para el software ZwCAD, que comercializará el proyecto.

El precio que se cobrará será el referencial o precio de venta sugerido por el fabricante (ZwSoft) cuyo precio por licencia stand alone (por usuario) es U\$ 1,000.00 dólares americanos (ver Tabla 17) al cual para el caso del mercado peruano se agregará el impuesto general a las ventas (18\%).

\section{Tabla 17}

Precios de venta de software AutoCAD y ZwCAD

\begin{tabular}{llcl}
\hline \multicolumn{1}{c}{ Descripción } & \multicolumn{1}{c}{ Fuente } & Ubicación & Precio S/ \\
\hline AutoCAD Suscription anual & Business Technology & (ver Anexo 9) & $5,923.50$ \\
ZwCAD Pro & Propuesta ZwSoft & (ver Anexo 1) & $\mathbf{3 , 3 0 0 . 0 0}$ \\
\hline
\end{tabular}

Nota. Los precios son recopilados del distribuidor de AutoCAD llamado Business Technology S.A. y la propuesta para distribuidor de ZwSoft para el caso del proyecto considerando un tipo de cambio de s/ 3.30 


\subsubsection{Estrategia de Plaza y Distribución}

La estrategia de distribución será directa, ya que las licencias son electrónicas, las cuales se entregan y activan de manera electrónica, específicamente mediante correo electrónico donde se indica el o los seriales y demás datos para su activación, similar a la siguiente figura (ver Figura 44).

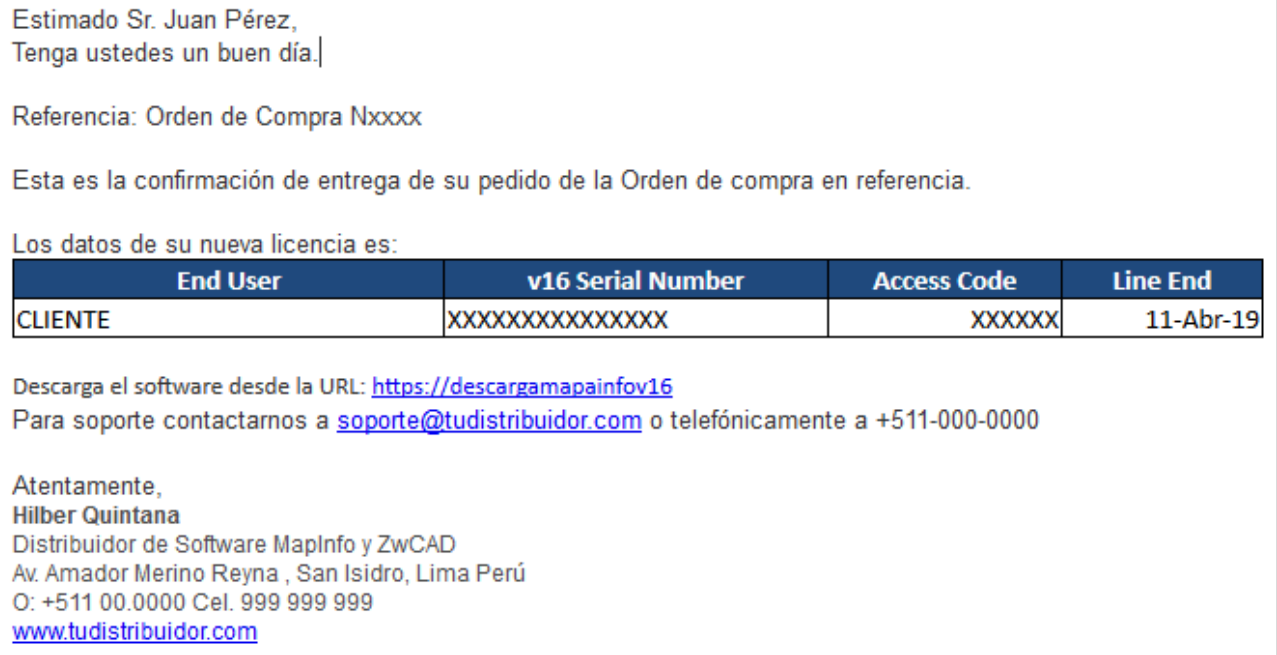

Figura 43. Modelo referencial de entrega de licencia electrónica

Luego se programará una visita presencial para la Instalación, configuración, sugerencias o recomendaciones de uso, siempre que la instalación sea en Lima Metropolitana o El Callao, con la finalidad de satisfacer la necesidad identificada en el estudio de mercado "Personal Calificado" y "Soporte Presencial". Para el caso de provincias, el servicio será realizado remotamente (si el cliente lo permite) o vía telefónica, además de enviar un manual sencillo de instalación y configuración. 


\subsubsection{Estrategia de Promoción y publicidad}

La estrategia de promoción y publicidad tendrá el objetivo de posicionar la Imagen de la empresa (Proyecto) y los productos (soluciones) comercializados, el cual estará orientado a ventas de productos industriales o B2B cuya venta es técnica consultiva.

a. La principal estrategia de promoción y publicidad serán directas (Kother \& Armstrong, 2007), y estarán representados por el personal calificado, específicamente por el Ejecutivo Comercial y el Consultor Senior (Ingeniero de negocios), quienes realizaran visitas coordinadas con los prospectos pertenecientes a las empresas del sector Minería que se encuentran en la base de datos de Perú Top 10,000 2017, para que de manera consultiva presenten las bondades y beneficios costo que otorga los productos comercializados por nuestra compañía, mostrando en todo momento puntualidad, respeto y profesionalismo.

b. Las presentaciones estarán orientadas a los usuarios, jefes de sistemas, jefes de las áreas de ingeniería, medio ambiente o exploraciones preferentemente, dónde además de realizar una presentación profesional, se debe transmitir el mensaje "Somos una organización que brinda soluciones en sistemas CAD y GIS enfocados al sector minero y que contamos con personal altamente calificado".

c. Complementariamente se utilizará el correo electrónico como medio de comunicación. También se tiene contemplado un evento de introducción, 
dichos medios de comunicación son los preferidos en la investigación de mercados, mediante la pregunta 16 ¿Mediante qué medios le gustaría recibir información sobre soluciones CAD y GIS? Y los resultados fueron: el 59.72\% prefieren mediante "Correo Electrónico" y un 36.11\% mediante "Eventos"

d. Como estrategia de introducción se realizará un evento en el Swissotel, posteriormente mediante correo electrónico personalizado, capacitaciones básicas de 4 horas anuales cada vez que se lanza una nueva versión.

\section{Evento de lanzamiento}

En el cual se realizará una presentación de la empresa, las marcas que se representa, productos, funcionalidades y equipo técnico comercial.

\section{Datos del evento:}

Base de datos $\quad: 465$ empresas

Estimado de asistencia $\quad: 60$ empresas

Fecha y hora : por definir

\section{Programa de la inauguración:}

- Presentación de la empresa

- Presentación de las marcas que se representa y productos

- Beneficios de los productos y sus aplicaciones

- Presentación del equipo técnico y comercial. 


\section{Presupuesto de la inauguración:}

Considerando que el evento se realizará en las instalaciones de un hotel de prestigio, la inversión se detalla a continuación (ver Tabla 16)

\section{Tabla 18}

Presupuesto de lanzamiento

\begin{tabular}{lcrrrr}
\hline \multicolumn{7}{c}{ Inversión Pre Operativo } \\
\hline Descripción & Cantidad & $\begin{array}{c}\text { Costo } \\
\text { Unitario } \$\end{array}$ & $\begin{array}{c}\text { Costo } \\
\text { Total sin } \\
\text { IGV S/ }\end{array}$ & IGV & $\begin{array}{c}\text { Total con } \\
\text { IGV S/ }\end{array}$ \\
\hline Instalaciones del hotel & 1 & $3,500.00$ & $11,550.00$ & $2,079.00$ & $13,629.00$ \\
Material POP & 1 & 500.00 & $1,650.00$ & 297.00 & $1,947.00$ \\
Souvenirs & 1 & 230.00 & 759.00 & 136.62 & 895.62 \\
\hline Total Inversión Pre & & & $13,959.00$ & $2,512.62$ & $16,471.62$ \\
Operativo & & & &
\end{tabular}

Nota. Los precios son recopilados según propuesta de swishotel fueron dólares y para efectos del proyecto se viene considerando un tipo de cambio de s/ 3.30. Material POP se refiere a artículos publicitarios como material publicitarios

\section{Herramientas para la inauguración:}

- Instalaciones del hotel, incluye el alquiler de centro de convenciones, el acceso web, las redes de comunicación, el catering y los servicios multimedia.

- Material Pop, hace mención a los trípticos de la solución que entregaremos a los asistentes.

- Souvenirs, es el material publicitario como lapiceros o llaveros.

- Otros, este fondo es para cubrir cualquier gasto adicional. 


\section{Plan de Publicidad anual}

El material POP constara de trípticos de la solución CAD y GIS, las mismas que serán, físicas y virtuales, que nos servirán para llegar a nuestros clientes vía email o a través de su Ejecutivo Comercial.

Para todas estas acciones tomaremos en cuenta los siguientes aspectos:

Público Objetivo: Son las empresas de los sectores de Minería.

Objetivos: Desarrollar un posicionamiento de marca y reforzar el concepto de Diseño Asistido por Computadora (CAD) y Sistema de Información Geográfica (GIS).

\section{Tabla 19}

Presupuesto de Marketing

\begin{tabular}{lr}
\hline \multicolumn{1}{c}{ Descripción } & Total Anual S/ \\
\hline Mantenimiento de página web (Honorarios) & 660.00 \\
Pasajes de Ejecutivo Comercial y Consultor senior & $3,960.00$ \\
\hline
\end{tabular}

Nota. El mantenimiento está referido al honorario del personal externo y los pasajes de ejecutivos son considerados en este rublo ya que nuestro principal medio de promoción y publicidad será mediante las presentaciones y demos de estos ejecutivos

\subsubsection{Estrategia de Personas}

En cualquier actividad el factor humano es el más importante, porque de ello dependerá el éxito o fracaso de cualquier proyecto, por lo que el bienestar de los colaboradores en general merece la importancia más alta, para el cual se implementará la estrategia de pertenencia, motivación que valoran los colaboradores de Backus y Johnston quienes ocupan por cuarto 
año consecutivo como la mejor empresa para laborar, en el ranking de merco Talentos (Cruzado, 2018) para el cual se implementará las siguientes acciones.

\section{a. Contratación de colaboradores}

Indagar mediante Certificado Policial, Certificado de Antecedentes Penales, Certificado de Domicilio y verificación mediante referencias personales, a todos los postulantes que cumplan con los requisitos técnicos y de conocimiento antes de ser contratados, para seleccionar al colaborador adecuado.

\section{- Administrador General}

Función de planificar, organizar, dirigir y controlar el servicio de consultoría; con el propósito de mantener el servicio según los parámetros de la empresa; optimizando la asignación de los recursos; mejorando continuamente la calidad de servicio; atrayendo, motivando y capacitando adecuadamente al personal. Además, brindar el soporte a los Consultores Senior en la atención de cada cliente.

\section{Perfil}

Educación: Estudios Universitarios en Ingeniería de Sistemas, Industrial, Administración o afines. Preferente con Maestría en Administración de Negocios

Experiencia: 03 años desempeñándose en cargo de jefatura en empresas del sector 
Formación en Gestión de Proyectos, CRM, entre otros.

Conocimiento de Sistemas de Información Geográfica. Office nivel avanzado. Idioma inglés avanzado (mínimo intermedio)

\section{- Consultor Senior}

Responsable de realizar las presentaciones técnicas como ingeniero de negocios, además identificar y atender las necesidades técnicas GIS y CAD de los clientes asignados, dentro del plazo establecido; organizar y controlar los entregables y fidelizar la cartera asignada.

\section{Perfil}

Educación: Estudios técnico o universitarios con especialización en ciencias de la tierra.

Experiencia: 5 años desempeñando funciones en consultoría en Sistemas CAD y Geociencia.

Formación: Cursos o especializaciones en Sistemas CAD, Geociencia o Localización Inteligente, Conocimientos de Ofimática, Office nivel intermedio, Idioma inglés intermedio o avanzado.

\section{- Ejecutivo Comercial}

Planificar y elaborar el presupuesto de ventas; generar valor a través del logro de objetivos de ventas; buscar nuevas oportunidades de negocio; realizar la evaluación económica de nuevos proyectos; administrar los procesos comerciales. 


\section{Perfil}

Educación: Profesional bachiller o titulado de las carreras de Administración, Ingeniería Industrial, Economía o afines.

Experiencia: 3 años de experiencia como ejecutivo de ventas en empresas de Tecnología. Buen manejo de personal y de equipos de ventas.

Formación: Conocimientos de finanzas y gestión de proyectos, Office nivel avanzado, Idioma inglés intermedio.

\section{- Responsable de Sistemas}

Realizar las configuraciones e instalaciones de los programas de Sistema de Información Geográfica y Diseñó Asistido por Computadora a clientes y responsable de la administración y buen funcionamiento de los sistemas TI de la empresa.

\section{Perfil}

Educación: Universitario o técnico, egresado o Bachiller en Ingeniería de Sistemas o afines

Experiencia: 3 años desempeñando funciones del área de sistemas o similar.

Formación: Con Cursos en Sistemas de Información Geográfica y Diseño Asistido por Computadora, Office nivel avanzado, Idioma inglés avanzado. 
- Asistente Administrativo

Administrar efectivamente los pedidos recibidos por os Consultores Senior, así como garantizar la adecuada atención a los clientes.

\section{b. Capacitación}

Además de la capacitación de inducción, como parte de la política de personas se realizará capacitaciones constantes las que son impartidos por los fabricantes de software vía online y fomentar el desarrollo profesional mediante préstamos.

\section{c. Integración}

Se celebrará todos los cumpleaños de forma obligatoria deben participar todos los colaboradores, dicha celebración no debe superar las 3 horas y evitar bebidas alcohólicas.

\section{d. Compromiso}

Se realizará reuniones quincenales con la finalidad de analizar el contexto y analizar los avances de las tareas y desarrollar sugerencias y alternativas de solución en equipo.

\section{e. Salud}

Además de tener en planilla para tener derecho a estar asegurado en Essalud, se fomentará la práctica deportiva y hábito de consumo de productos saludables. 


\section{f. Retención de Talentos}

Como política de retención de talentos se incluirá como parte del accionariado a colaboradores comprometidos que sean proactivos, busquen desafíos y aptitud para el cambio constante, premiando los logros con acciones equivalentes a la productividad de cada uno.

\subsubsection{Estrategia de Procesos}

Para el proyecto se seguirá la estrategia de enfoque repetitivo, en razón que las actividades son repetitivas pasando por una secuencia de tareas.

La estrategia se desarrollará siguiendo las siguientes actividades “Prospección”, “Compra”, "Comercialización” y "Servicio al Cliente”.

\subsubsection{Estrategia de Presencia física}

La presencia física del proyecto estará presente mediante los siguientes medios: Página Web y Remoto.

\section{Página WEB}

Se implementará una página web informativa e interactiva, que identifique cuando un usuario ingresa a la misma y alerte para su atención online a cualquier requerimiento. 


\section{Acceso Remoto}

Tiene relación con lo anterior, pero la presencia física mediante acceso remoto tendrá múltiples soluciones, incluyendo soporte, asesoría y presentación.

\subsection{Estrategia de ventas}

La estrategia de ventas será netamente técnica al tratarse de productos especializados y comercio B2B, es decir venta directa, como menciona (Kother \& Armstrong, 2007).

\subsubsection{Plan de ventas}

Los ejecutivos comerciales deberán realizar entre 6 visitas semanales acompañados por el consultor senior como soporte para la parte técnica, los mismos que al concluir el mes deben haber realizado en promedio 24 visitas, considerando un tiempo promedio de estancia en cada cliente entre 1 y 2 horas.

Todas las presentaciones deben estar divididas en dos partes (1) técnica y (2) comercial, para el cual deben ser convocados a la reunión usuarios y decisores de la compañía visitada.

El ejecutivo comercial deberá poseer una excelente expresión verbal para que la comunicación sea clara y fluida, cuyo principal trabajo consistirá en:

- Obtener citas con clientes potenciales y realizar visitas periódicas según nivel de importancia del cliente. 
- Realizar presentaciones e informes de rendimiento y ahorro en el cliente.

- Presentación de nuevos productos o servicios de darse el caso.

- Atención de sugerencias, quejas y/o reclamos.

El ejecutivo comercial contará con capacitaciones constantes no solo del área de soporte (Consultor y responsable de sistemas), sino también de la marca representada a fin de promocionar mejor los productos y otorgar un mayor énfasis al valor agregado.

\subsubsection{Política de servicios y garantías}

Como política de servicios las atenciones a reclamos, consultas, instalaciones u otro de orden técnico o comercial, deben ser resueltos dentro de las 24 horas, para el cual se debe generar un tiket de incidencia para hacer seguimiento al caso, en caso sea un problema con el producto el cual no solucionó los técnicos, este último debe reportar al fabricante y hacer el seguimiento hasta el informe final, paralelamente debe informar al cliente las acciones que se están realizando.

Las garantías a los productos se encuentran garantizadas por los fabricantes, quienes están en la obligación de brindar las soluciones a los casos por defectos de fabrica (desarrollo) del software o problemas de compatibilidad, el cual cubre hasta por un año después de realizado la compra, para mantener vigente el servicio, el cliente debe hacer el pago anual o bianual correspondientes. 


\section{CAPÍTULO VI}

\section{Pronóstico de ventas}

En este capítulo se detalla el pronóstico de las ventas proyectadas a cuatro años, incluyendo los respectivos fundamentos, supuestos, justificación, análisis de riesgos y aspectos críticos que afectan al proyecto.

\subsection{Fundamentos y supuestos}

Los fundamentos y supuestos se sustentan en los resultados obtenidos en la investigación de mercados (Cualitativos y cuantitativos), el crecimiento del sector Minería y las capacidades del proyecto.

\subsection{Justificación}

El pronóstico se justifica en los resultados obtenidos en la investigación de mercado y el crecimiento del sector minería, cuyos factores son:

La mayoría de usuarios no se encuentra satisfechos con la atención de su proveedor, ya que solamente el $43.06 \%$ calificó como "bueno" a su proveedor de software GIS, siendo la diferencia como "Indiferente" con 51.39\% y "malo" con 5.56\%. Para el caso de software CAD el $73.61 \%$ calificaron a su proveedor como "bueno" y un 1.39\% como "muy bueno", pero hay un 25\% que se muestra "Indiferente"

La aceptación de un nuevo proveedor de software CAD y GIS es alentador, ya que la mayoría de entrevistados indicaron que "Probablemente Consumiría" y "Definitivamente Consumiría" con un $66.67 \%$ y $1.39 \%$ respectivamente. 


\section{Para el Inicio de Operaciones}

El Resultado del Mercado Objetivo Se hará un ajuste al resultado del mercado Objetivo, ya que dicho resultado equivale a un $32 \%$ del mercado Efectivo, por lo que aplicando un criterio razonable se considera iniciar con el 50\% del mercado Objetivo (16\% de participación de mercado), es decir 102 licencias de ZwCAD y 138 licencias MapInfo Pro (ver Tabla 19).

\section{Tabla 20}

Proyección de ventas de licencias ZwCAD y MapInfo Pro

\begin{tabular}{lccc}
\hline \multicolumn{1}{c}{ Proyección de Ventas (\# Licencias) } & $\begin{array}{c}\text { Mdo. } \\
\text { Efectivo }\end{array}$ & $\begin{array}{c}\text { Mdo. } \\
\text { Objetivo }\end{array}$ & Año 1 \\
\hline Licencias ZwCAD & 633 & 203 & 102 \\
Licencias MapInfo Pro & 859 & 276 & 138 \\
Participación \% & $100 \%$ & $32 \%$ & $16 \%$ \\
\hline
\end{tabular}

Nota. La proyección de ventas para el año 1 en número de licencias y equivale al $50 \%$ del mercado objetivo.

\section{Para los años posteriores}

Para los años sucesivos se considera el ingreso por renovación de soporte y mantenimiento anual en base a los resultado de la encuesta representa el $76.39 \%$ de las ventas del año anterior, sustentado en resultados de la encuesta que corresponde a aquellos que realizan mantenimientos anuales; además de incluir el crecimiento del sector minero para las ventas nuevas, la proyección de crecimiento anual en inversión del sector Minería para los siguientes años es 6\% según (BBVA Reserch, 2017) y proyecciones del BCR de $11.8 \%$. El cual incluye nuevas inversiones e incremento de las existentes. Con el que se estima un crecimiento conservador de $6 \%$ en la proyección de las ventas (Ver Tabla 20). 


\section{Tabla 21}

Crecimiento del sector en nuevas inversiones

\begin{tabular}{lrrr}
\multicolumn{1}{c}{ Sector } & $\mathbf{2 0 1 6}$ & $\mathbf{2 0 1 5}$ & $\mathbf{2 0 1 4}$ \\
\hline Minería \# total de empresas & 465 & 375 & 288 \\
Minería Nuevas empresas & 90 & 87 & \\
Incremento \% de nuevas empresas & $\mathbf{2 4 \%}$ & $\mathbf{3 0 . 2 \%}$ \\
\hline
\end{tabular}

Nota. El crecimiento es en nuevas empresas en el sector, adaptado de The Top 100002017

Otro aspecto considerar para la proyección, es considerar aquellas empresas que adquirieron el software, normalmente incrementa sus licencias cuando inician nuevos proyectos.

Además, aquellas empresas que no realizan mantenimiento por más de dos años no tienen derecho a realizar actualizaciones de acuerdo a las condiciones de los fabricantes, por lo que deben adquirir nuevas licencias en caso requieran usar la versión vigente, convirtiéndose en nuevas oportunidades para la venta de nuevas licencias, que según la investigación de mercados son aquellos que no pagan el mantenimiento el cual es un $23.61 \%$ (ver Tabla 21)

\section{Tabla 22}

Proyección de ventas de licencias y mnatenimientos de software CAD y GIS

\begin{tabular}{lrrrrrr}
\hline Proyección de Ventas (\# Licencias) & Año 0 & Año 1 & Año 2 & Año 3 & Año 4 & Año 5 \\
\hline Licencias CAD & & 102 & 107 & 112 & 118 & 124 \\
Licencias GIS & 138 & 145 & 152 & 160 & 168 \\
Asesorías y Capacitaciones & 6 & 7 & 8 & 8 & 8 \\
Mantenimiento CAD & & 78 & 82 & 86 & 90 \\
Mantenimiento GIS & & 105 & 111 & 116 & 122 \\
\hline
\end{tabular}

Nota. Proyección basada en el 50\% de mercado objetivo para el año 1 y crecimiento anual de 5\% para los años posteriores. Los mantenimientos equivalen al $76.39 \%$ de las licencias vendidas en el año anterior. 


\subsection{Análisis de los riesgos y aspectos críticos que impactan en el proyecto}

Los aspectos críticos a tener en cuenta en este proyecto son tres, (1) Mantener el personal calificado y su constante actualización, (2) La variación en la inversión minera, (3) El precio de los metales principalmente el cobre y el oro. 


\section{CAPÍTULO VII}

\section{Ingeniería del proyecto}

En la ingeniería del proyecto se encuentra contemplado la realización de lo siguiente: (1) estudio de ingeniería, como el modelamiento y selección de los procesos del proyecto, selección del equipamiento necesario, el lay out y la distribución de equipos y maquinarias de ser necesario. (2) determinación del tamaño del proyecto, para el cual se analizará la proyección de crecimiento, disponibilidad de recursos con lo que se cuenta, la tecnología a ser empleada, la flexibilidad para reacomodarse, con lo que se determinará el tamaño ideal del proyecto. (3) estudio de localización, permitirá definir los factores locacionales, las consideraciones legales, que contempla identificar el marco legal y ordenamiento jurídico del proyecto. (4) Determinación de la localización óptima, donde se determinará la localización del proyecto, considerando los factores que afectan a la empresa materia del presente proyecto.

\subsection{Estudio de ingeniería}

Como se menciona en la introducción de este capítulo, en el estudio de ingeniería se realizará el modelamiento y selección de los procesos de la comercialización de software especializado, se determinará el equipamiento necesario, el lay out y la respectiva distribución de los equipos, con la finalidad de establecer con claridad:

- Los procesos de atención y las operaciones necesarias para la comercialización de software especializado en GIS y CAD.

- Los recursos y equipamiento necesarios. 


\subsubsection{Modelamiento y selección de procesos productivos}

Nuestro modelo de negocio para la comercialización de software especializado para medio ambiente, ingeniería y sistema de información geográfica, consiste en desarrollar cuatro actividades o procesos fundamentales, las cuales son: (1) Prospección, (2) Compra o adquisición del software, (3) Actividad comercial y (4) Servicio al cliente (ver Figura

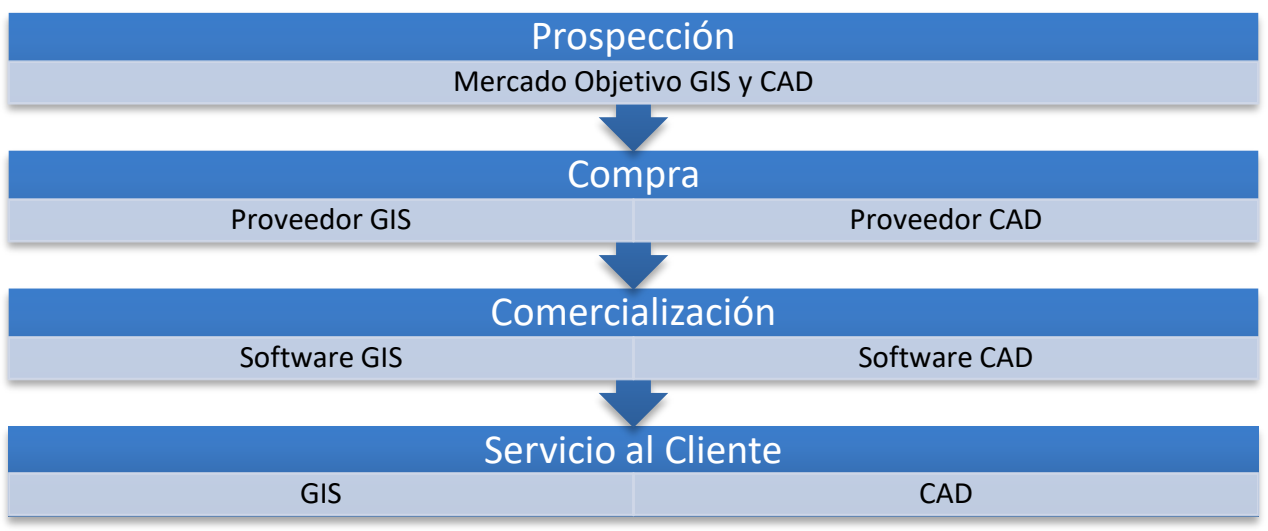

Figura 44. Proceso productivo del proyecto

\section{(1) Prospección.}

En esta etapa la coordinadora realizará el contacto inicial con los prospectos y la concertación de juntas para la presentación y demo de los productos GIS y CAD, para el cual utilizará la base de datos correspondiente al sector Minería de la publicación impresa Perú Top 10002017 (Perú Top Publications, 2017). Las juntas o reuniones son programadas por lo menos con 5 días de anticipación. (ver Figura 46) 


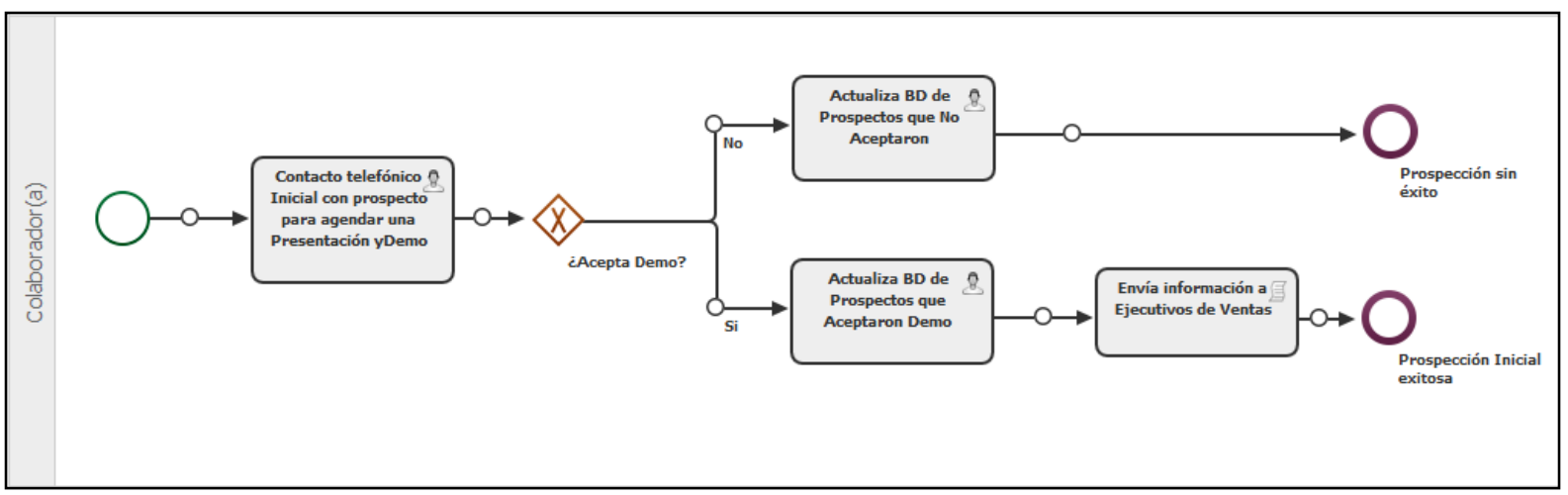

Figura 45. Proceso de prospección. Elaboración propia

Seguidamente, un ejecutivo de venta y un ingeniero de negocios

visitarán al cliente, donde harán la presentación y demo de los productos, donde también deben recopilar información, como: presupuesto y tiempo de ejecución de posible compra, pudiendo darse más de una junta adicional con el objetivo de aclarar o presentar a otros decisores. Este proceso demora unos 15 días y en caso de ser exitoso 15 días adicionales para la generación de la orden de compra por parte del cliente (ver Figura 47).

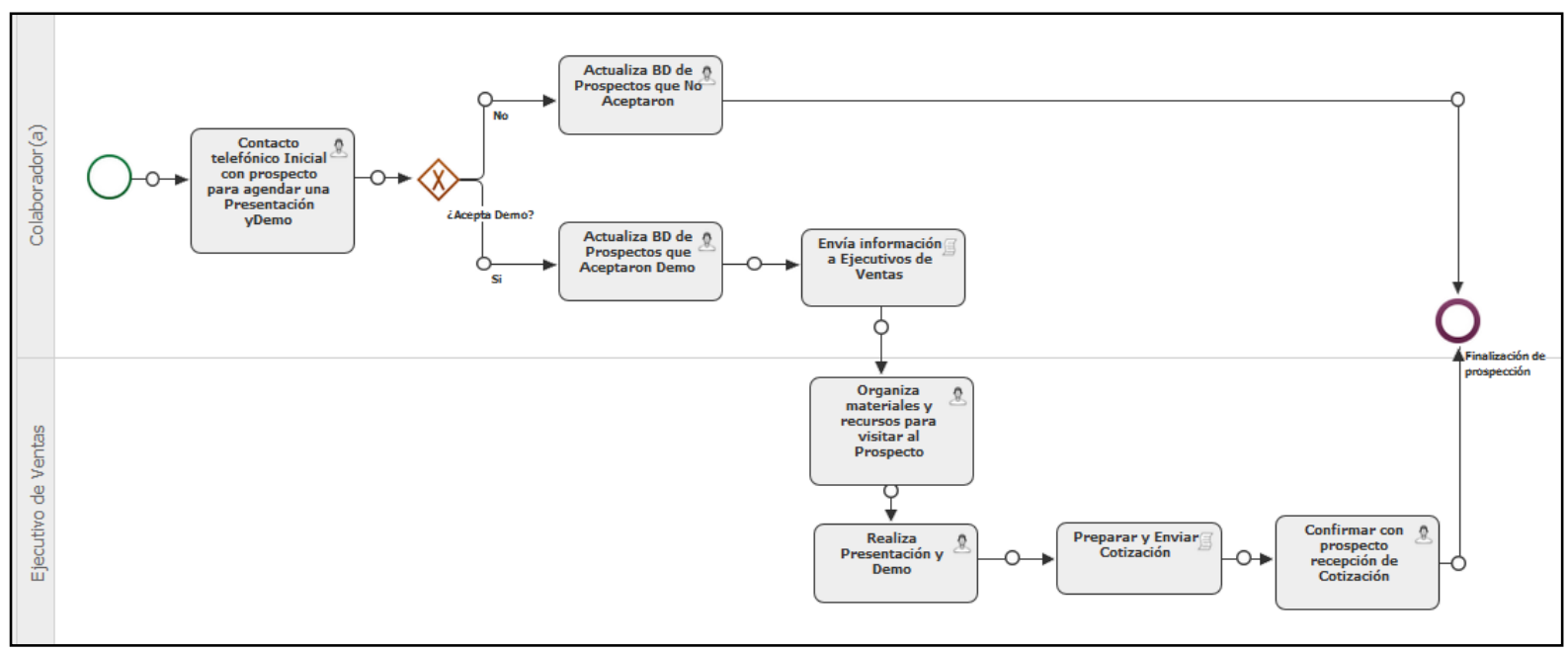

Figura 46. Proceso de prospección. Elaboración propia 


\section{(2) Compra.}

Se inicia con la recepción de la Orden de compra o servicio del cliente. En esta etapa se procede con la compra de los productos de acuerdo a la cantidad solicitada por cada cliente. Se debe elaborar la Orden de Compra para enviar al fabricante, conforme a la marca o tipo de producto ordenado por el cliente (GIS o CAD), luego realizar la transferencia bancaria o mediante tarjeta de crédito el cual dependerá del monto y las modalidades de pago aceptadas por los fabricantes. Una vez confirmado el pago el fabricante envía mediante correo electrónico las respectivas licencias o seriales de los productos ordenados, el cual una vez recibido se debe ordenar en la propia base de datos con el cual culmina el proceso de compra. El tiempo estimado para este proceso es 3 días aproximadamente (ver Figura 48).

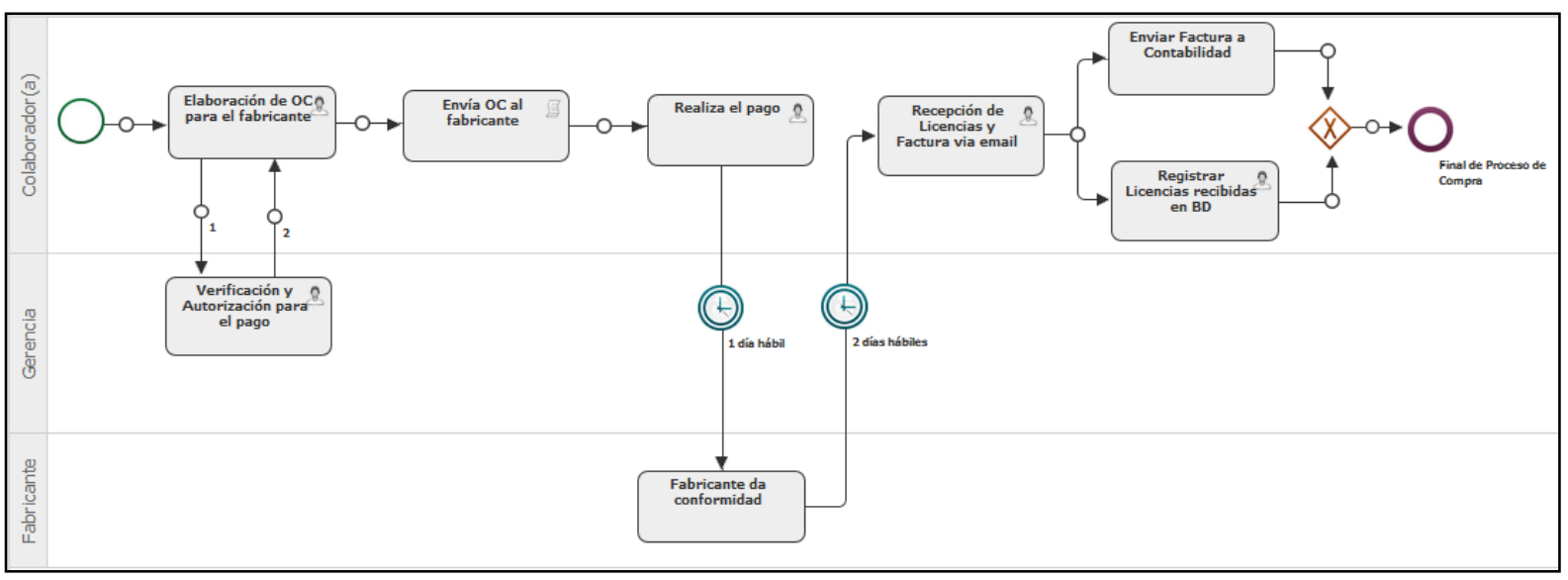

Figura 47. Proceso de compra o adquisición. Elaboración propia

\section{(3) Comercialización}

El proceso de comercialización, específicamente llamado ventas se inicia con la entrega o envío de las licencias ordenadas por el cliente, luego se solicita la conformidad de entrega para emitir y enviar la 
respectiva factura, pasado el tiempo de pago convenido con el cliente se verifica el cumplimiento, en caso contrario se procede a indagar el motivo del retraso y hacer seguimiento hasta concretar la cobranza. De acuerdo a los resultados de la encuesta el tiempo estimado de pago de las empresas mineras a su proveedores de software es aproximadamente 30 días, pero este debemos agregar 7 días por la gestión de conformidad y entrega de comprobante de pago (ver Figura 49).

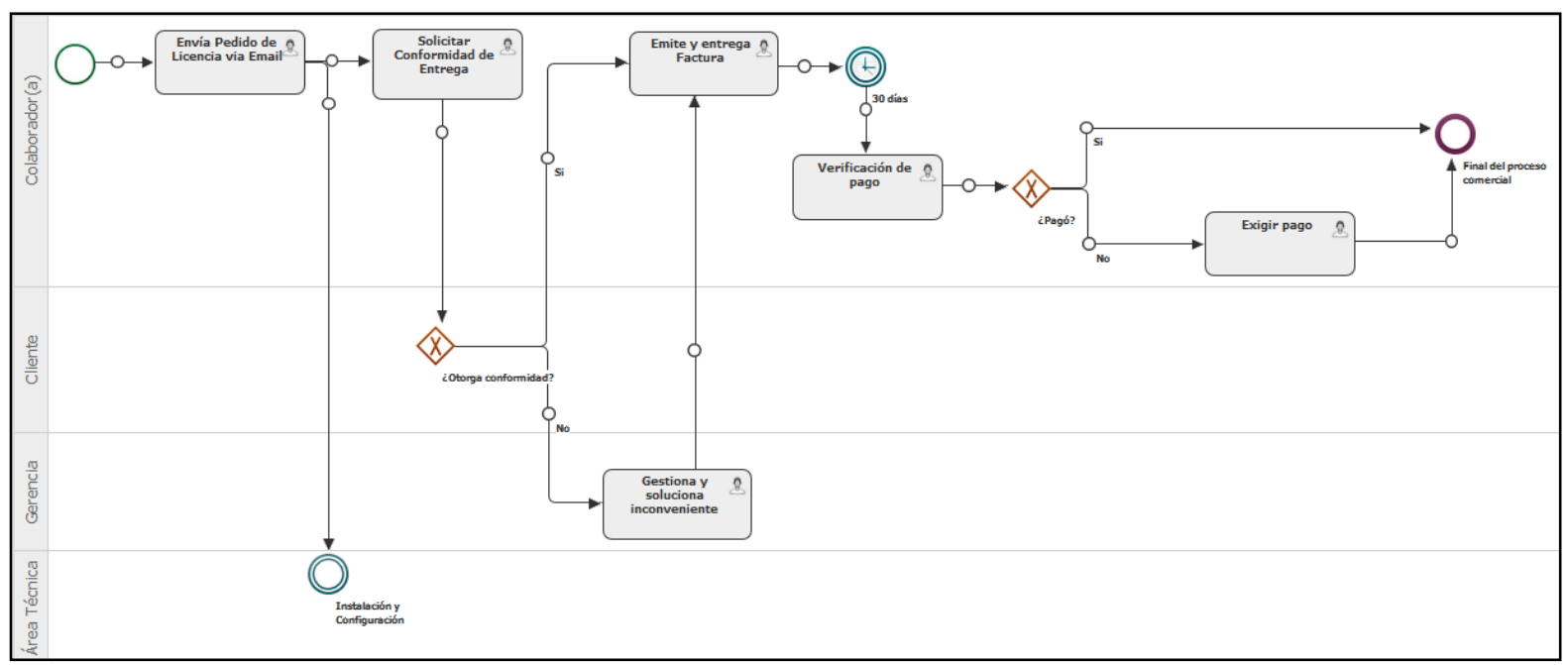

Figura 48. Proceso de comercialización. Elaboración propia

\section{(4) Servicio al cliente}

Es el proceso que exige el cumplimiento pleno de todas las areas de la empresa, el cual inicia con la solicitud o reclamo de los prospectos o clientes, registrando y codificando cada una de estas para el seguimiento respectivo. Una vez codificado se deriva al área correspondiente para la atención a la solicitud o incidente hasta el cierre del caso con la conformidad del cliente o prospecto. Este proceso es permanente de lunes a viernes en el horario de 9am a 6pm (ver Figura $50)$. 


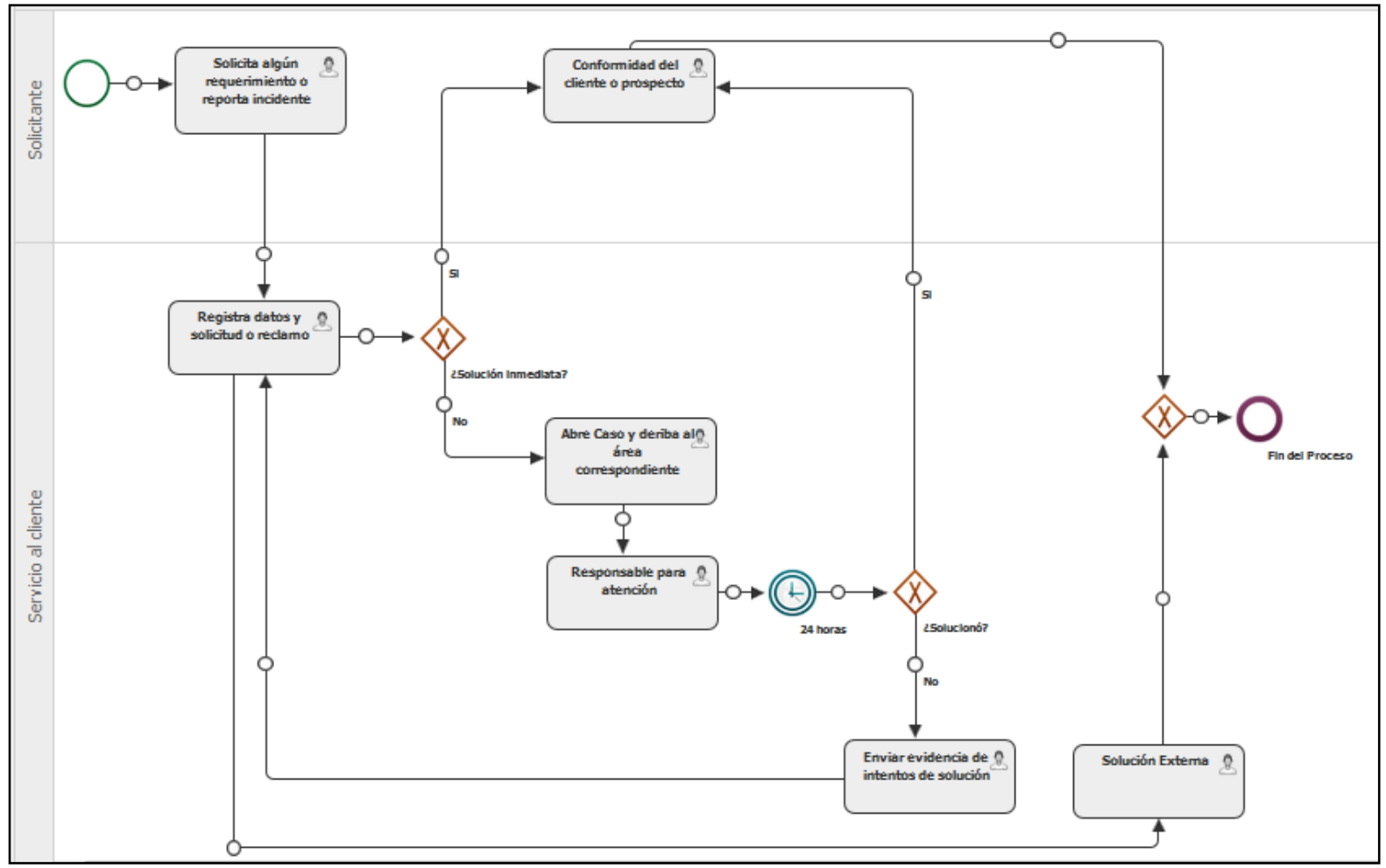

Figura 49. Proceso de servicio al cliente. Elaboración propia

\subsubsection{Selección del equipamiento}

Los equipamientos informáticos e inmobiliarios requeridos para el proyecto son los siguientes (ver Tabla 22)

\section{Tabla 23}

\section{Selección de Equipamiento}

\begin{tabular}{lc}
\hline \multicolumn{1}{c}{ Activo - Administración } & Cantidad \\
\hline PC Dell core i5, 500GB, 8GB RAM, Monitor de 20" & 5 \\
MacBook Air 13.3" 128 GB & 3 \\
Teléfono fijo y anexos & 6 \\
Escritorio Modelo cómputo & 5 \\
Sillas & 8 \\
Escritorio Modular para juntas & 1 \\
Impresora Multifuncional HP & 1 \\
Estante puerta alta 200x80x30 & 2 \\
Servidor DELL & 1 \\
Rack para servidor y accesorios & 1 \\
\hline
\end{tabular}

Nota. Los recursos son el total estimado para el proyecto 


\subsubsection{Lay out}

El lay out o plano de distribución de la oficina tendrá la siguiente distribución, pudiendo variar radicalmente, en razón que no es determinante.

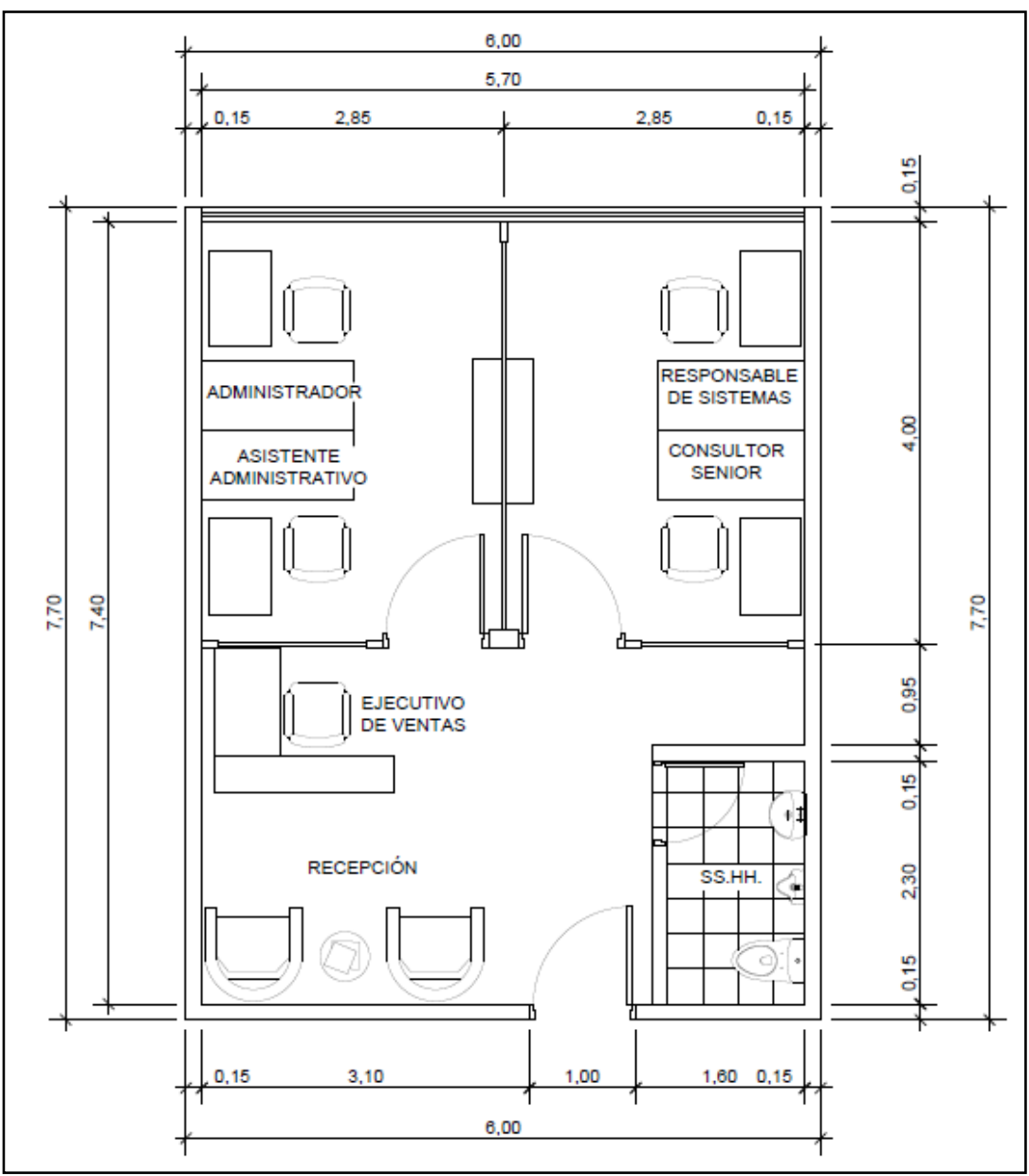

Figura 50. Lay Out o plano de distribución de oficina. Elaboración propia

\subsubsection{Distribución de equipos y maquinarias}

La distribución de equipos y maquinarias para el caso del proyecto no es relevante, por lo que no se especifica. 


\subsection{Determinación del tamaño}

El tamaño de la empresa, se ajusta en base a la forma de cómo se encuentra organizado. Para este proyecto los recursos humanos necesarios estarán conformados por el Administrador, Secretaria, Ejecutivos de ventas, Consultores y Técnicos, para el cual hemos determinado utilizar un área de $42 \mathrm{~m} 2$

\subsubsection{Proyección de crecimiento}

La proyección de crecimiento se encuentra ligada al crecimiento de la inversión minera en el Perú y la incursión en nuevos sectores como el de la construcción.

\section{a. Corto Plazo.}

La estimación de crecimiento en el primer año es la consolidación y posicionamiento de la empresa

\section{b. Mediano Plazo.}

La estimación de crecimiento para el segundo y tercer año es proporcional al crecimiento de la inversión minera.

\section{c. Largo Plazo.}

El crecimiento que se estima a partir del tercer año es mantener el proporcional al crecimiento del sector minero, además de inclusión de nuevos productos a nuestra cartera de productos. Todos ellos relacionados con soluciones para Geomática, el cual incluye a software CAD, GIS, Teledetección, etc. 


\subsubsection{Recursos}

Los principales recursos requeridos para el proyecto son tecnológicos, humanos y financieros.

\subsubsection{Tecnología}

Como el proyecto es la comercialización de software especializado, cuyos productos son parte de la tecnología de información (TI), por lo que el campo tecnológico el principal desafío sobre el que el proyecto se desarrollará, tanto para sus procesos internos, como para la comercialización de los productos y el valor agregado que se pretende entregar a los clientes.

\subsubsection{Flexibilidad}

El modelo del proyecto permite el cambio rápido en caso de tener una mayor demanda.

\subsubsection{Selección del tamaño ideal}

El tamaño físico ideal es irrelevante para este proyecto, en razón que la venta es técnica consultiva con visita a prospectos y clientes.

\subsection{Estudio de localización}

El estudio de localización, permitirá identificar el lugar más apropiado para el funcionamiento de la empresa, evaluando los factores que los afectan. 


\subsubsection{Definición de factores locacionales}

La localización de nuestro centro de operaciones es un factor de mucha importancia en nuestro modelo de negocio para brindar un servicio de calidad, para ello se ha decidido evaluar factores técnicos, tributarios, de acceso y disponibilidad de espacio. Por tal motivo y para una mejor evaluación hemos definido dos etapas: la Macro localización y Micro localización.

\subsubsection{Consideraciones legales}

Para nuestro proyecto los aspectos legales considerados son aquellas normas relacionados con la comercialización de software como persona jurídica con actividad comercial.

Es importante mencionar que el software es un bien que se encuentra protegido por los gobiernos, con las leyes de derecho de autor y brindan protección a creadores de bienes de propiedad intelectual, conocido también como copyright.

El Derecho de Autor es un derecho humano, el cual se encuentra reconocido como tal en el artículo 27.2 de la Declaración Universal de los Derechos Humanos:

“Toda persona tiene derecho a la protección de los intereses morales y materiales que le correspondan por razón de las producciones cientificas, literarias o artísticas de que sean autora." 
Según (INDECOPI, 2017) el software es un bien inmaterial, quiere decir que tiene derechos incorporales.

\subsubsection{Identificación de marco legal}

El marco legar es la Constitución Política del Perú, específicamente las Leyes y sus respectivos reglamentos de los organismos competentes, entre las que se encuentran:

- Ley No 26887. Ley General de Sociedades y sus modificaciones.

- Ley $\mathrm{N}^{\circ}$ 28976. Ley Marco de Licencia de Funcionamiento y sus modificaciones mediante Decreto Legislativo $\mathrm{N}^{\circ} 1271$

\subsubsection{Ordenamiento Jurídico de la empresa}

Según el ordenamiento Jurídico es el sistema de normas, es decir es normativo. Conforme al ordenamiento jurídico peruano, para la constitución y funcionamiento de una empresa jurídica se debe formalizar la constitución en la SUNARP y para el funcionamiento en la SUNAT y la respectiva Municipalidad de la jurisdicción donde funcionará el mismo.

\section{Forma Societaria}

Las formas societarias se dan de acuerdo a las necesidades de cada empresa y se elige a la que se ajuste a los requerimientos de la misma. El proyecto se constituirá como personería jurídica, del tipo de Sociedad Anónima Cerrada, regulada dentro del Régimen de 
la Ley General de Sociedades Ley $N^{\circ}$ 26887, en el Título I, Artículo $\mathrm{N}^{\circ} 234$.

Los requisitos principales de una Sociedad Anónima Cerrada:

- Nacimiento: voluntario.

- Mínimo: 2 accionistas (regla); máximo: 20 accionistas.

- Cuenta con denominación social.

- El capital social está representado por acciones y se conforma con los aportes de los accionistas.

- No puede inscribir sus acciones en el Registro Público del Mercado de Valores.

- La responsabilidad de los socios se encuentra limitada por el monto de su aporte, por lo que ordinariamente no responden personalmente con su patrimonio por las deudas u obligaciones de la empresa.

- Cuenta con directorio facultativo.

- Los socios tienen derecho de adquisición preferente de acciones en caso de que algún socio desee transferirlas a persona extraña a la sociedad o incluso a otro socio, salvo que el estatuto indique lo contrario.

Los órganos de la empresa son:

- Junta General de Accionistas: Representa a todos los accionistas de la empresa, es el órgano máximo.

- Directorio: Es el segundo órgano en importancia de la sociedad y está conformado al menos por tres (3) personas. Es facultativo 
en esta clase de sociedad, careciendo de sentido si los directores serían los mismos accionistas, pues éstos siempre se podrán reunir en la junta general. En este caso la empresa no contará con Directorio.

- Gerente: Es el encargado de la administración y representación de la empresa.

\section{Proceso para la Constitución de Persona Jurídica}

Los pasos para la formalización y funcionamiento son las siguientes:

1. Búsqueda y reserva de nombre de la Personería Jurídica en la SUNARP, la que una vez aceptada por esta entidad queda reservada por un periodo de 30 días, mientras dura los trámites de formalización.

2. Elaboración de Minuta de Constitución, la cual es un documento privado elaborado y firmado por un abogado, donde se constituye la sociedad entre todos los socios y firmado por todos, encaso de ser casados también debe firmar el cónyuge. Para el caso de una pequeña o mediana empresa, este proceso puede realizarse en el ministerio de trabajo o en un notario directamente.

3. Luego la Notaría realiza la Escritura Pública y eleva a Registros Públicos (SUNARP) donde queda constituido la personería 
jurídica de la sociedad, para el cual previamente se debe realizar los pagos por derechos registrales y notariales.

4. Una vez constituida la empresa, se realiza la inscripción ante la SUNAT donde se obtiene la identificación de contribuyente el cual es llamado Registro único de Contribuyente (RUC) que consta de 11 dígitos numéricos, a la vez autorizan la emisión de los comprobantes de pago (Sunat, 2018).

5. Posteriormente se realiza la inscripción ante ESSALUD a todos los colaboradores que se encuentran en planilla.

6. Finalmente se tramita la Licencia de Funcionamiento y Defensa Civil en la municipalidad del lugar donde funcionará la empresa, para nuestro caso en la Municipalidad Distrital de San Isidro.

\section{Registro de Marcas y Patentes}

Opcionalmente se recomienda el registro de la razón comercial o marca del proyecto (Nombre de la empresa) la cual será registrada en la Dirección de Signos Distintivos del Instituto Nacional de Defensa de la Competencia y de la Protección de la Propiedad Intelectual (Indecopi, 2018).

Los pasos que debemos hacer para registrar nuestra marca son los siguientes: 
- Presentar tres ejemplares del formato de la solicitud correspondiente, indicando los datos del solicitante (incluyendo su domicilio para que se puedan remitir las notificaciones de las mismas).

- En caso de contar con un representante, adjuntar los poderes correspondientes, sus datos de identificación y su domicilio.

- Indicar cuál es el signo a registrar. Si éste posee elementos gráficos o logotipos, se deberá adjuntar su reproducción (tres copias de $5 \mathrm{~cm}$ de largo y $5 \mathrm{~cm}$. de ancho aproximadamente y a colores, si se desea proteger también los colores).

- Determinar expresamente cuáles son los productos, servicios o actividades económicas que se desea registrar, así como la clase a la que pertenece.

- Adjuntar la constancia de pago, realizado previamente por derechos de trámite cuyo costo equivale al $14.46 \%$ de la Unidad Impositiva Tributaria (UIT) por clase solicitada. El monto se cancela en la Caja del INDECOPI.

- La Dirección tiene un plazo de 15 días hábiles para realizar su examen formal, una vez completados los requisitos en el plazo establecido, se otorga la orden de publicación por única vez, con 
lo cual se debe acudir a las oficinas del diario oficial El Peruano y solicitar la divulgación.

- El costo de la misma debe ser asumido por el solicitante.

- Dentro del plazo de 30 días hábiles de recibida la orden de publicación, el solicitante debe realizar su divulgación en el diario oficial El Peruano.

\section{Licencias y Autorizaciones}

Para este proceso deberemos contar con los siguientes requisitos:

1. Formulario de Solicitud o Declaración Jurada debidamente llenada, que incluya:

a. Número de R.U.C. de la empresa.

b. Copia de D.N.I. o Carné de Extranjería del representante legal de la empresa.

2. Vigencia de poder de representante legal, en el caso de personas jurídicas u otros entes colectivos.

3. Declaración Jurada de Observancia de Condiciones de Seguridad.

4. Derecho de Trámite." 


\section{Certificado de Seguridad}

Adicional al trámite de la licencia deberemos gestionar el Certificado de Seguridad emitido por Defensa Civil. Para ello, nuestro local debe cumplir con todas las normas que nos exigen y presentar los siguientes documentos:

1. Derecho de inspección (2\% de la UIT).

2. Declaración Jurada de Observancia de condiciones de seguridad, según formato aprobado con nuevo reglamento de ITSDC (Inspecciones Técnicas de Seguridad en Defensa Civil).

3. Copia de la cartilla de seguridad y/o Plan de Seguridad en Defensa Civil (incluye plano de señalización y evacuación).

4. Copia del DNI del titular o carta poder simple del propietario al representante legal con copia de DNI.

\section{Legislación Laboral}

La empresa se encuentra dentro del Régimen de la Ley General de Sociedades, específicamente se encontrará dentro de la denominación de "Pequeña Empresa", ya que el número de empleados con el que se contará será de 1 a 100 trabajadores.

Las características laborales que debemos tener para empezar nuestras operaciones en este régimen son las siguientes:

- Derecho a la remuneración mínima vital de S/. 900.00 mensuales y asignación familiar correspondiente al 10\% del 
sueldo básico del trabajador para aquellos empleados que tengan hijos menores de 18 años o que tengan hijos que se encuentren realizando estudios universitarios.

- Derecho laboral de la jornada de 8 horas diarias o 48 horas semanales y un descanso semanal de 24 horas. El trabajador tiene derecho a 24 horas consecutivas de descanso como mínimo y a una remuneración del día de descanso que será proporcional a la de los días laborables.

- Los trabajadores tienen derecho a Licencias por enfermedad o embarazo.

- El régimen reconoce el derecho laboral de vacaciones, 30 días calendarios por cada año completo de servicios.

- Para el caso de despido injustificado, el trabajador tiene derecho a una indemnización de hasta 1.5 remuneraciones por cada año completo trabajado, con un tope máximo 8 años 0 remuneraciones.

- El régimen reconoce el derecho laboral de 30 días de CTS por año.

- Los trabajadores tienen derecho a percibir 2 gratificaciones, una por Fiestas Patrias y la otra por Navidad, equivalentes al $100 \%$ de la remuneración.

- Al pago de utilidades a los trabajadores siempre y cuando la empresa cuente con más de 20 trabajadores de ser así se remunerará en un plazo de 30 días después de haber realizado la declaración jurada de la renta anual de la empresa. 
- Los trabajadores tienen derecho a ser afiliados regulares del Régimen Contributivo de ESSALUD. Además, debemos adecuarnos, al Seguro Complementario de Trabajo de Riesgo y la Ley de Seguridad y Salud en el trabajo, a cargo de su empleador.

- Respecto a las pensiones el nuevo régimen contempla el derecho de los empleados a aporta a la ONP $13 \%$ o AFP de preferencia del empleado.

- Los contratos serán sujetos a modalidad, que da como máximo la contratación hasta de 5 años y el trabajador está sujeto a 3 meses de periodo de prueba pudiendo el empleador dar resolución del contrato durante estos meses. Esta modalidad de contrato está contemplada el decreto legislativo $\mathrm{N}^{\circ} 728$ aprobado por D.S $\mathrm{N}^{\circ}$ 003-97-TR- Ley de la Productividad y Competitividad Laboral; dicho contrato será por un periodo de 3 y 6 meses, según el puesto de trabajo, el cual será renovado si el trabajo cumple con las expectativas de la empresa.

\section{Legislación Tributaria}

El sistema tributario peruano está regulado por diversas normas. El artículo 74 de la Constitución Política del Perú de 1993 establece que los tributos se crean, modifican o derogan exclusivamente por medio de una Ley (Sunat,2018).

La empresa conforme al Decreto Legislativo No. 771, denominado como la "Ley Marco del Sistema Tributario Nacional, 
debe acogerse a una serie de impuestos y normas de carácter tributario, entre las principales tenemos:

Impuesto a la Renta; el cual grava los ingresos de las personas naturales y empresas, y por el que se tiene que pagar el $10 \%$ hasta 15 UIT y $29.5 \%$ para mayor a 15 UIT de la utilidad obtenida en el ejercicio anterior.

Debido al monto de facturación proyectado correspondería al proyecto el Régimen MYPE Tributario, el cual es para aquellas empresas que tengan ingresos inferiores a 1700 UIT, que reduce el pago del Impuesto a la renta, conforme se indica a continuación (ver Tabla 23).

\section{Tabla 24}

Impuesto a la renta

\begin{tabular}{lr}
\hline \multicolumn{1}{c}{ Renta Neta Anual } & \multicolumn{1}{c}{ Tasas } \\
\hline Hasta 15 UIT & $10 \%$ \\
Más de 15 UIT & $29.5 \%$ \\
\hline
\end{tabular}

EI Impuesto General a las Ventas que grava con el $18 \%$ del precio de venta, de los bienes, y de los servicios prestados por la empresa a nuestros clientes. Se pagará mensualmente dentro de los primeros días del siguiente mes, esto va a depender del último dígito del RUC, según calendario establecido (Sunat, 2018). 
Impuesto Predial y Arbitrios Municipales; que se paga a

la municipalidad correspondiente, sobre el valor del predio en alquiler donde nos ubicamos. El pago de este impuesto deberá estar especificado en el contrato de alquiler.

\subsection{Determinación de la localización óptima}

\subsubsection{Macro localización}

La macro localización permite identificar la zona o distrito, para el cual se identificaron cinco variables o factores (ver Tabla 24)

Tabla 25

Evaluación de Macro localización

\begin{tabular}{lccccccc}
\hline \multirow{2}{*}{ Variables } & \multirow{2}{*}{ Peso } & \multicolumn{2}{c}{ San Isidro } & \multicolumn{2}{c}{ Surco } & \multicolumn{2}{c}{ San Borja } \\
\cline { 3 - 8 } & & Escala & Calificación & Escala & Calificación & Escala & Calificación \\
\hline Precio de alquiler m2 & 0.4 & 4 & 1.6 & 3 & 1.2 & 2 & 0.8 \\
Cercanía al cliente & 0.3 & 5 & 1.5 & 3 & 0.9 & 3 & 0.9 \\
Facilidad de Licencias & 0.1 & 6 & 0.6 & 6 & 0.6 & 6 & 0.6 \\
Disponibilidad de Locales & 0.1 & 4 & 0.4 & 4 & 0.4 & 4 & 0.4 \\
Seguridad de la zona & 0.1 & 4 & 0.4 & 4 & 0.4 & 5 & 0.5 \\
\hline \multicolumn{1}{c}{ Total } & $\mathbf{1}$ & & $\mathbf{4 . 5}$ & & $\mathbf{3 . 5}$ & & $\mathbf{3 . 2}$ \\
\hline
\end{tabular}

Nota. Los factores y peso de calificación considerados son subjetivos en base a opiniones de expertos

\subsubsection{Micro localización}

Para determinar la ubicación específica de la oficina se analizaron cinco variables o factores (ver Tabla 25) 
Tabla 26

Evaluación de Micro localización.

\begin{tabular}{lccccc}
\hline \multirow{2}{*}{\multicolumn{1}{c}{ Variables }} & \multirow{2}{*}{ Peso } & \multicolumn{2}{c}{$\begin{array}{c}\text { Av. Amador Merino } \\
\text { Reyna 42m2 }\end{array}$} & \multicolumn{2}{c}{$\begin{array}{c}\text { Av. Canaval y Moreyra } \\
\text { 80m2 }\end{array}$} \\
\cline { 3 - 6 } & & Escala & Calificación & Escala & Calificación \\
\hline Precio de alquiler m2 & 0.4 & 3 & 1.2 & 2 & 0.8 \\
Cercanía al cliente & 0.3 & 3 & 0.9 & 3 & 0.9 \\
Facilidad de Licencias & 0.1 & 6 & 0.6 & 6 & 0.6 \\
Disponibilidad de Locales & 0.1 & 4 & 0.4 & 4 & 0.4 \\
Seguridad de la zona & 0.1 & 4 & 0.4 & 5 & 0.5 \\
\hline \multicolumn{1}{c}{ Total } & $\mathbf{1}$ & & $\mathbf{3 . 5}$ & & $\mathbf{3 . 2}$ \\
\hline
\end{tabular}

Nota. Los factores y peso de calificación considerados son subjetivos en base a opiniones de expertos

En base al análisis y resultado obtenido en la escala de calificación de macro y micro localización, se ha determinado alquilar la oficina de Av. Amador Merino Reyna, el mismo que cuenta con $42 \mathrm{mt} 2$ lo que nos permitirá desarrollar el proyecto.

\section{Ubicación de Oficina}

La ubicación de la oficina en base al resultado del análisis anterior, se ha dispuesto que sea en el distrito de San Isidro.

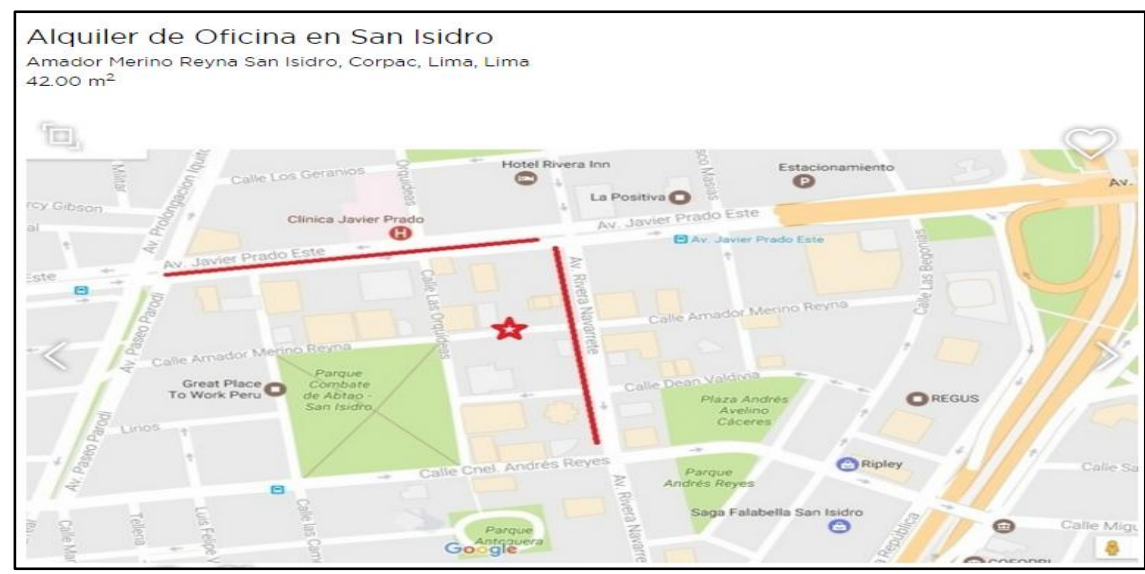

Figura 51. Plano de ubicación de la oficina elegida. Fuente: Google Maps 


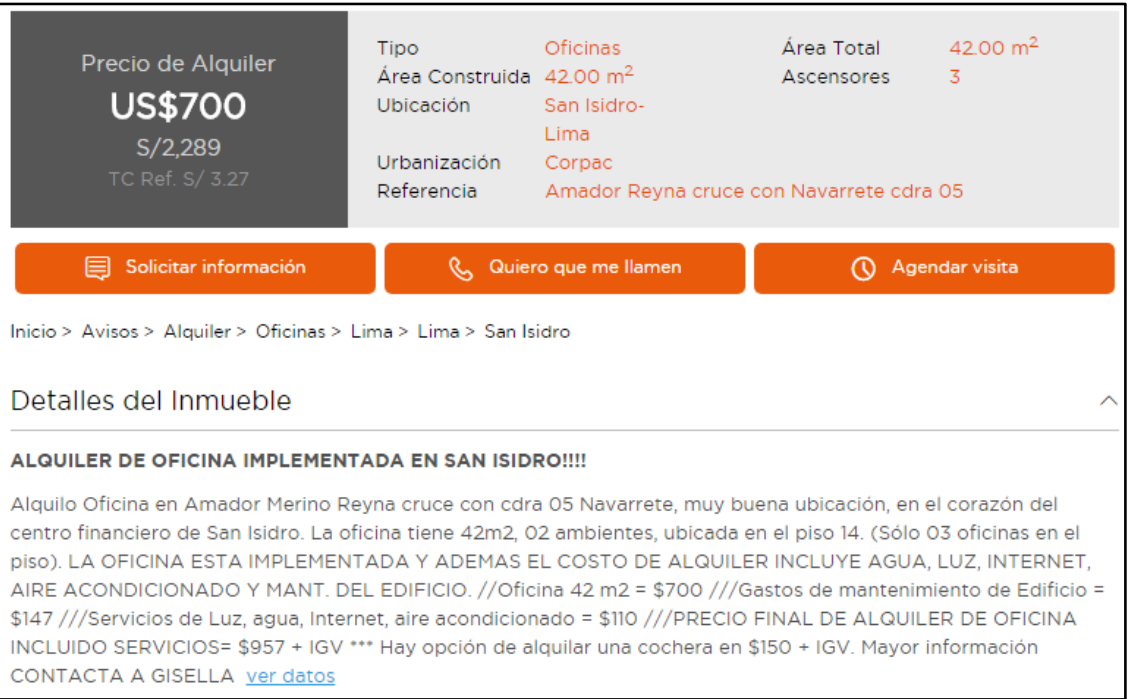

Figura 52 Detalle de inmueble. Fuente: Adondevivir.com

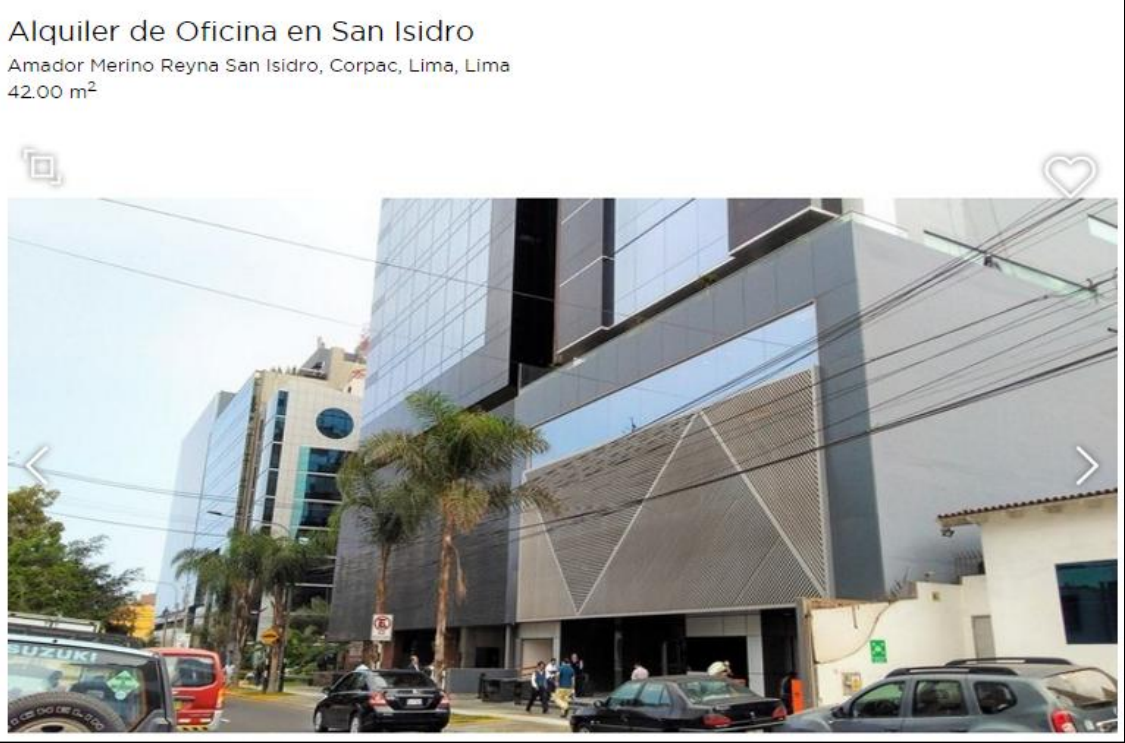

Figura 53. Imagen del edificio de la oficina. Fuente: Adondevivir.com

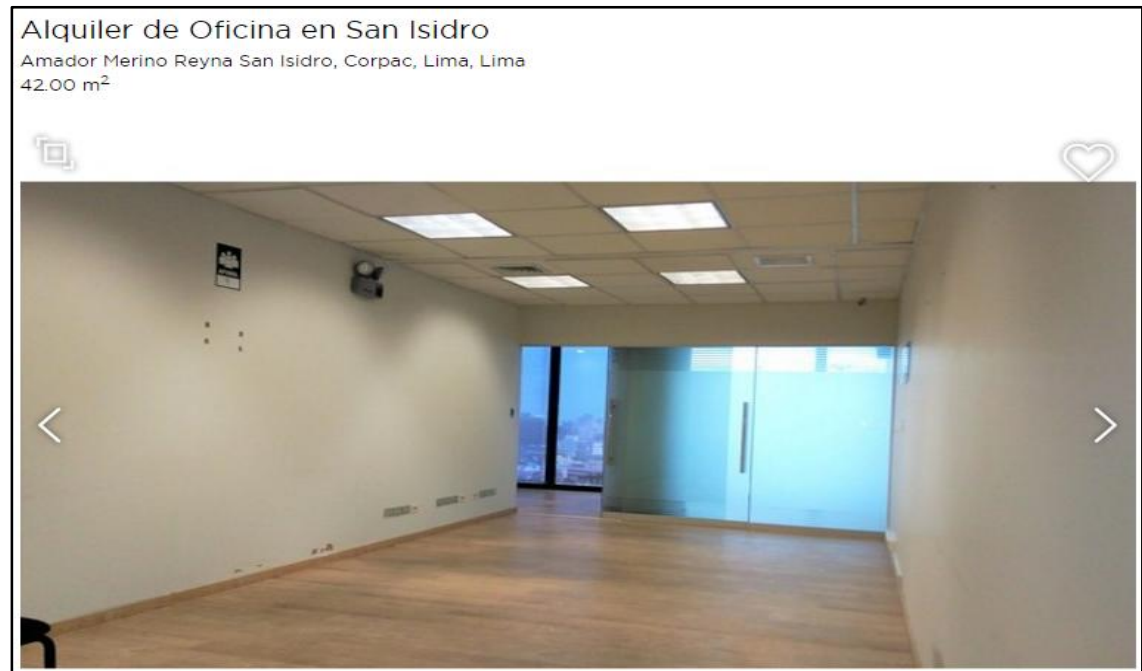

Figura 54. Imagen del edificio de la oficina. Fuente: Adondevivir.com 


\section{CAPÍTULO VIII}

\section{Aspectos Organizacionales}

El presente capítulo se desarrolla la caracterización de la cultura organizacional deseada (Visión, Misión y Valores), estrategia del negocio, ventaja competitiva, estructura organizacional, perfiles de puestos claves, remuneraciones e incentivos y política de recursos humanos.

\subsection{Caracterización de la cultura organizacional deseada}

La cultura organizacional en una organización es como la personalidad para las personas, por lo que la implementación de los valores, costumbres, visión y misión deben ser de pleno conocimiento y ser orientados a su cumplimiento por todos los colaboradores de la organización.

\subsubsection{Visión}

Liderar el mercado peruano de soluciones en sistema de información geográfica e ingeniería relacionado con la geografía y medio ambiente, basados en nuestra gente, innovación continua y aplicación de nuevas tecnologías.

\subsubsection{Misión}

Brindamos soluciones para medio ambiente, ingeniería y sistema de información geográfica con el alto nivel y compromiso de nuestra gente. 


\subsubsection{Principios}

- Pasión por nuestros clientes.

○ Compromiso

○ Transparencia

○ Confianza

\subsection{Formulación de estrategias de negocio}

La estrategia de negocio conforme a la definición de Porter (2010), son:

- Liderazgo en costos

- Diferenciación

- Enfoque

Para el caso del proyecto la estrategia de negocio a seguir es el de "Enfoque" (Porter, 2010), ya que nuestro público objetivo es especializado del sector minero, que desarrollan actividades relacionados con el medio ambiente, ingeniería y soluciones en sistema de información geográfica. Nuestros productos son verticales enfocados a al sector minería, para medioambiente e ingeniería mediante GIS y CAD.

\subsection{Determinación de las ventajas competitivas críticas}

Porter (2010) en su libro "ventaja competitiva" manifiesta que la ventaja competitiva son los aspectos o procesos que son difíciles de ser imitados y aquellas organizaciones que tienen ventaja competitiva, son la que está en mejores condiciones para competir, en consecuencia obtienen mejores resultados respecto a otras que estando en similares condiciones y no tengan ventaja competitiva. 
En ese sentido, la competencia central o ventaja competitiva del proyecto será atender con Consultor Senior en sistemas CAD y Geociencia, que continuamente serán capacitados por los fabricantes de los productos comercializados, con la finalidad de identificar y satisfacer las necesidades de los clientes para maximizar el beneficio y minimizar el costo psicológico de los mismos.

\subsection{Diseño de la estructura organizacional deseada}

La estructura organizacional comprende tres niveles jerárquicos simples con la finalidad de que los procesos sean directos para una atención eficaz y eficiente.

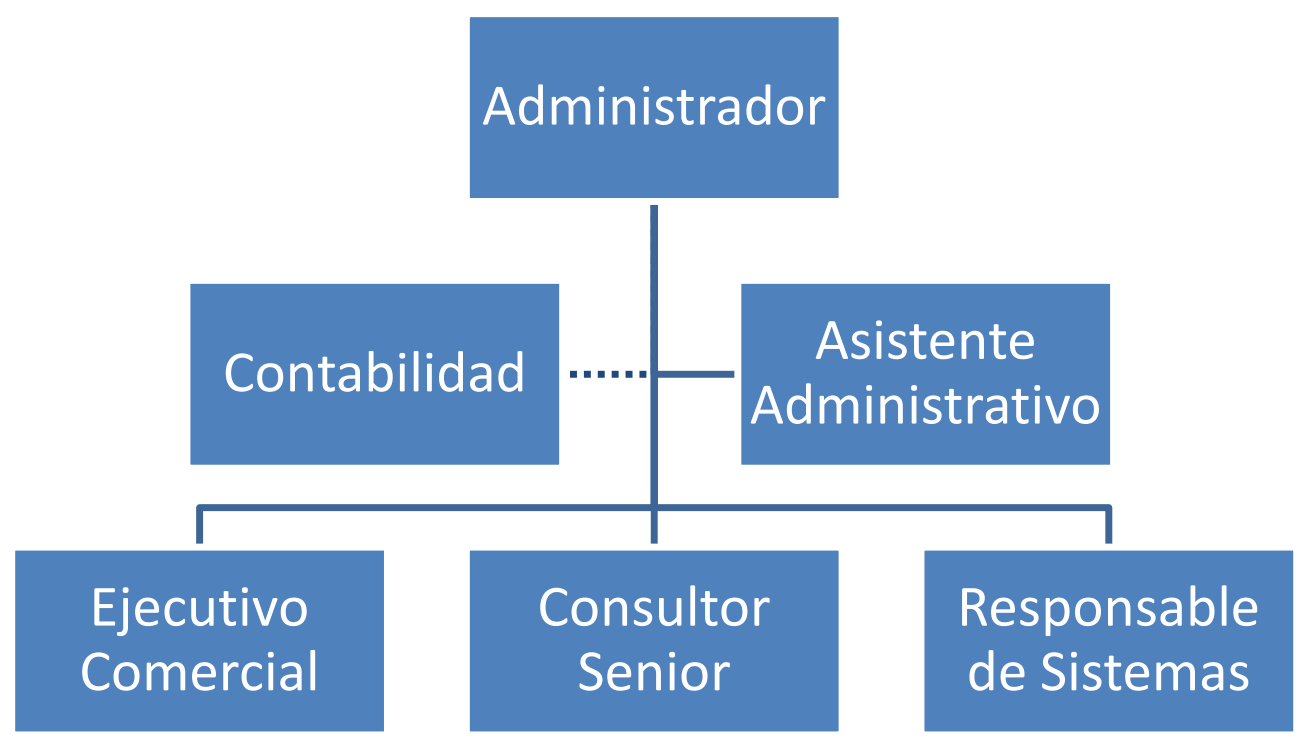

Figura 55. Estructura organizacional del proyecto

\subsection{Diseño de los perfiles de los puestos clave}

El requerimiento y diseño de los perfiles de los puestos para el proyecto se encuentran realizados en base a la proyección de mercado y sus necesidades, con el que se estima satisfacer los requerimiento y necesidades de los clientes y el buen funcionamiento organizacional; dichos puestos son (1) Administrador General (ver 
Tabla 26), (2) Consultor Senior (ver Tabla 27), (3) Ejecutivo Comercial (ver Tabla

28), (4) Asistente Administrativo (ver Tabla 29).y (5) Responsable de Sistemas (ver

Tabla 30).

\section{Tabla 27}

\section{Perfil de Administrador General}

\begin{tabular}{ll}
\hline & \multicolumn{1}{c}{ Administrador General } \\
\hline Puesto o Cargo & Administrador General \\
Área & Administración \\
Reporta a: & Accionistas \\
Le reportan: & Todos \\
Relaciones Internas & Todos los colaboradores \\
Relaciones Externas & Clientes, proveedores, gobierno y sociedad. \\
& \\
& \multicolumn{2}{c}{ Propósito del Cargo } \\
\hline
\end{tabular}

Planificar, organizar, dirigir y controlar el servicio de consultoría; con el propósito de mantener el servicio según los parámetros de la empresa; optimizando la asignación de los recursos; mejorando continuamente la calidad de servicio; atrayendo, motivando y capacitando adecuadamente al personal. Además brindar el soporte a los Consultores Senior en la atención de cada cliente.

\section{Funciones}

1. Supervisar la atención de las consultorías.

2. Revisar los costos operacionales mensuales.

3. Controlar y proyectar la prospección de clientes.

4. Control de los costos directos e indirectos.

5. Administración y control del personal.

6. Análisis de indicadores claves de gestión.

7. Seguimiento a la facturación de los servicios de consultoría.

8. Informar a los clientes del status de sus proyectos.

9. Conocer y cumplir los Políticas y Procedimientos relacionados a sus actividades

10. Otras funciones que le sean inherentes a su cargo.

Competencias

\begin{tabular}{|c|c|c|}
\hline \multirow[t]{2}{*}{ Educación } & $\begin{array}{l}\text { Estudios Universitarios en Ingeniería de } \\
\text { Sistemas, Industrial, Administración o } \\
\text { afines. }\end{array}$ & $\begin{array}{l}\text { Egresado o Bachiller en Ingeniería de } \\
\text { Sistemas, Industrial, Administración o } \\
\text { afines }\end{array}$ \\
\hline & Maestría en Administración de Negocios & Magister en MBA \\
\hline Experiencia & $\begin{array}{l}03 \text { años desempeñándose en cargo de } \\
\text { jefatura en empresas del sector }\end{array}$ & $\begin{array}{l}05 \text { años desempeñando funciones } \\
\text { similares. }\end{array}$ \\
\hline \multirow{4}{*}{ Formación } & Deseable con Cursos en Servicio al cliente & $\begin{array}{l}\text { Con Cursos en Gestión de Proyectos, } \\
\text { CRM, entre otros }\end{array}$ \\
\hline & $\begin{array}{l}\text { De preferencia con office nivel intermedio } \\
(*)\end{array}$ & $\begin{array}{l}\text { Conocimiento de Sistemas de } \\
\text { Información Geográfica }\end{array}$ \\
\hline & Idioma: inglés intermedio $(*)$ & Office nivel avanzado $(*)$ \\
\hline & & Idioma: inglés avanzado $(*)$ \\
\hline
\end{tabular}


Nota. (*) Significa que es indispensable. Elaboración propia.

\section{Tabla 28}

\section{Perfil de Consultor Senior}

\begin{tabular}{ll}
\hline & \\
\hline Puesto o Cargo & Consultor Senior \\
Área & Ventas \\
Reporta a: & Administrador Genior \\
Le reportan: & Ninguno \\
Relaciones Internas & Todos los colaboradores \\
Relaciones Externas & Clientes y proveedores
\end{tabular}

\section{Propósito del Cargo}

Responsable de realizar las presentaciones técnicas como ingeniero de negocios, además identificar y atender las necesidades técnicas GIS y CAD de los clientes asignados, dentro del plazo establecido; organizar y controlar los entregables y fidelizar la cartera asignada. Además será el encargado dictar las capacitaciones CAD y GIS para los clientes.

\section{Funciones}

1. Programar las visitas a los clientes asignados.

2. Revisar el cumplimiento de los entregables.

3. Elaborar y presentar al Gerente un resumen de los principales clientes y negocios logrados mes a mes según el plan de prospectos y/o targets, y como ello aporta al volumen general de ventas, por líneas.

4. Informar los avances de cada proyecto al Gerente General.

5. Supervisar que se cumplan con los controles de calidad según los estándares.

6. Analizar las oportunidades de negocios y definir el potencial de ventas en la cartera.

7. Conocer y cumplir los Políticas y Procedimientos relacionados a sus actividades.

8. Dictar las capacitaciones CAD y GIS a los clientes.

8. Otras funciones que le sean inherentes a su cargo.

Perfil del Cargo

Competencias Mínimo

Estudios técnicos o universitarios con

Educación especialización en ciencias de la tierra.

\section{Óptimo}

Egresado o Bachiller en Ingeniería de Sistemas, Geógrafo, Geólogo, etc.

Maestría en Catastro, Geociencia 8 años desempeñando funciones

Experiencia

5 años desempeñando funciones en consultoría en Sistemas CAD y Geociencia.

Con conocimientos de Ofimática

Formación

$$
\begin{aligned}
& \text { Office nivel intermedio }(*) \\
& \text { Idioma: inglés intermedio }(*)
\end{aligned}
$$
similares.

Con Cursos en Sistemas de Información Geográfica y Diseño Asistido por Computadora

Office nivel avanzado $(*)$ Idioma: inglés avanzado $(*)$

Nota. (*) Significa que es indispensable. Elaboración propia. 
Tabla 29

\section{Perfil de Ejecutivo Comercial}

\begin{tabular}{|c|c|}
\hline & Ejecutivo Comercial \\
\hline Puesto o Cargo & Ejecutivo de Ventas \\
\hline Área & Ventas \\
\hline $\begin{array}{l}\text { Reporta a: } \\
\text { Le reportan: }\end{array}$ & Administrador General \\
\hline Relaciones Internas & Todos los colaboradores \\
\hline Relaciones Externas & Clientes y proveedores \\
\hline
\end{tabular}

Propósito del Cargo

Planificar y elaborar el presupuesto de ventas; generar valor a través del logro de objetivos de ventas; buscar nuevas oportunidades de negocio; realizar la evaluación económica de nuevos proyectos; administrar los procesos comerciales.

\section{Funciones}

1. Organizar y gestionar las juntas con los prospectos de la BD del sector

2. Reuniones con Administrador General y Consultor Senior para revisar el resultado de Proyección ventas, presupuesto, los targets, entre otros.

3. Elaboración de la propuesta a presentar a los clientes por los Asesores Comerciales (talleres, soporte técnico, inversión, y otros).

4. Seguimiento y control de las fichas de créditos para su aprobación.

5. Revisión de los precios especiales que los Asesores Comerciales sugieren cotizar.

6. Seguimiento al cumplimiento del programa de soporte técnico ofrecido a los clientes por los Asesores Comerciales.

7. Visitar a los clientes cuantas veces sea necesario

8. Presentación de los resultados de ventas trimestral (cada tres meses).

9. Elaboración de los avances de las ventas y presupuesto por semana.

10. Analizar las oportunidades de los negocios y definir el potencial de ventas en los clientes por contratos y de los Asesores Comerciales.

11. Otras funciones que le sean inherentes a su cargo.

Competencias

\begin{tabular}{ll}
\hline Educación & $\begin{array}{l}\text { Estudios técnicos o universitarios en } \\
\text { Administración, Ingeniería Industrial o } \\
\text { carreras afines. }\end{array}$ \\
\hline Experiencia & 2 años cumpliendo funciones similares. \\
\hline Formación & $\begin{array}{l}\text { Cursos complementarios en ventas u otros } \\
\text { afines. }\end{array}$
\end{tabular}

Formación

\section{Mínimo}

Óptimo

Profesional bachiller o titulado de las carreras de Administración, Ingeniería Industrial, Economía o afines.

3 años de experiencia como ejecutivo de ventas en empresas de Tecnología. Buen manejo de personal y de equipos de ventas.

Conocimientos de finanzas y gestión de proyectos.

Office nivel avanzado (*)

Idioma: inglés intermedio $(*)$

Nota. (*) Significa que es indispensable. Elaboración propia. 


\section{Tabla 30}

\section{Perfil de Responsable de Sistemas}

\begin{tabular}{ll}
\hline & \multicolumn{1}{c}{ Responsable de Sistemas } \\
\hline Puesto o Cargo & Responsable de Sistemas \\
Área & Administración \\
Reporta a: & Administrador General \\
Le reportan: & Ninguno \\
Relaciones Internas & Todos los colaboradores \\
Relaciones Externas & Clientes y proveedores
\end{tabular}

\section{Propósito del Cargo}

Realizar las configuraciones e instalaciones de los programas de Sistema de Información Geográfica y Diseñó Asistido por Computadora a clientes y responsable de la administración y buen funcionamiento de los sistemas TI de la empresa.

\section{Funciones}

1. Realizar las configuraciones en la herramienta de acuerdo a las necesidades de cada cliente.

2. Coordinar con el Consultor Senior el avance de las tareas.

3. Revisar los cronogramas de cada cliente y realizar la coordinación respectiva para su facturación inmediata.

4. Participar de reuniones periódicas con la gerencia y Consultores Funcionales para evaluar respuesta del mercado, problemas en el desarrollo de sus labores, o cualquier otro asunto que tenga que ver con la herramienta.

5. Mantener actualizado la BD de cliente donde indica los datos del cliente, servicios realizados, visitas efectuadas, otros.

6. Elaborar el calendario de las presentaciones y de informes técnicos desempeño de los productos y sustento respectivo a clientes.

7. Conocer y cumplir los Políticas y Procedimientos relacionados a sus actividades

8. Otras funciones que le sean inherentes a su cargo.

$\begin{array}{lll}\text { Competencias } & \text { Mínimo } & \text { Óptimo }\end{array}$

\begin{tabular}{lll}
\hline Educación & $\begin{array}{l}\text { Estudios técnicos o universitarios en } \\
\text { sistemas o afines }\end{array}$ & $\begin{array}{l}\text { Egresado o Bachiller en Ingeniería de } \\
\text { Sistemas o afines }\end{array}$ \\
\hline Experiencia & $\begin{array}{l}1 \text { año desempeñando funciones en el área } \\
\text { de sistemas }\end{array}$ & $\begin{array}{l}3 \text { años desempeñando funciones } \\
\text { similares. }\end{array}$ \\
\hline Formación & Con conocimientos de Ofimática & $\begin{array}{l}\text { Con Cursos en Sistemas de Información } \\
\text { Geográfica y Diseño Asistido por } \\
\text { Computadora }\end{array}$ \\
& Office nivel intermedio $(*)$ & $\begin{array}{l}\text { Office nivel avanzado }(*) \\
\text { Idioma: inglés avanzado }(*)\end{array}$ \\
\hline
\end{tabular}

Nota. (*) Significa que es indispensable. Elaboración propia. 


\section{Tabla 31}

Perfil de Asistente Administrativo

\begin{tabular}{ll}
\hline & \multicolumn{1}{c}{ Asistente Administrativo } \\
\hline Puesto o Cargo & Asistente de Administración \\
Área & Administración \\
Reporta a: & Administrador General \\
Le reportan: & Ninguno \\
Relaciones Internas & Todos los colaboradores \\
Relaciones Externas & Clientes y proveedores \\
& \multicolumn{2}{c}{ Propósito del Cargo } \\
\hline
\end{tabular}

Administrar efectivamente los pedidos recibidos por os Consultores Senior, así como garantizar la adecuada atención a los clientes.

Funciones

1. Enviar órdenes de compra ya procesadas del día anterior a despacho.

2. Coordinar con la facturación la emisión de facturas.

3. Consolidar la documentación (Guías de remisión con facturas) para su Cobranza.

4. Consolidar documentos (emisores) que reporta a Contabilidad de forma periódica (mensualmente).

5. Atender a los clientes (Presencial, telefónicamente y vía email)

6. Listar las facturas que estén sujetas a detracción.

7. Archivar documentos varios.

8. Realizar seguimiento a las órdenes de compra.
Competencias
Mínimo
Óptimo

\begin{tabular}{lll} 
Educación & $\begin{array}{l}\text { Estudios técnicos o universitarios Bachiller } \\
\text { en Marketing, Ingeniería Industrial, } \\
\text { Administración o carreras afines. }\end{array}$ & $\begin{array}{l}\text { Profesional o técnico egresado de } \\
\text { Administración, Economía, Carreras } \\
\text { afines. }\end{array}$ \\
\hline Experiencia & Mínima 1 año en puestos similares & $\begin{array}{l}\text { Experiencia mínima de } 2 \text { a } 3 \text { años en } \\
\text { empresas comerciales en el área de } \\
\text { atención al cliente. }\end{array}$ \\
\hline Formación & Office nivel intermedio $(*)$ & $\begin{array}{l}\text { Office nivel avanzado }(*) \\
\text { Idioma: inglés intermedio }(*)\end{array}$ \\
\hline
\end{tabular}

Nota. (*) Significa que es indispensable. Elaboración propia.

\subsection{Remuneraciones, compensaciones e incentivos}

Las remuneraciones son fijas con excepción del Ejecutivo Comercial, quien tendrá dos formas de percibir sus ingresos (1) Fijo y (2) variable, el cual equivale a $5 \%$ de las ventas, Las remuneraciones fijas se encuentran detalladas a continuación (ver Tabla 31). 


\section{Tabla 32}

Remuneraciones mensuales

\begin{tabular}{lccr}
\hline \multicolumn{1}{c}{ Personal } & Cantidad & Régimen & $\begin{array}{c}\text { Total } \\
\text { Remun. } \\
\text { Mensual S/ }\end{array}$ \\
\hline Administrador & 1 & General & $6,600.00$ \\
Asistente de Administración & 1 & General & $1,980.00$ \\
Técnico de soporte & 1 & General & $2,310.00$ \\
Consultor Senior & 1 & General & $6,600.00$ \\
Ejecutivo comercial & 1 & General & $1,650.00$ \\
\hline
\end{tabular}

- A todos los trabajadores en planilla les corresponde Vacaciones, Gratificaciones y CTS.

- La asignación familiar está contemplada dentro del sueldo, para aquellos trabajadores que tengan hijos menores de edad.

- Los trabajadores podrán elegir sistema de pensiones de su preferencia sea AFP o ONP.

- Los trabajadores cuentan con seguro social y no EPS.

\subsection{Política de recursos humanos}

La política de recursos humanos se planifica estrictamente cumpliendo con las normas establecidas por las leyes laborales vigentes, en los alcances del Decreto Supremo No $003-97-T R$ Ley $N^{o} 728$

\section{La modalidad de contratación}

Será bajo el contrato de necesidades de mercado que da como máximo la contratación hasta de 5 años del trabajador y el trabajador está sujeto a 3 meses de prueba pudiendo el empleador rescindir el contrato durante estos meses este modalidad de contrato esta versado el decreto legislativo N728 aprobado por D.S N 
003-97-TR-ley de la productividad y la competitividad laboral dicho contrato será por un periodo de 6 meses, el cual será renovado si la empresa lo desea. La forma de convocatoria de personal se dará mediante anuncios en periódicos, páginas web como computrabajo, bumeran, tecsup, senati y/o por recomendación. La forma de contratación se realizará según los niveles del organigrama funcional.

Administrador General, suscribirá un contrato por 01 año, por jornada de trabajo completo (8 horas).

Responsable de Sistemas y Asistente Administrativo, suscribirá un contrato por 1 año, a tiempo completo (8 horas) y renovable de acuerdo a la evaluación de desempeño del jefe inmediato.

Consultor Senior, suscribirá un contrato por 1 año a tiempo parcial, (24 horas semanales) y renovable de acuerdo a la evaluación de desempeño del jefe inmediato.

Ejecutivo Comercial, suscribirán un contrato por 1 año, a tiempo completo (8 horas) en horarios completo y renovables de acuerdo a la evaluación de desempeño del jefe inmediato. El caso de remuneración para el ejecutivo comercial será una parte Fija y otro variable (5\% de las ventas).

\section{Horario de trabajo}

Estará dividido de la siguiente manera:

Personal administrativo de lunes a viernes de 8:00 am a 5:00 pm 


\section{CAPÍTULO IX}

\section{Planificación financiera}

En el presente capítulo se desarrollará la planificación financiera, la Inversión, financiamiento, presupuestos base, Presupuesto de resultado.

\subsection{La inversión}

Por el lado de la inversión se desarrollará la inversión Pre Operativa, Capital de trabajo, costo del proyecto e inversión futura.

\subsubsection{Inversión pre-operativa}

En la inversión Pre Operativa se considera la inversión necesaria para la constitución y contratos de representación de las dos marcas a representar (ver Tabla 32)

\section{Tabla 33}

Inversión Pre Operativo

\begin{tabular}{lcrrr}
\hline \multicolumn{1}{c}{ Activo - Intangibles } & Cantidad & $\begin{array}{c}\text { Costo Total } \\
\text { sin IGV S/ }\end{array}$ & IGV & $\begin{array}{c}\text { Total con } \\
\text { IGV S/ }\end{array}$ \\
\hline Búsqueda y reserva de nombre en SUNARP & 1 & 23.10 & 23.10 \\
Elaboración de Minuta & 1 & 462.00 & 462.00 \\
Elevar la escritura Pública en SUNARP & 1 & 316.80 & 316.80 \\
Gastos Notariales y Registrales & 1 & 914.10 & 49.86 & 963.96 \\
Legalización de Libros Contables Electrónicos & 1 & 165.00 & 9.00 & 174.00 \\
Legalizar Libro de Planillas & 1 & 23.10 & 1.26 & 24.36 \\
Registro de marca & 1 & 544.50 & 544.50 \\
Publicación en el diario El Peruano & 1 & 16.50 & 0.90 & 17.40 \\
Licencia de Funcionamiento & 1 & 148.50 & 148.50 \\
Certificado de Defensa Civil & 1 & 92.40 & 92.40 \\
Pago por representación Pitney Bowes Software & 1 & $16,500.00$ & $16,500.00$ \\
Pago por representación ZWSoft & 1 & $16,500.00$ & 118.80 & $2,296.80$ \\
Licencia MS Windows Server 2016 & 1 & $2,178.00$ & $2,140.20$ \\
Licencia MS Exchange 2016 & 1 & $2,029.50$ & 110.70 & $2,140.00$ \\
\hline & & $39,913.50$ & 290.52 & $40,204.02$ \\
\hline
\end{tabular}

Nota. La inversión por representación de las dos marcas equivale a \$5,000 cada una y se encuentran indicados en el Anexo 1 y anexo 2. 


\subsubsection{Inversión en capital de trabajo}

Para determinar la inversión del capital de trabajo, se utilizó el método del mayor déficit acumulado (ver Tabla 33).

La proyección de capital de trabajo para los años dos, tres cuatro y cinco se determinó hallando el ratio del capital necesario y los ingresos para el primer año (12.53\%) multiplicado por los ingresos proyectados de los siguientes años (ver Tabla 34)

\section{Tabla 34}

Inversión en Capital de Trabajo Anualizado

\begin{tabular}{|c|c|c|c|c|c|c|}
\hline CAPITAL DE TRABAJO & AÑO 0 & AÑO 1 & AÑO 2 & AÑO 3 & AÑO 4 & AÑO 5 \\
\hline Ingresos & & $1,474,803$ & $1,831,823$ & $1,923,415$ & $2,019,585$ & $2,120,564$ \\
\hline Capital de trabajo necesario & & 185,749 & 230,715 & 242,251 & 254,363 & 267,082 \\
\hline Inversión en capital de trabajo & $-185,749$ & $-44,966$ & $-11,536$ & $-12,112$ & $-12,718$ & $-13,354$ \\
\hline
\end{tabular}

Nota. La inversión en capital de trabajo determinado corresponde a los incrementales y son para ser usados en el año siguiente al determinado. 


\section{Tabla 35}

Determinación del capital de trabajo Inicial

\begin{tabular}{|c|c|c|c|c|c|c|c|c|c|c|c|c|c|}
\hline Descripción & Mes 0 & Mes 1 & Mes 2 & Mes 3 & Mes 4 & Mes 5 & Mes 6 & Mes 7 & Mes 8 & Mes 9 & Mes 10 & Mes 11 & Mes 12 \\
\hline \multicolumn{14}{|l|}{ INGRESOS } \\
\hline Ingreso $\mathrm{x}$ venta Software CAD S/ & & & & 19,800 & 19,800 & 33,000 & 33,000 & 39,600 & 39,600 & 36,300 & 36,300 & 39,600 & 39,600 \\
\hline Ingreso $\mathrm{x}$ venta Software GIS S/ & & & & 47,421 & $\begin{array}{r}94,842 \\
7,920\end{array}$ & 94,842 & $\begin{array}{r}110,649 \\
7,920\end{array}$ & 110,649 & $\begin{array}{r}126,456 \\
7,920\end{array}$ & 126,456 & $\begin{array}{r}126,456 \\
7,920\end{array}$ & $\begin{array}{r}126,456 \\
7,920\end{array}$ & $\begin{array}{r}126,456 \\
7,920\end{array}$ \\
\hline Ingreso Neto (S/) & & & & 67,221 & 122,562 & 127,842 & 151,569 & 150,249 & 173,976 & 162,756 & 170,676 & 173,976 & 173,976 \\
\hline I.G.V. & & & & 12,100 & 22,061 & 23,012 & 27,282 & 27,045 & 31,316 & 29,296 & 30,722 & 31,316 & 31,316 \\
\hline Total Ingresos (S/) & & & & 79,321 & 144,623 & 150,854 & 178,851 & 177,294 & 205,292 & 192,052 & 201,398 & 205,292 & 205,292 \\
\hline Total Ingresos( S/) Cobro 30 días & & & & & 79,321 & 144,623 & 150,854 & 178,851 & 177,294 & 205,292 & 192,052 & 201,398 & 205,292 \\
\hline
\end{tabular}

\section{EGRESOS}

Compra de software CAD (S/)

Compra de software GIS (S/)

Total Planilla de Ventas

Total Gastos en Prom y Pub

Total Planilla de Adm.

Total Otros Gastos de Adm.

Total Neto Gastos Generales

I.G.V.

Egreso Gastos Generales (S/)

Pago IGV

Adelanto de IR (2\% Ventas)

Total Egresos (S/)

$\begin{array}{rrr} & & 9, \\ & & 30, \\ 8,993 & 8,993 & 12, \\ 660 & 330 & \\ 11,870 & 11,870 & 11,87 \\ 560 & 560 & \\ 3,252 & 3,252 & 3, \\ 585 & 585 & \\ 3,838 & 3,838 & 3,83\end{array}$

9,900

\begin{tabular}{|c|c|c|c|c|c|c|c|c|c|c|c|c|}
\hline Total Egresos (S/) & 25,920 & 25,590 & 71,322 & 131,597 & 150,332 & 155,784 & 169,609 & 174,731 & 166,773 & 172,242 & 189,375 & 217,682 \\
\hline Flujo de Efectivo (Ingr - Egre) & $-25,920$ & $-25,590$ & $-71,322$ & $-52,277$ & $-5,709$ & $-4,931$ & 9,243 & 2,562 & 38,519 & 19,810 & 12,023 & $-12,391$ \\
\hline Efectivo Acumulado & $-25,920$ & $-51,511$ & $-122,833$ & $-175,110$ & $-180,818$ & $-185,749$ & $-176,506$ & $-173,944$ & $-135,425$ & $-115,615$ & $-103,592$ & $-115,983$ \\
\hline
\end{tabular}

Capital de Trabajo 185,749

Nota: El cálculo se realizó utilizando el mayor déficit acumulado que se encuentra en el mes 8, correspondiente a S/ 185,749 


\subsubsection{Costo del proyecto}

El costo o inversión total del proyecto en Activos tangibles,

Intangibles y Pre Operativos y capital de trabajo, equivale a S/ 289,234 (ver

Tabla 36).

\section{Tabla 36}

Costo del proyecto

\begin{tabular}{lrrr}
\hline \multicolumn{1}{c}{ Inversión } & $\begin{array}{c}\text { Costo Total sin } \\
\text { IGV S/ }\end{array}$ & IGV & Total en S/ \\
\hline Inversión en Activos Tangibles & 39,669 & 7,140 & 46,810 \\
Inversión en Activos Intangibles \& Pre Operativos & 53,873 & 2,803 & 56,676 \\
Inversión en Capital de Trabajo & 185,749 & & 185,749 \\
\hline \multicolumn{1}{c}{ Total Inversión } & $\mathbf{2 7 9 , 2 7 1}$ & $\mathbf{9 , 9 4 4}$ & 289,234 \\
\hline
\end{tabular}

Nota. La inversión total del proyecto equivale a S/ 289,234

\subsubsection{Inversiones futuras}

Se estima inversión en activos tangibles al tercer año de operación, el cual corresponde a la adquisición de nuevos equipos de cómputo, que equivale al monto indicado líneas abajo (ver Tabla 37)

\section{Tabla 37}

Inversiones futuras

\begin{tabular}{|c|c|c|c|}
\hline Inversión & $\begin{array}{c}\text { Costo Total sin } \\
\text { IGV S/ }\end{array}$ & IGV & Total en S/ \\
\hline PC Dell core i5, 500GB, 8GB RAM, Monitor de 20" & 12,623 & 2,272 & 14,895 \\
\hline MacBook Air 13.3" 128 GB & 14,751 & 2,655 & 17,406 \\
\hline Total Inversión & 27,374 & 4,927 & 32,301 \\
\hline
\end{tabular}

Nota. La inversión futura para el tercer año se estima en S/ 32,301, 5 pc Dell y 3 Notebook Apple 


\subsection{Financiamiento}

En el presente proyecto no se contempla obtener ningún financiamiento, al tratarse de una empresa nueva, por lo que realmente no aplicaría a un financiamiento bancario.

\subsubsection{Endeudamiento y condiciones}

Como se menciona en el capítulo anterior, el proyecto no incurre en financiamiento.

\subsubsection{Capital y costo de oportunidad}

El capital requerido equivale a S/ 287,209 Soles, el cual será cubierto el $100 \%$ por los accionistas interesados en la inversión del presente proyecto.

El Costo de Oportunidad (COK) es determinado mediante el uso del modelo CAPM (Capital Asset Pricing Model), cuya fórmula es la siguiente:

$$
C O K=R f+B(R m-R f)
$$

Donde:

Rf : Rendimiento libre de riesgo

B : Beta del proyecto

$\mathrm{Rm}$ : Rendimiento del mercado 
En el Perú ninguna de las empresas que comercializan software cotiza en la bolsa, por lo que se determinará utilizando el beta desapalancado (por no contar con financiamiento) de las empresas de software de Estados Unidos, de los últimos 10 años obtenidos mediante Damodaran (2018), a cuyo resultado se agregará el Riesgo País del Perú, ya que el proyecto se realizará en el Perú, además se incrementará un $2.5 \%$ al resultado, por el riesgo de un proyecto nuevo (ver Tabla 38).

\section{Apalancamos Beta}

$$
\boldsymbol{B}_{\boldsymbol{A}}=B_{d}\left(1+\frac{\mathrm{D}}{\mathrm{E}}(1-T)\right.
$$

Donde:

$$
\begin{aligned}
& \boldsymbol{B}_{\boldsymbol{A}}=0.94 \quad \text { : Beta Apalancado } \\
& \mathrm{D} \quad=0 \% \quad \text { : Deuda } \\
& \mathrm{E} \quad=100 \% \quad: \text { Capital } \\
& \mathrm{T}=41 \% \quad: \text { Tasa de Impuesto a la Renta } \\
& \boldsymbol{B}_{\boldsymbol{a}}=0.94\left(1+\frac{0 \%}{100 \%}\right)(1-41 \%)=\mathbf{0 . 9 4}
\end{aligned}
$$

El beta apalancado es igual al beta desapalancado, por no haber incurrido en deuda (Deuda cero), por lo tanto usamos 0.94 como beta del proyecto. 


\section{Cálculo del COK}

$$
C O K_{\$ \text { Perú }}=R f+B(R m-R f)+R p
$$

Donde:

$$
\begin{array}{ll}
\text { Rf }=4.29 & : \text { Rendimiento libre de riesgo USA } 10 \text { year T. Bond } \\
\mathrm{B}=0.94 & : \text { Beta del proyecto } \\
\mathrm{Rm}=10.27 & : \text { Rendimiento del mercado(S\&P }(2008-2017) \\
\mathrm{Rp}=1.29 & : \text { Riesgo País de Perú al 28/03/2018 } \\
& \\
\text { COK }_{\$ \text { Perú }}=4.29 \%+0.94(10.27 \%-4.29 \%)+1.29 \%=\mathbf{1 1 . 2 0} \%
\end{array}
$$

Luego se procedió hacer el ajuste del $\boldsymbol{C O} \boldsymbol{K}_{\$ \text { Perú }}$ a $\boldsymbol{C O} \boldsymbol{K}_{\boldsymbol{S} / \text { Perú, para }}$ el cual se utilizó el siguiente modelo:

$$
\begin{aligned}
& \boldsymbol{C O K}_{S / \text { Perú }}=\operatorname{COK}_{\$ \text { Perú }}\left(\frac{\text { Inflación Perú }}{\text { Inflación USA }}\right) \\
& \boldsymbol{C O K}_{S / \text { Perú }}=11.20 \%\left(\frac{2.75 \%}{1.67 \%}\right)=18.46 \%
\end{aligned}
$$

Adicionalmente en base a la recomendación de expertos, se puede agregar hasta un $7 \%$ por el riesgo de ser una empresa nueva, por lo que estimamos agregar un 2.5\%, con el que el Cok del Proyecto sería 20.96\%

$$
\text { COK }_{\text {Proy }}=18.46 \%+2.5 \%=20.96 \%
$$




\section{Tabla 38}

Determinación del Costo de Oportunidad (COK)

\begin{tabular}{llc}
\hline \multicolumn{1}{c}{ Cuentes } & \multicolumn{1}{c}{ Variables } & Indicador \\
\hline Damodaran S\&P (2008-2017) & Rendimiento del mercado USA & $10.27 \%$ \\
Damodaran 10 year T. Bond (2008-2017) & Tasa libre de riesgo USA (T-Bonds) & $4.29 \%$ \\
Sector Software (System \& Application) & Beta desapalancada & 0.94 \\
Proyecto & $\%$ D & $0 \%$ \\
Proyecto & $\%$ E & $100 \%$ \\
Riesgo pais (28 de Marzo, 2018) & Riesgo pais & $1.29 \%$ \\
Sunat & Impuesto a la renta & $29.5 \%$ \\
Bl = Bu x (1 + D/E x (1-T)) & Beta Apalancado & 0.94 \\
\hline COK = Rf + B x (Rm - Rf) + Rp (COK Perú U\$) & COK (Perú U\$) & $11.20 \%$ \\
\hline COK = Rf + B x (Rm - Rf) + Rp (COK Perú S/) & COK (Perú S/) & $18.46 \%$ \\
\hline Ajuste por riesgo de nuevo proyecto & & $2.50 \%$ \\
\hline COK & COK (Proyecto) & $20.96 \%$ \\
\hline
\end{tabular}

Nota: El riesgo Pyme es por tratarse de una inversión nueva y no contar con el respaldo financiero.

\subsubsection{Costo de capital promedio ponderado}

El Costo del Capital Promedio Ponderado, es el mismo que el COK, ya que el proyecto no cuenta con financiamiento.

\section{Tabla 39}

Determinación del Costo Promedio Ponderado de Capital (WACC)

\begin{tabular}{|c|c|c|c|}
\hline Capital & Monto & $\%$ & $\begin{array}{c}\text { Costo de } \\
\text { capital }\end{array}$ \\
\hline Deuda & $\mathrm{S} /$. & $0.00 \%$ & $0.00 \%$ \\
\hline Capital propio & S/. 289,234 & $100 \%$ & $20.96 \%$ \\
\hline Total & S/. 289,234 & $100 \%$ & \\
\hline
\end{tabular}

Costo promedio ponderado capital (WACC)

$20.96 \%$

Nota: El Costo promedio ponderado de capital es el mismo que el COK por no mantener deuda 


\subsection{Presupuestos Base}

Respecto al presupuesto base se desarrollará el presupuesto de ventas, de compras, de costo de ventas, gastos administrativos, etc.

\subsubsection{Presupuestos de ventas}

El presupuesto de ventas estimado para los cinco años se muestra a continuación (ver Tabla 40).

\section{Tabla 40}

Presupuesto de ventas proyectado

\begin{tabular}{|c|c|c|c|c|c|c|}
\hline Descripción & Año 0 & Año 1 & Año 2 & Año 3 & Año 4 & Año 5 \\
\hline Venta de Software CAD (S/) & & $336,600.00$ & $353,430.00$ & $371,102.00$ & $389,657.00$ & $409,139.00$ \\
\hline Venta de Software GIS (S/) & & $1,090,683.00$ & $1,145,217.00$ & $1,202,478.00$ & $1,262,602.00$ & $1,325,732.00$ \\
\hline Capacitación y Asesoría & & $47,520.00$ & $49,896.00$ & $52,391.00$ & $55,010.00$ & $57,761.00$ \\
\hline Mantenimiento Anual CAD (76.39\% x 25\%) & & & $66,807.00$ & $70,147.00$ & $73,654.00$ & $77,337.00$ \\
\hline Mantenimiento Anual GIS (76.39\% x 25\%) & & & $216,473.00$ & $227,297.00$ & $238,662.00$ & $250,595.00$ \\
\hline Total sin IGV & & $1,474,803.00$ & $1,831,823.00$ & $1,923,415.00$ & $2,019,585.00$ & $2,120,564.00$ \\
\hline IGV $(18 \%)$ & & $265,465.00$ & $329,728.00$ & $346,215.00$ & $363,525.00$ & $381,702.00$ \\
\hline Total Ventas S/ & & $1,740,268.00$ & $2,161,551.00$ & $2,269,630.00$ & $2,383,110.00$ & $2,502,266.00$ \\
\hline
\end{tabular}

Nota: La estimación incluye el ingreso por el concepto de mantenimiento a partir del segundo año

\subsubsection{Presupuestos de costos de ventas}

El presupuesto de costo de ventas son las licencias y el costo del mantenimiento adquirido a los respectivos fabricantes (ver Tabla 41).

\section{Tabla 41}

Presupuesto de costo de ventas

\begin{tabular}{|c|c|c|c|c|c|c|}
\hline Descripción & Año 0 & Año 1 & Año 2 & Año 3 & Año 4 & Año 5 \\
\hline Compra de Software CAD (S/) & & $168,300.00$ & $176,715.00$ & $185,551.00$ & $194,829.00$ & $204,570.00$ \\
\hline Compra de Software GIS (S/) & & $763,478.00$ & $801,652.00$ & $841,735.00$ & $883,821.00$ & $928,012.00$ \\
\hline Compra de Mantenimiento Anual CAD S/ & & & $33,404.00$ & $35,074.00$ & $36,827.00$ & $38,669.00$ \\
\hline Compra de Mantenimiento Anual GIS S/ & & & $173,178.00$ & $181,838.00$ & $190,930.00$ & $200,476.00$ \\
\hline Total sin IGV & & $931,778.00$ & $1,184,949.00$ & $1,244,198.00$ & $1,306,407.00$ & $1,371,727.00$ \\
\hline IGV $(18 \%)$ No aplica x importación no físico & & 0.00 & 0.00 & 0.00 & 0.00 & 0.00 \\
\hline Total Costo de Ventas S/ & & $931,778.00$ & $1,184,949.00$ & $1,244,198.00$ & $1,306,407.00$ & $1,371,727.00$ \\
\hline
\end{tabular}

Nota: No aplica IGV por ser una importación de un bien intangible. 


\subsubsection{Presupuestos de gastos administrativos}

El presupuesto de gasto de administración comprende el pago de planilla del personal de administración y gastos de alquiler de oficina, pagos de servicios de mantenimiento de edificio y los servicios de agua y electricidad (ver Tabla 42).

\section{Tabla 42}

Presupuesto de gastos de administración

\begin{tabular}{|c|c|c|c|c|c|c|}
\hline Descripción & Año 0 & Año 1 & Año 2 & Año 3 & Año 4 & Año 5 \\
\hline Total Planilla de Administración & & $177,071.40$ & $177,071.40$ & $177,071.40$ & $177,071.40$ & $177,071.40$ \\
\hline Total Otros Gastos de Adm. & & $6,720.00$ & $6,720.00$ & $6,720.00$ & $6,720.00$ & $6,720.00$ \\
\hline Total Neto Gastos Generales & & $39,029.36$ & $39,029.36$ & $39,029.36$ & $39,029.36$ & $39,029.36$ \\
\hline Total Neto en Gastos de Adm. & & 222,821.00 & 222,821.00 & 222,821.00 & $222,821.00$ & $222,821.00$ \\
\hline $\operatorname{IGV}(18 \%)$ & & $7,025.00$ & $7,025.00$ & $7,025.00$ & $7,025.00$ & $7,025.00$ \\
\hline Total Ventas \$ & & $229,846.00$ & $229,846.00$ & $229,846.00$ & $229,846.00$ & $229,846.00$ \\
\hline
\end{tabular}

Nota: El presupuesto de planilla incluye todos los beneficios del trabajador conforme a ley.

\subsubsection{Presupuestos de marketing y ventas}

El presupuesto de marketing y ventas se encuentra detallado en el cuadro siguiente (ver Tabla 43). 


\section{Tabla 43}

Presupuesto de gastos de ventas y marketing

\begin{tabular}{|c|c|c|c|c|c|c|}
\hline Descripción & Año 0 & Año 1 & Año 2 & Año 3 & Año 4 & Año 5 \\
\hline \multicolumn{7}{|l|}{ PLANILLA } \\
\hline Ejecutivo de Ventas & & $19,800.00$ & $19,800.00$ & $19,800.00$ & $19,800.00$ & $19,800.00$ \\
\hline Ejecutivo de Ventas (Variable 5\% Vtas) & & $73,740.15$ & $91,591.15$ & $96,170.75$ & $100,979.25$ & $106,028.20$ \\
\hline Consultor Senior & & $79,200.00$ & $79,200.00$ & $79,200.00$ & $79,200.00$ & $79,200.00$ \\
\hline Consultor Senior (Variable x Capacitación) & & $19,008.00$ & $19,008.00$ & $19,958.40$ & $20,956.40$ & $22,004.00$ \\
\hline Total Planilla Base de Ventas & & $191,748.15$ & 209,599.15 & $215,129.15$ & $220,935.65$ & $227,032.20$ \\
\hline Gratificaciones & & $15,979.01$ & $15,979.01$ & $15,979.01$ & $15,979.01$ & $15,979.01$ \\
\hline CTS & & $15,979.01$ & $15,979.01$ & $15,979.01$ & $15,979.01$ & $15,979.01$ \\
\hline Vacaciones & & $15,979.01$ & $15,979.01$ & $15,979.01$ & $15,979.01$ & $15,979.01$ \\
\hline Essalud & & $21,571.67$ & $21,571.67$ & $21,571.67$ & $21,571.67$ & $21,571.67$ \\
\hline Total Planilla de Ventas & & $261,256.85$ & 279,107.85 & $284,637.85$ & $290,444.35$ & $296,540.90$ \\
\hline \multicolumn{7}{|l|}{ PROMOCIÓN Y PUBLICIDAD } \\
\hline $\begin{array}{l}\text { Movilidad de Ejecutivo Comercial y } \\
\text { Consultor senior }\end{array}$ & & $3,960.00$ & $3,960.00$ & $3,960.00$ & $3,960.00$ & $3,960.00$ \\
\hline Total Gastos en Prom. y Public. & & $4,290.00$ & $4,290.00$ & $4,290.00$ & $4,290.00$ & $4,290.00$ \\
\hline Total Neto en Gastos de Ventas & & $265,547.00$ & $283,398.00$ & $288,928.00$ & $294,734.00$ & $300,831.00$ \\
\hline IGV $(18 \%)$ & & 0.00 & 0.00 & 0.00 & 0.00 & 0.00 \\
\hline Total en Gastos de Ventas \$ & & $265,547.00$ & $283,398.00$ & 288,928.00 & $294,734.00$ & $300,831.00$ \\
\hline
\end{tabular}

Nota: Los gastos variables para el ejecutivo de ventas corresponden al $5 \%$ de las ventas. El presupuesto de planilla incluye todos los beneficios del trabajador conforme a ley.

\subsection{Presupuestos de resultados}

El presupuesto de resultados se encuentra considerado el estado de ganancias y pérdidas, balance proyectado y el flujo de caja proyectado.

\subsubsection{Estado de ganancias y pérdidas proyectado}

El estado de ganancias y pérdidas proyectado para los cinco años muestra que las utilidades son positivas desde el primer año, el cual inicia con S/ 23,922 (ver Tabla 44) 


\section{Tabla 44}

Estado de ganancias y perdidas proyectado

\section{Estado de Resultados}

(Expresado en Soles)

\begin{tabular}{|c|c|c|c|c|c|c|}
\hline & Año 0 & Año 1 & Año 2 & Año 3 & Año 4 & Año 5 \\
\hline Ventas Netas & & $1,474,803$ & $1,831,823$ & $1,923,415$ & $2,019,585$ & $2,120,564$ \\
\hline (-) Costo de Ventas & & $(931,778)$ & $(1,184,949)$ & $(1,244,198)$ & $(1,306,407)$ & $(1,371,727)$ \\
\hline Utilidad Bruta & & 543,025 & 646,874 & 679,217 & 713,178 & $\mathbf{7 4 8 , 8 3 7}$ \\
\hline (-) Gastos de Administración & & $(222,821)$ & $(222,821)$ & $(222,821)$ & $(222,821)$ & $(222,821)$ \\
\hline (-) Gasto de Ventas y Mkt & & $(265,547)$ & $(283,398)$ & $(288,928)$ & $(294,734)$ & $(300,831)$ \\
\hline Utilidad Operativa & & 54,657 & 140,655 & 167,468 & 195,623 & 225,185 \\
\hline $\begin{array}{l}\text { (+/-) Ingresos o Gastos Fin. } \\
\text { (-) Depreciación }\end{array}$ & & $(9,693)$ & $(9,693)$ & $(9,693)$ & $(16,536)$ & $(7,741)$ \\
\hline $\begin{array}{l}\text { Utilidad antes de } \\
\text { Impuestos }\end{array}$ & & 44,964 & 130,962 & 157,775 & $\mathbf{1 7 9 , 0 8 7}$ & 217,444 \\
\hline $\begin{array}{l}\text { (-) Impuesto a la Renta } \\
(29.5 \%)\end{array}$ & & $(4,496)$ & $(26,934)$ & $(34,844)$ & $(41,131)$ & $(52,446)$ \\
\hline Utilidad Neta & & 40,468 & 104,028 & 122,931 & 137,956 & 164,998 \\
\hline
\end{tabular}

Fuente: Elaboración propia. 


\subsubsection{Balance proyectado}

El Balance general proyectado para cinco años se muestra a continuación (ver Tabla 45).

\section{Tabla 45}

Balance general proyectado

\section{Balance General}

(Expresado en Soles)

\begin{tabular}{|c|c|c|c|c|c|c|}
\hline & Año 0 & Año 1 & Año 2 & Año 3 & Año 4 & Año 5 \\
\hline \multicolumn{7}{|l|}{ ACTIVO } \\
\hline \multicolumn{7}{|l|}{$\underline{\text { Activo Corriente }}$} \\
\hline Caja y Bancos & 185,749 & 15,138 & 117,323 & 210,462 & 352,236 & 511,621 \\
\hline Crédito Fiscal de IGV & 9,944 & & & & & \\
\hline Cuentas por cobrar comerciales & 0 & 245,801 & 305,304 & 320,569 & 336,598 & 353,427 \\
\hline Total Activo Corriente & 195,693 & 260,939 & 422,627 & 531,031 & 688,834 & 865,048 \\
\hline \multicolumn{7}{|l|}{ Activo No Corriente } \\
\hline Activo Tangible (IME) & 39,669 & 39,669 & 39,669 & 67,043 & 67,043 & 67,043 \\
\hline (-) Depreciación Acumulada & & $(9,693)$ & $(19,386)$ & $(29,079)$ & $(45,615)$ & $(53,356)$ \\
\hline Activo Intangibles & 53,873 & 53,873 & 53,873 & 53,873 & 53,873 & 53,873 \\
\hline Total Activo No Corriente & $\mathbf{9 3 , 5 4 2}$ & 83,849 & 74,156 & $\mathbf{9 1 , 8 3 7}$ & 75,300 & 67,559 \\
\hline TOTAL ACTIVOS & 289,234 & 344,788 & 496,783 & 622,868 & 764,134 & $\mathbf{9 3 2 , 6 0 8}$ \\
\hline \multicolumn{7}{|l|}{ PASIVO } \\
\hline \multicolumn{7}{|l|}{ Pasivo Corriente } \\
\hline Otras cuentas por pagar & & 5,994 & 7,444 & 7,817 & 8,208 & 8,618 \\
\hline Tributos por pagar (IGV) & & 9,092 & 55,608 & 58,389 & 61,308 & 64,374 \\
\hline Total Pasivo Corriente & $\mathbf{0}$ & 15,085 & 63,053 & 66,206 & 69,516 & 72,992 \\
\hline
\end{tabular}

Pasivo No Corriente

Cuentas por pagar a Largo Plazo

Otras Obligaciones a Largo Plazo

\begin{tabular}{lrrrrrr}
\hline Total Pasivo No Corriente & $\mathbf{0}$ & $\mathbf{0}$ & $\mathbf{0}$ & $\mathbf{0}$ & $\mathbf{0}$ & $\mathbf{0}$ \\
\hline TOTAL PASIVOS & $\mathbf{0}$ & $\mathbf{1 5 , 0 8 5}$ & $\mathbf{6 3 , 0 5 3}$ & $\mathbf{6 6 , 2 0 6}$ & $\mathbf{6 9 , 5 1 6}$ & $\mathbf{7 2 , 9 9 2}$ \\
\hline PATRIMONIO & & & & & & \\
Capital & 289,234 & 289,234 & 289,234 & 289,234 & 289,234 & 289,234 \\
Resultados acumulados & & 0 & 40,468 & 144,496 & 267,427 & 405,383 \\
Resultado del ejercicio & & 40,468 & 104,028 & 122,931 & 137,956 & 164,998 \\
\hline TOTAL PATRIMONIO & $\mathbf{2 8 9 , 2 3 4}$ & $\mathbf{3 2 9 , 7 0 2}$ & $\mathbf{4 3 3 , 7 3 0}$ & $\mathbf{5 5 6 , 6 6 2}$ & $\mathbf{6 9 4 , 6 1 8}$ & $\mathbf{8 5 9 , 6 1 6}$ \\
\hline TOTAL PASIVOS Y & $\mathbf{2 8 9 , 2 3 4}$ & $\mathbf{3 4 4 , 7 8 8}$ & $\mathbf{4 9 6 , 7 8 3}$ & $\mathbf{6 2 2 , 8 6 8}$ & $\mathbf{7 6 4 , 1 3 4}$ & $\mathbf{9 3 2 , 6 0 8}$ \\
PATRIMONIO & & & & & &
\end{tabular}

Fuente: Elaboración propia. 


\subsubsection{Flujo de caja proyectado}

A continuación se muestra el flujo de caja proyectado a partir de la utilidad bruta (ver Tabla 46).

\section{Tabla 46}

Flujo de caja proyectado

\section{Flujo de Caja}

(Expresado en Soles)

\begin{tabular}{lrrrrrr}
\hline & Año 0 & \multicolumn{1}{c}{ Año 1 } & \multicolumn{1}{c}{ Año 2 } & \multicolumn{1}{c}{ Año 3 } & \multicolumn{1}{c}{ Año 4 } & Año 5 \\
\hline UTILIDAD NETA & 40,468 & 104,028 & 122,931 & 137,956 & 164,998 \\
(+) Depreciación & & 9,693 & 9,693 & 9,693 & 16,536 & 7,741
\end{tabular}

\begin{tabular}{lrrrrrr}
\hline FGO & $\mathbf{0}$ & $\mathbf{5 0 , 1 6 1}$ & $\mathbf{1 1 3 , 7 2 1}$ & $\mathbf{1 3 2 , 6 2 4}$ & $\mathbf{1 5 4 , 4 9 2}$ & $\mathbf{1 7 2 , 7 3 9}$ \\
\hline (-) Inversión en Capital de Trabajo & $(185,749)$ & $(44,966)$ & $(11,536)$ & $(12,112)$ & $(12,718)$ & $(13,354)$
\end{tabular}

\begin{tabular}{|c|c|c|c|c|c|c|}
\hline FCO & $(185,749)$ & 5,195 & 102,185 & 120,512 & 141,774 & 159,385 \\
\hline $\begin{array}{l}\text { (-) Inversión en Activos Fijos / } \\
\text { Futuros }\end{array}$ & $(39,669)$ & & & $(27,374)$ & & \\
\hline (-) Inversión en Activos Intangibles & $(39,914)$ & & & & & \\
\hline (-) Inversión Pre Operativos & $(13,959)$ & & & & & \\
\hline (+) IGV Neto & $(9,944)$ & & & & & \\
\hline (-) Pago de IGV & & 9,944 & & & & \\
\hline FCI & $(289,234)$ & 15,138 & 102,185 & 93,138 & 141,774 & 159,385 \\
\hline
\end{tabular}

(+) Préstamo

(-) Amortización de la Deuda

Escudo Fiscal

Flujo de Caja Financiero FCF

$(289,234)$

$15,138 \quad 102,185$

93,138

141,774

159,385

Fuente: Elaboración propia. 


\section{CAPÍTULO X}

\section{Evaluación económica financiera}

En el presente capítulo se evalúa el riesgo, para el cual se la TIR, el VAN, el ROE y otros ratios relevantes.

\subsection{Evaluación financiera}

Los detalles, análisis e interpretación de los principales indicadores mencionados en el párrafo anterior se muestran a continuación.

\subsubsection{TIR}

La tasa interna de retorno del proyecto calculado es $37.08 \%$ siendo este el beneficio que otorgaría el proyecto, el cual supera al COK de $20.96 \%$ exigido por los accionistas (ver Tabla 47).

\section{Tabla 47}

La tasa interna de retorno (TIR)

\begin{tabular}{|c|c|c|c|c|c|c|c|}
\hline Flujo de Caja Económico & $(289,234)$ & 15,138 & 102,185 & 93,138 & 141,774 & 159,385 & \\
\hline \multicolumn{8}{|l|}{$\begin{array}{l}\text { Préstamo } \\
\text { (-) Amortización de la Deuda } \\
\text { Escudo Fiscal }\end{array}$} \\
\hline \multirow[t]{2}{*}{ Flujo de Caja Financiero } & $(289,234)$ & 15,138 & 102,185 & 93,138 & 141,774 & 159,385 & 760,385 \\
\hline & & & & & & & Perpetuidad \\
\hline Tasa de Descuento (COK) & $20.96 \%$ & & & & & & \\
\hline TIR & $37.08 \%$ & & & & & & \\
\hline
\end{tabular}




\subsubsection{VAN}

El valor presente neto del flujo proyectado nos muestra un saldo positivo de S/ 216,267 Soles, el cual fue calculado usando el COK de $20.96 \%$ como tasa de descuento, en razón que el proyecto no mantiene deuda, por lo que se utilizó el flujo económico. (ver Tabla 48)

\section{Tabla 48}

El valor actual neto (VAN)

\begin{tabular}{lllllll}
\hline Flujo de Caja Económico & $(289,234)$ & 15,138 & 102,185 & 93,138 & 141,774 & 159,385 \\
\hline
\end{tabular}

Préstamo

(-) Amortización de la Deuda

Escudo Fiscal

\begin{tabular}{|c|c|c|c|c|c|c|c|}
\hline Flujo de Caja Financiero & $(289,234)$ & 15,138 & 102,185 & 93,138 & 141,774 & 159,385 & 760,385 \\
\hline & & & & & & & Perpetuidad \\
\hline Tasa de Descuento (COK) & $20.96 \%$ & & & & & & \\
\hline VAN & 216,267 & & & & & & \\
\hline
\end{tabular}

\subsubsection{ROE}

El indicador que mide la rentabilidad del capital, y según el cálculo realizado el rendimiento de los fondos propios para los siguientes años se muestra a continuación (ver Tabla 49)

Tabla 49

Retorno de la Inversión

\begin{tabular}{lccccr}
\hline \multicolumn{1}{c}{ Ratios de Rentabilidad } & Año 1 & Año 2 & Año 3 & \multicolumn{1}{c}{ Año 4 } & Año 5 \\
\hline ROE (Return on Equity) & $12.27 \%$ & $23.98 \%$ & $22.08 \%$ & $19.86 \%$ & $19.19 \%$ \\
\hline
\end{tabular}

Fuente: Elaboración propia. 
El resultado obtenido no indica que por cada S/ 1 Sol invertido, el retorno es $12.27 \%$ el primer año y a partir del segundo año mejora el nivel en promedio a un $21 \%$ aproximadamente.

\subsubsection{Ratios}

Otros ratios de rentabilidad como el Margen Bruto, Margen Operativo y Margen Neto, no permiten identificar que los gastos operativos disminuyen drásticamente la Utilidad Bruta. (ver Tabla 50)

\section{Tabla 50}

Otros ratios de rentabilidad

\begin{tabular}{lrrrrr}
\hline \multicolumn{1}{c}{ Ratios de Rentabilidad } & \multicolumn{1}{c}{ Año 1 } & \multicolumn{1}{c}{ Año 2 } & \multicolumn{1}{c}{ Año 3 } & \multicolumn{1}{c}{ Año 4 } & Año 5 \\
\hline Margen Bruto & $36.82 \%$ & $35.31 \%$ & $35.31 \%$ & $35.31 \%$ & $35.31 \%$ \\
Margen Operativo & $3.71 \%$ & $7.68 \%$ & $8.71 \%$ & $9.69 \%$ & $10.62 \%$ \\
Margen Neto (Utilidad Neta /Ventas) & $2.74 \%$ & $5.68 \%$ & $6.39 \%$ & $6.83 \%$ & $7.78 \%$ \\
\hline
\end{tabular}

Fuente: Elaboración propia.

\subsection{Análisis de riesgo}

El análisis de riesgo se desarrolló el análisis de punto de equilibrio, de sensibilidad y el análisis de escenarios.

\subsubsection{Análisis de punto de equilibrio}

Este indicador nos permite identificar la cantidad mínima que se debe comercializar para no estar en pérdida, es decir es el punto donde no se gana ni se pierde (ver Tabla 51) 


\section{Tabla 51}

Análisis de punto de equilibrio

\begin{tabular}{|c|c|c|c|c|c|c|c|c|c|c|}
\hline \multirow{2}{*}{ Descripción } & \multicolumn{2}{|c|}{ Año 1} & \multicolumn{2}{|c|}{ Año 2} & \multicolumn{2}{|c|}{ Año 3} & \multicolumn{2}{|c|}{ Año 4} & \multicolumn{2}{|c|}{ Año 5} \\
\hline & CAD & GIS & CAD & GIS & CAD & GIS & CAD & GIS & CAD & GIS \\
\hline Mezcla de Productos & $42.5 \%$ & $57.5 \%$ & $42.5 \%$ & $57.5 \%$ & $42.5 \%$ & $57.5 \%$ & $42.5 \%$ & $57.5 \%$ & $42.5 \%$ & $57.5 \%$ \\
\hline Valor Venta Unit & 3,300 & 7,904 & 3,924 & 9,397 & 3,924 & 9,397 & 3,924 & 9,397 & 3,924 & 9,397 \\
\hline Costo Var Unit & 1,650 & 5,532 & 1,650 & 6,578 & 1,650 & 6,578 & 1,650 & 6,578 & 1,650 & 6,578 \\
\hline $\mathrm{MCU}(\mathrm{Vv}-\mathrm{Cvu})$ & 1,650 & 2,371 & 2,274 & 2,819 & 2,274 & 2,819 & 2,274 & 2,819 & 2,274 & 2,819 \\
\hline $\mathrm{MC}$ unitario prom & \multicolumn{2}{|c|}{2,065} & \multicolumn{2}{|c|}{2,587} & \multicolumn{2}{|c|}{2,587} & \multicolumn{2}{|c|}{2,587} & \multicolumn{2}{|c|}{2,587} \\
\hline CFT & \multicolumn{2}{|c|}{498,061} & \multicolumn{2}{|c|}{515,912} & \multicolumn{2}{|c|}{521,442} & \multicolumn{2}{|c|}{534,091} & \multicolumn{2}{|c|}{531,393} \\
\hline $\mathrm{PE}$ Unid = CFT $/ \mathrm{Mcu}$ & \multicolumn{2}{|c|}{241} & \multicolumn{2}{|c|}{199} & \multicolumn{2}{|c|}{202} & 206 & & \multicolumn{2}{|c|}{205} \\
\hline Punto de Equ. (Unid) & 103 & 139 & 85 & 115 & 86 & 116 & 88 & 119 & 87 & 118 \\
\hline Punto de Equ S/ & 338,336 & $1,096,309$ & 332,508 & $1,077,425$ & 336,073 & $1,088,974$ & 344,225 & $1,115,391$ & 342,486 & $1,109,756$ \\
\hline
\end{tabular}

Fuente: Elaboración propia.

Como se observa el primer año se debe vender 103 licencias de Software CAD y 139 Licencias de software GIS, que equivale S/ 338,336 y S/ 1'096,309 respectivamente. Para el segundo año se reduce a 85 Licencias CAD y 105 licencias GIS que equivale a S/ 332,508 y S/ 1'077,425 respectivamente, manteniendo cantidades y montos similares para los siguientes años.

\subsubsection{Análisis de sensibilidad}

El análisis de sensibilidad nos permite identificar riesgos haciendo cambios variables, para el caso del proyecto analizaremos cinco variables principales del proyecto, Ingresos, Costo de ventas, Gastos de Administración, Gasto de ventas y tasa del COK.

Se ha elaborado un cuadro de escenario que varían desde $-20 \%$ hasta $+20 \%$ para identificar la variación del VAN a diferentes niveles dentro del 
rango analizado. El proceso se realiza para cada una de las variables

seleccionadas, los resultados se muestran a continuación (ver Tabla 52).

\section{Tabla 52}

Análisis de sensibilidad

\begin{tabular}{|c|c|c|c|c|c|}
\hline \multicolumn{2}{|c|}{ INGRESOS } & \multicolumn{2}{|c|}{ COSTO DE VENTAS } & \multicolumn{2}{|c|}{ GASTO DE ADM } \\
\hline $0.0 \%$ & S/ 216,267 & $0.0 \%$ & S/ 216,267 & $0.0 \%$ & S/ 216,267 \\
\hline$-20.0 \%$ & $-S / 71,473$ & $-20.0 \%$ & $S / 1,318,729$ & $-20.0 \%$ & $S / 420,899$ \\
\hline$-17.5 \%$ & $-S / 35,506$ & $-17.5 \%$ & $S / 1,180,921$ & $-17.5 \%$ & $\mathrm{~S} / 395,320$ \\
\hline$-15.0 \%$ & $S / 462$ & $-15.0 \%$ & $S / 1,043,113$ & $-15.0 \%$ & $S / 369,741$ \\
\hline$-12.5 \%$ & $S / 36,429$ & $-12.5 \%$ & $S / 905,306$ & $-12.5 \%$ & $S / 344,162$ \\
\hline$-10.0 \%$ & $S / 72,397$ & $-10.0 \%$ & $S / 767,498$ & $-10.0 \%$ & $S / 318,583$ \\
\hline$-7.5 \%$ & $S / 108,364$ & $-7.5 \%$ & $S / 629,690$ & $-7.5 \%$ & $S / 293,004$ \\
\hline$-5.0 \%$ & $S / 144,332$ & $-5.0 \%$ & $S / 491,882$ & $-5.0 \%$ & $S / 267,425$ \\
\hline$-2.5 \%$ & S/180,299 & $-2.5 \%$ & $S / 354,075$ & $-2.5 \%$ & $S / 241,846$ \\
\hline $0.0 \%$ & $S / 216,267$ & $0.0 \%$ & $S / 216,267$ & $0.0 \%$ & $S / 216,267$ \\
\hline $2.5 \%$ & $S / 252,234$ & $2.5 \%$ & $S / 78,459$ & $2.5 \%$ & $S / 190,688$ \\
\hline $5.0 \%$ & $S / 288,202$ & $5.0 \%$ & $-S / 59,349$ & $5.0 \%$ & $S / 165,109$ \\
\hline $7.5 \%$ & $S / 324,170$ & $7.5 \%$ & -S/197,156 & $7.5 \%$ & $S / 139,530$ \\
\hline $10.0 \%$ & $S / 360,137$ & $10.0 \%$ & $-S / 334,964$ & $10.0 \%$ & $S / 113,951$ \\
\hline $12.5 \%$ & S/396,105 & $12.5 \%$ & $-S / 472,772$ & $12.5 \%$ & $S / 88,372$ \\
\hline $15.0 \%$ & $S / 432,072$ & $15.0 \%$ & $-S / 610,579$ & $15.0 \%$ & $S / 62,793$ \\
\hline $17.5 \%$ & $S / 468,040$ & $17.5 \%$ & $-S / 748,387$ & $17.5 \%$ & $S / 37,214$ \\
\hline $20.0 \%$ & S/504,007 & $20.0 \%$ & -S/886,195 & $20.0 \%$ & $S / 11,635$ \\
\hline
\end{tabular}

\begin{tabular}{|c|r|}
\hline \multicolumn{2}{|c|}{ GASTO DE VENTAS } \\
\hline $0.0 \%$ & S/ 216,267 \\
\hline$-20.0 \%$ & $S / 473,965$ \\
\hline$-17.5 \%$ & $S / 441,753$ \\
\hline$-15.0 \%$ & $S / 409,541$ \\
\hline$-12.5 \%$ & $S / 377,328$ \\
\hline$-10.0 \%$ & $S / 345,116$ \\
\hline$-7.5 \%$ & $S / 312,904$ \\
\hline$-5.0 \%$ & $S / 280,692$ \\
\hline$-2.5 \%$ & $S / 248,479$ \\
\hline $0.0 \%$ & $S / 216,267$ \\
\hline $2.5 \%$ & $S / 184,055$ \\
\hline $5.0 \%$ & $S / 151,842$ \\
\hline $7.5 \%$ & $S / 119,630$ \\
\hline $10.0 \%$ & $S / 87,418$ \\
\hline $12.5 \%$ & $S / 55,206$ \\
\hline $15.0 \%$ & $S / 22,993$ \\
\hline $17.5 \%$ & $-S / 9,219$ \\
\hline $20.0 \%$ & $-S / 41,431$ \\
\hline
\end{tabular}

\begin{tabular}{|c|r|}
\hline \multicolumn{2}{|c|}{ TASA } \\
\hline $0.0 \%$ & S/ 216,267 \\
\hline$-20.0 \%$ & $S / 306,816$ \\
\hline$-17.5 \%$ & $S / 294,378$ \\
\hline$-15.0 \%$ & $S / 282,282$ \\
\hline$-12.5 \%$ & $S / 270,515$ \\
\hline$-10.0 \%$ & $S / 259,068$ \\
\hline$-7.5 \%$ & $S / 247,929$ \\
\hline$-5.0 \%$ & $S / 237,089$ \\
\hline$-2.5 \%$ & $S / 226,538$ \\
\hline $0.0 \%$ & $S / 216,267$ \\
\hline $2.5 \%$ & $S / 206,267$ \\
\hline $5.0 \%$ & $S / 196,530$ \\
\hline $7.5 \%$ & $S / 187,047$ \\
\hline $10.0 \%$ & $S / 177,810$ \\
\hline $12.5 \%$ & $S / 168,812$ \\
\hline $15.0 \%$ & $S / 160,045$ \\
\hline $17.5 \%$ & $S / 151,502$ \\
\hline $20.0 \%$ & $S / 143,176$ \\
\hline
\end{tabular}

Fuente: Elaboración propia, basado en asesoría Usil

Los resultado nos indican que si los ingresos disminuyen en $17.5 \% \mathrm{o}$ más el VAN llega a ser negativo.

Respecto al costo de ventas, si esta variable se incrementa en 5\% o más, el VAN se haría negativo.

El gasto de administración dentro del rango de $-20 \%$ hasta $+20 \%$ no representa ningún riesgo.

Si el gasto de ventas se incrementa en $17.5 \%$ el van se hace negativo, pero disminuido a $\mathrm{S} /-9,219$ 
A cualquier nivel de análisis dentro del rango propuesto, la variación de la tasa a cualquier nivel es positiva.

\subsubsection{Análisis de escenarios}

El análisis de escenarios nos permite analizar más de una variable simultáneamente, para el caso de proyecto analizaremos dos variables que se identificó previamente.

El Análisis de Ingresos - Costos (ver Tabla 53) y los resultado de dicho análisis estadístico (ver Tabla 55).

El análisis de Ingresos - Gastos (Ver Tabla 54) y los resultado de dicho análisis estadístico (ver Tabla 56). 


\section{Tabla 53}

\section{Análisis de escenarios (Ingreso - Costo de ventas)}

\begin{tabular}{|c|c|c|c|c|c|c|c|c|c|c|c|c|c|c|c|c|c|c|c|c|c|}
\hline $\begin{array}{l}\text { S/ } \\
145,941\end{array}$ & $50 \%$ & $45 \%$ & $40 \%$ & $35 \%$ & $30 \%$ & $25 \%$ & $20 \%$ & $15 \%$ & $10 \%$ & $5 \%$ & $0 \%$ & $-5 \%$ & $-10 \%$ & $-15 \%$ & $-20 \%$ & $-25 \%$ & $-30 \%$ & $-35 \%$ & $-40 \%$ & $-45 \%$ & $0 \%$ \\
\hline $50 \%$ & $-5 / 968,420$ & $-5 / 785,741$ & $-5 / 603,063$ & $-5 / 420,384$ & $-5 / 237,705$ & $-5 / 55,026$ & $s / 127,652$ & $s / 310,331$ & $5 / 493,010$ & $5 / 675,689$ & $\mathrm{~s} / 858,367$ & $\begin{array}{l}s / 1,041,04 \\
6\end{array}$ & $\begin{array}{r}5 / 1,223,72 \\
5\end{array}$ & $\begin{array}{r}5 / 1,406,40 \\
4\end{array}$ & $\begin{array}{r}5 / 1,589,08 \\
2\end{array}$ & $\begin{array}{r}5 / 1,771,76 \\
1\end{array}$ & $\begin{array}{r}5 / 1,954,44 \\
0\end{array}$ & $\begin{array}{r}s / 2,137,11 \\
9\end{array}$ & $\begin{array}{r}5 / 2,319,79 \\
7\end{array}$ & $5 / 2,502,47$ & $\begin{array}{r}S / 2,685,15 \\
5\end{array}$ \\
\hline $45 \%$ & $s / 1,039,663$ & $-5 / 856,984$ & $-5 / 674,305$ & $-5 / 491,627$ & $-5 / 308,948$ & $-5 / 126,269$ & $s / 56,410$ & $s / 239,088$ & $S / 421,767$ & $s / 604,446$ & $s / 787,125$ & $s / 969,803$ & $\begin{array}{r}S / 1,152,48 \\
2\end{array}$ & $\begin{array}{r}5 / 1,335,16 \\
1\end{array}$ & $\begin{array}{c}s / 1,517,84 \\
0\end{array}$ & $\begin{array}{r}5 / 1,700,51 \\
9\end{array}$ & $\begin{array}{r}5 / 1,883,19 \\
7\end{array}$ & $5 / 2,065,87$ & $\begin{array}{r}5 / 2,248,55 \\
5\end{array}$ & $\begin{array}{r}5 / 2,431,23 \\
4\end{array}$ & $s / 2,613,91$ \\
\hline $40 \%$ & $s / 1,110,906$ & $-s / 928,227$ & $-5 / 745,548$ & $-S / 562,869$ & $-5 / 380,191$ & $-S / 197,512$ & $-5 / 14,833$ & $\mathrm{~S} / 167,846$ & $\mathrm{~s} / 350,525$ & $\mathrm{~s} / 533,203$ & $\mathrm{~s} / 715,882$ & $\mathrm{~s} / 898,561$ & $\begin{array}{r}s / 1,081,24 \\
0\end{array}$ & $\begin{array}{r}5 / 1,263,91 \\
8\end{array}$ & $\begin{array}{r}5 / 1,446,59 \\
7\end{array}$ & $\begin{array}{r}5 / 1,629,27 \\
6\end{array}$ & $\begin{array}{r}5 / 1,811,95 \\
5\end{array}$ & $\begin{array}{r}5 / 1,994,63 \\
3\end{array}$ & $\begin{array}{r}s / 2,177,31 \\
2\end{array}$ & $\begin{array}{r}5 / 2,359,99 \\
1\end{array}$ & $\begin{array}{r}s / 2,542,67 \\
0\end{array}$ \\
\hline $35 \%$ & $s / 1,182,148$ & $-5 / 999,469$ & $-s / 816,791$ & $-5 / 634,112$ & $-5 / 451,433$ & $-5 / 268,754$ & $-5 / 86,076$ & $5 / 96,603$ & $s / 279,282$ & $\mathrm{~s} / 461,961$ & $s / 644,639$ & $s / 827,318$ & $\begin{array}{r}S / 1,009,99 \\
7\end{array}$ & $\begin{array}{r}s / 1,192,67 \\
6\end{array}$ & $\begin{array}{r}S / 1,375,35 \\
4\end{array}$ & $\begin{array}{r}S / 1,558,03 \\
3\end{array}$ & $\begin{array}{r}S / 1,740,71 \\
2\end{array}$ & $\begin{array}{r}\mathrm{s} / 1,923,39 \\
1\end{array}$ & $\begin{array}{r}S / 2,106,06 \\
9\end{array}$ & $\begin{array}{r}S / 2,288,74 \\
8\end{array}$ & $\begin{array}{r}S / 2,471,42 \\
7\end{array}$ \\
\hline $30 \%$ & $s / 1,253,391$ & $s / 1,070,712$ & $-5 / 888,033$ & $-5 / 705,355$ & $-5 / 522,676$ & $-5 / 339,997$ & $-s / 157,318$ & $5 / 25,360$ & $\mathrm{~s} / 208,039$ & $S / 390,718$ & $\mathrm{~S} / 573,397$ & $S / 756,075$ & $\mathrm{~s} / 938,754$ & $\begin{array}{r}5 / 1,121,43 \\
3\end{array}$ & $\begin{array}{r}5 / 1,304,11 \\
2\end{array}$ & $\begin{array}{r}s / 1,486,79 \\
0\end{array}$ & $\begin{array}{r}5 / 1,669,46 \\
9\end{array}$ & $\begin{array}{r}5 / 1,852,14 \\
8\end{array}$ & $\begin{array}{r}s / 2,034,82 \\
7\end{array}$ & $\begin{array}{r}S / 2,217,50 \\
5\end{array}$ & $\begin{array}{r}S / 2,400,18 \\
4\end{array}$ \\
\hline $25 \%$ & $s / 1,324,634$ & $s / 1,141,955$ & $-s / 959,276$ & $-5 / 776,597$ & $-5 / 593,919$ & $-5 / 411,240$ & $-5 / 228,561$ & $-5 / 45,882$ & $\mathrm{~S} / 136,796$ & $\mathrm{~S} / 319,475$ & $\mathrm{~S} / 502,154$ & $5 / 684,833$ & $\mathrm{~s} / 867,512$ & $\begin{array}{r}s / 1,050,19 \\
0\end{array}$ & $\begin{array}{r}5 / 1,232,86 \\
9\end{array}$ & $\begin{array}{r}5 / 1,415,54 \\
8\end{array}$ & $\begin{array}{r}5 / 1,598,22 \\
7\end{array}$ & $\begin{array}{r}s / 1,780,90 \\
5\end{array}$ & $\begin{array}{r}5 / 1,963,58 \\
4\end{array}$ & $\begin{array}{r}5 / 2,146,26 \\
3\end{array}$ & $\begin{array}{r}s / 2,328,94 \\
2\end{array}$ \\
\hline $20 \%$ & $s / 1,395,876$ & $s / 1,213,197$ & $s / 1,030,519$ & $-5 / 847,840$ & $-s / 665,161$ & $-5 / 482,482$ & $-5 / 299,804$ & $-s / 117,125$ & $\mathrm{~s} / 65,554$ & $\mathrm{~S} / 248,233$ & $\mathrm{~S} / 430,911$ & $s / 613,590$ & S/796,269 & $\mathrm{s} / 978,948$ & $\begin{array}{r}S / 1,161,62 \\
6\end{array}$ & $\begin{array}{r}s / 1,344,30 \\
5\end{array}$ & $\begin{array}{r}S / 1,526,98 \\
4\end{array}$ & $\begin{array}{r}S / 1,709,66 \\
3\end{array}$ & $\begin{array}{r}S / 1,892,34 \\
1\end{array}$ & $\begin{array}{r}s / 2,075,02 \\
0\end{array}$ & $\begin{array}{r}s / 2,257,69 \\
9\end{array}$ \\
\hline $15 \%$ & $s / 1,467,119$ & $s / 1,284,4$ & $s / 1,101,7$ & $-5 / 919,083$ & $-5 / 736,404$ & -5/553,725 & 371,04 & $-s / 188,36$ & $-5 / 5,68$ & $s / 176,99$ & 359,6 & $s / 542,34$ & 725,026 & $5 / 907,705$ & $\begin{array}{r}5 / 1,090,38 \\
4\end{array}$ & $\begin{array}{r}5 / 1,273,06 \\
2\end{array}$ & $\begin{array}{r}S / 1,455,74 \\
1\end{array}$ & $\begin{array}{r}s / 1,638,42 \\
0\end{array}$ & $\begin{array}{r}5 / 1,821,09 \\
9\end{array}$ & $\begin{array}{r}5 / 2,003,77 \\
7\end{array}$ & $\begin{array}{r}S / 2,186,45 \\
6\end{array}$ \\
\hline $10 \%$ & $s / 1,538,362$ & $s / 1,355,683$ & $s / 1,173,004$ & $-s / 990,325$ & -5/807,647 & $-5 / 624,968$ & $-5 / 442,289$ & $-s / 259,610$ & $-5 / 76,932$ & $s / 105,747$ & $\mathrm{~S} / 288,426$ & $s / 471,105$ & $\mathrm{~s} / 653,783$ & $\mathrm{~s} / 836,462$ & $\begin{array}{r}S / 1,019,14 \\
1\end{array}$ & $\begin{array}{r}S / 1,201,82 \\
0\end{array}$ & $\begin{array}{r}S / 1,384,49 \\
9\end{array}$ & $\begin{array}{r}5 / 1,567,17 \\
7\end{array}$ & $\begin{array}{r}5 / 1,749,85 \\
6\end{array}$ & $\begin{array}{r}s / 1,932,53 \\
5\end{array}$ & $\begin{array}{l}S / 2,15,21 \\
4\end{array}$ \\
\hline $5 \%$ & $s / 1,609,604$ & $s / 1,426,926$ & $s / 1,244,247$ & $\mathrm{~s} / 1,061,568$ & $-5 / 878,889$ & $-s / 696,210$ & $-s / 513,532$ & $-5 / 330,853$ & S/148, & $\mathrm{s} / 34,505$ & 217,183 & $\mathrm{~s} / 399,862$ & $\mathrm{~S} / 582,541$ & $\mathrm{~s} / 765,220$ & $\mathrm{~S} / 947,898$ & $\begin{array}{r}s / 1,130,57 \\
7\end{array}$ & $\begin{array}{r}5 / 1,313,25 \\
6\end{array}$ & $\begin{array}{r}S / 1,495,93 \\
5\end{array}$ & $\begin{array}{r}5 / 1,678,61 \\
3\end{array}$ & $\begin{array}{r}5 / 1,861,29 \\
2\end{array}$ & $\begin{array}{r}s / 2,043,97 \\
1\end{array}$ \\
\hline $0 \%$ & $s / 1,680,847$ & $5 / 1,498,1$ & $s / 1,315,4$ & 132, & $-5 / 950,1$ & 767,4 & 884, & (402, & $s / 219$ & /36,738 & $\mathrm{s} / 145,941$ & 328,6 & 511,298 & $s / 693,977$ & $\mathrm{~s} / 876,656$ & $\begin{array}{r}5 / 1,059,33 \\
4\end{array}$ & $\begin{array}{r}5 /, 242,01 \\
{ }_{3}\end{array}$ & $\begin{array}{r}s / 1,424,69 \\
2\end{array}$ & $\begin{array}{r}5 / 1,607,37 \\
1\end{array}$ & $\begin{array}{r}5 / 1,790,04 \\
9\end{array}$ & $\begin{array}{r}5 / 1,972,72 \\
8\end{array}$ \\
\hline$-5 \%$ & $s / 1,752,090$ & $s / 1,569,411$ & $s / 1,386,732$ & $s / 1,204,053$ & $\mathrm{~s} / 1,021,375$ & $-5 / 838,6$ & 656,0 & $-5 / 473,3$ & $\mathrm{~s} / 290,660$ & $\mathrm{~S} / 107,981$ & $\mathrm{~s} / 74, \mathrm{G}$ & $\mathrm{S} / 257,377$ & /440,055 & 222, & $\mathrm{s} / 805,413$ & $\mathrm{~S} / 988,092$ & $\begin{array}{r}s / 1,170,77 \\
0\end{array}$ & $\begin{array}{r}S / 1,353,44 \\
9\end{array}$ & $\begin{array}{r}5 / 1,536,12 \\
8\end{array}$ & $\begin{array}{r}S / 1,718,80 \\
7\end{array}$ & $\begin{array}{r}S / 1,901,48 \\
6\end{array}$ \\
\hline$-10 \%$ & $\mathrm{~s} / 1,823,332$ & $s / 1,640,654$ & $\mathrm{~s} / 1,457,975$ & $s / 1,275,296$ & $s / 1,092,617$ & $-5 / 909,9=$ & $-5 / 727,2$ & $-5 / 544,5$ & $\mathrm{~s} / 361,902$ & $\mathrm{~S} / 179,223$ & $5 / 3,4$ & S/186,1 & $\mathrm{s} / 368,813$ & 5/551,492 & $\mathrm{s} / 734,170$ & $S / 916,849$ & $\begin{array}{r}5 / 1,099,52 \\
8\end{array}$ & $\begin{array}{r}5 / 1,282,20 \\
7\end{array}$ & $\begin{array}{r}S / 1,464,88 \\
5\end{array}$ & $\begin{array}{r}S / 1,647,56 \\
4\end{array}$ & $\begin{array}{r}S / 1,830,24 \\
3\end{array}$ \\
\hline$-15 \%$ & $\mathrm{~s} / 1,894,575$ & $s / 1,711,896$ & $s / 1,529,217$ & 346,539 & $163, \varepsilon$ & 881,1 & 998,5 & 615,8 & $s / 433,1$ & s/t & $-5 / 67$ & $S / 114, \varepsilon$ & 570 & & 28 & $\mathrm{~S} / 845,606$ & $\begin{array}{r}5 / 1,028,28 \\
5\end{array}$ & $s / 1,210,96$ & $\begin{array}{r}5 / 1,393,64 \\
3\end{array}$ & $\begin{array}{r}5 / 1,576,32 \\
1\end{array}$ & $\begin{array}{r}S / 1,759,00 \\
0\end{array}$ \\
\hline $20 \%$ & $\mathrm{~s} / 1,965,818$ & $s / 1,783,139$ & $s / 1,600,460$ & $s / 1,417,781$ & $s / 1,235,103$ & $s / 1,052,424$ & 1869,7 & $-5 / 687$, & $\mathrm{S} / 504,388$ & $\mathrm{~s} / 321,709$ & $\mathrm{~s} / 139,030$ & /43,649 & $\mathrm{s} / 226,327$ & $5 / 409,006$ & S/591,685 & $s / 77$ & $5 / 957,042$ & $\begin{array}{r}S / 1,139,72 \\
1\end{array}$ & $\begin{array}{r}S / 1,322,40 \\
0\end{array}$ & $\begin{array}{r}S / 1,505,07 \\
9\end{array}$ & $\begin{array}{r}S / 1,687,75 \\
7\end{array}$ \\
\hline$-25 \%$ & $s / 2,037,060$ & $\mathrm{~s} / 1,854,382$ & $S / 1,671,703$ & $S / 1,489,024$ & $S / 1,306,345$ & $s / 1,123,667$ & 994,9 & $-5 / 758,3$ & $S / 575,630$ & $\mathrm{~S} / 392,952$ & $\mathrm{~s} / 210,273$ & $-5 / 27,5$ & $\mathrm{~s} / 155,085$ & $5 / 33$ & $5 / 520,442$ & $\mathrm{~s} / 703,121$ & $5 / 885,800$ & $\begin{array}{r}s / 1,068,47 \\
g\end{array}$ & $\begin{array}{r}s / 1,251,15 \\
7\end{array}$ & $\begin{array}{r}.83 \\
6\end{array}$ & $\begin{array}{l}1,616,51 \\
5\end{array}$ \\
\hline$-30 \%$ & $s / 2,108,303$ & $s / 1,925,624$ & $s / 1,742,946$ & $s / 1,560,267$ & $s / 1,377,588$ & $s / 1,194,909$ & $s / 1,012,230$ & $-5 / 829,552$ & $S / 646,873$ & $\mathrm{~s} / 464,194$ & $\mathrm{~s} / 281,515$ & $-5 / 98,837$ & $\mathrm{~S} / 83,842$ & $\mathrm{~s} / 266,521$ & $\mathrm{~s} / 449,200$ & $\mathrm{~S} / 631,878$ & $\mathrm{~s} / 814,557$ & $\mathrm{~s} / 997,236$ & $\begin{array}{r}S / 1,179,91 \\
5\end{array}$ & $\begin{array}{r}S / 1,362,59 \\
3\end{array}$ & $\begin{array}{r}S / 1,545,27 \\
2\end{array}$ \\
\hline$-35 \%$ & $s / 2,179,546$ & $s / 1,996,867$ & $\mathrm{~s} / 1,814,188$ & $s / 1,631,509$ & $5 / 1,448,831$ & $s / 1,266,152$ & $s / 1,083,473$ & $-5 / 900,794$ & $\mathrm{~s} / 718,116$ & $\mathrm{~S} / 535,437$ & $\mathrm{~s} / 352,758$ & $-5 / 170,079$ & $\mathrm{~s} / 12,599$ & $\mathrm{~s} / 195,278$ & $s / 377,957$ & 636 & 314 & $s / 925,993$ & $\begin{array}{r}s / 1,108,67 \\
2\end{array}$ & $\begin{array}{r}5 / 1,291,35 \\
1\end{array}$ & , \\
\hline$-40 \%$ & $s / 2,250,788$ & $s / 2,068,110$ & $s / 1,885,431$ & $s / 1,702,752$ & $s / 1,520,073$ & $s / 1,337,395$ & $\mathrm{~s} / 1,154,716$ & $-5 / 972,037$ & $s / 789,3$ & $s / 606,680$ & 124,001 & $-5 / 241,322$ & $-5 / 58,643$ & $\mathrm{~s} / 124,035$ & $5 / 306,714$ & $s / 489,393$ & $5 / 672,072$ & $s / 854,750$ & $\begin{array}{r}5 / 1,037,42 \\
9\end{array}$ & $\begin{array}{r}5 / 1,220,10 \\
8\end{array}$ & $\begin{array}{l}1,402,78 \\
7\end{array}$ \\
\hline$-45 \%$ & $s / 2,322,031$ & $s / 2,139,352$ & $S / 1,956,674$ & 1,773,995 & $5 / 1,591,316$ & $5 / 1,408,637$ & $s / 1,225,959$ & $S / 1,043,280$ & S/860,601 & S/677,922 & $5 / 495,243$ & $-5 / 312$, & $-s / 1$ & & 72 & 150 & 329 & 508 & $S / 966,187$ & $\begin{array}{r}86 \\
5\end{array}$ & ${ }_{4}^{54}$ \\
\hline$-50 \%$ & $\mathrm{~S} / 2,393,274$ & 10,595 & , , & 5,237 & 2,559 & 9,880 & (77,201 & 14,522 & 9931,844 & 49,165 & 1566,486 & $-5 / 383,807$ & $-s / 201,129$ & $-s / 18,450$ & $\mathrm{~s} / 164,229$ & $\mathrm{~s} / 346,908$ & $\mathrm{~s} / 529,586$ & $s / 712,265$ & $\mathrm{~S} / 894,944$ & $\begin{array}{r}5 / 1,077,62 \\
3\end{array}$ & $\begin{array}{r}S / 1,260,30 \\
1\end{array}$ \\
\hline
\end{tabular}




\section{Tabla 54}

Análisis de escenarios (Ingreso - Gasto de ventas)

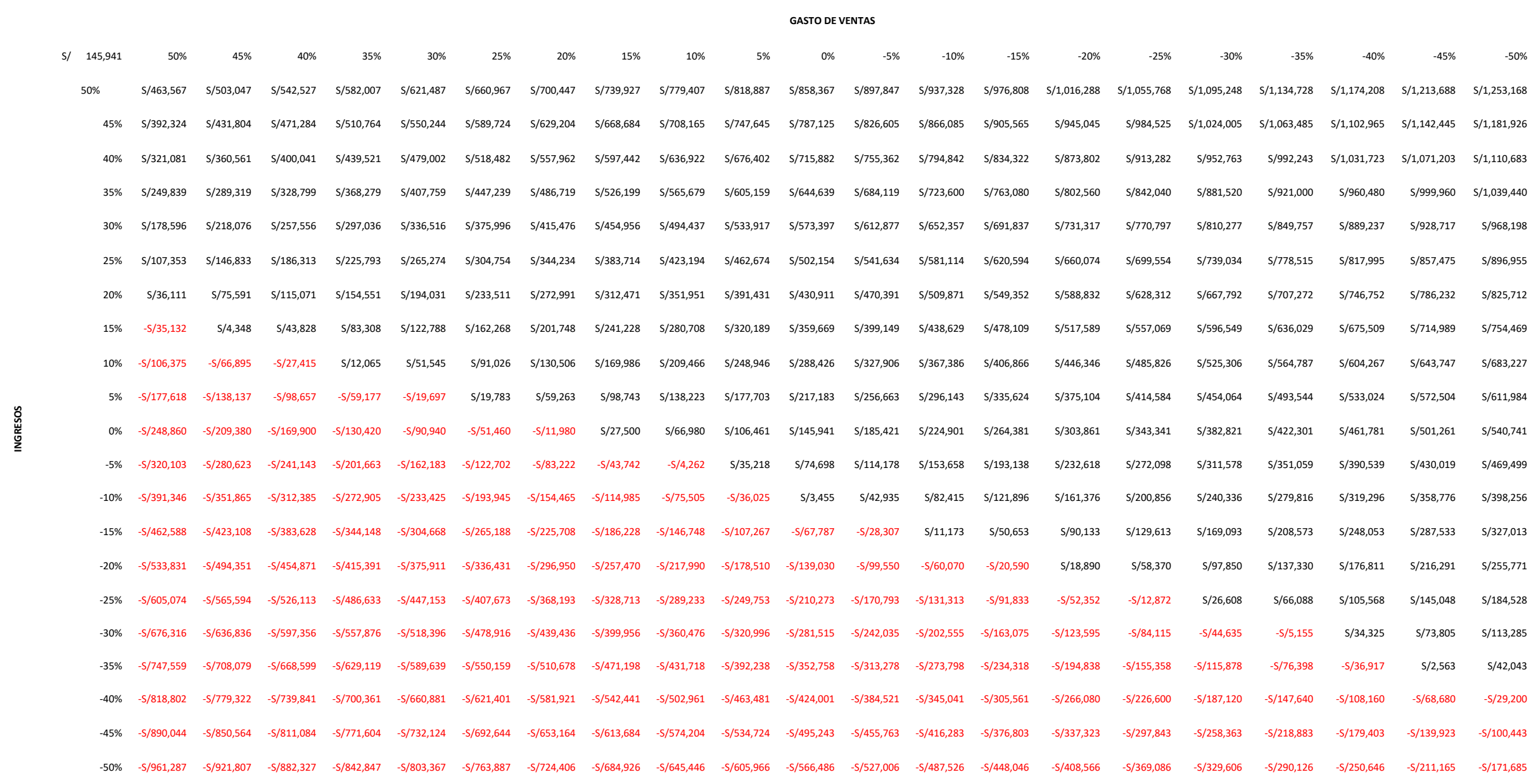




\section{Tabla 55}

Resultado de análisis de escenarios (Ingresos - Costo de ventas)

\begin{tabular}{llr}
\hline \multicolumn{3}{c}{ Ingreso - Costo de ventas } \\
\hline Eventos & 441 & \\
VAN + & 288 & $56.2 \%$ \\
VAN - & 193 & $43.8 \%$ \\
\hline
\end{tabular}

El resultado del análisis de escenario considerando las dos variables más críticos encontrado en el análisis individual (Ingresos y Costo de Ventas), nos muestra estadísticamente que analizados 441 eventos, que la probabilidad que el proyecto tenga éxito es $56.2 \%$ y $43.8 \%$ que sea un fracaso.

\section{Tabla 56}

Resultado de análisis de escenarios (Ingresos - Gasto de ventas)

\begin{tabular}{llr}
\hline \multicolumn{3}{c}{ Ingreso - Gasto de ventas } \\
\hline Eventos & 441 & \\
VAN + & 284 & $64.4 \%$ \\
VAN - & 157 & $35.6 \%$ \\
\hline
\end{tabular}

En el análisis de escenario considerando las variables Ingresos y Gasto de Ventas, nos muestra estadísticamente que analizados 441 eventos, la probabilidad que el proyecto tenga éxito es $64.4 \%$ y $35.6 \%$ que sea un fracaso. 


\section{CAPÍTULO XI}

\section{Conclusiones y recomendaciones}

A continuación se detallaremos las conclusiones y recomendaciones a las que se ha llegado en esta investigación.

\subsection{Conclusiones.}

a. La industria del comercio de software se encuentra en la etapa de crecimiento, impulsado por la transformación digital, necesidad obligada para cualquier organización competitiva.

b. La tendencia va hacia una nueva forma de comercialización las que será en modalidad de servicios, cuyos cobros serán por tiempo, es decir de manera anual, luego semestral, mensual y finalmente en un largo plazo se hará por minutos, lo que significa que algunos serán atendidos directamente por el fabricante, pero para los software especializados como el del proyecto aún serán necesario los distribuidores autorizados.

c. El comercio de sistemas informáticos basados en mapas (geolocalización) tiene un gran porvenir, ya que la tendencia es vincularse con las tecnologías de BIG Data e Inteligencia Artificial. 
d. El comercio de sistemas CAD y GIS es especializado y requiere de personal calificado para satisfacer plenamente las necesidades del cliente final, por lo que este factor es crítico.

e. De acuerdo con la investigación de mercado, existe mercado insatisfecho identificado que necesita ser atendido y con deseos de cambiar de proveedor que cuente con personal calificado y atención presencial, por lo que las estrategias propuestas están orientadas a estas actividades que es de gran valor para el cliente.

f. En cuanto a los requerimientos técnicos y organizacionales, se formalizará una personería jurídica y tramitar los permisos correspondientes para el funcionamiento y pago de tributos correspondiente (Sunarp, Municipalidad y Sunat), cuya oficina para su operación estará ubicado en el distrito de San Isidro. La organización debe estar compuesto por un administrador, asistente administrativo, consultor, ejecutivo comercial y responsable de sistema.

g. La inversión para la ejecución del proyecto se estima en S/ 289,234 que se encuentran comprendidas en activos fijo, pre operativos y capital de trabajo, estimando una inversión futura de S/ 32,301 para renovación de equipos informáticos al tercer año, todas con capital propio.

h. La rentabilidad determinada del proyecto otorga una TIR $37.08 \%$ y un riesgo de $35.6 \%$ y $43.8 \%$ que comprende a los factores de Costo de ventas y gastos de ventas respectivamente. 
i. El comercio de software es un mercado de alto riesgo, pero de gran oportunidad.

\subsection{Recomendaciones.}

a. Para reducir el riesgo se recomienda incrementar la oferta de servicios como la capacitación a nivel avanzado o consultorías para temas específicos, cuyo precio de venta promedio es de \$75 la hora y su respectivo costo máximo \$35 la hora.

b. Para hacer más rentable se debe atender una mayor cantidad de sectores, que trabajan con componente geográfico, como entidades públicas, comercio de productos y todos que gestionan territorios, con el que se podrá colocar una mayor cantidad de licencias.

c. Mantener en constante actualización a los colaboradores, ya que es un sector que convive con los cambios constantes. La organización debe tener como cultura facilidad al cambio constante.

d. Hacer parte del accionariado a colaboradores comprometidos que sean proactivos, busquen desafíos y aptitud para el cambio constante. 
ANEXOS 
Anexo 1

Propuesta para Distribuidores de ZwSoft

\section{Propuesta Comercial para Distribuidores}

En el Primer año, zWSOFT colaborará con el Distribuidor bajo del contrato del Distribuidor Autorizado de ZWCAD.

A. Estructura de precios recomendables para Distribuidor Autorizado de ZWCAD

Los precios al cliente final sugeridos (SRP) son:

ZWCAD2018 Professional: US\$999

En el primer año, ofrecemos el 50\% de margen para nuestro Distribuidor autorizado, es decir, los precios para el Distribuidor son

ZWCAD2018 Professional: us\$500

B. Proyección de ventas:

Se exige a nuestro Distribuidor que tenga metas de ventas mínimas trimestrales y anuales. Generalmente, en el primer año de colaboración, nuestra meta requerida de ventas minimas anuales desde ZWSOFT es la cantidad de 40 licencias nuevas.

(Para ser más adecuada este meta, nuestro nuevo Distribuidor puede proporcionarnos un volumen racional anual y trimestral según su inversión en el primer año de colaboración y situación actual)

C. Derechos que tiene el Distribuidor Autorizado de ZWCAD:

$\checkmark$ El certificado de Distribuidor Autorizado de ZWCAD.

$\checkmark$ colocamos la información de su empresa en la lista de parters en nuestra página web oficial.

$\checkmark$ Proporcionamos al Distribuidor una cierta cantidad de oportunidades de ventas generadas por nuestro marketing global.

$\checkmark$ ofrecemos el apoyo técnico, comercial, de mercadeo y todas las capacitaciones al respecto a nuestro Distribuidor.

D. Requerimientos desde parte de ZWSOFT:

1) Un grupo enfocado en las ventas de ZWCAD.

2) Cuota requerida de entrada de US\$5000. El nuevo Distribuidor tendría que realizar la transferencia de este monto dentro de 10 dias después de firmar el contrato oficial.

3) Asegurar la Inversión básica del mercadeo local sobre la marca ZWCAD.

4) Cumple con las políticas de canales de ZWCAD para proteger la buena marca y el precio adecuado a los usuarios finales de ZWCAD en el mercado local. 
Anexo 2

Propuesta para Distribuidores de Pitney Bowes Software

\section{EXHIBIT 1}

\section{A. $\quad \underline{T e r r i t o r y}$}

Peru, Ecuador, Colombia and Central America.

B. Software

\begin{tabular}{|c|c|}
\hline Licensed Materials* & $\begin{array}{c}\text { Type of } \\
\text { Operating System }\end{array}$ \\
\hline $\begin{array}{l}\text { Location Intelligence Portfolio: } \\
\text { MapInfo Professional } \\
\text { MapXtreme .NET } \\
\text { MapXtreme Java } \\
\text { Discover } \\
\text { Data Quality } \\
\text { Spectrum } \\
\text { LI Solutions in general }\end{array}$ & All available \\
\hline
\end{tabular}

\section{Fees}

\begin{tabular}{|l|c|}
\hline \multicolumn{1}{|c|}{ Licensed Materials* } & \multicolumn{1}{|c|}{ Fees } \\
\hline Location Intelligence Portfolio: & \\
$\begin{array}{l}\text { MapInfo Professional } \\
\text { MapXtreme.NET } \\
\text { MapXtreme Java } \\
\text { Discover } \\
\text { Data Quality } \\
\text { Spectrum } \\
\text { Li Solutions in general }\end{array}$ & $\begin{array}{c}\text { New licenses 40\% } \\
\text { Maintenance discount 20\% } \\
\text { Upgrades 20\% }\end{array}$ \\
\hline
\end{tabular}

\begin{tabular}{|c|c|c|c|c|}
\hline & \multicolumn{3}{|c|}{ Part Code(s) } & \multirow{2}{*}{ Standard Retail Price } \\
\hline & MI Pro & MATS & BING & \\
\hline Standard & $\begin{array}{c}\text { 1MINPGLWN1600N } \\
\$ \mathbf{1}, \mathbf{6 5 0}\end{array}$ & $\begin{array}{c}\text { 6MIAPGLWNMATSM } \\
\$ 495\end{array}$ & & $\$ 2,145$ \\
\hline
\end{tabular}




\section{Anexo 3}

\section{Guía de Preguntas para expertos en sistemas CAD y GIS}

\section{Objetivo de la entrevista:}

Conocer las necesidades, problemas específicos, orientación de la industria, valor y motivaciones para el uso de software CAD y GIS.

Sr. ............., con su permiso, estamos iniciando la grabación en audio de esta entrevista que usted nos va conceder, el cual agradecemos infinitamente ya que entendemos lo valioso de su tiempo.

Soy..........., estudiante de la Maestría en Administración de Negocios de la Universidad San Ignacio de Loyola. Como le mencioné al momento de concertar esta reunión, estamos realizando una investigación para un trabajo académico, respecto a la comercialización, usos y beneficios de software para Ingeniería, medioambiente y sistemas de información geográfica, por lo que su retroalimentación será de mucha importancia.

\section{Sobre perfil profesional del experto:}

¿Solicitar un resumen profesional, el tiempo y cargo que desempeña en su empresa?

\section{Sobre la empresa:}

¿Cuál es la actividad principal de su empresa?

\section{Sobre los sistemas y soluciones CAD y GIS:}

¿Qué son sistemas CAD y GIS?

¿Cuál o cuáles son sus principales usos y aplicaciones? 
¿Qué compañías desarrollan estas tecnologías?

¿Cuál es la tendencia de la tecnología CAD y GIS?

\section{Sobre el mercado de soluciones CAD y GIS:}

¿Qué tipo de organizaciones usan sistemas CAD y GIS?

¿Cómo se encuentra el mercado de sistemas CAD y GIS?

¿Qué marca o marcas de software CAD y GIS son los más usados en el Perú?

¿Cuál es el nivel de uso de software o sistemas CAD y GIS en el Perú?

¿Cómo ha variado la demanda por servicios y productos CAD y GIS en el Perú?

¿Qué sectores potenciales existen sin ser atendidos con soluciones CAD y GIS?

¿Qué tipo de usuarios comprenden rápidamente la utilidad de sistemas CAD y GIS?

¿Qué tipo de usuarios son reacios en comprender la utilidad de sistemas CAD y GIS?

\section{Sobre expertos en sistemas CAD y GIS:}

¿Cómo se encuentra el mercado de expertos o consultores en sistemas CAD y GIS?

¿Cuánto es el ingreso (sueldo u honorarios) mensual a un experto CAD y GIS?

¿Qué competencias se requiere para ser un experto en CAD y GIS? 


\section{Anexo 4}

\section{Guía de Preguntas para Gerente de Sistemas y Usuarios}

\section{Objetivo de la entrevista:}

Conocer el nivel tecnológico, necesidades o problemas específicos de la industria, importancia, valor y motivaciones para la compra de software.

Sr............., con su permiso, estamos iniciando la grabación en audio de esta entrevista que usted nos va conceder, el cual agradecemos infinitamente ya que entendemos lo valioso de su tiempo.

Buen día, soy..........., estudiante de la Maestría en Administración de Negocios de la Universidad San Ignacio de Loyola. Como le mencioné al momento de concertar esta reunión, estamos realizando una investigación respecto al usos de software para un trabajo académico, por lo que su retroalimentación será de mucha importancia y para dejar constancia esta entrevista está siendo gravado en audio.

\section{Sobre perfil profesional:}

¿Con todo respeto, puede realizar un resumen profesional de usted, el tiempo y cargo que desempeña en esta empresa?

\section{Sobre la empresa:}

¿Cuál es la actividad principal de su empresa?

¿Cuántos colaboradores tiene su empresa en cada área?

¿Cuál es el nivel tecnológico de su empresa?

¿Existe apertura a múltiples tecnologías? 


\section{Sobre el uso de software:}

¿Qué es lo que más valoran para la inversión en software?

¿Cómo organización tienen política para el uso de software?

¿En esa política se contempla el pago anual para mantenimiento y soporte? (Si tiene el anterior)

¿Cuánto invierten en tecnología de información anualmente?

¿Qué porcentaje de lo mencionado es destinado a software?

¿Qué tipo de software utilizan en su organización?

¿Utilizan algún software CAD o GIS? (Si no es mencionado en la respuesta anterior)

¿Cuántas licencias de software CAD o GIS tienen en su empresa?

¿Conoce otras marcas (desarrolladores) de software CAD y GIS?

¿Cuáles son las razones que determinaron la compra de software CAD y GIS?

¿Cuál sería el aspecto o razón más importante para cambiar de marca de software?

¿Cuál es el proceso para decidir la inversión en software?

¿Quién o quienes deciden la inversión en software?

\section{Sobre proveedores de software:}

¿Quién o quiénes son sus principales proveedores de software?

¿Cómo calificaría el servicio de su o sus principales proveedores de software?

¿Se encuentra satisfecho con el nivel de atención de su proveedor de software?

¿Qué aspectos debe mejorar sus proveedoras de software? 


\section{Anexo 5}

\section{Guía de Preguntas para ejecutivos de distribuidores de software}

\section{Objetivo de la entrevista:}

Conocer las necesidades, problemas específicos, orientación de la industria, valor otorgado por proveedores y motivaciones para el comercio de software.

Sr. , con su permiso, estamos iniciando la grabación en audio de esta entrevista que usted nos va conceder, el cual agradecemos infinitamente ya que entendemos lo valioso de su tiempo.

Buen día, soy............, estudiante de la Maestría en Administración de Negocios de la Universidad San Ignacio de Loyola. Como le mencioné al momento de concertar esta reunión, estamos realizando una investigación respecto al usos de software para un trabajo académico, por lo que su retroalimentación será de mucha importancia y para dejar constancia esta entrevista está siendo gravado en audio.

\section{Sobre perfil profesional:}

¿Con todo respeto, puede realizar un resumen profesional de usted, el tiempo y cargo que desempeña en esta empresa?

\section{Sobre la empresa:}

¿Cuál es la actividad principal de su empresa?

¿Cuántos colaboradores tienen en cada área?

¿Cuál es el área o región de atención de su empresa? 
¿Cuánto es su facturación anual de su empresa?

¿Cuánto es su facturación en software CAD y GIS?

¿Cuál es la forma de remuneración a sus vendedores?

¿Qué costos o gastos críticos se debe considerar en el comercio de software CAD y GIS?

\section{Sobre sus proveedores de software:}

¿Existe alguna restricción para la comercialización de software?

¿Quiénes son sus proveedores de software?

¿A cuántas marcas de software representa su empresa?

¿Tiene algún contrato de representación exclusivo de alguna marca?

¿Qué porcentaje de descuento les otorgan sus proveedores de software?

\section{Sobre sus clientes y uso de software:}

¿Quiénes son sus principales clientes de software?

¿Qué tipos de software tiene mayor demanda?

¿Qué tipos de empresa (clientes) invierte más en software CAD y GIS?

¿Qué porcentaje de sus clientes pagan los mantenimientos de sus licencias de software?

\section{Sobre competidores (otros proveedores de software):}

¿Quién o quiénes son sus principales competidores de software?

¿Quién o quiénes son sus principales competidores de software CAD y GIS?

¿Cuál o cuáles son sus ventajas competitivas de sus competidores?

¿Cuál o cuáles son sus debilidades de sus competidores?

¿Sabe cuánto facturan anualmente sus principales competidores? 
Sobre tendencia de software:

¿Cuál es la tendencia de la industria de software?

¿Cuál es la tendencia del comercio de software?

¿Qué aspectos considera usted que valora sus clientes CAD y GIS? 


\section{Anexo 6 \\ Transcripción de entrevista en profundidad a Dr. Marino Carhuapoma \\ Expertos en sistemas CAD y GIS}

Entrevistador: Sr. Carhuapoma, con su permiso, estamos iniciando la grabación en audio de esta entrevista que usted nos va conceder, el cual agradecemos infinitamente ya que entendemos lo valioso de su tiempo.

Soy Hilber Quintana, estudiante de la Maestría en Administración de Negocios de la Universidad San Ignacio de Loyola. Como le mencioné al momento de concertar esta reunión, estamos realizando una investigación para un trabajo académico, respecto a la comercialización, usos y beneficios de software para Ingeniería, medioambiente y sistemas de información geográfica; por lo que su retroalimentación será de mucha importancia.

Con todo respeto, agradeceremos realizar un resumen de su perfil profesional, el tiempo y cargo que desempeña en esta empresa.

Entrevistado: Muy bien Hilber, muchas gracias por la consideración con todo gusto podré atenderlo. En cuanto a mi resumen profesional, está basado en desarrollo de soluciones en tecnologías de información geográficas, ya mi información de maestría y de doctorado también fue en tecnología de información geográfica.

Entrevistador: hum

Entrevistado: Y mis trabajos actuales son de asesor en el Ministerio de Energía y Minas, he trabajado también para empresas privadas haciendo consultorías en sistemas de 
información geográfica. Mi experiencia... Estamos hablando de al menos diez años en soluciones específicas de tecnologías de información geográfica.

\section{Entrevistador: Ok.}

Entrevistado: Si bien usted me estaba comentando de soluciones CAD y GIS (no eh). Mi experiencia especifica seria en GIS más que en CAD ¿no? Pero de todas maneras voy intentar, también eh...

Entrevistador: En la medida que...

Entrevistado: Si, en la medida que puedo responder algunas preguntas de $\mathrm{CAD}$, lo cual no es mi especialidad.

Entrevistador: Ok... ¿Cuál es la actividad principal de su empresa? Entrevistado: Bien, mi consultoría es eh... actual, quizá el más importante es en cuanto a la formalización de minería informal ¿no? en el Perú para el Ministerio de Energía y Minas. Entrevistador: ¿En esta actividad emplean bastante lo que es el sistema CAD o GIS u otros productos?

Entrevistado: Si. Específicamente estamos......estamos empleando digamos masivamente el uso de tecnologías de información geográfica. Desde tener aplicaciones de georeferenciación para actividades mineras (de estos mineros) para poder hacer estrategias de intervención basados en conglomerados, basados en densidades geográficas de los mineros mismos geo localizados.

Entrevistador: Ok. Entonces para entender un poquito mejor, para tener más claro eh... por favor ¿Puede decirnos? ¿Qué son sistemas CAD o soluciones o software CAD y GIS?

Entrevistado: Bien eh... los sistemas CAD y GIS están relacionados a sistemas gráficos, sistemas que están relacionados con mapas ¿no? con información geo referenciada o se podría decir ubicada geográficamente. 


\section{Entrevistador: ;Ya!}

Entrevistado: Entonces... los GIS y los CAD permiten relacionar también esta información gráfica geo referenciada con una base de datos relacional, que finalmente se puede transformar en una gran oportunidad para explotar información.

Entrevistador: Ok. o sea ¿Cuál o cuáles son sus principales usos de estas aplicaciones o soluciones?

Entrevistado: Eh... como le decía el principal aporte de los sistemas gráficos es la relación que hacen entre la información gráfica en si espacial y la información alfanumérica o base de datos. Y de la relación de ambos se puede obtener mayor información para tomar decisiones. Como le comentaba en este caso sobre el conglomerado por ejemplo.

\section{Entrevistador: Ya.}

Entrevistado: Nosotros tomamos decisiones de estrategias de intervención. Ya no como antes se hacía por ejemplo: por distritos, por provincias que son ubicaciones geográficas, pero son administrativas. Pero con los conglomerados la idea ya no es simplemente administrativo sino geográfico, porque podría estar en varios distritos o uno solo pero sabemos en qué zona geográfica están los mineros, agrupados con densidad espacial.

Entrevistador: Uhm ya, ya, ya. ¿Eso también permite hacer la tecnología CAD, o solamente la tecnología GIS?

Entrevistado: Eh... específicamente lo que estoy comentando sólo haría la tecnología GIS.

\section{Entrevistador: Ya.}

Entrevistado: Si bien, la tecnología CAD serviría para poder eh... como un soporte ¿no? para generar cartografía base. Podría servir también para poder ya hacer por ejemplo, ya información más de detalle, por ejemplo estoy hablando yo de actividades mineras. Pero dentro de las actividades ya hay pues bocaminas, hay galerías ¿no? Ya dentro de las 
actividades... Ese detalle quizás ya se puede usar el CAD. Justamente el CAD es eso ¿no?, dibujo asistido por computador, entonces que necesita detalles, que necesita muchas funciones de dibujo.

Entrevistador: Perfecto. Y estas tecnologías, estos software. ¿Qué compañías lo desarrollan? ¿Son empresas locales o empresas extranjeras? En todo caso las principales (compañías) que desarrollan estas tecnologías.

Entrevistado: Claro, siempre diferenciando los CAD y GIS Eh... ¿No? Porque no hay, o sea, hay pocas empresas que...... Estén haciendo ambas cosas a la vez ¿no? Por ejemplo acá en Perú tenemos empresas de GIS como: Telemática que digamos que distribuye el $95 \%$ digamos en el mercado GIS. En el CAD por ejemplo también otra empresa que es líder sería Autodesk, que también domina con un porcentaje parecido en el mercado peruano, en el CAD, hablando.

Entrevistador: Ya. Pero eso eh... son empresas que desarrollan. Mi pregunta va por el lado de ¿Quiénes desarrollan estos softwares o estas tecnologías? O sea ¿Localmente no se encuentran?

Entrevistado: Claro, ellos son distribuidores (ambos). O sea en CAD por ejemplo el Autodesk es la compañía multinacional que fabrica el producto, pero los que distribuyen en el Perú al menos son varios, varias empresas peruanas. Y lo mismo en GIS, la que fabrica es una empresa americana (multinacional) y los que lo distribuye Telemática, que le comentaba.

Entrevistador: Ya.

Entrevistado: Pero, soluciones de fábrica de software de CAD y GIS en el Perú existen muy pocas ¿no? Existen algunas, pero son insipientes. No tienen un mercado grande ¿no?

Entrevistador: Ya. Y como lo ve o ¿Cuál es la tendencia de estas tecnologías (CAD y GIS)? O en todo caso del que más conoce ¿no? 
Entrevistado: ¿La tendencia en qué sentido?

Entrevistador: Digamos, en el sentido de uso, de preferencias ¿Cómo lo ve? ¿De qué está en crecimiento? ¿O ya es estable?

Entrevistador: ¡Ah ya! lo que pasa, hay una evolución digamos. Yo podría decir que el CAD es más antiguo que el GIS (y de hecho lo es) y la siguiente fase después de pasar el CAD, GIS seria digamos quizás este... Ya la inteligencia de posicionamiento.

Entrevistador: Ok. O sea ¿Hacia ese lado...?

Entrevistado: Yo creo que la tendencia va por ahí. Y la inteligencia de posicionamiento se va nutrir de varias cosas como por ejemplo la big data, por ejemplo.

Entrevistador: Ah, perfecto. Entonces a eso va la tendencia actualmente.

Ok. Sobre otro punto que quisiera saber es: ¿Qué tipo de organizaciones usan estos sistemas CAD y GIS? ¿A quiénes les beneficia más? o ¿Menos? No sé, bajo su experiencia.

Entrevistado: Claro, las tecnologías GIS en sí, pueden ser usadas por la gran mayoría de compañías, especialmente por las compañías o instituciones que trabajan con información de territorios ¿no? Por ejemplo, ¿Quiénes trabajan con territorios en el gobierno? Son los gobernadores nacionales, los ministerios, los gobiernos regionales locales también administran finalmente territorios, espacios públicos. Y de la misma forma las empresas privadas o compañías privadas, algunos trabajan con territorios, algunos no. La mayoría que trabajan con territorio son consumo masivo, por ejemplo, telecomunicaciones, transporte ¿no? Que tienen que ver con información que está relacionado con el territorio.

Entrevistador: Ah ok. Nos decía... Me gustaría que nos pueda indicar un poquito más detallado ¿Cómo se encuentra el mercado de este tipo de soluciones en la actualidad? Hablando acá en el Perú. ¿Cómo lo ve usted? ¿Hay demanda? O sea las empresas eh... ¿Hay muchas empresas que usan esta tecnología? 
Entrevistado: ¡Ah ya!. Yo creo que está en crecimiento la demanda de uso de estas tecnologías eh... En los últimos tiempos (años) ha habido bastante promoción, eventos, cursos en cuanto al uso de tecnologías de información geográfica. De hecho en este gobierno por ejemplo, se ha creado en la PCM la secretaría de gobierno digital, dentro del cual está la oficina de infraestructura de datos espaciales que promueve los estándares ¿no? Para poder implementar soluciones de tecnologías de información geográfica y compartir también información geográfica a nivel gobierno. De la misma forma en las empresas privadas ha habido, digamos, mayor demanda en estos últimos tiempos de acuerdo a la experiencia que tengo. Y ha habido también la creación de digamos, sucursales o subsidiarias de compañías transnacionales, por ejemplo, Hexagon, Carto, Gis cloud.

Hay varias compañías que han sido creados en los últimos cinco años o menos y se han extendido por todo el mundo (de las que te estoy hablando Carto, etc.) ya están en Perú con una subsidiarias o sucursales, que están haciendo ya trabajos para diferente compañías.

Entrevistador: Y ¿Qué marca principales dominan el mercado?

Entrevistado: No, si como lo había dicho el 95\% del mercado está dominado por en cuanto a GIS por Esri de ArcGIS y en cuanto a CAD esta por Autodesk, sin quitar que si hay muchas soluciones. O sea tecnológicamente hablando que son lo mismo pero, están posicionados por cuestiones de estrategias de mercado que han sabido aplicar.

Entrevistador: O sea esa parte explícame un poquito más, o sea no me queda claro ¿Qué quiere decir?

Entrevistado: O sea que hay soluciones por ejemplo en GIS ¿no? tan buenos como el ArcGIS ¿no? hay Mapinfo, hay Geoconcept, hay varios productos hasta en software libre que hacen las mismas funciones, pero no están estratégicamente posicionados en el mercado en la mente del consumidor del funcionario, del gerente que va a adquirir este producto y por eso que no lo están usando. 
Y en el CAD igual hay productos que ofrecen la misma librería, las mismas funciones que el Autodesk hasta los mismos comandos ¿no? Y hasta también en cuanto a costos. Cuestan mucho menos, por ejemplo el ZwCAD, el IntelliCAD, hay varios que no están siendo usados por temas de posicionamientos.

Entrevistador: Ya. ¿Qué sectores potenciales existen sin ser atendidos en estos sectores? O sea me refiero a CAD, GIS para atención a... con soluciones para medio ambiente. El GIS por decir ¿Es aplicable al medio ambiente?

Entrevistado: Si claro, por supuesto, ahora todas las carreras de medio ambiente están llevando cursos de GIS. En GIS, creo que, hay un tema pendiente acá en Perú al menos que he visto. No se está usando mucho en turismo por ejemplo, que en otros países si se usa. Turismo que no lo está usando, estadística no lo está usando mucho, la parte de... hay carreras de estadísticas acá en el Perú que van de frente, la estadística de Business Intelligent, pero no pasan por la parte geográfica porque no tienen ese conocimiento, que deberían tener pienso yo. Como le había comentado hay una relación estrecha entre base de datos e información geográfica ¿no?

Entonces un estadístico analiza la información alfa numérico pero mientras no tenga conocimiento de la parte geográfica, no puede llegar al concepto que le estaba comentando la tendencia que es la tendencia de posicionamiento.

Entrevistador: ¿O sea quiere decir que Business Intelligent sería una competencia de un GIS?

Entrevistado: No ¡eh!... Es un concepto que te permite hacer inteligencia de un negocio en general, de información alfa numérica principalmente con cuadros, con gráficos. Y la inteligencia geográfica si podemos llamarlo así, transformaría esa información grafica de cuadros de barras ¿no? a información en mapas. Mapas de calor, mapas de temáticos, mapas de tendencia, mapas de segmentación etc. ¿no? 
Entrevistador: Ok ¿Qué tipos de usuarios? Hay algunos usuarios que de frente se van sin hacer el uso de un sistema GIS, pero ¿Qué tipos de usuarios o por qué sucede eso? ¿Qué tipos de usuarios aprenden o utilizan más rápidamente estos tipos de sistemas?

Entrevistado: ¡Ah! de hecho todos los que son sistemas de información geográfico está relacionado a dos profesiones (digamos), por un lado los de base de datos, informática, computación y por el otro lado están los geógrafos, los arquitectos, los que hacen ciencias de la tierra medio ambiente, forestales, ingenieros geógrafos, cartógrafos, topógrafos ¿no? todos los que tienen que ver con ciencias de la tierra y los que tienen que ver con el mundo de la computación.

\section{Entrevistador: Ok.}

Entrevistado: Pero, también he visto en los últimos tiempos que hay, justo lo que usted me preguntaba ¿no? Que hay zonas no exploradas por ejemplo los sociólogos están usando GIS bastante ahora, los planificadores, los economistas. Los economistas que se especializan en planificación por ejemplo. Ahora ya están usando el GIS, porque la planificación no puede estar basados solo en conocimientos de fondo médico ¿no?, porque finalmente planifican si es para el gobierno, territorios. Si no tienen información gráfica la planificación no es tan efectiva.

Entrevistador: ¿O sea que el tener datos alfanuméricos es limitado respecto a tener información de manera geográfica?

Entrevistado: Si, de hecho.

Entrevistador: ¿Cuál sería esa ventaja digamos?

Entrevistado: Le voy a hacer este ejemplo de mi trabajo actual. Por ejemplo el planificador estratégico, cuando acá en formalización minera antes de que usáramos la tecnología de información geográfica, hacia ok. Tengo 25 departamentos, tengo digamos un ejemplo 25 millones, entonces cuanto yo voy a enviar a cada región para el propósito de la 
formalización minera. Entonces decimos un millón a cada región ¿sí?, entonces bueno es una primera etapa, después hicieron otro análisis dijeron: "pero la cantidad de mineros que hay por región, entonces al menos pudieron clasificar mejor”. Pero con los conglomerados que le digo ya no se envía los presupuestos por región sino se envía presupuesto por conglomerado. Entonces en el Perú se ha detectado ocho conglomerados.

Uno de los conglomerados por ejemplo esta en Puno y otro cerca está en Arequipa. Si hablamos por departamentos Arequipa y Puno se llevan como el 50\% del presupuesto.

Entrevistador: ¿Ese análisis lo puedo hacer de manera alfanumérico? ¿O es muy complicado?

Entrevistado: Antes se hizo de manera alfanumérico pero no tenían el lugar donde posicionar las oficinas de atención rápida, entonces ahora tienen oficinas de atención rápida en cada conglomerado que está cerca de los mineros. Entonces con esto el éxito está garantizado. Por ejemplo en este caso del trabajo que se ha hecho en los cuatro años anteriores, con estrategias de documentos anteriores, han formalizado como a cien. Ahora aplicando la nueva estrategia de conglomerados en lo que va de este tiempo ya se han formalizado más de mil. Entonces ahí están los resultados de la aplicación de las estrategias en conglomerados.

Entrevistador: Sr. Carhuapoma, respecto a los expertos ¿Cómo se encuentra este mercado? ¿Hay muchos, pocos, regulares expertos en el medio?

Entrevistado: Yo creo que ha aumentado bastante, de hecho en las últimas conferencias que he asistido he visto muchos consultores extranjeros. Colombia, Brasil, Argentina, España, Francia.

Entrevistador: ¿Atendiendo en el mercado peruano?

Entrevistado: Si.

Entrevistador: ¿Quiere decir que han llegado? 
Entrevistado: $\mathrm{Si}$, entonces aquí hay consultores especializados que están atendiendo en el mercado peruano, también hay peruanos no muchos, entonces creo que si han aumentado bastante en cuanto a expertos en estos temas.

Entrevistador: Y ¿Cuánto es el ingreso (sueldo u honorarios) mensual aproximado? O el rango que manejan, que se les pagan a un experto:

Entrevistado: Creo que debe estar entre unos 3000 a 4000 dólares en cuanto a los expertos normales ¿no? Pero ya hay los top que están más arriba ¿no?

Entrevistador: ¿Qué competencias se requiere para ser un experto en CAD y GIS? O tal vez una formación especial así:

Entrevistado: Como le comentaba al inicio, el mundo de los GIS es la mezcla de dos cosas: conocimientos de temas territoriales y conocimiento de computación o base de datos ¿no? La mezcla de ambas cosas produce este especialista experto en estos temas. Entonces los estudios que se requieren son de esas carreras.

Entrevistador: Nos hablaba anteriormente de empresas que acá ya comercializan estos productos ¿Creo que nos hablaba de una empresa en particular que domina el mercado? ¿Podría decirnos quién o cuantas empresas más existen aparte de ellas? ¿Si no me equivoco nos mencionó de telemática que era una de ellas?

Entrevistado: Si. Telemática representa el software más usado en el Perú, que el ArcGIS. Hay otras empresas GIS que existen en el mercado peruano.

Entrevistador: Esta empresa que mencionó ¿Es la principal empresa que distribuye este tipo de productos?

Entrevistado: El único. La que pasa es la estrategia de Esri, que es la compañía trasnacional que representa a Telemática solo puede tener un distribuidor por país. Entonces es el único distribuidor de ArcGIS en el Perú. 
Entrevistador: ¿El otro 5\% del mercado digamos en la actualidad que empresas son? Conoce de ellos:

Entrevistado: Sí, hay varias. Uno es Intech Group Perú, que representa a Mapinfo, otra esta Química Suiza que representa a Hexagon, otra que representa a Geoconcept y otras empresas nuevas que han llegado de Carto, GIS Cloud que son nuevas tendencias en el mundo, pero ya están atendiendo en el Perú.

Entrevistador: ¿Y esta principal empresa que maneja el 95\% del mercado (que atiende al 95\% del mercado) cual cree que es su principal ventaja competitiva? ¿Y cuál es en todo caso su principal debilidad?

Entrevistado: Su ventaja no sé si es de la empresa más que del producto. ¿De la empresa? Yo no lo veo sino más bien del producto. Es decir si cambiamos de empresa, el producto va a seguir teniendo el mismo éxito porque el producto está posicionado.

Entrevistador: Ok.

Entrevistado: Entonces. Yo no podría ni conozco por dentro como es la empresa ni he trabajado para ellos, exactamente no sé cuál es su estrategia. Pero no he visto mucho movimiento a nivel de marketing y la estrategia de posicionamiento de esta empresa, pero si del producto que tienen cursos y siempre están con la última tecnología, con la última tendencia. Entonces es el producto.

Entrevistador: ¿Es el producto entonces?

Entrevistado: Su debilidad quizás se podría ver si es de la empresa en cuanto a su inversión en recursos humanos, porque he visto casos en que habido proyectos en que no han podido atender y simplemente tuvieron que contratar a consultores o a otras empresas que dominan el mismo producto en otro país. Eso es una debilidad que entiendo que en los últimos tiempos supongo que están invirtiendo en eso. 
Entrevistador: ¿Qué deberían hacer estas empresas que tienen el 5\% para ganar una mayor participación de mercado? De acuerdo a su punto de vista.

Entrevistado: Es mas de mi punto de vista sino de mi experiencia, que en un momento estoy promocionando un producto por ejemplo que hemos hecho una solución para catastro a raíz de mi maestría en ingeniería de catastro. Y a pesar que este software que hablamos de Telemática que es muy bueno etc. Hasta este momento no ha podido hacer una solución adecuada específica para catastro en el Perú, entonces hemos podido directamente competir y de hecho hemos ganado las veces que me ha tocado. Porque la solución que hemos hecho está pensado en el mercado, es más estaba hecho con software libre. En costo, en oportunidad, en la profundidad de la solución en cualquier caso podíamos ganar. Entonces yo creo que las empresas que están pensando subir esa brecha, tendrían que pensar en mercados verticales (soluciones verticales) y hacer soluciones específicas pensando en el mercado porque ellos son tan grandes que tienen todo el mercado como producto pero no están pensando en soluciones específicas, pienso en opinión personal que eso podría ser una buena oportunidad. 


\section{Anexo 7 \\ Entrevista en profundidad a César Palacios Torres \\ Experto en CAD}

\section{Objetivo de la entrevista:}

Conocer el nivel tecnológico, necesidades o problemas específicos de la industria, importancia, valor y motivaciones para la compra de software.

Entrevistador: Sr. Torres, con su permiso, estamos iniciando la grabación en audio de esta entrevista que usted nos va conceder, el cual agradecemos infinitamente ya que entendemos lo valioso de su tiempo.

Soy Hilber Quintana, estudiante de la Maestría en Administración de Negocios de la Universidad San Ignacio de Loyola. Como le mencioné al momento de concertar esta reunión, estamos realizando una investigación para un trabajo académico, respecto a la comercialización, usos y beneficios de software para Ingeniería, medioambiente y sistemas de información geográfica; por lo que su retroalimentación será de mucha importancia.

Entrevistador: Con todo respeto, agradeceremos realizar un resumen de su perfil profesional, el tiempo y cargo que desempeña en esta empresa.

Entrevistado: Bueno, yo soy técnico egresado de SENCICO y también de CIBERTEC, en CIBERTEC en las áreas de sistemas y en SENCICO como técnico en diseño civil, en esta empresa tengo 10 años de experiencia y en los últimos 7 años estoy encargado del área de CAD GIS y mi posición es de CAD Manager. 
Entrevistador: ¿Cuál es la actividad principal de su empresa?

La empresa es Ausenco y es una corporación con presencia en varios países del mundo y acá en Perú también tiene la presencia, y básicamente Ausenco es una consultora en desarrollo de proyectos mineros y nuestro principal cliente son las mineras, a quienes les brindamos todo nuestro 2:59 y experiencia para el desarrollo de sus proyectos que es básicamente en la parte de la minería

Entrevistador: ¿Cuántos colaboradores tiene su empresa en cada área?

Entrevistado: En la empresa aproximadamente se tiene de 200 a 250 personas que estarían distribuidos entre las principales áreas que son: las áreas de ingeniería, el área de Campo que digamos es el área de 3:30 Cecua que viene a ser los que están haciendo las inspecciones en campo, en los proyectos, y el área Administrativa. En la área Administrativa se tienen aproximadamente 50 personas, en las áreas de Ingeniería aproximadamente 150 y en el área de Campo unas 50 personas.

Entrevistador:¿Cuál es el nivel tecnológico de su empresa?

Entrevistado: Actualmente, los estándares que manejamos como lo mencioné es una empresa que con presencia mundial, entonces, nosotros corporativamente tenemos unos estándares a los cuales, nosotros acá en Perú tenemos que alinearnos con en el estándar corporativo, sin embargo, sabemos que en cada país también varían los estándares, pero tratamos de estar a la vanguardia acá en Perú con los clientes que tenemos locales

Entrevistador: ¿Existe apertura a múltiples tecnologías?

Entrevistado: Sí, estamos abiertas a múltiples tecnologías porque tenemos varios clientes y varios requerimientos que no son constantes en todos los clientes y eso hace que nosotros tengamos múltiples tecnologías

Entrevistador: ¿Qué es lo que más valoran para la inversión en software? 
Entrevistado: Lo que se valora principalmente es la experiencia que tenga el proveedor y que cumplan con los requerimientos que nosotros deseamos, con la necesidad de que tengamos nosotros que cubrir que para con nuestros clientes y uno que también es importantes es el precio.

Entrevistador: ¿Cómo organización tienen política para el uso de software?

Por supuesto, si tenemos políticas, como comenté tenemos varios usuarios y tenemos política global.

Entrevistador: ¿En esa política se contempla el pago anual para mantenimiento y soporte? (Si tiene el anterior)

Entrevistado: En la gran mayoría de nuestro software realizamos pagos anuales por el mantenimiento y soporte.

Entrevistado:¿Cuánto invierten en tecnología de información anualmente?

En el caso del hardware, relativamente se va cambiando año tras año para poder equipararnos de un buen hardware para tener la plataforma necesaria para las actualizaciones del software que vengamos usando.

Entrevistador: ¿Qué porcentaje de lo mencionado es destinado a software?

Entrevistado: La inversión es de un aproximado de 120,000 dólares solamente dirigido para software.

Entrevistador: ¿Qué tipo de software utilizan en su organización?

Entrevistado: El software que más usamos son CAD, GIS y una menor parte seria la enfocada a diseño civil

Entrevistador: ¿Cuántas licencias de software CAD o GIS tienen en su empresa?

Entrevistado: Para los que es CAD tenemos unos 60 a 70 usuarios y lo que es GIS es unos 10 usuarios, es decir, unas 10 licencias.

Entrevistador: ¿Conoce otras marcas (desarrolladores) de software CAD y GIS? 
Entrevistado: No, nosotros tenemos que asegurar que esta información que vamos a generar esté acorde con la mayoría de nuestros clientes, entonces, estamos hablando de productos de Autodesk o de Bentley, que localmente es poca la demanda de Bentley, pero en la gran mayoría es por parte de Autodesk. En el caso de GIS es 9:39 ArcView, Esri y de Mapinfo. También, utilizamos otras marcas para lo que es la parte administrativa como Microsoft u Oracle.

Entrevistador: ¿Cuáles son las razones que determinaron la compra de software CAD y GIS?

Entrevistado: No, básicamente que cubran nuestros requerimientos y necesidades principalmente.

Entrevistador: ¿Cuál sería el aspecto o razón más importante para cambiar de marca de software?

Entrevistado: Básicamente, como vuelvo a repetir, la importancia es asegurar que la información que vamos a compartir con nuestros clientes sea en el mismo lenguaje y asegurarnos de eso y no tener inconvenientes con la entrega de nuestros productos finales.

Entrevistado:¿Cuál es el proceso para decidir la inversión en software?

Varía dependiendo del monto, si los montos son menores solo bastaría con la firma de manager o del gerente de ingeniería y del gerente general, pero en el caso de una alta inversión, se espera de la aprobación del CFO que es el Chief Financial Officer que viene a ser el jefe corporativo.

Entrevistador: ¿Quién o quiénes son sus principales proveedores de software?

Entrevistado: A nivel corporativo, ya se hace una compra desde Brisbane, Australia, los encargados de las tecnologías de información. Y a nivel local, tenemos por ejemplo la empresa Replica quien básicamente nos provee de software para ingeniería, ya que ellos son representantes de Autodesk. 
Entrevistador: ¿Cómo calificaría el servicio de su o sus principales proveedores de software?

Entrevistado: Buenos, porque frecuentemente nos hacen llamadas para saber cómo nos está yendo con el software o ver si tenemos inquietudes, muchas veces nos visitan o a hacen work shops para mostrarnos unas nuevas herramientas de los productos nuevos.

Entrevistador: ¿Se encuentra satisfecho con el nivel de atención de su proveedor de software?

Entrevistado: Sí, estamos satisfechos con la atención.

Entrevistador: ¿Qué aspectos debe mejorar sus proveedoras de software?

Entrevistado: Bueno, este proveedor hasta el momento nos tiene contentos, pero una gran alternativa seria que nos brinde un soporte multi-usuario, es decir, que todos los usuarios se puedan conectar en un minuto con un soporte directo de esta empresa y no contactarnos y perder 1 o 2 horas tratando de solucionar un problema, sino que sea instantáneo. 


\section{Anexo 8 \\ Entrevista en profundidad a César Palacios \\ Experto en CAD y GIS}

\section{Objetivo de la entrevista:}

Conocer el nivel tecnológico, necesidades o problemas específicos de la industria, importancia, valor y motivaciones para la compra de software.

Entrevistador: Sr. César Palacios, con su permiso, estamos iniciando la grabación en audio de esta entrevista que usted nos va conceder, el cual agradecemos infinitamente ya que entendemos lo valioso de su tiempo.

Soy Hilber Quintana, estudiante de la Maestría en Administración de Negocios de la Universidad San Ignacio de Loyola. Como le mencioné al momento de concertar esta reunión, estamos realizando una investigación para un trabajo académico, respecto a la comercialización, usos y beneficios de software para Ingeniería, medioambiente y sistemas de información geográfica; por lo que su retroalimentación será de mucha importancia.

Entrevistador: ¿Con todo respeto, agradeceremos realizar un resumen de su perfil profesional, el tiempo y cargo que desempeña en esta empresa?

Entrevistador: Mi nombre es César Palacios, mi cargo es de Preventista civil, cuento con más 22 años de ejercicio laboral en los cuales me he dedicado a realizar trabajos de CAD GIS y en este momento estamos haciendo un modelamiento.

Entrevistador: ¿Cuál es la actividad principal de su empresa?

Entrevistado: La empresa se dedica al diseño de estructuras para la minería, ya sean estajos, accesos y toda estructura referente a la minería.

Entrevistador: ¿Cuántos colaboradores tiene su empresa en cada área? 
Entrevistado: Actualmente, la empresa cuenta con más de 20 colaboradores: entre ingenieros, contadores, profesionales técnicos y profesionales de campo.

Entrevistador: ¿Cuál es el nivel tecnológico de su empresa?

Entrevistado: En cuanto a esto quiero mencionar que debido a la naturaleza de los trabajos que se efectúan en cuanto a la minería debo decir que el nivel tecnológico es mediano-alto debido a que tenemos buena infraestructura.

Entrevistador: ¿Existe apertura a múltiples tecnologías?

Entrevistado: No, es multidisciplinario. El hecho de que se requieran procedimientos muy elaborados necesita computadoras muy fuertes. Es múltiple, porque también en el caso de contabilidad no los necesitan. En resumen estamos con la tecnología media-alta.

Entrevistador: ¿Qué es lo que más valoran para la inversión en software?

Entrevistado: Primero debemos saber que los software generalmente nos ahorran trabajo, pero algunos simplemente nos dan un indicio. Nosotros valoramos la proximidad a la exactitud que ofrece el software, que es lo que generalmente buscan todas las empresas.

Entrevistador: ¿Cómo organización tienen política para el uso de software?

Entrevistado: Lastimosamente, no existe en esta empresa, donde actualmente laboro, una política para el uso de software.

Hay dos áreas muy marcadas donde trabajo, lo que es cálculos para las probables fallas de estructuras, donde la empresa tiene mucho cuidado y los software que han adquirido son muy caros los cuales sí tienen mantenimiento. La segunda área, que es donde nosotros diseñamos, a veces simplemente nos indican que laboremos con AutoCAD.

Entrevistador: ¿Cuánto invierten en tecnología de información anualmente?

Entrevistado: No tengo esa información, no tomo esas decisiones en ese sentido.

Entrevistador: ¿Qué tipo de software utilizan en su organización? 
Entrevistado: Todo lo referente a la minería ya sea productos CAD, GIS, de modelamiento de recursos mineros, programas para diseños de la vida misma de una mina. Es una gran variedad que se utiliza.

Entrevistador: ¿Cuántas licencias de software CAD o GIS tienen en su empresa?

Entrevistado: En cuando a Civil 3D contamos con 2 licencias, con SB Office para cálculos de fallas también contamos con 2 licencias, que son los software más caros que tenemos. A parte de estos, están los básicos como el Office y el Windows que no son muchos software licenciados.

Entrevistador: ¿Conoce otras marcas (desarrolladores) de software CAD y GIS?

Entrevistado: Conozco de algunos que se usa en la empresa como de la firma Bentley que viene a ser el Microstation, InRoads que permiten hacer cosas mejores que Civil 3D. Aunque el detalle, es que no tienen mucha presencia en nuestro mercado laboral y sobre todo no hay muchos sitios donde se pueda aprender sobre estos software. Adicionalmente, conozco el software Leapfrog que es un programa muy bueno, aunque la empresa no cuenta con este software. Conozco que en el mercado existe mucha variedad de software que no son muy utilizados, pero que tienen mucho potencial.

Entrevistador: ¿Cuál sería el aspecto o razón más importante para cambiar de marca de software?

Entrevistado: Como le mencioné anteriormente, la razón principal sería el desempeño. Cada vez que los software se vuelven más elaborados requieren de más máquinas; por ejemplo, en el caso de que me ofrezcan un software que requiera de solo una máquina sin muchas características puedo realizar las mismas cosas que realizaba anteriormente, sin duda cambiaría de software.

Entrevistador: ¿Cuál es el proceso para decidir la inversión en software? 
Entrevistado: Dependiendo de qué trabajo se viene desempeñando, es decir, cuando hay requerimientos de los trabajos que tenemos recién se genera el proceso para decidir la inversión de un software, no es que tengamos los software en reserva.

Entrevistador: ¿Quién o quienes deciden la inversión en software?

Entrevistado: Como dije anteriormente, no estoy muy enterado de este aspecto. Yo supongo que sí sería el gerente general quien tome esta decisión cuando haya requerimiento.

Entrevistador: ¿Quién o quiénes son sus principales proveedores de software?

Entrevistado: No, en este sentido la empresa es muy hermética. Nosotros simplemente damos el nombre del software que necesitamos y luego no tenemos acceso a más.

Entrevistador:¿Cómo calificaría el servicio de su o sus principales proveedores de software?

Ahora trabajamos con el modelo de negocio que vienen a alquilar una membrecía, con eso hacemos pequeñas absoluciones de algunas cosas que estén fallando, generalmente ya no se hacen a los distribuidores del software directamente. Cabe mencionar, que ahora con la apertura de los medios de comunicación como youtube, la solución que podemos encontrar es más rápida y de manera más estructurada.

Entrevistador: ¿Qué aspectos debe mejorar sus proveedoras de software?

Entrevistado: Que abran un canal muy extenso de enseñanza, porque generalmente las empresas que solicitan software solo tienen 10 o 20 horas de curso y luego ya no hay más cursos de enseñanza adicional. También podría ser algo así como un curso de novedades sobre las nuevas versiones de software, esto sería un aspecto positivo para conservar a sus clientes. 


\author{
Anexo 9 \\ Entrevista en profundidad a Ruben Cabanillas \\ Jefe de Área CAD y GIS en KNIGHT PIESOLD CONSULTORES S.A.
}

\title{
Objetivo de la entrevista:
}

Conocer el nivel tecnológico, necesidades o problemas específicos de la industria, importancia, valor y motivaciones para la compra de software.

Entrevistador: Sr. Cabanillas, con su permiso, estamos iniciando la grabación en audio de esta entrevista que usted nos va conceder, el cual agradecemos infinitamente ya que entendemos lo valioso de su tiempo.

Soy Hilber Quintana, estudiante de la Maestría en Administración de Negocios de la Universidad San Ignacio de Loyola. Como le mencioné al momento de concertar esta reunión, estamos realizando una investigación para un trabajo académico, respecto a la comercialización, usos y beneficios de software para Ingeniería, medioambiente y sistemas de información geográfica; por lo que su retroalimentación será de mucha importancia.

Entrevistador: Con todo respeto, agradeceremos realizar un resumen de su perfil profesional, el tiempo y cargo que desempeña en esta empresa

Entrevistado: Mi nombre es Rubén Cabanillas, llevo laborando 20 años en esta empresa que es 3:35 Constructores y actualmente me desempeño como gerente del área de CAD y GIS.

Entrevistador:¿Cuál es la actividad principal de su empresa? 
Entrevistado: La actividad que realizamos es de la consultoría para las compañías mineras, diseño de ingeniería y tanto para el área del medio ambiente

Entrevistador: ¿Cuántos colaboradores tiene su empresa en cada área?

Entrevistado: De un aproximado de 80 personas.

Entrevistador: ¿Cuál es el nivel tecnológico de su empresa?

Entrevistado: Se tiene el uso del software comercial y también software de alta tecnología en la especialidad de CAD y GIS.

Entrevistador: ¿Existe apertura a múltiples tecnologías?

Entrevistado: Bueno, se trabaja con marcas más comerciales en este caso la línea Autodesk y la línea Esri, pero también estamos abierto a otras marcas pequeñas o aplicaciones hechos por terceros o propias.

Entrevistador: ¿Qué es lo que más valoran para la inversión en software?

Entrevistado: Básicamente, la productividad, porque mientras más posibilidades de hacer más rápido nuestras actividades que nos brinde un software, obviamente será más rentable para nosotros y más interesante para estudiarlo y analizarlo.

Entrevistador: ¿Como organización tienen política para el uso de software?

Entrevistado: Se tiene políticas tanto como la compra, para el uso y también para el tema de seguridad

Entrevistador: ¿En esa política se contempla el pago anual para mantenimiento y soporte?

\section{Entrevistado: Si.}

Entrevistador: ¿Cuánto invierten en tecnología de información anualmente?

Entrevistado: Esa información es confidencial, pero normalmente lo que se hace es renovar cierta cantidad de licencias, porque muchos de los software que se tiene se renueva anualmente, entonces, la inversión se basa de esos software que se utiliza. 
Entrevistador: ¿Qué porcentaje de lo mencionado es destinado a software?

Entrevistado: En un aproximado de 50000 dólares.

Entrevistador: ¿Qué tipo de software utilizan en su organización?

Entrevistado: En caso de la línea de CAD lo manejamos con la empresa Autodesk, el cual se utiliza Autocad para lo que es diseño y Civil 3D para el diseño de ingeniería, en el caso la línea GIS se maneja con la empresa Esri, lo que es Arc GIS y toda la plataforma.

Entrevistador: ¿Cuántas licencias de software CAD o GIS tienen en su empresa?

Entrevistado: En un aproximado de 12 estaciones de Autodesk y unas 4 a 5 de Esri.

Entrevistador:¿Conoce otras marcas (desarrolladores) de software CAD y GIS?

\section{Entrevistado: Si.}

Entrevistador: ¿Cuáles son las razones que determinaron la compra de software CAD y GIS?

Como ya mencioné, la productividad y también una parte importante sería la experiencia en el mercado con las personas manejando el software, porque uno puede tener un software muy interesante, pero si no se encuentra quién lo maneje sería complicado encontrar personas que lo compren.

Entrevistador: ¿Cuál sería el aspecto o razón más importante para cambiar de marca de software?

Entrevistado: La productividad, como ya mencioné, ya que si otra marca o aplicación nos demuestra que, lo que hacemos lo podemos hacer más rápido se puede probar otras opciones.

Entrevistador: ¿Cuál es el proceso para decidir la inversión en software?

Entrevistado: En este caso, nosotros somos un equipo de trabajo conformado por diversas gerencias como: las áreas de ingeniería, CAD, GIS y la Gerencia general, de acuerdo a un presupuesto anual. 
Entrevistador: ¿Quién o quienes deciden la inversión en software?

Entrevistado: La gerencia general.

Entrevistador: ¿Quién o quiénes son sus principales proveedores de software?

Entrevistado: La empresa Profile y la empresa Telemática.

Entrevistador: ¿Cómo calificaría el servicio de su o sus principales proveedores de software?

Entrevistado: 8:35

Entrevistador: ¿Se encuentra satisfecho con el nivel de atención de su proveedor de software?

Entrevistado: En líneas generales, sí nos encontramos satisfechos.

Entrevistador: ¿Qué aspectos debe mejorar sus proveedoras de software?

Entrevistado: Básicamente, la parte de soporte, debido a que si bien nosotros asumimos que ya manejamos el software, pues sería interesante recibir algún tipo de capacitación especializada por la compra o tener cierto tipo de soporte al cual podamos acudir en un momento determinado. 


\section{Anexo 10}

\section{Ficha técnica}

\begin{tabular}{|c|c|}
\hline & Ficha Técnica \\
\hline Objetivo & $\begin{array}{l}\text { Determinar el tamaño del mercado, frecuencia de compra, } \\
\text { problemas específicos de la industria (forma de pagos, } \\
\text { ciclo evolutivo), identificar el valor, aspectos y } \\
\text { motivaciones que determinan la compra de software para } \\
\text { Ingeniería, medioambiente y sistemas de información } \\
\text { geográfica, conocidos como CAD y GIS. }\end{array}$ \\
\hline Población meta u Objetivo & $\begin{array}{l}\text { Colaboradores (empleados) que son jefes o gerentes de } \\
\text { sistemas, ingenieros, jefes o gerentes de compras } \\
\text { (elemento), que trabajen en una empresa minera } \\
\text { comprendida en las Top } 100002017 \text { (unidad de } \\
\text { muestreo), en el territorio peruano (Extensión) durante el } \\
\text { periodo desde el } 5 \text { de enero al } 17 \text { de febrero del } 2018 \\
\text { (tiempo). }\end{array}$ \\
\hline Marco Muestral & $\begin{array}{l}\text { La base de datos de las Top } 100002017 \text { correspondiente } \\
\text { al sector minería. }\end{array}$ \\
\hline $\begin{array}{l}\text { Técnica (Tipo) de } \\
\text { Muestreo }\end{array}$ & Probabilístico, aleatorio simple. \\
\hline $\begin{array}{l}\text { Técnica de Recolección } \\
\text { (Instrumento) }\end{array}$ & $\begin{array}{l}\text { Cuestionario estructurado, (compuesto principalmente por } \\
\text { preguntas cerradas) encuestas personales cara a cara, cuya } \\
\text { duración estimada es de } 10 \text { minutos. }\end{array}$ \\
\hline Ámbito Geográfico & Lima Metropolitana \\
\hline Tamaño de la muestra & 80 encuestas efectivas \\
\hline Margen de Error & $+/-10 \%$, con un nivel de confianza de $95 \%$ \\
\hline Realización & Del 05 de enero al 17 de febrero de 2018 \\
\hline
\end{tabular}




\section{Anexo 11}

\section{Cuestionario de Encuesta}

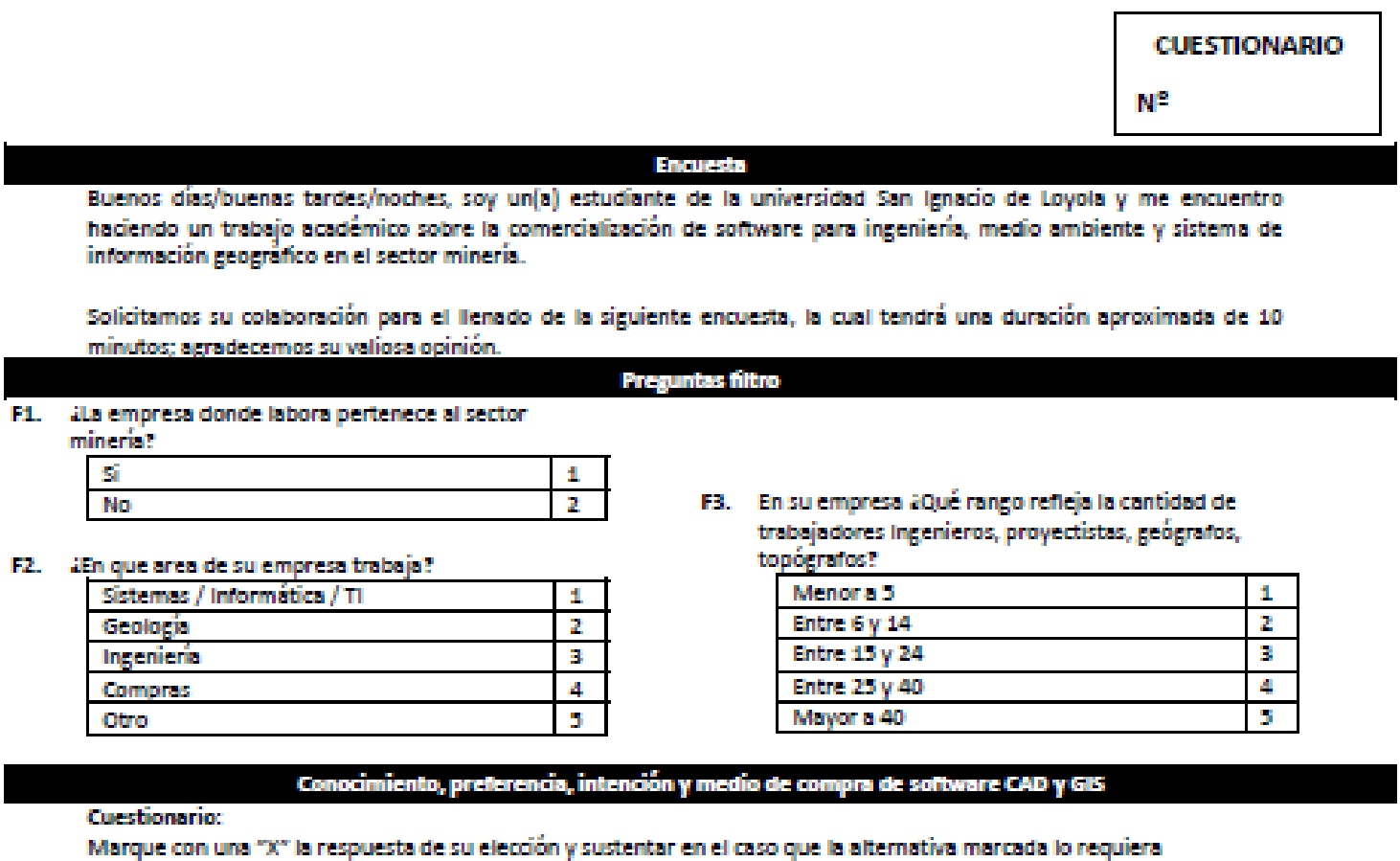

P1. ¿Qué marcas de software CAD usan en su empresa?

\begin{tabular}{|l|c|}
\hline Microstation (Bertiev] & 1 \\
\hline ArchiCAD (ArchicAD) & 2 \\
\hline AutoCAD [Autodesk) & 3 \\
\hline ZWCAD (ZWSOrt) & 4 \\
\hline Otro (Especificar) & 5 \\
\hline
\end{tabular}

P2. ¿Ciartas licencias de softwsre CAD tienen en su empresa?

\begin{tabular}{|l|l|}
\hline Menor a 5 & 1 \\
\hline Entre 6 y 14 & 2 \\
\hline Entre 15 y 24 & 3 \\
\hline Entre 25 y 40 & 4 \\
\hline Mayor a 40 & 5 \\
\hline
\end{tabular}

P3. ¿Cuántas licencias de sortwsre CAD tienen planificado adquirir el este sño?

\begin{tabular}{|l|l|}
\hline Ninguno & 1 \\
\hline 2 Licencias & 2 \\
\hline 3 Licencias & 3 \\
\hline 4 Licencias & 4 \\
\hline 5 Licencias & 5 \\
\hline Mayor a 5 licencias & 6 \\
\hline
\end{tabular}

P4. ¿Qué marcas de softivare GIS usan en su empresa?

\begin{tabular}{|l|c|}
\hline Bentley Map [Bentisy) & 1 \\
\hline Pitney Bowes (Mapinfo) & 2 \\
\hline Intergraph (Geomedia) & 3 \\
\hline Esri (ArcGi5) & 4 \\
\hline Otro (Espeóficar) & 5 \\
\hline
\end{tabular}

P5. ¿Qiantas licencias de sortware GIS tienen en su empresa:

\begin{tabular}{|l|l|}
\hline Menor a 5 & 1 \\
\hline Entre 6 y 14 & 2 \\
\hline Entre 15 y 24 & 3 \\
\hline Entre 25 y 40 & 4 \\
\hline Mayor a 40 & 5 \\
\hline
\end{tabular}

P6. ¿Cuántas licenoisz de software GIS tienen plenificado sdquirir el este año?

\begin{tabular}{|l|l|}
\hline Ninguno & 1 \\
\hline 2 Licencias & 2 \\
\hline 3 Licencias & 3 \\
\hline 4 Licencias & 4 \\
\hline 5 Licencias & 5 \\
\hline Mayor a 5 licenciss & 6 \\
\hline
\end{tabular}

\section{Proveedor actual de gethware CAD y GIS y gredo de satistucción}

P7. iQué empresa es su proveedor de sortwore GIS:

\begin{tabular}{|l|l|}
\hline Cardo Concultants S.A.C. & 1 \\
\hline Intech Group Peru S.A.C. & 2 \\
\hline Profile Conculting & 3 \\
\hline Macrotec Data & 4 \\
\hline Telemática S.A. & 5 \\
\hline Softland Perú & 6 \\
\hline Otros (especificar) & 7 \\
\hline
\end{tabular}

P8. En general aCómo calificaría a su proveedor de softwsre GIS: Marque una sola respuesta

\begin{tabular}{|l|l|}
\hline Muy malo & 1 \\
\hline Malo & 2 \\
\hline Indiferente & 3 \\
\hline Bueno & 4 \\
\hline Excelente & 5 \\
\hline
\end{tabular}


P9. ¿Qué empresa es su proveedor de software CAD?

\begin{tabular}{|l|l|}
\hline Business Solutions & 1 \\
\hline Replica SRL & 2 \\
\hline Profile Consulting & 3 \\
\hline Macrotec Data & 4 \\
\hline Semco CAD & 5 \\
\hline Softland Perú & 6 \\
\hline Otros (especificar) & 7 \\
\hline
\end{tabular}

P10. En general ¿Cómo calificaria a su proveedor de software CAD? Marque una sola respuesta

\begin{tabular}{|l|l|}
\hline Muy malo & 1 \\
\hline Malo & 2 \\
\hline Indiferente & 3 \\
\hline Bueno & 4 \\
\hline Excelente & 5 \\
\hline
\end{tabular}

Motivación y frecuencia de actualización de software

P11. ¿Qué es lo que le motina a comprar una determinada marca de software? Marque una sola respuesta

\begin{tabular}{|l|c|}
\hline Marca & 1 \\
\hline Precio & 2 \\
\hline Funcionalidad & 3 \\
\hline Diseño & 4 \\
\hline Otros (especifiar) & 5 \\
\hline
\end{tabular}

P12. ¿Con que frecuencia actualizan las licencias de software de suempresa?

\begin{tabular}{|l|l|}
\hline No realiza actualización ni mantenimiento & 1 \\
\hline Cada 1 año & 2 \\
\hline Cada 2 años & 3 \\
\hline Cada 3 años & 4 \\
\hline Cada 4 años & 5 \\
\hline
\end{tabular}

\section{Decisión de compra y tiempo de pago a proveedores de software}

P13. ¿Cuándo o por qué adquieren nuevas licencias de software?

\begin{tabular}{|l|l|}
\hline Nuevas versiones del software & 1 \\
\hline Nuevos proyectos en la empresa & 2 \\
\hline Compatibilidad con otros requerimientos & 3 \\
\hline Otros (Especificar) & 4 \\
\hline
\end{tabular}

P14. En su empresa ¿Cuál es tiempo estimado de pagos a proveedores de software?

\begin{tabular}{|l|l|}
\hline Contado contraentrega & 1 \\
\hline Pago 15 dias & 2 \\
\hline Pago 30 dias & 3 \\
\hline Pago a 45 dias & 4 \\
\hline Pago a 60 dias & 5 \\
\hline Pago a 90 dias & 6 \\
\hline
\end{tabular}

\section{Wivel de aceptación de nuevo proveedor y medio de comunicación preferido de software CAD y GIS}

P15. Si ingresa al mercado un nuevo proveedor con los software ZWGAD (CAD) y Maplofo, (GI5) ¿Consumiria dichos productos?

\begin{tabular}{|l|c|}
\hline Definitivamente Sl compraria & 1 \\
\hline Probablemente Sl compraria & 2 \\
\hline Indeciso & 3 \\
\hline Posiblemente NO compraria & 4 \\
\hline Definitivamente NO compraria & 5 \\
\hline
\end{tabular}

P16. ¿Mediante qué medios le gustaria recibir informacoón sobre soluoiones CAD y GI5?

\begin{tabular}{|l|l|}
\hline Correo Electrónico & 1 \\
\hline Facebook & 2 \\
\hline Página Web & 3 \\
\hline Eventos & 4 \\
\hline Otros (Especificar) & 5 \\
\hline
\end{tabular}

\section{Necesidades no cubiertas y valor relevente para el cliente}

P17. ¿Qué servicios adicionales le gustaria recibir de un proveedor de software CAD o GIS?

\begin{tabular}{|l|l|}
\hline Capacitación & 1 \\
\hline Hardware especialiado & 2 \\
\hline Servicio de consultoria & 3 \\
\hline Otros (especifior) & 4 \\
\hline
\end{tabular}

P18. En orden de importancia, establexca usted el criterio que más valora de un proveedor de software, para el cual se deberá considerar, 1 como el criterio más importante, asi sucesivamente, siendo 7 el menos importante.

\begin{tabular}{|l|l|}
\hline Soporte presencial & 1 \\
\hline Soporte online & 2 \\
\hline Tiempo de entreya & 3 \\
\hline Descuento-Predo & 4 \\
\hline Garantia & 5 \\
\hline Personal calificado & 6 \\
\hline Amabilidad de empleados & 7 \\
\hline
\end{tabular}


Anexo 12

Precio de licencia ArcGIS

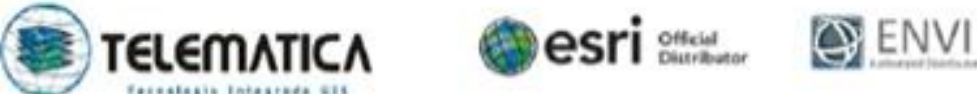

Numero de Cotización:

Empresa:

Referencia:

Fechx
COTZ-000)

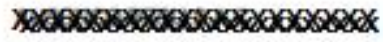

Licencias Nuevas ArcGIS Desidop Basic

$\mathbf{x \times 0 \times 0 1 8}$

\begin{tabular}{|c|c|c|c|}
\hline Producis & Preco Unitario & Caredad & Precio tocal \\
\hline AreGIS Desktop Basic Single Use & PEN 10.191,000 & 1,00 & PEN $10,191,000$ \\
\hline
\end{tabular}

Condiciones Comersiales:

Tiempo de Entrega. Dentro de los 30 dias posteriores de recbida y aceptada la O/C o Contrato.

Forma de Pago: Pago adelantado, a través de PAGO ÚNICO. Ya que les entregamos bienes intang bles materializados en el Acta de entrega de códigos con sus licencias debidamente actualicadas en versión vigente.

El software es descargable desde la paigina Web del fabricante. No se dspone de Media Magnética.

Lugar de Entregax Se realizará en el Almacén de la insttución u oficina del cliente. La entrega del producto es mediante el "Acta de Códigos y Originalidad de Licencia".

Validez de la propuesta: 30 dias a partir de la fecha.

Precio: Los precios locales, estain expresados en Soles e induyen IGV (18\%).

Precedimiente de Comora:

1. Enviar su Orden de Compra / Orden de Senvicio al correo del Ejecutivo de Cuentas a quien presentaron su solichud de compra o al írea de Ventas Corporativas de nuestra empresa (uentas gielematica compe)

2. Luego de ello y suscrito el Contrato respectivo (en caso apique), se remitrá la entrega del Producto en las instalaciones del cliente.

3. Envia copia del Voucher de depósto al correo yentasuletelematica com pe por el monto de la adquisición e indicando el $\mathrm{N}^{*}$ RUCIONI sepin corresponda. B depósto podrá realizarse a cualquiera de las siguientes cuentas:

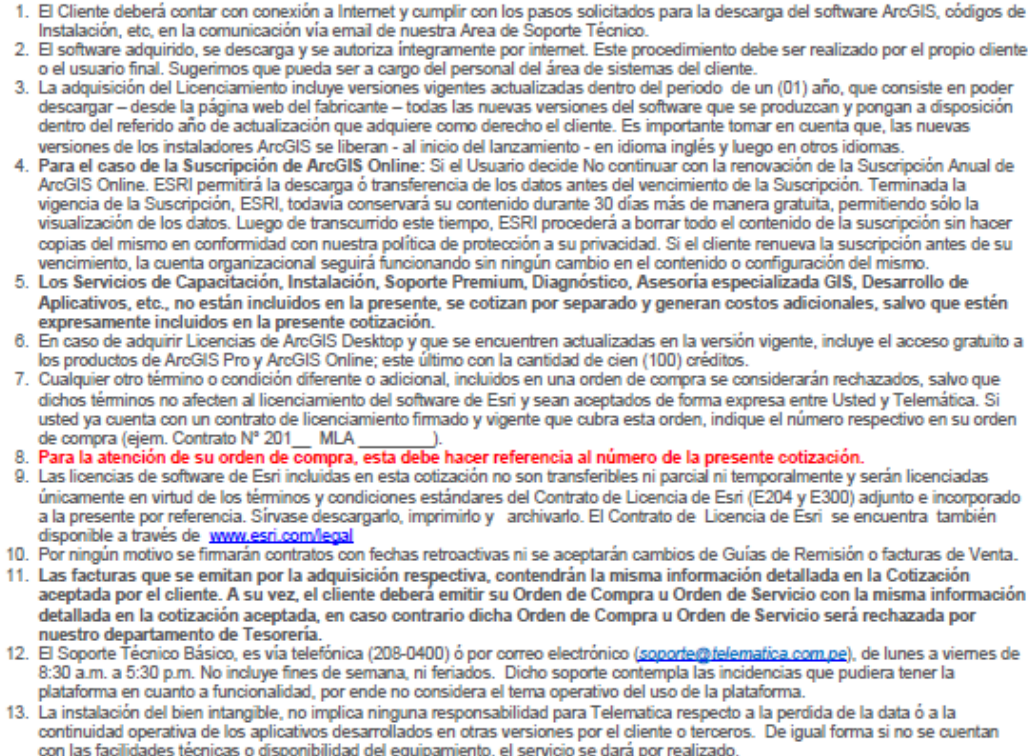

10. Por ningún motivo se fimarín contratos con fechas retroactivas ni se aceptarán cambios de Guias de Remisión o facturas de Venta. Las facturas que se emitan por la adquisición respectiva, contendrán la misma información detallada en la Cotización aceptada por el cliente. A su vez, el cliente debera emitir su Orden de Compra u Orden de Servicio con la misma información detallada en la cotización aceptada, en caso contrario dicha Orden de Compra u Orden de Servicio será rechazada por

12. E Soporte Técnico Básico, es via telefónica (208-0400) ó por correo electrónico (soperteeftelematica compe), de lunes a viemes de 8:30 a m. a 5:30 p.m. No incluye fines de semana, ni feriados. Dicho soporte contempla las incidencias que pudiera tener la

plataforma en cuanto a funcionalidad, por ende no considera el terma operativo del uso de la plataforma.

13. La instalacion del bien intangble, no implica ninguna responsabilidad para Telemabca respecto a la percida de la data ó a la

continuidad operativa de los aplicativos desarrollados en otras versiones por el cliente o terceros. De igual forma si no se cuentan 


\section{BIBLIOGRAFÍA}

Carl McDaniel, Jr., \& Roger Gates (2016). Investigación de Mercados. México: 10ª edición, Cengage Learning.

Porter, M. (2004). Estrategia competitiva "Técnicas para el Análisis de los Sectores Industriales y de la Competencia". México, D.F.: 1st ed. CECSA

Porter, M. (2010). Estrategia Competitiva. Madrid, España: Ediciones Pirámide

Malhotra, N. K. (2008). Investigación de mercados. Pearson educación

Stoner, J. (1996). Responsabilidad social y ética. En: Autor, Administración. México D.F.: Prentice Hall-Hispanoamericana (pp. 103-168).

Kother, P., \& Armstrong, G. (2007). Marketing, version para latinoamérica. Pearson educación. (11 ed.). Mexico: D.F.

Perú Top Publications. (2017). Peru: The Top 10,000 Companies. Lima, Perú. Edición 2017. 


\section{REFERENCIAS ELECTRÓNICAS}

Bárbara, E. y Florencia, M. (2017, noviembre 24). Análisis Político Perú, 5 claves para entender la actualidad peruana. Recuperado de http://www.celag.org/5-claves-entenderla-actualidad-peruana

BBC. (2017, Enero 01). ¿Cuáles son las tendencias tecnológicas que marcarán 2017 ? Recuperado de http://www.bbc.com/mundo/noticias-38343954

BBVA Research. (2018). Perú, Situación del Sector Minero. Recuperado de https://www.bbvaresearch.com/publicaciones/peru-situacion-del-sector-minero/

BTECH. (2018). ¿Qué es Btech? Recuperado de http://www.btech.com.pe/nosotros.html

Business Software Alliance. (2016). Encuesta Global de Software de BSA, Recuperado de http://globalstudy.bsa.org/2016/downloads/studies/BSA_GSS_es.pdf

Business Software Alliance. (2016). Unlicensed Software Use Still High Globally. Recuperado de http://globalstudy.bsa.org/2016/downloads/press/pr_global.pdf

Cruzado, D. (2018, Julio 06). Las claves para atraer al mejor capital humano, según los ganadores del Merco Talento 2018. Gestión, Recuperado de http://www.merco.info/pe/actualidad/resultados-merco-talento-2018 
Damodaran. (s.f.). Beta, Unlevered beta and other risk measures. Recuperado de http://www.stern.nyu.edu/ adamodar/pc/datasets/betas.xls

Datos Perú. (2018). Cardo Consultants S.A.C. Recuperado de https://www.datosperu.org/empresa-cardo-consultants-sac-20467038631.php

De La Quintana, J. (2017, Julio 13) Ordenan prisión preventiva para Ollanta Humala y Nadine Heredia. CNN, Recuperado de http://cnnespanol.cnn.com/2017/07/13/ordenanprision-para-ollanta-humala-y-nadine-heredia/\#0

El Comercio. (2017, Abril 04). Estos son los sueldos promedio en Lima. Recuperado de https://elcomercio.pe/economia/personal/ventas-son-sueldos-promedio-lima-414267

El Comercio. (2018, Abril 15). Ipsos: el primer sondeo con Martín Vizcarra como presidente. Recuperado de https://elcomercio.pe/politica/ipsos-primer-sondeo-martin-vizcarrapresidente-noticia-512207?foto $=1$

Gartner. (2017). Gartner Top 10 Strategic Technology Trends for 2018. Recuperado de https://www.gartner.com/smarterwithgartner/gartner-top-10-strategic-technologytrends-for-2018/

Gestión. (2017, Noviembre 24). Inteligencia Artificial, La Importancia de la Transformación Digital en las Empresas. Recuperado de https://gestion.pe/panelg/importanciatransformacion-digital-empresas-2205495 
Gómez, D. (2014) Qué son mercados de nicho, sus beneficios y ejemplos prácticos.

Recuperado de https://bienpensado.com/que-son-mercados-de-nicho-sus-beneficios-yejemplos-practicos/

Indeed. (2018). Sueldos en Ejecutivo/a de ventas en Perú. Recuperado de https://www.indeed.com.pe/salaries/Ejecutivo/a-de-ventas-Salaries

Ministerio de Economía y Finanzas. (2018). Estadística de Inversión, Inversión Privada en el Perú, 1950-2018. Recuperado de https://www.mef.gob.pe/es/acerca-de-lasasociaciones-publico-privadas-apps/manual-comparador-publico

Ministerio de Energía y Minas. (2018). Inversión Minera Metálica 1996 - 2017. Recuperado de http://mineria.minem.gob.pe/dashboard/inversion/

Ministerio de Trabajo. (2018), Normas Laborales-Fomento del empleo, Productividad y Competitividad Laboral. Recuperado de http://www.mintra.gob.pe/mostrarContenido.php?id=54

Parodi, C. (2017, Setiembre 29) Economía y Ruido Político. Gestión, Recuperado de http://blogs.gestion.pe/economiaparatodos/2017/09/economia-y-ruido-politico.html

Pitney Bowes. (2018). We remove complexity from commerce. Recuperado de https://www.pitneybowes.com/us/our-company.html

Profile Consulting Group. (2017). Nosotros. Recuperado de http://www.pcg.com.pe/nosotros 
Quorum Consulting Group. (2018). Tecnología de Información, La estructura de la Industria del Software. Recuperado de http://qcgpreciosdetransferencia.com/Industrias/Tecnologias-deInformacion/Estructura-del-la-industria-del-Software

Replica. (2018). Nosotros, Partner. Recuparado de https://replica.com.pe/

Softland Perú. (2017). Nosotros. Recuperado de https://www.softlandperu.com/nosotros/

Sunat. (2018). Impuestos a pagar, Impuesto a la Renta. Recuperado de http://orientacion.sunat.gob.pe/index.php/empresas-menu/regimen-mypetributario/6829-05-impuestos-a-pagar

Tecnoversia. (2017, Agosto 08). ¿Cuánto ganan los egresados técnicos en computación e informática en el Perú? Recuperado de https://tecnoversia.universia.edu.pe/infodetail/orientacion/empleabilidadingresos/ranking-cuanto-ganan-los-egresados-tecnicos-en-computacion-e-informaticaen-peru-1886.html\#

Telemática. (2018). Somos Telemática S.A. Recuperado de https://telematica.com.pe/telematica-30-anos/

Wikipedia. (2018). Industria del software, Desarrollo producción y venta. Recuperado de https://es.wikipedia.org/wiki/Industria_del_software 
ZwSoft. (2018). About ZWSOFT. Recuperado de https://www.zwsoft.com/zwcad/zwsoftcompany 